\title{
SUMMARY AND EVALUATION OF
}

FUEL DYNAMICS TRANSIENT-OVERPOWER EXPERIMENTS:

STATUS 1974

by

L. W. Deitrich, R. C. Doerner,

T. H. Hughes, and A. E. Wright

BASE TECHNOLOGY

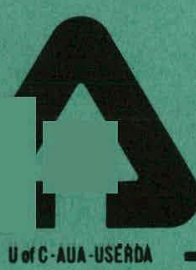

ARGONNE NATIONAL LABORATORY, ARGONNE, ILLINOIS

Prepared for the U. S. ENERGY RESEARCH

AND DEVELOPMENT ADMINISTRATION

under Contract W-31-109-Eng-38 


\section{DISCLAIMER}

This report was prepared as an account of work sponsored by an agency of the United States Government. Neither the United States Government nor any agency Thereof, nor any of their employees, makes any warranty, express or implied, or assumes any legal liability or responsibility for the accuracy, completeness, or usefulness of any information, apparatus, product, or process disclosed, or represents that its use would not infringe privately owned rights. Reference herein to any specific commercial product, process, or service by trade name, trademark, manufacturer, or otherwise does not necessarily constitute or imply its endorsement, recommendation, or favoring by the United States Government or any agency thereof. The views and opinions of authors expressed herein do not necessarily state or reflect those of the United States Government or any agency thereof. 


\section{DISCLAIMER}

Portions of this document may be illegible in electronic image products. Images are produced from the best available original document. 
The facilities of Argonne National Laboratory are owned by the United States Government. Under the terms of a contract (W-31-109-Eng-38) between the U. S. Energy Research and Development Administration, Argonne Universities Association and The University of Chicago, the University employs the staff and operates the Laboratory in accordance with policies and programs formulated, approved and reviewed by the Association.

\section{MEMBERS OF ARGONNE UNIVERSITIES ASSOCIATION}

The University of Arizona

Carnegie-Mellon University

Case Western Reserve University

The University of Chicago

University of Cincinnati

Illinois Institute of Technology

University of Illinois

Indiana University

Iowa State University

The University of Iowa
Kansas State University

The University of Kansas

Loyola University

Marquette University

Michigan State University

The University of Michigan

University of Minnesota

University of Missouri

Northwestern University

University of Nutre Dame
The Ohio State University

Ohio University

The Pennsylvania State University

Purdue University

Saint Louis University

Southern Illinois University

The University of Texas at Austin

Washington University

Wayne State University

The University of Wisconsin

NOTICE

This report was prepared as an account of work sponsored by the United States Government. Neither the United States nor the United States Energy Research and Development Administration, nor any of their employees, nor any of their contractors, subcontractors, or their employees, makes any warranty, express or implied, or assumes any legal liability or responsibility for the accuracy, completeness or usefulness of any information, apparatus, product or process disclosed, or represents that its use would not infringe privately-owned rights. Mention of commercial products, their manufacturers, or their suppliers in this publication does not imply or connote approval or disapproval of the product by Argonne National Laboratory or the U. S. Energy Research and Development Administration

Printed in the United States of America

Available from

National Technical Information Service

U. S. Department of Commerce

5285 Port Royal Road

Springfield, Virginia 22161

Price: Printed Copy $\$ 7.25 ;$ Microfiche $\$ 3.00$ 


\title{
ARGONNE NATIONA L LABORATORY 9700 South Cass Avenue Argonne, Illinois 60439
}

\author{
SUMMARY AND EVALUATION OF \\ STATUS 1974 \\ by \\ L. W. Deitrich, R. C. Doerner, \\ T. H. Hughes, and A. E. Wright
}

FUEL DYNAMICS TRANSIENT-OVERPOWER EXPERIMENTS:

Reactor Analysis and Safety Division

June 1977

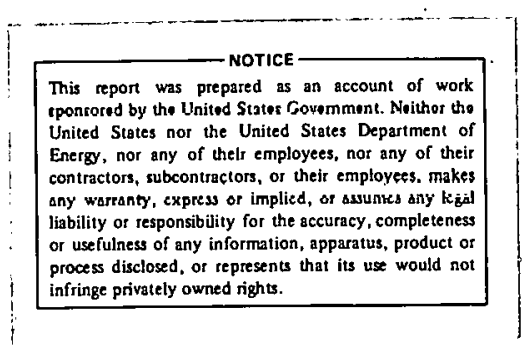


THIS PAGE

WAS INTENTIONALLY

LEFT BLANK 
TABLE OF CONTENTS

Page

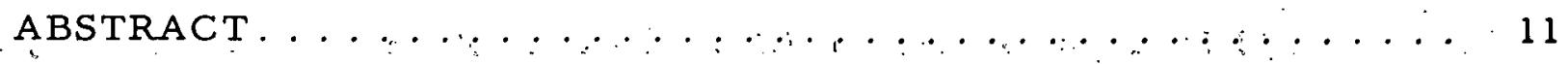

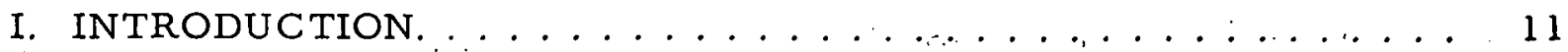

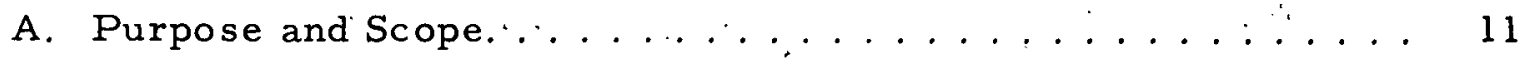

B. The Fuel Dynamics TOP Test Program. . . . . . . . . 12

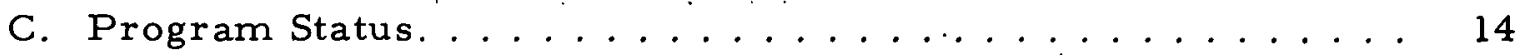

D. Summary of Majọr Test Conclusions. ... . . . . . . . . . 14

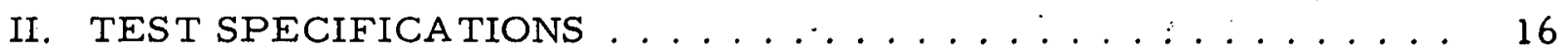

A. Fuel Pins. ........................... 16

B. Fuel-holder Design ..................... 19

C. Power Distributions. ..................... 20

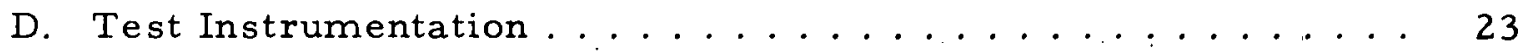

E. Reactor Power Transients ................ 25

F. Correlation to FTR Accident Conditions ........... 26

III. EXPERIMENTAL RESULTS . . . . . . . . . . . . . . . 31

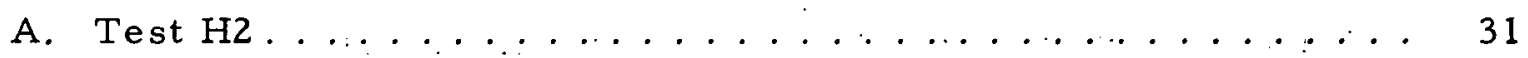

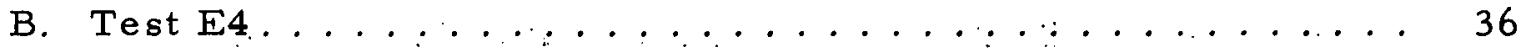

C. TestEl ........................ 40

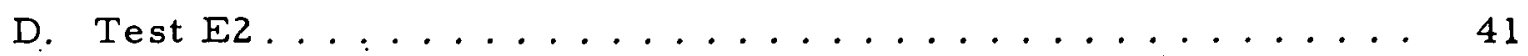

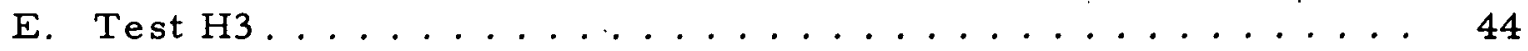

F. Test $\mathrm{H} 4 \ldots \ldots \ldots \ldots \ldots \ldots \ldots$

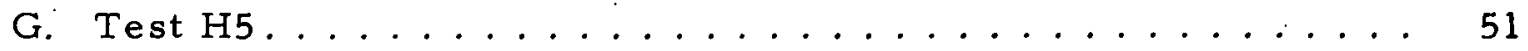

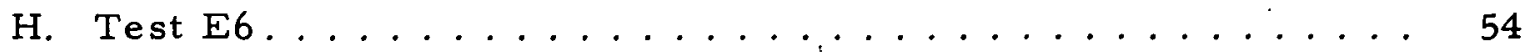

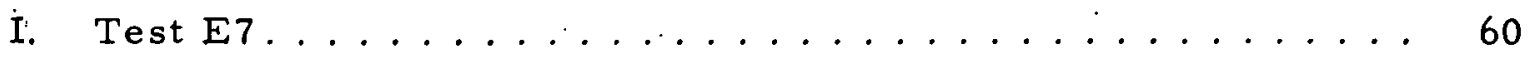

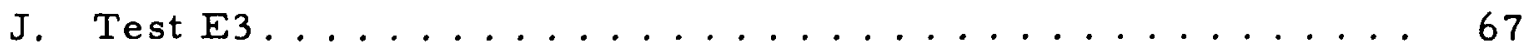


TABLE OF CONTENTS

Page

IV. SUMMARY, INTERPRETATIONS, AND COMPARISONS . . . . . . 70

A. Failure Characterization . . . . . . . . . . . 70

1. Failure Criteria . . . . . . . . . . . . . . . 70

2. Location and Nature of Failure . . . . . . . . . 76

B. Fuel Motion . . . . . . . . . . . . . . . . . . . . . . . 79

1. Prefailure Criteria .................. 80

2. Postfailure Motion and Final Fuel Disposition........ 81

C. Fuel-Coolant Interaction. . . . . . . . . . . . . 85

V. RELATION OF TESTS TO THE FTR .............. 88

A. Fuel Pins. ...................... 88

B. Test-section Characteristics. . . . . . . . . . . . 89

C. Loop Chàracteristics. . . . . . . . . . . . . . . . . 91

D. Summary ............................. 93

APPENDIXES

A. Test Hardware . . . . . . . . . . . . . . . . . . 94

B. Thermal-Hydraulic and Stress-Strain Calculations . . . . . 105

C. Input Data for COBRA Thermal-Hydraulic Calculations . . . . 108

D. Posttest Neutron Radiographs . . . . . . . . . . . . . . 119

ACKNOWLEDGMENTS . . . . . . . . . . . . . . . . . . . . . 124

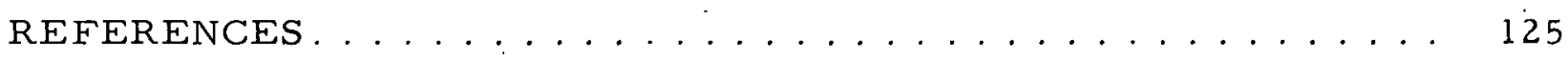




\section{LIST OF FIGURES}

No.

Title

Page

1. Fuel Pins Used in Fuel Dynamics Tests... . . . . . . . . . 17

2. Metallographic Cross Section of PNL-17 Pin ......... 18

3. Metallographic Cross Section of NUMEC-F Pin. . . . . . . ..... 19

4. Distribution of Fission Gases in Sibling Pin. . . . . . . . . 20

5. Fuel-holder Cross Sections.................... 21

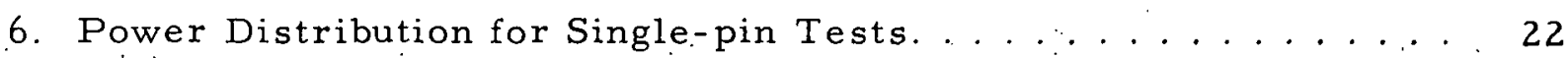

7. Power Distributions for Seven-pin Tests . . . . . . . . . 22

8. Characteristics of Natural Transients in TREAT. . . . . . . 26.

9. Characteristics of Shaped Transients in TREAT . . . . . . . 26

10. Comparison of Test H2 and FTR Thermal Histories. . . . . . 27.

11. Comparison of Test E4 and FTR Thermal Histories. . . . . . . . 27.

12. Comparison of Test $\mathrm{H} 3$ and FTR Thermal Histories. . . . . . . 28

13. Comparison of Test $\mathrm{H} 4$ and FTR Thermal Histories. . . . . . 28

14. Comparison of Test H5 and FTR Thermal Histories. ... . . . . 29

15. Comparison of Test E6 and FTR Thermal Histories. . . . . . 29

16. Comparison of Test E7 and FTR Thermal Histories. . . . . . 30

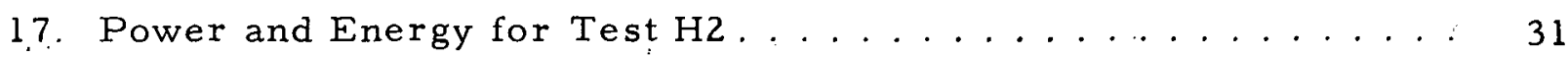

18. Flow and Inlet Pressure Data for Test $\mathrm{H} 2 \ldots \ldots \ldots . \ldots \ldots$

19. Integrated Flow (Void History) in Test $\mathrm{H} 2 \ldots \ldots \ldots \ldots \ldots \ldots . \ldots . \ldots 32$

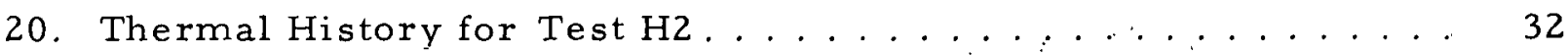

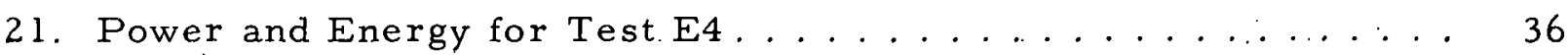

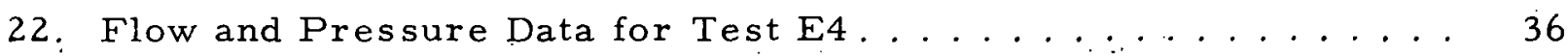

23. Integrated Flow and Void Volume for Test E4 . . . . . . . . 37

24. Temperature History for Test E4 . . . . . . . . . . . . . 37

25. Power Transient for Test El . . . . . . . . . . . . 40

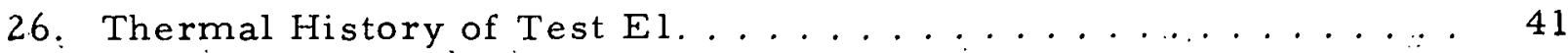

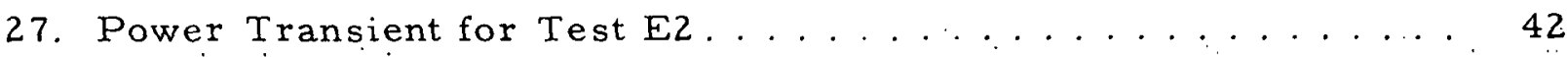

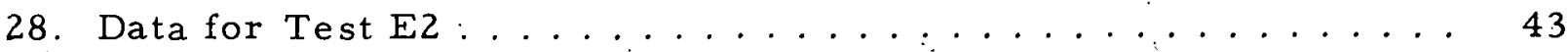

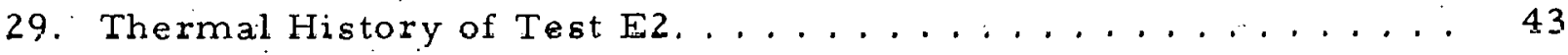




\section{LIST OF FIGURES}

No.

Title

Page

30. Power and Temperatures for Test $\mathrm{H} 3 \ldots \ldots \ldots \ldots . \ldots . \ldots 45$

31. Thermal History of Central Pin for Test H3 . . . . . . . . . 46

32. Thermal History of Hottest Peripheral Pin for Test H3 . . . . . 46

33. Change in Fission-gas Distribution due to Test H3. . . . . . . 47

34. Power and Temperatures for Test H4 . . . . . . . . . . 48

35. Thermal History of Central Pin for Test H4 . . . . . . . . . . 49

36. Thermal History of Hottest Peripheral Pin for Test H4 . . . . . 51

37. Power and Temperatures for Test H5 . . . . . . . . . . 52

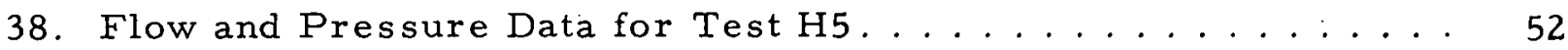

39. Thermal History of Central Pin for Test H5 . . . . . . . . . 53

40. Thermal History of Hottest Peripheral Pin for Test H5 . . . . . . 54

41. Power and Energy for Test E6 . . . . . . . . . . . . 56

42. Flow and Pressure Data for Test E6 . . . . . . . . . . 56

43. Integrated Flow Volumes for Test E6 . . . . . . . . . . . 57

44. Void Volume for Test E6. . . . . . . . . . . . . . . . . 57

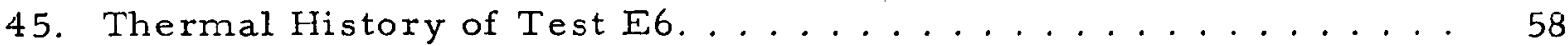

46. Thermal-Mechanical History of Central Pin in Test E6 . . . . . . 59

47. Power and Energy for Test E7 ...............6 61

48. Flow Data for Test E7 ................... 61

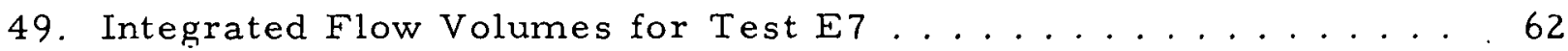

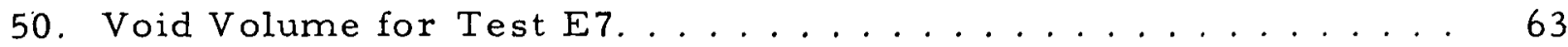

51. Single- and Two-phase Flow Interfaces for Test E7 . . . . . . 63

52. Thermal-Mechanical History of Central Pin for Test E7. . . . 65

53. Thermal History of Hottest Peripheral Pin for Test E7 . . . . 66

54. Power and Energy for Test E3 . . . . . . . . . . . 67

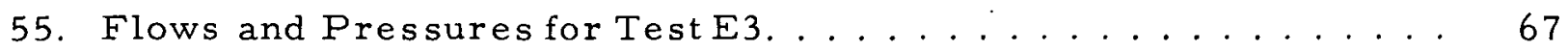

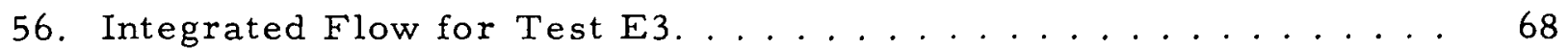

57. Thermal History of Test E3. . . . . . . . . . . . . . 69

58. Mechanical History for Test E3 . . . . . . . . . . . 69 


\section{LIST OF FIGURES}

No: Title

$\underline{\text { Page }}$

59. Results for Failure Threshold. . . . . . . . . . . . . . . . 70

60. Rate Effect on Failure Threshold. . . . . . . . . . . . . 70

A.1. TREAT Facility . . . . . . . . . . . . . . . . . 94

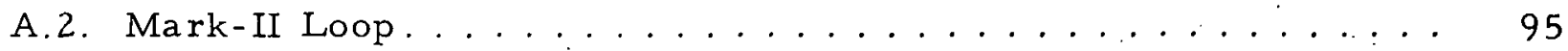

A.3. Loop-plenum Section and Test Sections for Tests H2, E4, and H5 . 97

A.4. Test Sections for Tests E2 and E3 and Pump Leg of Loop ...... 98

A.5. Loop-plenum Section and Test Section for Test E6 . . . . . . . : 99

A.6. Loop-plenum Section and Test Section for Test E7 ... . . . . . 100

B.1. Simplified Flow Diagram of COBRA/DEFORM Linkage . . ...... 107

C.1. Rod and Channel Layout Used in COBRA Calculations for TestE3. 111

C.2. Rod and Channel Layout Used in COBRA Calculations for

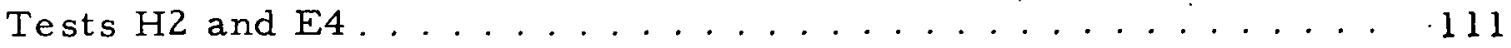

C.3. Rod and Channel Layout Used in COBRA Calculations for Tests $\mathrm{H} 3$ and H5 . . . . . . . . . . . . . . 112

C.4. Rod and Channel Layout Used in COBRA Calculations for Tests E6 and E7...................... 112

D. 1. Posttest Neutron Radiograph for Test H4 . . . . . . . . . . 120

D.2. Posttest Neutron Radiograph for Test H5 . . . . . . . . . 121

D. 3. Posttest Neutron Radiograph for Tést E6 . . . . . . . . . . . . 122

D.4. Posttest Neutron Radiograph for Test E7 . . . . . . . . . . 123 


\section{LIST OF TABLES}

No.

Title

Page

I. Fuel Dynamics TOP Test Program through FY $1974 \ldots \ldots 13$

II. Status of Fuel Dynamics Tests. . . . . . . . . . . . . . 14

III. Test Conditions. ..................... 16

IV Fuel-pin Characteristics ................. 17

V. Instrumentation Summary for TOP Tests. . . . . . . . . . 24

VI. Summary Scenario for Test H2 . . . . . . . . . . . 35

VII. Summary Scenario for Test E4 . . . . . . . . . . . 39

VIII. Summary Scenario for Test E2 . . . . . . . . . . . . 44

IX. Summary Scenario for Test $\mathrm{H}_{4} \ldots \ldots \ldots \ldots$. . . . . . . . 50

X. Summary Scenario for Test $\mathrm{H} 5 \ldots \ldots \ldots 5$

XI. Summary Scenario for Test E6 . . . . . . . . . . . . 660

XII. Summary Scenario for Test E7 ............... . 66 66

XIII. Thermal Conditions in Fuel Dynamics Tests . . . . . . . . . 71

XIV. Quantities Related to Coolant Dynamics and Fuel-Coolant

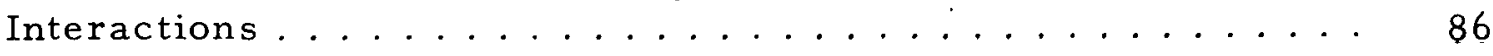

XV. Geometric Parameters of Test Sections ............ 89

A.1. Loop Flow Parameters for Test EL . . . . . . . . . . . 101

A.2. Loop Flow Parameters for Tests $\mathrm{H} 2$ and E4. . . . . . . . 102

A.3. Loop Flow Parameters for Test E3 . . . . . . . . . . . . 102

A.4. Loop Flow Parameters for Test H5 .............. 103

A.5. Loop Flow Farameters for 'lest E' ............. 103

A.6. Loop Flow Parameters for Test E7 . . . . . . . . . . . . 104

C.1. Sodium Properties. . . . . . . . . . . . . . . 108

C.2. Fuel and Cladding Properties . . . . . . . . . . 109

C.3. Hydraulic Parameters Common to All Tests . . . . . . . . . 109

C.4. Input Parameters for Sensitivity Calculations. . . . . . . . 110

C.5. Results from Sensitivity Calculations . . . . . . . . . . 110

C.6. Subchannel Input Data. . . . . . . . . . . . . . 113

C.7. Duct-wall Lengths of Contact................ 113 


\section{LIST OF TABLES}

No.

Title

Page

C.8. Radial Power Factors ......................114

C.9. Axial Distribution of Heat Flux ................ 114

C. 10. Radial Power Distribution in Fuel . . . . . . . . . . . 115

C.11. Miscellaneous Input Data ................... 116

C.12. Forcing Functions for E-series Tests............. 117

C.13. Forcing Functions for $\mathrm{H}$-series Tests. ...........118 
THIS PAGE

WAS INTENTIONALLY

LEFT BLANK 


\title{
SUMMARY AND EVALUATION OF \\ FUEL DYNAMICS TRANSIENT-OVERPOWER EXPERIMENTS: STATUS 1.974
}

by

L. W. Deitrich, R. C. Doerner,

T. H. Hughes, and A. E. Wright

\begin{abstract}
A BSTRACT
This report summarizes and evaluates experiments conducted in the Transient Reactor Test Facility (TREAT) using the Mark-II loop facility. The tests discussed are of the $E$ and $\mathrm{H}$ series. Detailed descriptions of test conditions and test results as of February 1974 are presented. Since all data have not been acquired on all experiments, this report must be considered interim in nature. Particular emphasis is placed on data relevant to Fast Test Reactor (FTR) safety-analysis efforts.
\end{abstract}

\section{INTRODUCTION}

A. Purpose and Scope

Since mid-1969, the Fuel Dynamics program has conducted a number of in-pile experiments in the TREAT facility, using the Mark-II sodium loop and stainless steel-clad oxide-fuel pins. This status report summarizes the results now available from those experiments related to the Transient Overpower Hypothetical Core Disruptive Accident (TOP HCDA) in the Fast Test Reactor (FTR).

Results of experiments in two series, the $H$ and $E$ series, are summarized. The H-series experiments (of which four are discussed) were originally intended to determine the failure threshold for FTR-type fuel pins with energy input not much in excess of the failure energy. As the accident analysis developed and the needs for experimental verification became better defined, the $\mathrm{H}$ series was reoriented towards study of fuel-element response to simulated $0.5-1 \$ /$ s ramp-reactivity-addition transients.

The E-series experiments (of. which six are discussed) were originally intended to examine not only the failure threshold, but also the events after failure, particularly fuel motion. Generally, E-series tests used higherenergy, faster transients than did $\mathrm{H}$-series tests, and as the program developed, the tests were oriented towards simulation of $3-5 \$ / \mathrm{s}$ ramp accidents. 
Early experiments ( $\mathrm{E} 1, \mathrm{E} 2, \mathrm{E} 3, \mathrm{E} 4$, and $\mathrm{H} 2$ ) used "natural" TREAT transients starting from isothermal conditions. Later tests used the TREAT feedbackcontrol system (which became operational in 1971) to produce a shaped transient in which a power burst simulating the FTR power excursion follows a preheat phase during which fuel temperatures representative of steady-state irradiation conditions are attained.

Regardless of the nominal designation of an experiment, an attempt has been made to obtain and present as much information as possible on failure threshold and fuel motion. Particular attention has been given to calculation of the thermal history of the test fuel during the transient, to definition of conditions at failure, to determination of the location and mode of failure, to description of pre- and postfailure fuel motion, and to information related to fuel-coolant interactions. Of necessity, much of the fuel-motion infurration is qualitalive.

\section{B. The Fuel Dynamics TOP Test Program}

The program of Fuel Dynamics experiments in support of the TOP HCDA analysis has emphasized the dependence of failure threshold and fuel motion on fuel mic rostructure and on transient rates. Thus far, tests have been conducted on fresh pins and on two different types of EBR-II irradiated, prototypic, mixed-oxide pins. Three early tests (El, E2, and E3) used $\mathrm{UO}_{2}$ fuel pins with Type 304 stainless steel cladding.

Fresh fuel pins were tested alone in $\mathrm{H2}, \mathrm{E} 4, \mathrm{EL}$, and $\mathrm{E} 2$, and in conjunction with ir radiated pins in $\mathrm{H} 3, \mathrm{H} 4, \mathrm{H} 5$, and $\mathrm{E} 6$. In most cases, the fresh fuel was unrestructured with no irradiation exposure before the test. (Five fresh pins were used in both $\mathrm{H3}$ and H5.) Fresh fuel is thought to be capable of sustaining very large fractions of melting betore cladding tailure, and to fail by local cladding meltthrough due to local boiling and subsequent cooling loss at the surface. The experimental results from the Fuel Dynamics tests tend to confirm this hypothesis.

High-power-irradiated fuel typified by NUMEC-F pins was used in H4, E6, and E7. This fuel had a fully developed central void and columnar, equiaxed, and unrestructured regions. Due to the flat axial power shape in EBR-II, the pins have essentially the same structure along their entire length. Therefore, they have a microstructure representative of that of the central portion of a high-power FTR pin. Such fuel is thought to be the most resistant to failure of the irradiated pins tested, since the captive fission gas is confined to the equiaxed and unrestructured fuel at the very outer portion of the fuel. Release of this tission gas as temperatues close to melting are attained, which results in rapid loading of the cladding, is postulated to lead to failure of preirradiated fuel.

Nominally "intermediate-power" fuel was tested in $\mathrm{H} 3$ and $\mathrm{H} 5$. The PNL-1 7 pins used have some features of high-power fuel, in that columnar and 
equiaxed regions are found, with little gas in the columnar and inner parts of the equiaxed regions. No significant central void is present. This fuel should have a lower failure threshold than that of the high-power fuel. It is typical of the fuel structure expected near the ends of the high-power FTR pins. As with the NUMEC-F pins, the structure of the PNL-17 pins is fairly uniform axially, although the columnar region does not extend to the ends of the fuel column.

The relationship of the various Fuel Dynamics tests is summarized in Table I. All tests were conducted using the TREAT reactor and a Mark-II loop, described in Appendix A. The test data included reactor power, flow, and pressure at the pin-bundle inlet and outlet; inlet and outlet sodium temperatures, and certain other temperatures depending on the experiment; and measurements with the fast-neutron hodoscope. This latter instrument system, also described in Appendix A, provided direct observation of fuel motion by following fission-neutron sources during the transient. Neutron radiographs of the experiment hardware provided data on posttest fuel disposition, which was greatly augmented by posttest physical examination. The "postmortem" also yielded much valuable data on details of the remains, including microscopic characteristics of both fuel deposits and fines.

TABLE I.l. Fuel Dynamics TOP Test Program through FY 1974

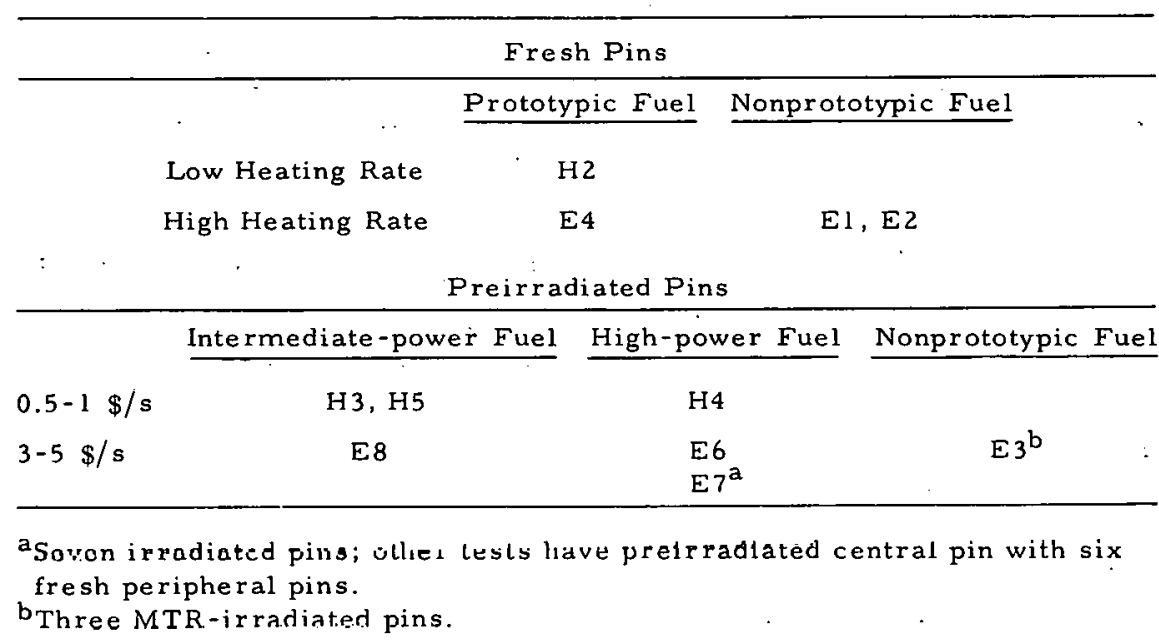

Since many parameters of interest cannot be measured in characterizing a test, one must resort to calculation to obtain these values. In fact, such calculations require a substantial effort, both in development of tools, and in evaluation of results. The calculational tools and input are discussed in Appendixes $B$ and $C$. Most calculations reported here were performed using a invalified version of the COBRA-IIIM program, which in itself is a modification of COBRA-III, incorporating fuel-pin heat transfer: Cladding mechanical calculations were done using DEFORM- $\amalg$, which has been linked to COBRA-IIIM such that it receives temperature distributions calculated in a manner appropriate to the test geometry. 


\section{Program Status}

Table II summarizes the status of work on the various tests discussed in this report. Essentially, thermal histories and failure threshold data have been completed for each test, as has posttest neutron radiography. Hodoscope results available as of spring 1974 are included. Similarly, posttest examination results as of spring 1974 are included. Data related to Test $\mathrm{H} 4$ are included in the tabulations, and preliminary $\mathrm{H} 4$ results are factored into the discussions and conclusions.

TABLE II. Status of Fuel Dynamics Testsa

\begin{tabular}{|c|c|c|c|c|c|c|c|}
\hline \multirow[b]{3}{*}{ Test } & \multicolumn{2}{|c|}{ Calculations } & \multicolumn{2}{|c|}{-} & \multirow{2}{*}{\multicolumn{3}{|c|}{ Posttest Examinations }} \\
\hline & Thermal & Failure & Hodoscope & Neutron & & & \\
\hline & History & Threshold & Analysis & Radiography & Macro & Micro & Fines \\
\hline El & $\mathrm{C}$ & c & C & $\mathrm{C}$ & $\mathrm{C}$ & $\mathrm{C}$ & $N / A$ \\
\hline $\mathrm{E2}$ & $\ddot{c}$ & $\mathrm{C}$ & $\mathbf{Q}$ & $r$ & $\mathrm{C}$ & $\mathrm{C}$ & C \\
\hline E3 & $\mathrm{C}$ & $\mathrm{C}$ & $Q$ & $\mathrm{c}$ & $\mathrm{C}$ & $\mathrm{C}$ & $\mathrm{N}$ \\
\hline $\mathrm{E} 4$ & $\mathrm{C}$ & $\mathrm{C}$ & No data & $\mathrm{C}$ & $\mathrm{C}$ & $\mathrm{C}$ & C \\
\hline E6 & $\mathrm{C}$ & $\mathrm{C}$ & $\mathbf{N}$ & $\mathrm{C}$ & $\mathrm{N}$ & $\mathrm{N}$ & $\mathrm{N}$ \\
\hline E7 & $\because$ & $\mathrm{C}$ & I & $\mathrm{C}$ & $\mathbf{N}$ & $\mathrm{N}$ & $\mathrm{N}$ \\
\hline $\mathrm{H} 2$ & $\mathrm{C}$ & C & C & C & $c$ & $c$ & $c$ \\
\hline $\mathrm{H} 3$ & C & C & $\mathrm{C}$ & C & C & C & $\mathrm{N} / \mathrm{A}$ \\
\hline $\mathrm{H} 5$ & C & C & I & C & $\mathrm{N}$ & $\mathrm{N}$ & $\mathrm{N}$ \\
\hline $\mathrm{H} 4$ & $C$ & C & $\mathbf{N}$ & C & $\mathrm{N}$ & $\mathrm{N}$ & $\mathrm{N}$ \\
\hline
\end{tabular}

${ }^{a} \mathrm{C}=$ work complete; $\mathrm{I}=$ interim results available; $\mathrm{N}=$ no results available; $\mathrm{N} / \mathrm{A}=$ not applicable; $\mathrm{Q}=$ qualitative results only.

Work on Tests El, E2, H2, E4, and H3 is considered complete. Continued analysis and interpretation of Tests E3, H5, E6, E7, and $\mathrm{H} 4$ has been performed and will be reported in a sequel to the present report.

This report, then, represents a "snapshot" of our interpretations as of spring 1974.

D. Summary of Major "Test Conclusions

Based on the test data and analysis described in this report, the following conclusions appear to be in order. Note that, since certain items of information expected are lacking, such as posttest examination and hodoscope results for the later tests ( $\mathrm{H} 4, \mathrm{H} 5, \mathrm{E} 6$, and $\mathrm{E} 7$ ), some modifications in these conclusions may be necessary.

Fresh fuel pins tested at relatively high thermal rates can sustain very high fuel enthalpy and melt fraction without failure. Ultimate failure of these pins followed a period of local boiling during which cooling loss, at least locally, would be sustained. The mechanism of failure appears to be cladding melthrough. Failure-threshold measurements at lower thermal rates are not available for fresh fuel. The only data are for peripheral pins in tests having a central ir radiated pin, which is thought to have failed first, inducing peripheral pin failure. 
At low the rmal rates (equivalent to $\sim 0.5 \$ / \mathrm{s}$ ), there is no significant difference between the failure thresholds of the two types of irradiated fuel tested. Both samples appear to have failed as the melt front (solidus temperature) approached the radius at which the gas content of the fuel begins a rapid increase. Thus, an association of failure with gas release from the fuel is implied. The nature of failure is not definitively known, but the pressure data are consistent with an abrupt mechanical failure.

At higher thermal rates (equivalent to $3 \$ / \mathrm{s}$ ), data are available only for one type of fuel. The results are inconsistent, at least when cladding temperature is taken as the independent variable. However, both failures appear to have involved relatively large proportions of gas release from the cladding, and very small or absent pressure signals. A pinhole gas leak is thought to have bcen the mode of failure. The very high resistance to failure shown in one test (E6) suggests a rate effect on gas release and cladding pressurization.

Although determination of the precise location of initial failure is difficult in many cases due to extensive pin damage, the available evidence points toward failure in the top half of the pin. In fresh-fuel tests, the failure was near or even above the top of the fuel column. Irradiated pins tend to fail lower in the top half, near the location of maximum fuel enthalpy.

Prefailure fuel motion internal to the cladding occurred in early tests of fresh fuel, and appears to have relieved cladding strain so that failure was by melthrough. However, in later tests of irradiated fuel, and with fresh fuel of more prototypic design, this type of prefailure motion was not observed. Thus, these tests cannot now support assumption of gross prefailure axial motion in accident analysis.

Postfailure fuel motion presents a rather complex picture, with many possible influences extant. However, certain features appear common to the test results. First, the general trend of fuel motion is away from the cluster midplane and preferentially upward. The extent of axial motion is quite variable, but the net mulion is away from the midplane in all cases. Second, at least limited sweepout of fuel from the original fuel column into the upper pin structure occurred in each test involving failure. The extent of motion is variable, and a correlation with ramp rate or melt fraction has not been found. In tests of nominally prototypic fuel, little sweepout beyond the pin bundle is evident. Third, at least partial plugging of the flow path has occurred in every test. The locations and nalure of the blockages are not known at this time for the later tests. In the early tests, accumulations of once-molten fuel, fines, and/or cladding debris in the channels or at obstructions were the cause.

In each test in which fuel failure occurred, voiding of the coolant from the fuel region was indicated, reflecting a fuel-coolant thermal interaction and/or gas release into the coolant. In most cases, measurable pressure pulses accompanied the coolant accelerations and were monitored on transducers. Básed on the magnitudes of the measured pressure pulses, the 
indicated voiding rates, fuel-coolant mixing-zone pressures estimated from the coolant accelerations, and estimated work done on the coolant, there is no indication of a very energetic fuel-coolant interaction approaching the thermodynamic limits. Likewise, the observed accelerations do not imply very high pressures in the mixing zone.

\section{TEST SPECIFICATIONS}

The test specifications and conditions applicable to Fuel Dynarrics TOP tests are summarized in Table III. A more detailed discussion follows.

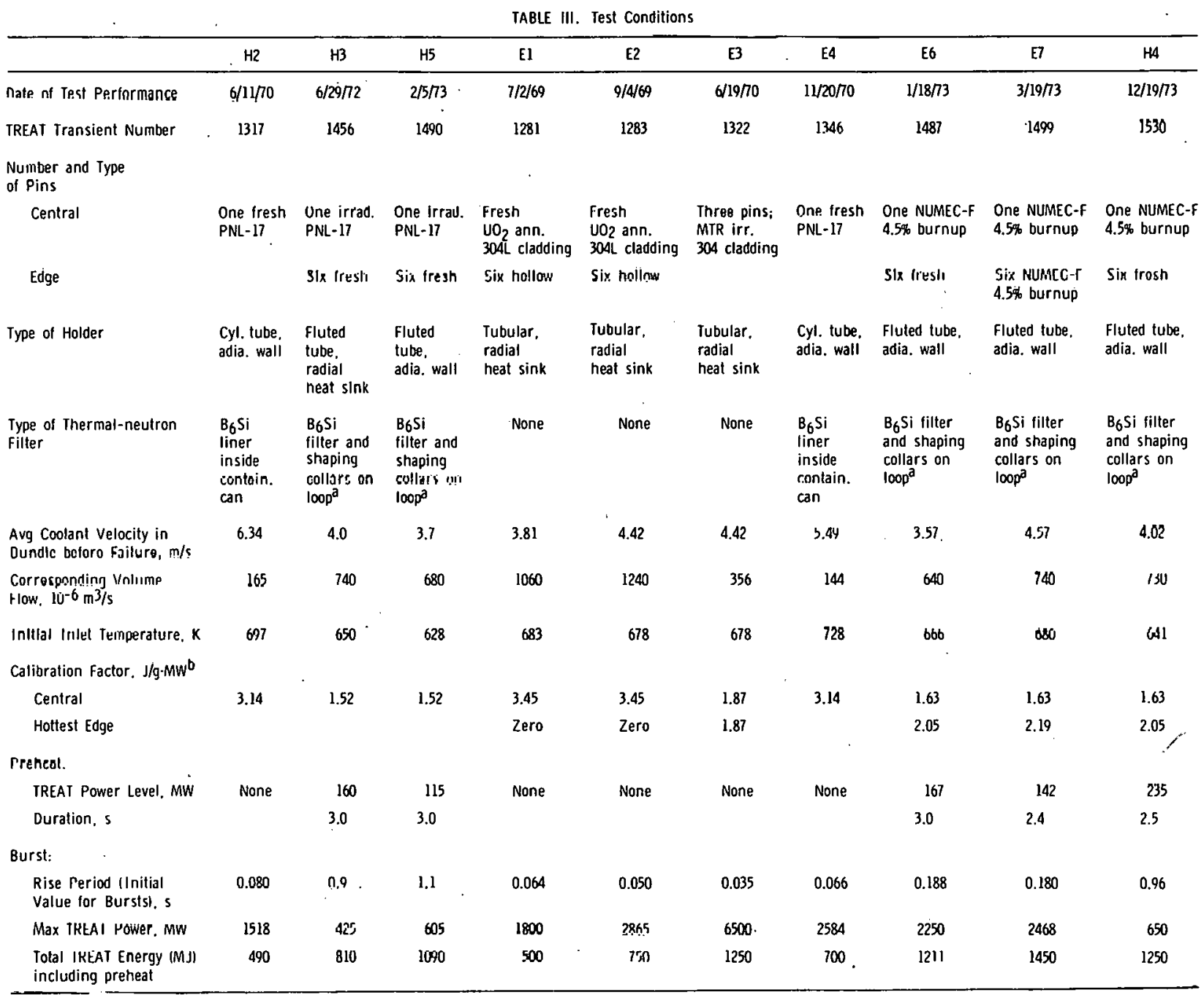

aFilter material covers pump stator shell also.

bvalue corresponding to 1.0 unit in Figs. 6 and 7.

\section{A. Fuel Pins}

The essential features of the fuel pins used in Fuel Dynamics tests are summarized in Table IV and Fig. 1. The irradiation-history data in Table IV are from pin-surveillance calculations, and the postirradiation data come from destructive examination of sibling pins. ${ }^{1-3}$ Variations between sibling pins and the actual test pins are not included. Table IV and Fig. I indicate that a 
wide variety of fuel pins have been tested in the Fuel Dynamics program. In many cases, pin selection for a given experiment was based largely on availability of irradiated pins suitable for modification for use in Mark-II loops.

TABLE IV. Fuel-pin Characteristics

\begin{tabular}{|c|c|c|c|c|}
\hline & $\begin{array}{l}\text { Fresh Pins } \\
\text { Used in } \\
\text { El and E2 }\end{array}$ & $\begin{array}{l}\text { Irradiated } \\
\text { Pins Used } \\
\quad \text { in E3 }\end{array}$ & $\begin{array}{c}\text { Irradiated } \\
\text { NUMEC-F Pins } \\
\text { Used in } \\
\text { E6, E7, and } \mathrm{H} 4\end{array}$ & $\begin{array}{c}\text { Irradiated } \\
\text { PNL-17 Pins } \\
\text { Used in } \\
\text { H3 and } \mathrm{H}^{\mathrm{a}}\end{array}$ \\
\hline \multicolumn{5}{|l|}{ As-fabricated Properties } \\
\hline Fuel composition & $100 \% \mathrm{UO}_{2}$ & $100 \% \mathrm{UO}_{2}$ & $\begin{array}{l}75 \% \mathrm{UO}_{2} \\
25 \% \mathrm{PuO}_{2}\end{array}$ & $\begin{array}{l}75 \% \mathrm{UO}_{2} \\
25 \% \mathrm{PuO}_{2}\end{array}$ \\
\hline Uranium enrichment, $\%$ & 13 & 13.3 & 76.9 & 65 \\
\hline Plutonium enrichment, $\%$ & - & - & 85.6 & 88 \\
\hline Fuel-pellet density \% TD & 93 & 91.3 & 89.9 & 93 \\
\hline Pellet diameter, $\mathrm{mm}$ & 6.25 & 3.81 & 4.93 & 4.93 \\
\hline Fuel-column length, $m$ & $\begin{array}{l}0.317(E 1) \\
0.287\left(E_{2}\right)\end{array}$ & 0.145 & 0.343 & 0.343 \\
\hline Cladding material & $\begin{array}{l}\text { 304L SS, } \\
\text { annealed }\end{array}$ & $304 \mathrm{SS}$ & $\begin{array}{l}316 \mathrm{SS} \\
20 \% \mathrm{CW}\end{array}$ & $\begin{array}{l}316 \mathrm{SS} \\
20 \% \mathrm{CW}\end{array}$ \\
\hline Cladding: ID, $\mathrm{mm}$ & 0.635 & 0.396 & 0.508 & 0.508 \\
\hline $\mathrm{OD}, \mathrm{mm}$ & 0.737 & 0.442 & 0.584 & 0.584 \\
\hline Fuel-Cladding diametral gap, $\mathrm{mm}$ & $0.08 \pm 0.03$ & 0.2 & 0.2 & 0.2 \\
\hline Overall pin length, $\mathrm{m}^{\mathrm{b}}$ & 0.4635 & 0.2254 & 1.1 & 0.7842 \\
\hline Spacer-wire diameter, $\mathrm{mm}$ & 1.44 & 1.2 & 1.0 & 1.4 \\
\hline \multicolumn{5}{|l|}{ Irradiation History } \\
\hline Reactor & - & MTR & EBR-II & EBR-II \\
\hline Burnup, at. $\%$ & - & $\begin{array}{l}4.82,4.83 \\
6.33\end{array}$ & 4.5 & 3.4 \\
\hline Power-level peak, $\mathrm{kW} / \mathrm{m}$ & - & - & $32.8-38.1$ & 33.8 \\
\hline Fluence, $10^{22} \mathrm{nvt}$ & - & - & $3.6-4.1$ & 3.2 \\
\hline Max cladding temp, $\mathrm{K}$ & - & - & $\sim 800$ & $\sim 800$ \\
\hline Max fuel temp, $\mathrm{K}$ & - & $\sim 2650$ & -2150 & - \\
\hline \multicolumn{5}{|l|}{ Postirradiation Properties (sibling-pin values) } \\
\hline Fission-gas volume, STP, $\mathrm{cm}^{3}$ & - & 22.3 & $53-61$ & 45 \\
\hline Fission-gas retention in fuel, $\%$ & - & 77 & 44 & 50 \\
\hline Plenum-gas pressure at room temp, $10^{5} \mathrm{~Pa}$ & - & 9.31 & 11.4 & 5.5 \\
\hline Central-void radius, $\mathrm{mm}$ & - & 0.25 & 0.58 & 0 \\
\hline Column-grain outer radius (midplane), $\mathrm{mm}$ & - & - & 1.6 & 1.1 \\
\hline Equiaxed-grain outer radius (midplane), $\mathrm{mm}$ & - & - & 2.1 & 1.8 \\
\hline Fuel-cladding residual radial gap, $\mathrm{mm}$ & - & 0.041 & 0.008 & $0.03-0.05$ \\
\hline
\end{tabular}

${ }^{\mathrm{a}}$ Fresh PNL-1 7 pins used in $\mathrm{H} 2$ and $\mathrm{H} 4$ with $1.0-\mathrm{mm}$ spacer wire. Special fresh pins used in $\mathrm{H} 3, \mathrm{H} 4$, $\mathrm{H} 5$, and $\mathrm{E} 6$ have similar composition.

${ }^{b}$ As modified for testing.

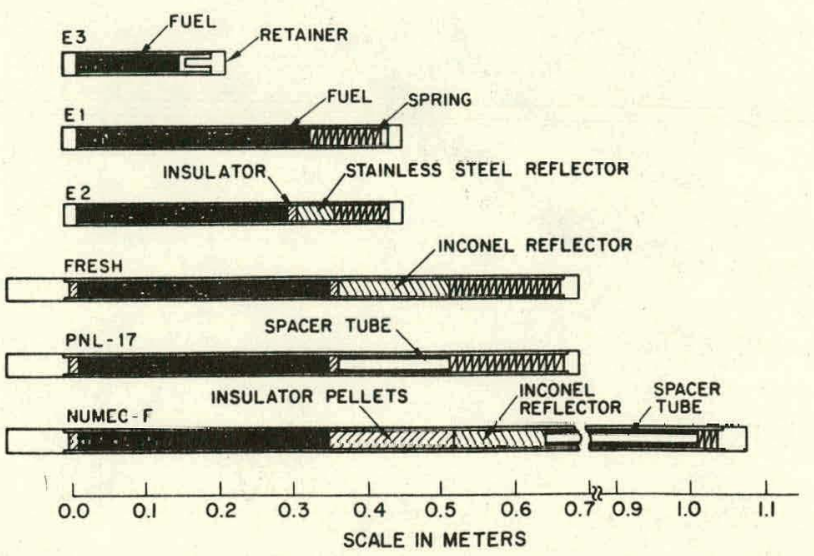

Fig. 1

Fuel Pins Used in Fuel Dynamics Tests. ANL Neg. No. 900-3714 Rev. 1. 
The two pins used in El and E2 differed primarily in the degree of axial restraint to fuel motion. Essentially no axial restraint was present in the $\mathrm{E} l$ pin, but inertial restraint was introduced for $\mathrm{E} 2$ to help ensure failure. The E3 pins had very high gas retention and were suitable for study of the effects of failure of "gassy" fuel. The pins used for Tests H2 and E4 were spare pins, constructed for, but not used in, the PNL-17 subassembly. They were shortened and the spacer was changed before use. Irradiated PNL-17 pins, also shortened, were used in Tests $\mathrm{H} 3$ and $\mathrm{H} 5$, but with the original spacer wire.

All the PNL-1 7 pins have a spacer tube on top of the fuel column in place of the more prototypic Inconel reflector piece. Except for an Inconel reflector, the "special" fresh pins used as peripheral pins in Tests $\mathrm{H} 3, \mathrm{H} 4$, H5, and E6 were nearly the same as the PNL-17 pins. The presence of the Inconel reflector contributes to the heat capacity above the fuel column and offers greater impediment to axial fuel motion than does the spacer tube. NUMEC-F fuel pins were used in Tests E6 and E7, shortened as murh as possible for use in Mark-II loop. These pins have a long insulator column, also a nonprototypic feature.

A metallographic cross section of the irradiated PNL-1 7 sibling pin is shown in Fig. 2, and a similar picture for the NUMEC-F pin is shown in

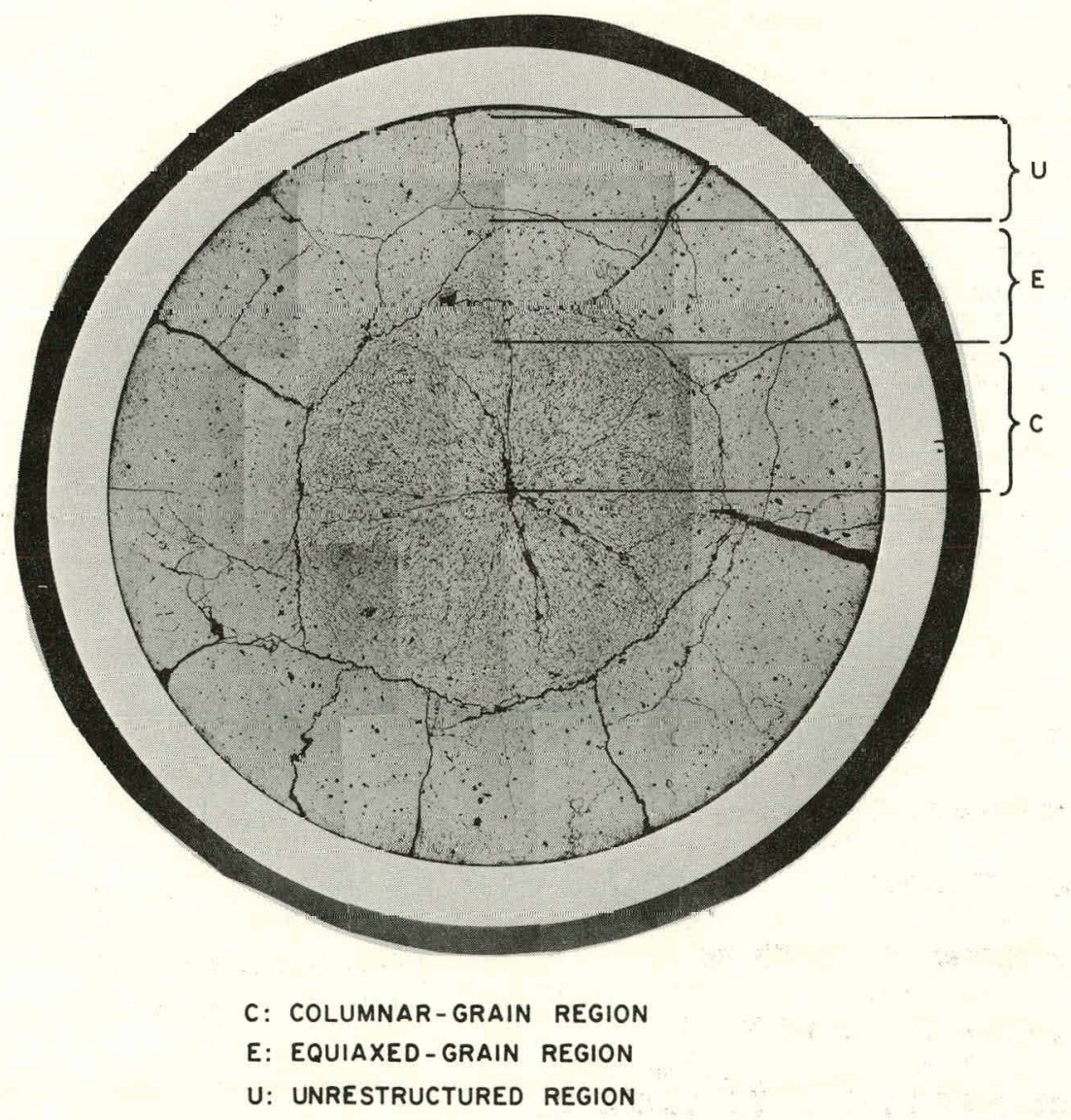

Fig. 2. Metallographic Cross Section of PNL-17 Pin. ANL Neg. No. 900-4006. 

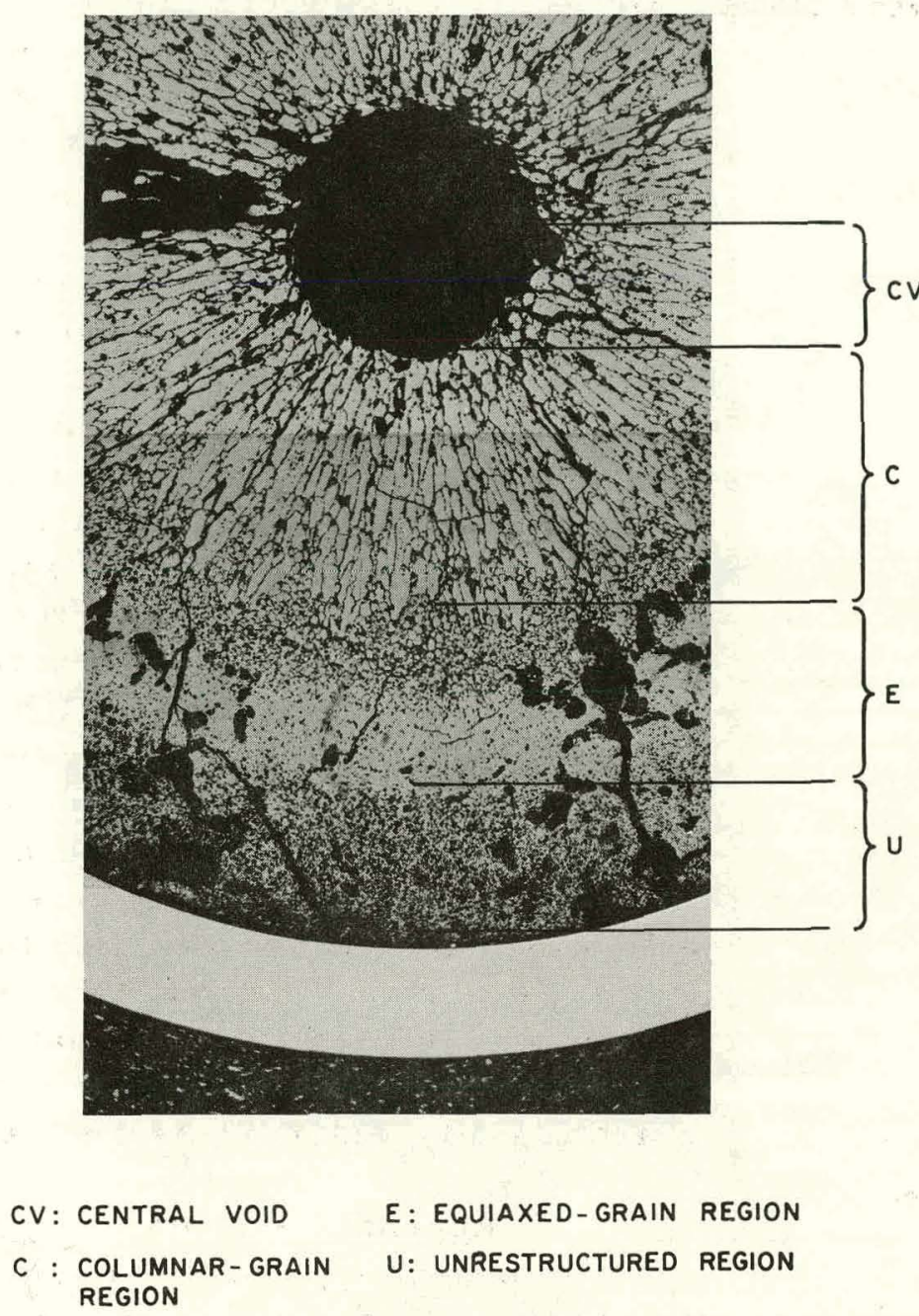

Fig. 3. Metallographic Cross Section of NUMEC-F Pin. ANL Neg. No. 900-4005.
Fig. 3. Figure 2 shows the presence of columnar, equiaxed, and unrestructured regions, but no central void. Thus, the fuel microstructure has features of both high-power and low-power fuel, and is called intermediate power.

Figure 4 gives the radial distribution of retained fissiongas concentration for each pin type. The two distributions are more characteristic of highpower fuel. The rather unusual features of microstructure and gas content in the PNL-1 7 pins result from irradiation at two power levels due to increase in EBR-II power level about midway in irradiation of the PNL-1 7 subassembly. Figure 3 shows the NUMEC-F pins to have a typical high-power structure with fully developed central void. Figure 4 shows an estimated (measurements not available) fission-gas distribution for the se pins, ${ }^{4}$ which is typical of that expected for high-power fuel.

The estimate was based on a comparison of operating temperature during steady-state irradiation, structural morphology, and total fission-gas release between the PNL-17 and NUMEC-F elements, along with the data for the PNL-17-10 pin. Comparison of the temperature profiles during steady-state irradiation indicated that similar values existed at the region boundaries in both cases. The gas-retention fractions in the various regions, taken to be those found for PNL-17-10 by laser sampling, were used with the volume fractions of the various structures to yield a total gas retention in the fuel of $\sim 31 \%$ at the midplane. This value corresponds to a release of $\sim 69 \%$ at the midplane and - $62 \%$ for the entire elerrent. Data for whole-element gas release in two sibling pins, N-013 and -159 , gave $\sim 56$ and $\sim 57 \%$. Thus the estimate is in fair agreement.

\section{B. Fuel-holder Design}

The fuel holder is the part of the lest hardware that establishes the boundary conditions immediately surrounding the pin bundle. Several different 
| COLUMNAR | EQUIAXED JUNRESTR| PNL-17 REGIONS

| VOID | COLUMNAR |EQ-AX|UNRES| NUMEC-F REGIONS

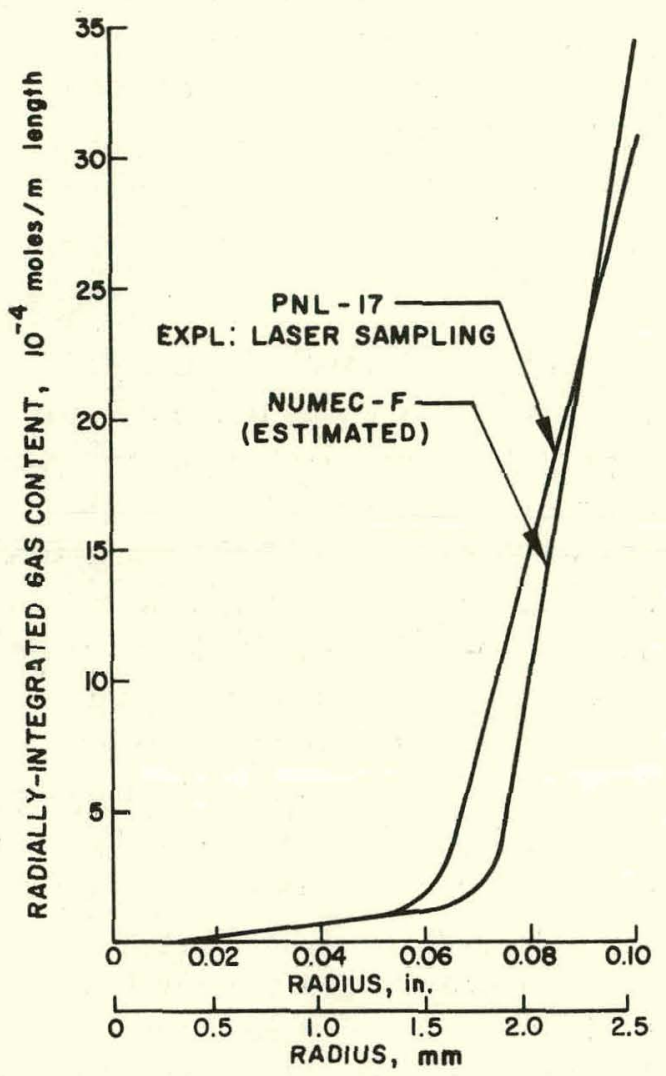

Fig. 4. Distribution of Fission Gases in Sibling Pin types have been used in Fuel

Dynamics tests according to the geometry of the cluster and the test requirements. A cross section of each type used is shown in Fig. 5.

Fuel holders are generally either "adiabatic" or "nonadiabatic," according to the extent to which radial heat transfer is impeded. Adiabatic holders have either a vacuum or a gas-filled annular space between the flow tube and the pressure-vessel wall of the loop. Single-pin adiabatic vacuum holders were used in Tests $\mathrm{H} 2$ and $\mathrm{E} 4$, whereas seven-pin gasfilled adiabatic holders were used in $\mathrm{H} 4, \mathrm{H} 5, \mathrm{E} 6$, and $\mathrm{E} 7$. In general, the tlow-tube walls were made as thin as practical to minimize the heat capacity. However, this feature also limited their mechanical strength, resistance to meltthrough, and rigidity under pressure loading.

Appendix A contains a diagram of each type of fucl holder

used. Again, several different designs have been used, depending on the geometrical requirements of the test. For example, the holder for E6 and H4 was specially designed to allow the longer NUMEC-F central pin to extend up into the loop plenum, with a support tube provided to position the upper part of the pin. The seven-pin E 7 holder allowed all seven pins to extend into the plenum and provided a baffle to help turn the flow downward into the pumpreturn leg. Appendix A gives flow-area and hydraulic-diameter data for the complete flow path for each experiment. Note that the pump leg of the loop is the same for all tests. This information may be used in dynamic simulations of an experiment and for back calculation of various pressure data.

\section{Power Distributions}

The power distribution obtained during a test is important, both as input information to calculations of test parameters and as a factor bearing on fuel motion. For a particular test, the power distribution is determined by a combination of calculation and experiment. The distribution is assumed to be separable into axial and radial components, both of which can be adjusted (within limits) to meet certain criteria. Figures 6 and 7 show the current best-estimate axial and radial distributions for the various TOP experiments. 


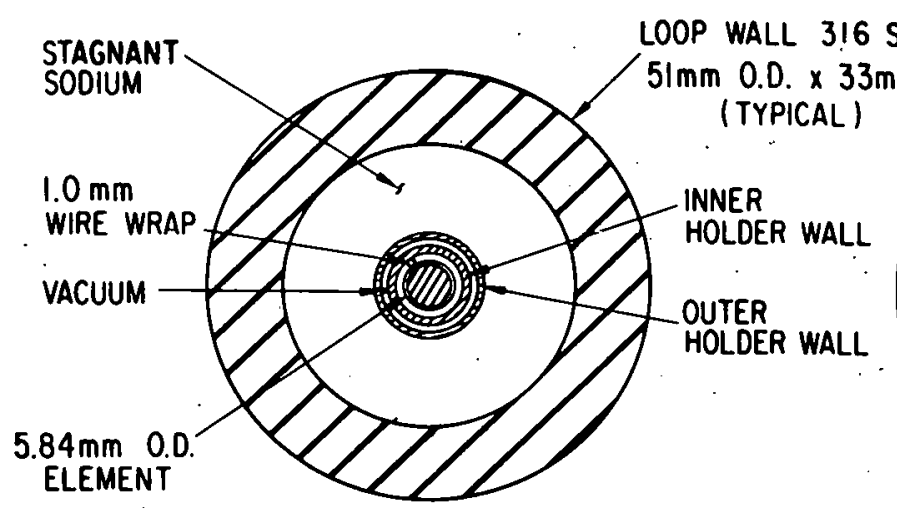

H2 /E 4

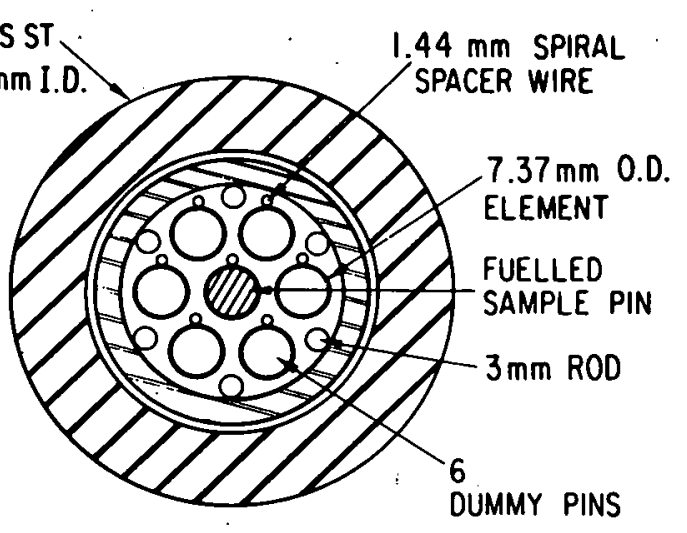

E1/E 2

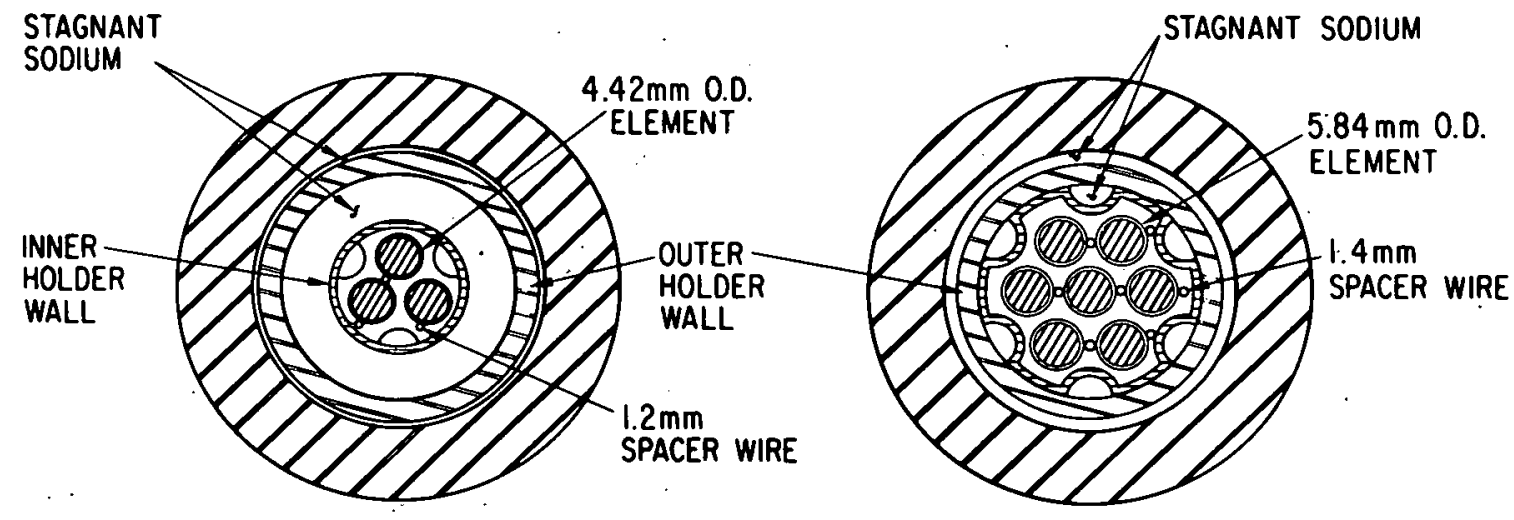

E3

H3

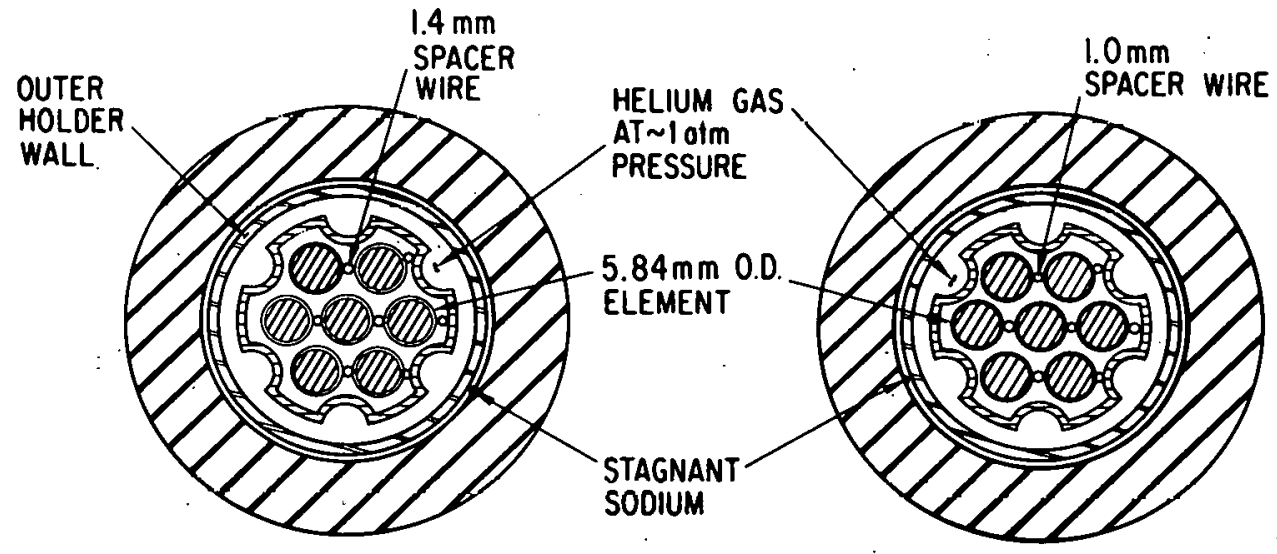

H4/H5/E6

E7

Fig. 5. Fuel-holder Cross Sections. ANL Neg. No. 900-3713 Rev. 2. 

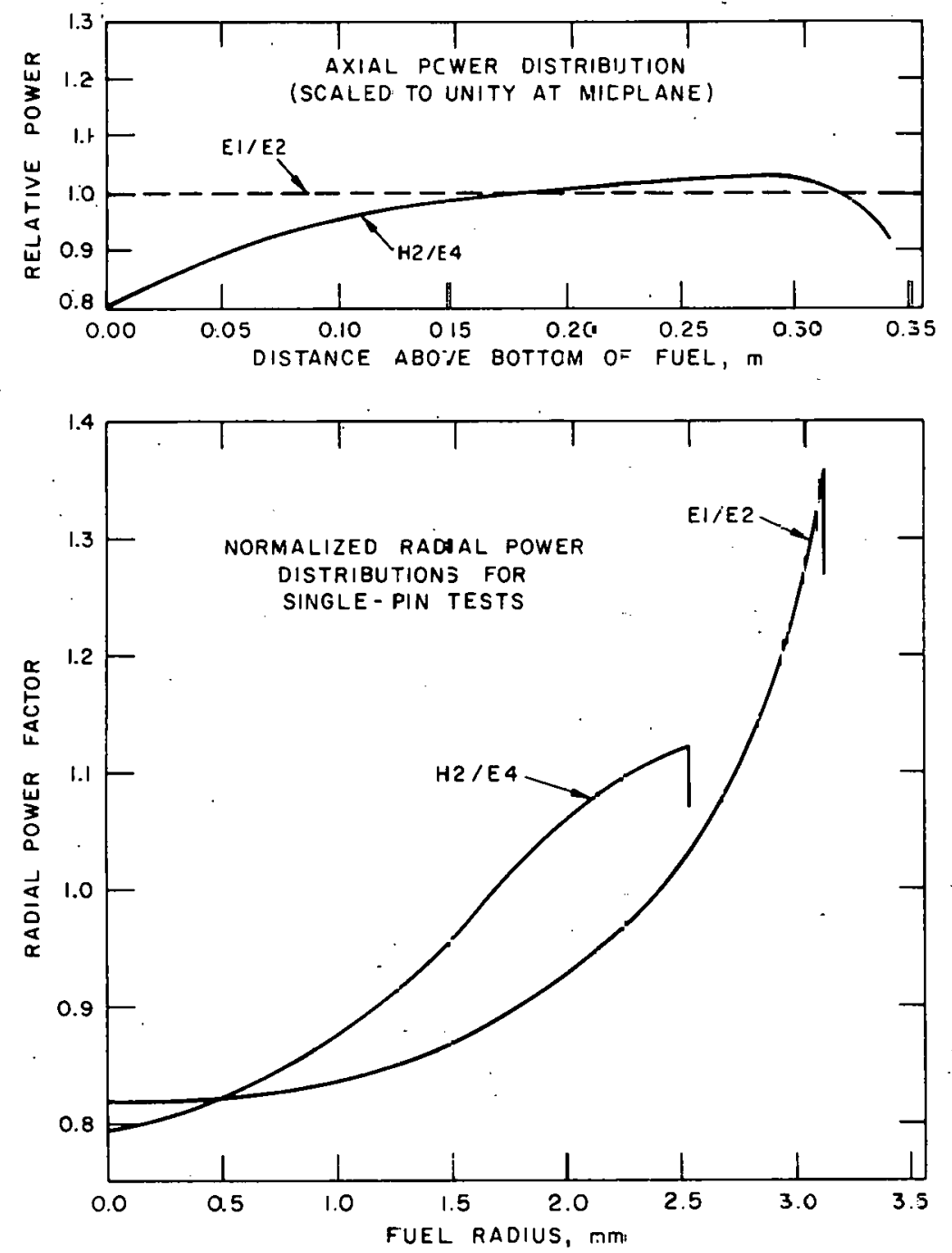

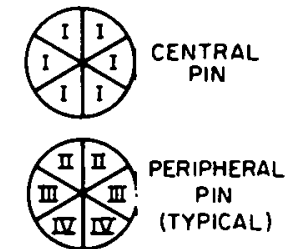

PIN SECTOR IOENTIFICATION (SECTORS II ALWAYS ADJACENT TO CENTRAL PIN)

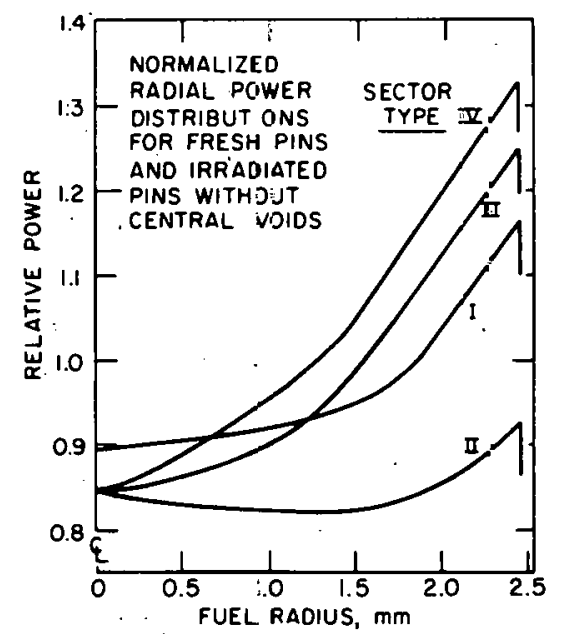

Fig. 7. Power Distributions for Seven-pin Tests
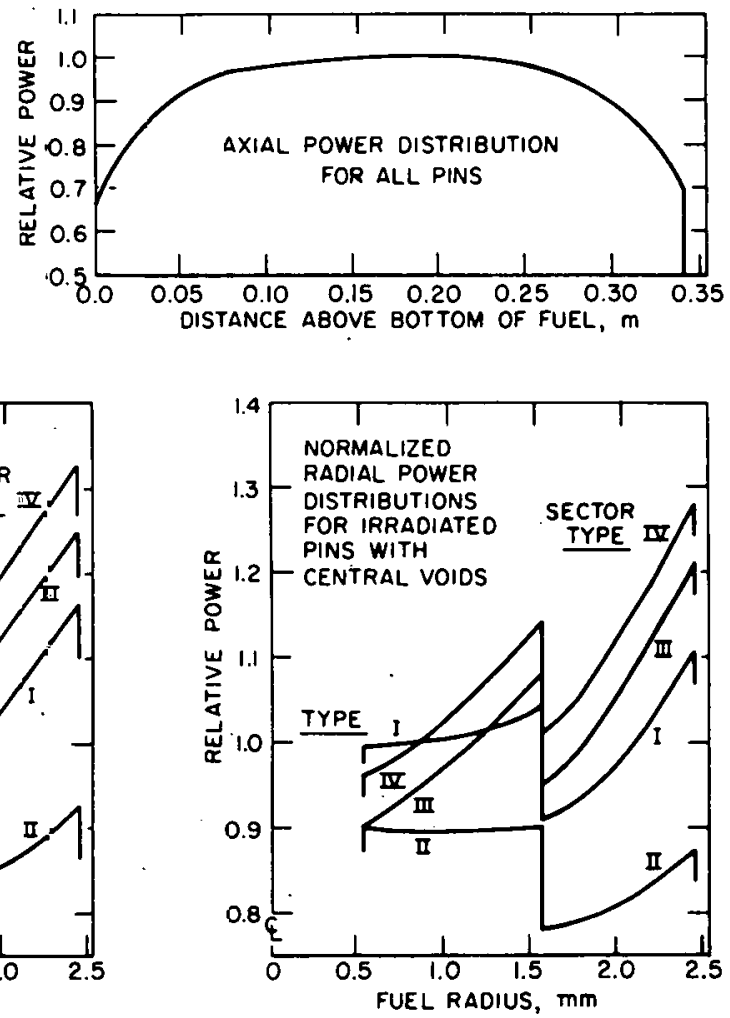

Fig. 6. Power Distribution for Single-pin Tests 
Early Tests E1, E2, and E3 were run without thermal-neutron filtering. The low enrichment of the test fuel and short fuel column led to acceptable radial power distribution without filtering. However, all the tests on mixed-oxide fuel pins have required thermal-neutron filtering to achieve an acceptable power distribution with the high effective enrichment. Tests $\mathrm{H} 2$ and $\mathrm{E} 4$ used $a \mathrm{~B}_{6} \mathrm{Si}$ filter which fit just inside the loop containment can and covered the entire loop. No axial shaping collars were used. This filtering method was not entirely satisfactory, because the'resulting radial power distribution was such that melting did not begin at the centerline.

Later Tests $\mathrm{H} 3, \mathrm{H} 4, \mathrm{H} 5, \mathrm{E} 6$, and $\mathrm{E} 7$ used $\mathrm{B}_{6} \mathrm{Si}$ filters applied directly to the loop wall and pump shell along with axial flux-shaping collars. The object of the collars was to produce an axial distribution coincident with that experienced by the irradiated pins during steady-state irradiation in EBR-II.

As one can see from Fig. 7, the power distribution in the seven-pin tests is quite complex. It has been characterized as a superposition of a radial distribution that is axisymmetric with respect to the axis of the central pin and a gradient across the cluster rising from flux depression on the pump side of the loop. For the calculations reported here, the central pin was taken to be axisymmetric, and each peripheral pin was taken to have the same intrapin distribution relative to the pin average power and with respect to a cluster radius through the axis of the pin. The radial power distribution used for calculations involving the NUMEC-F pins were corrected to account for redis tribution of fissile material during steady-state irradiation of the pins. Effects considered include different densities of the various structure zones and mi-. gration of fissile material due to temperature gradients. The basic calculations were supplied by HEDL. ${ }^{5}$

There was a substantial power gradient across the seven-pin cluster due to flux depression on the pump side of the loop. This gradient resulted in a power level in the coldest peripheral pin (toward the pump) that was only about $77 \%$ of that in the hottest peripheral pin (away from the pump). The two pins adjacent to the hottest one had the same power, while those adjacent to the coldest one had a power about $91 \%$ of the hottest. Central-pin and hottest-peripheral-pin calibration factors are given in Table III.

\section{Test Instrumentation}

As mentioned in Sec. I, instrumentation is provided in tests with the Mark-II loop for measurement of flow, pressure, temperature, and fuel movement. The instruments and their calibration are discussed here. Table V summarizes the instruments used for the Fuel Dynamics tests.

Loop flow was determined by two electromagnetic flowmeters, one measuring flow into the pin bundle and the other measuring flow out. The inlet flowmeter was located in the $19-\mathrm{mm}$-ID pipe just upstream of the entrance 
to the pin bundle; the outlet flowmeter was located about $0.89 \mathrm{~m}$ above the inlet. These locations were fixed by the loop design. In tests using NUMEC-F pins, the pins extended up through the outlet flowmeter.

TABLE V. Instrumentation Summary for TOP Tests ${ }^{a}$

\begin{tabular}{lcccccccccc}
\hline & H2 & H3 & H5 & El & E2 & E3 & E4 & E6 & E7 & H4 \\
\hline Inlet Flow & $\mathrm{x}$ & $\mathrm{x}$ & $\mathrm{N}$ & $\mathrm{x}$ & $\mathrm{x}$ & $\mathrm{x}$ & $\mathrm{x}$ & $\mathrm{x}$ & $\mathrm{x}$ & $\mathrm{x}$ \\
Outlet Flow & $\mathrm{x}$ & $\mathrm{x}$ & $\mathrm{x}$ & $\mathrm{x}$ & $\mathrm{x}$ & $\mathrm{x}$ & $\mathrm{x}$ & $\mathrm{x}$ & $\mathrm{x}$ & $\mathrm{x}$ \\
Inlet Pressure & $\mathrm{x}$ & $\mathrm{x}$ & $\mathrm{x}$ & $\mathrm{x}$ & $\mathrm{x}$ & $\mathrm{x}$ & $\mathrm{x}$ & $\mathrm{x}$ & $\mathrm{x}$ & $\mathrm{x}$ \\
Outlet Pressure & $\mathrm{N}$ & $\mathrm{x}$ & $\mathrm{x}$ & $\mathrm{x}$ & $\mathrm{x}$ & $\mathrm{x}$ & $\mathrm{x}$ & $\mathrm{x}$ & $\mathrm{x}$ & $\mathrm{x}$ \\
Inlel-sudiuin TC's & $\mathrm{l}$ & $\mathrm{l}$ & $\mathrm{l}$ & $\mathrm{l}$ & 1 & 1 & 1 & 2 & 2 & 2 \\
Outlet-sodium TC's & $\mathrm{I}$ & 5 & 3 & 1 & 1 & 4 & 1 & $<$ & 2 & 3 \\
Other TC's & $\mathrm{l}$ & $\mathrm{N}$ & 4 & 1 & 1 & $\mathrm{~N}$ & 1 & 3 & 4 & 7 \\
IIodoscope & $\mathrm{x}$ & $\mathrm{x}$ & $\mathrm{x}$ & $\mathrm{x}$ & $\mathrm{Q}$ & $\Omega$ & $\mathrm{N}$ & $\mathrm{x}$ & $\mathrm{x}$ & $\mathrm{x}$
\end{tabular}

$\mathrm{a}_{\mathrm{X}}=$ instrument present and operable; $\mathrm{N}=$ instrument not present or no usable data obtained; $Q$ = qualitative results only.

${ }^{\mathrm{b}}$ A uxiliary flowmeter in loop plenum added.

The inlet flowmeter was calibrated in place hy measuring the pressure drop across an orifice placed in the loop. A pressure-drop/flow curve for the orifice was determined out-of-loop using water. The outlet flowmeter was calibrated against the inlet flowmeter after test-section installation. A $1-A$ current was supplied to the magnet coils by a constant-current power supply. The dc output signal was fed directly to the TREAT amplifiers.

Pressure-measurement points were provided on the loop at locations just downstream of the inlet flowmeter and just upstream of the outlet flowmeter. Measurements were made using an unbonded-strain-gauge type of transducer mounted on $\mathrm{NaK}$-filled standoff tubes. A bellows separated the NaK from the loop sodium. The necessity for the standoff tubes arose primarily from space and operating-temperature limitations of the transducers. The Statham PG-732 transducer units wcrc factory-calibrated. Such calibrations were checked after installation of the standoff-tube assembly by comparison with the precision pressure gauge. A $5-\mathrm{V}, 5-\mathrm{kHz}$ excitation was supplied to the transducer by an oscillator-demodulator unit. The output signal, also of $5 \mathrm{kHz}$, was fed to the demodulator, which produced a dc signal that was fed to the TREAT amplifiers.

Temperatures were measured at various points near the pin bundle and in the supporting structure, using Chromel-Alumel thermocouples. Typically, measurements were taken at the pin-bundle inlet and outlet, and at one or more 
locations in the coolant stream, so that coolant temperatures or the presence of hot debris was determined. The exact placement of thermocouples varied from test to test:

All thermocouples were l:0-mm-dia stainless steel-sheathed with grounded junction. The wires were less than $0.25 \mathrm{~mm}$ in diameter and were insulated with magnesia. Individual thermocouples were not calibrated; standard calibration tables were assumed to apply. Important deviations from the standard curve were normally obvious, and small deviations (a few degrees) were not significant. The thermocouple signals were referenced to a $339 \mathrm{~K}$ cold junction.

From the TREAT amplifiers, signals were routed to one or two multispeed 14-track magnetic-tape recorder(s) which produced an FM record of the instrument signals. The same signals were fed to an oscillograph, which produced'a direct analog record of the signals. The magnetic tape was sampled at intervals as short as $\mathrm{l} \mathrm{ms}$ by an aralog-to-digital converter to produce digital data. These digital data formed the basis from much of the information reported.

Power-transient data were obtained from ionization chambers located in the reactor shield. Four signals were produced, two of which are used to determine the instantaneous power level and two to determine integrated power. Reactor power and reactor energy release are related to sample power and sample energy release through the power-calibration factor. This factor was derived from measurements of pin activation resulting from steadystate irradiation normalized to comparative activities of monitor wires exposed to steady-state and transient irradiations. Radiochemical analyses of fuel from the central pin and the hottest peripheral pin irradiated during Test $\mathrm{H} 3$, conducted as soon as possible after the test, provided confirmatory data on the radially averaged fission density due to transient irradiation.

\section{E. Reactor Power Transients}

The power transients used for the tests considered in this report fall into two categories: natural temperature-limited transients and shaped transients. Temperature-limited transients were initiated by a step insertion of reactivity, and the reactor power was allowed to vary naturally. The power was limited by the negative temperature coefficient of reactivity of the reactor, such that an approximately Gaussian power-time curve was obtained. The initial period, maximum power level, and integrated power were determined by the initial reactivity step, although the transient could be terminated early by a scram. Experiments using such transients included El, E2, E3, $\mathrm{E} 4$, and $\mathrm{H} 2$. In these cases, the initial condition was isothermal. Because the transient was initiated by a step reactivity increase, the power-time curve did not match that of a ramp accident. Transients typical of those used for the above tests are plotted in Fig. 8. 


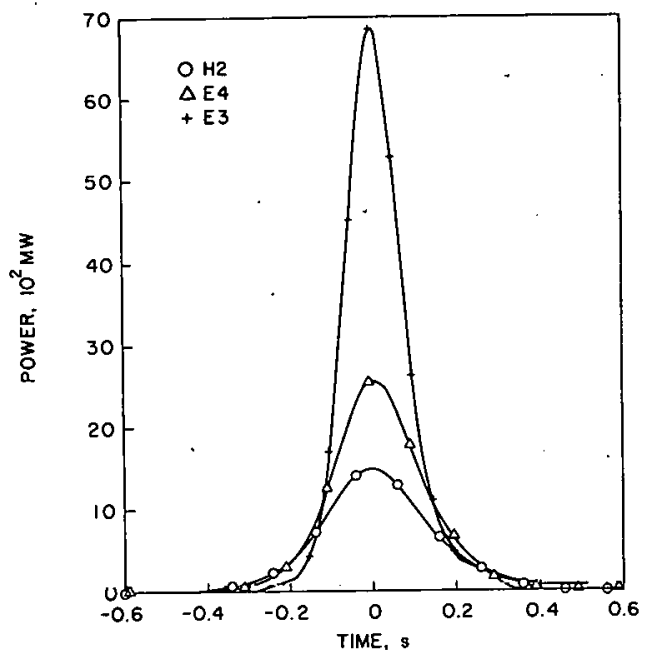

Fig. 8. Characteristics of Natural Transients in TREAT

Shaped transients using a feedbackcontrol system have been possible for the past 2 yr. In such transients, the power level or period can be prescribed as a function of time, and the control system will move rods to produce the desired curve. This system has been used to produce transients having a constant-power preheat phase followed by a power rise on a controlled period that produces a thermal history similar to that of a ramp reactivity-addition accident. Such transients were used for Tests $\mathrm{H} 3, \mathrm{H} 4, \mathrm{H} 5, \mathrm{E} 6$, and E7. The transients used are shown in Fig. 9.

\section{F. Correlation to FTR Accident Conditions}

Test conditions have been correlated to FTR accident conditions for each test in which prototypic fuel was used. The correlation was done by comparing the radially averaged fuel enthalpy and the cladding surface temperature calculated for the tests with corresponding values calculated for the FTR by HEDL. ${ }^{6}$ Comparisons were done using the axial midplane values. (Actually, values $25.4 \mathrm{~mm}$ above the midplane were used for the FTR cases.) For the E-series tests (and $\mathrm{H} 2$ ), the comparison was made with a $3 \$ / \mathrm{s}$-rampacident calculation; a $0.5 \$ / \mathrm{s}-$ ramp accident. calculation was used for comparison with the $\mathrm{H}$-series tests (except $\mathrm{H} 2$ ). In each accident calculation, pins having ratings of $40.7 \mathrm{~kW} / \mathrm{m}$ (high power) and $30^{\circ} \mathrm{kW} / \mathrm{m}$ (intermediate power) were considered.

The comparison was made by plotting the enthalpy-time and temperaturetime curves for the reactor and for the test. on the same scale, and then sliding one curve over the other until the best match was realized. Clearly, such a comparison is not unique. The time scale plotted is test time; the zero of the reactor-transient time scale is shifted as necessary.

Figures 10 and 11 illustrate the reor -

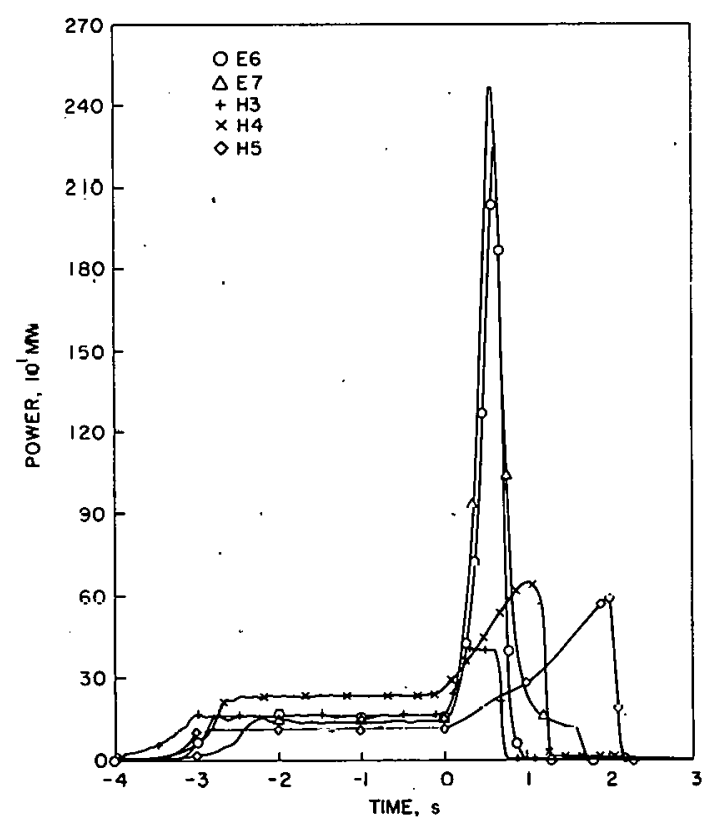

Fig. 9. Characteristics of Shaped Transients in TREAT relation of Tests $\mathrm{H} 2$ and E4, respectively, with the $3 \$ / \mathrm{s}$ FTR accident. One sees that the shapes of the thermal-history curves for the tests differs from the accident and exhibit more rapid changes early in the transient. However, by the time of pin failure (in the tests), the rates had decreased to values comparable to: or less than those of the accident. This behavior is especially notable tin the $\mathrm{H} 2$ case. 

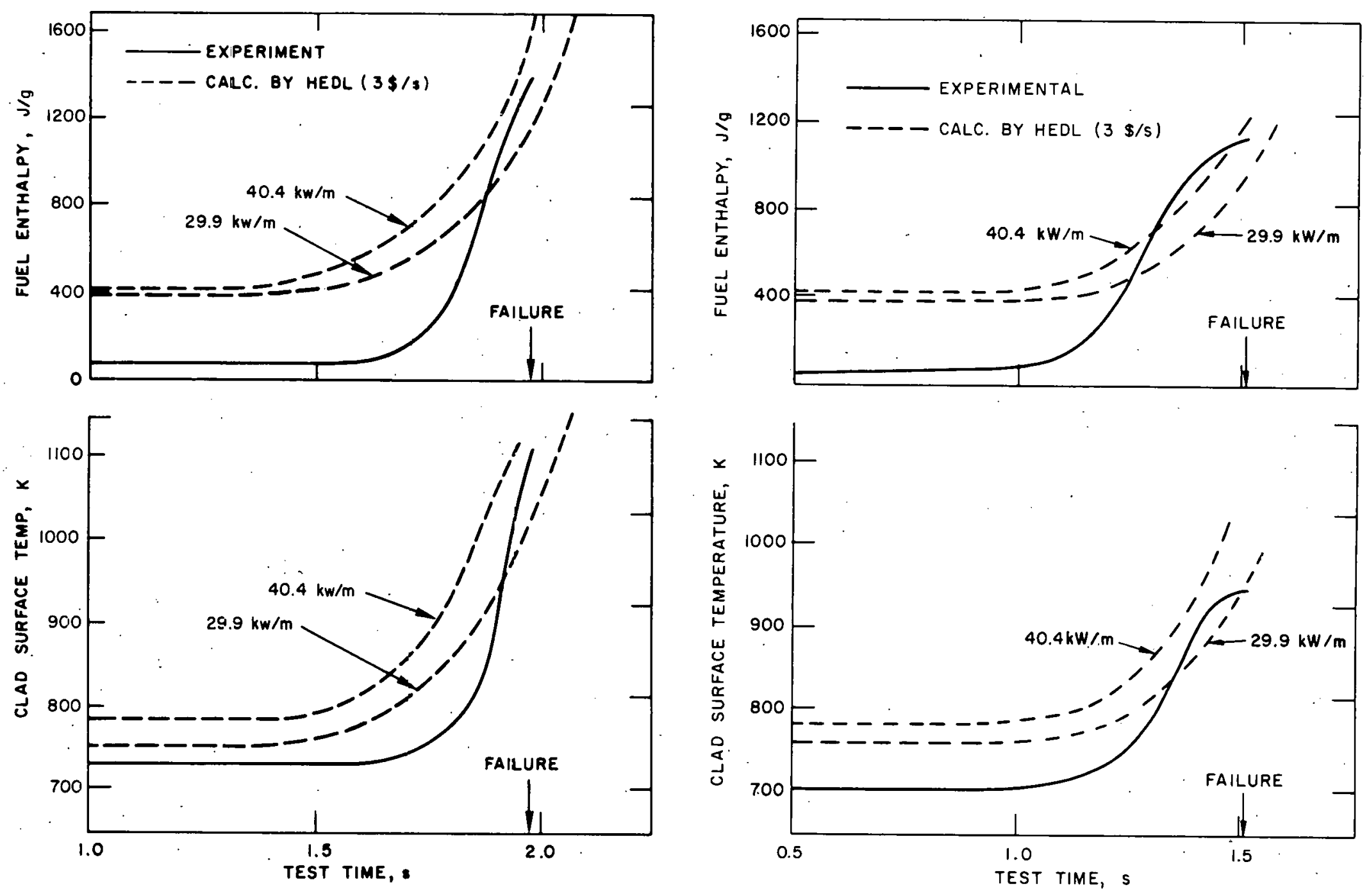

Fig. 10. Comparison of Test $\mathrm{H} 2$ and $\Xi T R$ Thermal Histories

Fig. 11. Comparison of Test E4 and FTR Thermal Histories 
A much better correlation is generally seen in Figs. $12-16$ in which correlations for the shaped transients $\mathrm{H} 3, \mathrm{H} 4, \mathrm{H} 5, \mathrm{E} 6$, and $\mathrm{E} 7$ are presented. The beneficial effect of the shaped transients is clearly indicated. Note that some tendency is exhibited for the $\mathrm{H}$-series tests to develop higher thermal rates late in the transients. In general, the deviations up to failure do not exceed $55.6 \mathrm{~K}$ or $42 \mathrm{~J} / \mathrm{m}$. Such agreement is quite good.
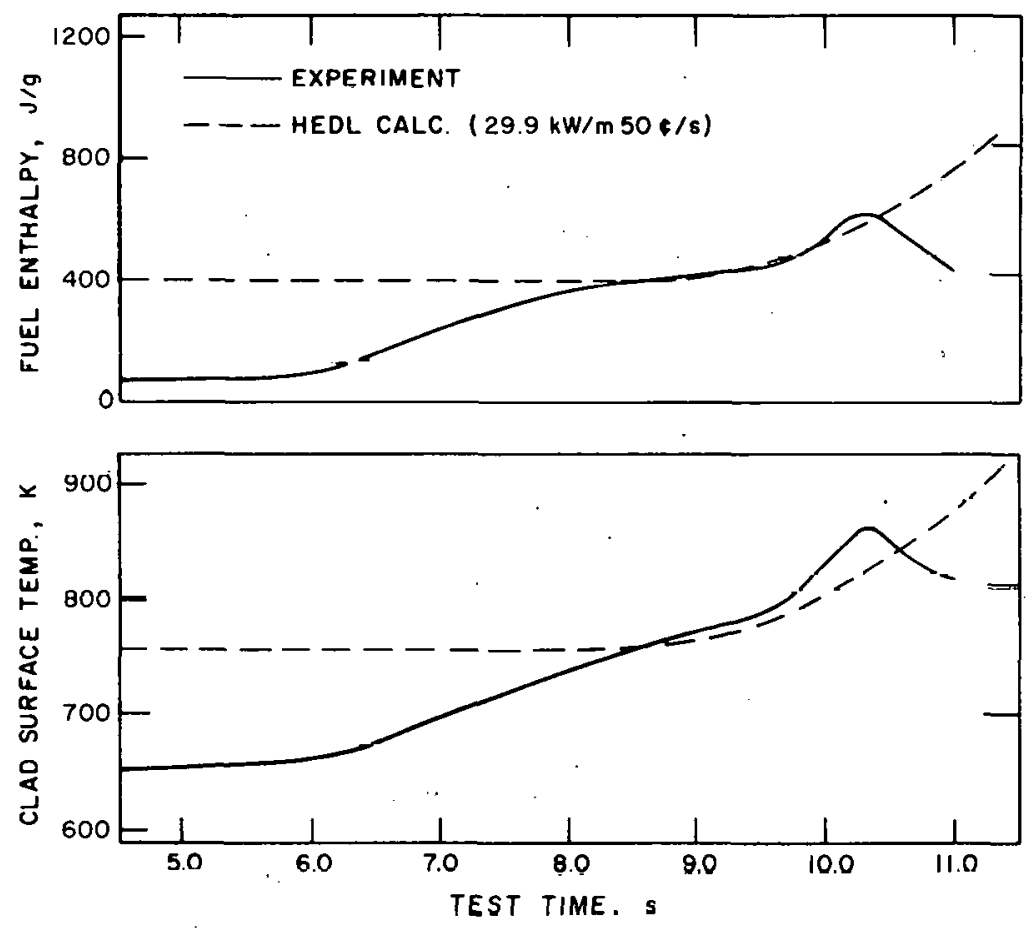

Fig. 12

Comparison of Test $\mathrm{H} 3$ and FTR Thermal Histories

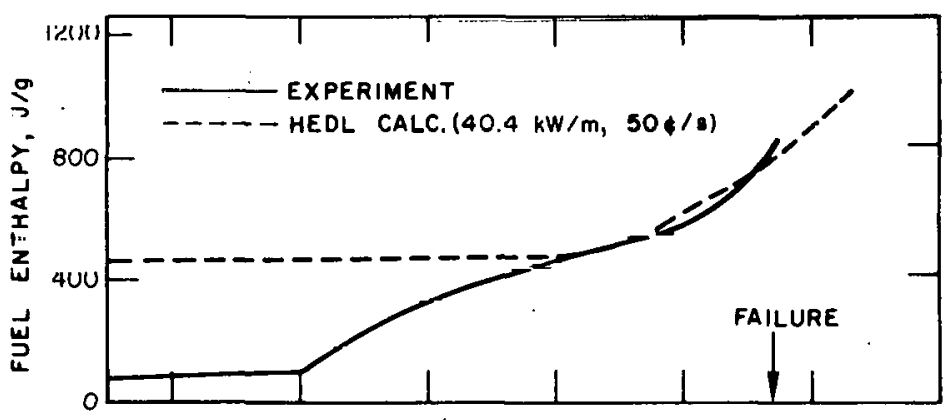

Fig. 13

Comparison of Test $\mathrm{H} 4$ and FTR Thermal Histories

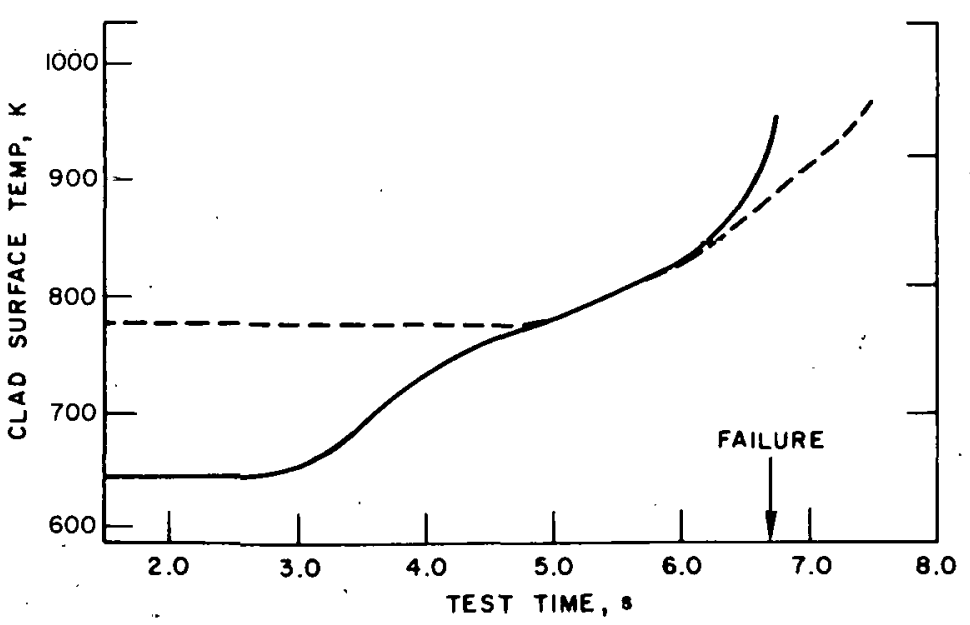



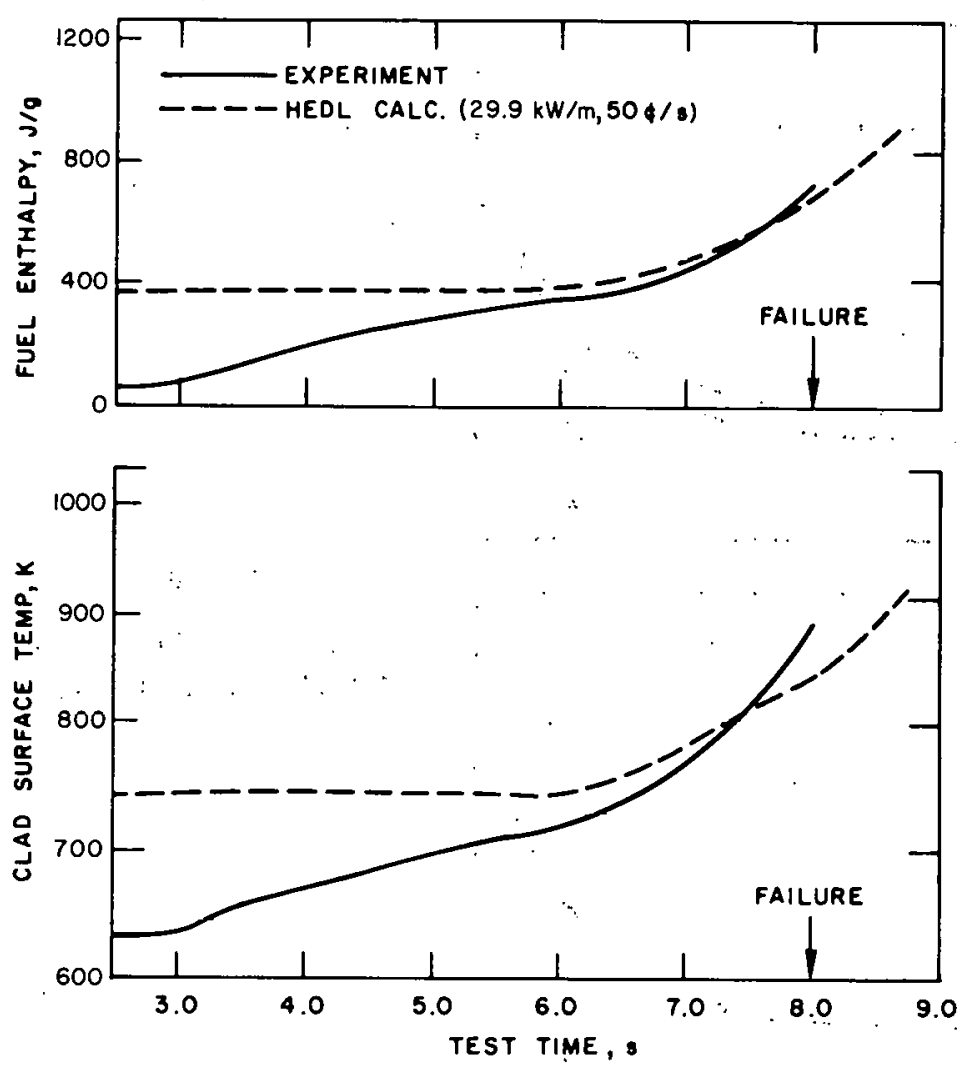

Fig. 14

Comparison of Test $\mathrm{H} 5$ and FTR .Thermal Histories

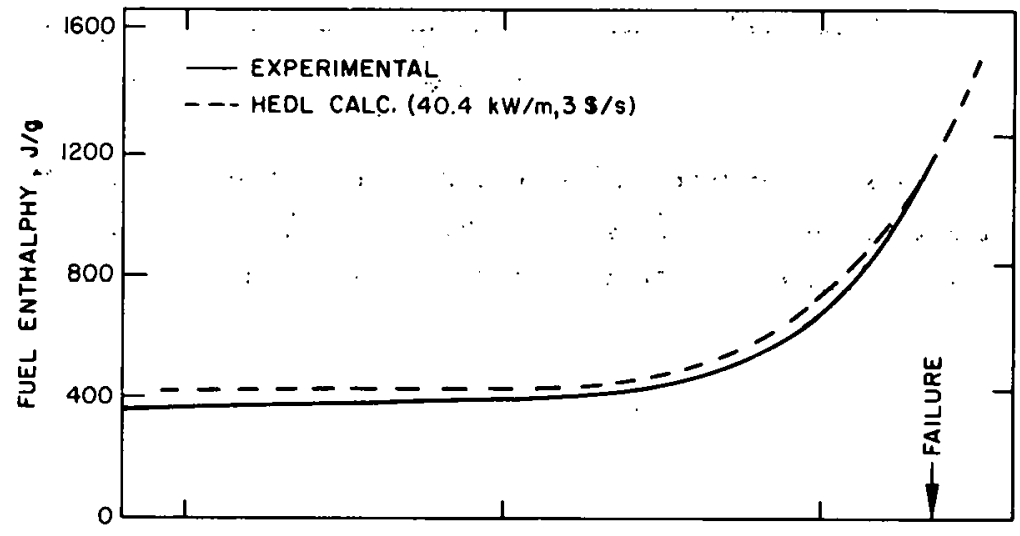

Fig. 15

Comparison of Test E6 and FTR Thermal Histories

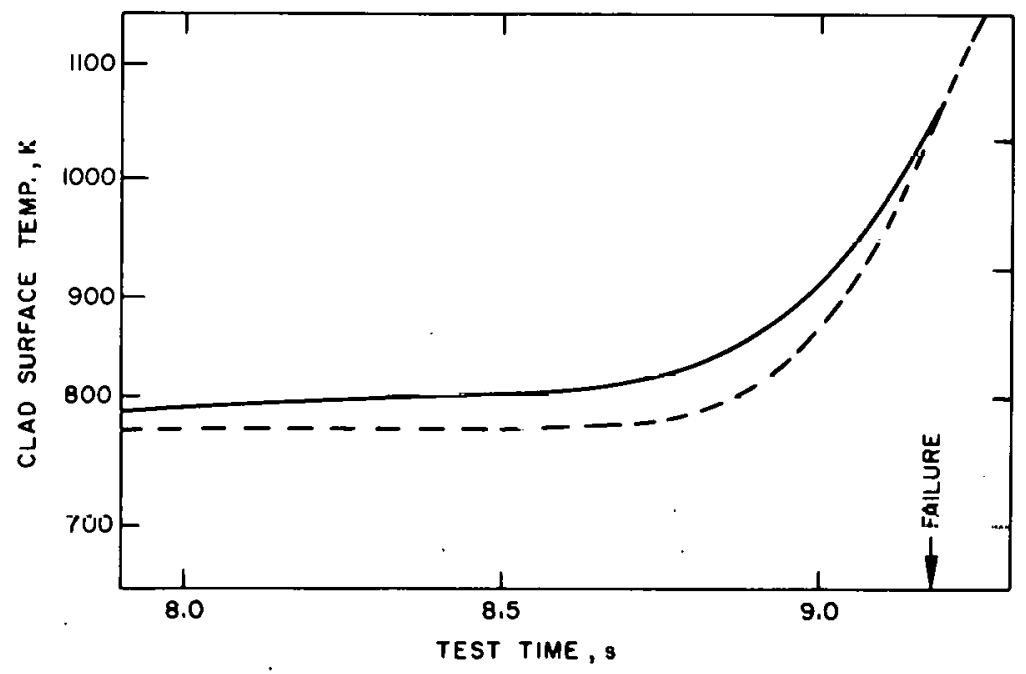



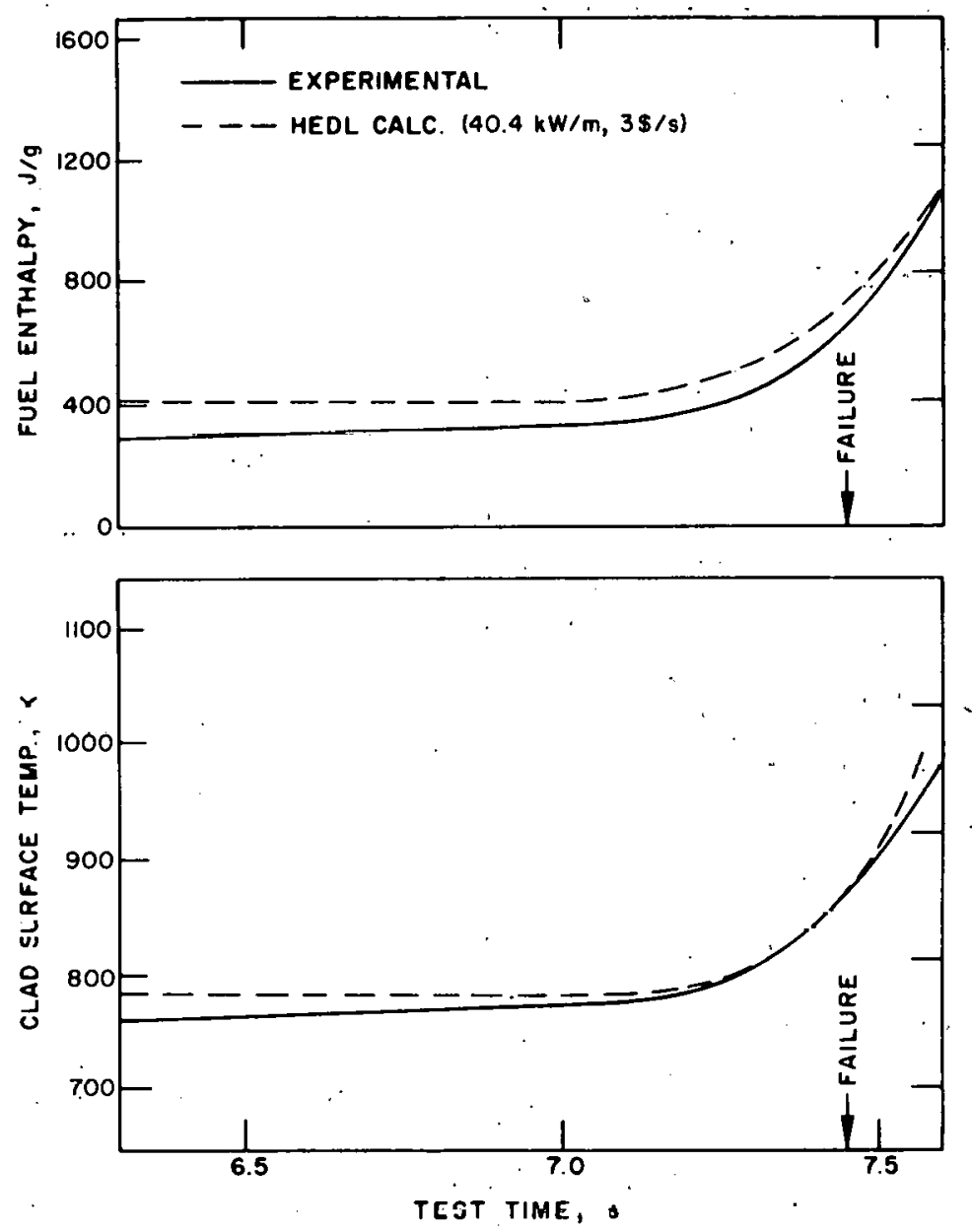

Fig. 16

Comparison of Test E7 and FTR Thermal Histories

Tests E6 and E7 show a very good correlation to the $3 \$ / \mathrm{s}$ FTR accident as indicated in Figs. 15 and 16 . The thermal rates and values at failure in the test correspond quite well to the FTR values. 


\section{EXPERIMENTAL RESULTS .}

This section summarizes the results of the experiments, discussed in this report. Included are a summary of the test data, the results of calculations of the thermal history of the fuel up to failure, a summary of hodoscope and posttest examination data where available, and a scenario of events during the test as derived from our current understanding of the data and calculations.

\section{A. Test $\mathrm{H} 2$}

Test H2 was the first Mark-II loop experiment in which an FFTFtype mixed-oxide fuel pin was heated to failure in an overpower transient simulation. A single PNL-17 fuel element (PNL-17-42) was used after modification by shortening to an overall length of $0.784 \mathrm{~m}$ and replacement of the spacer wire with one of $1.0-\mathrm{mm}$ diameter. The fuel holder was a doublewalled "adiabatic" design with the space between the tubes evacuated. Dimensions of the inner tube were $8.28 \mathrm{~mm}$ ID by $9.86 \mathrm{~mm}$ OD; the outer wall was $11.0-\mathrm{mm}$ ID by $12.6-\mathrm{mm}$ OD.

Figure 17 gives the TREAT power and energy histories for Test $\mathrm{H} 2$. Also included are the energy generated in the fuel and the retained fuel energy, both averaged radially at the elevation of the maximum values. Flow and pressure data from the test are plotted in Fig. 18. The pressure transducer at the outlet produced no data due to a failure in the readout circuitry. Integrated flows past the upper and lower flowmeters are shown in Fig. 19 with an arbitrary zero point on the scale. The difference between the values for the two flowmeters at any time is the net void volume at that time.
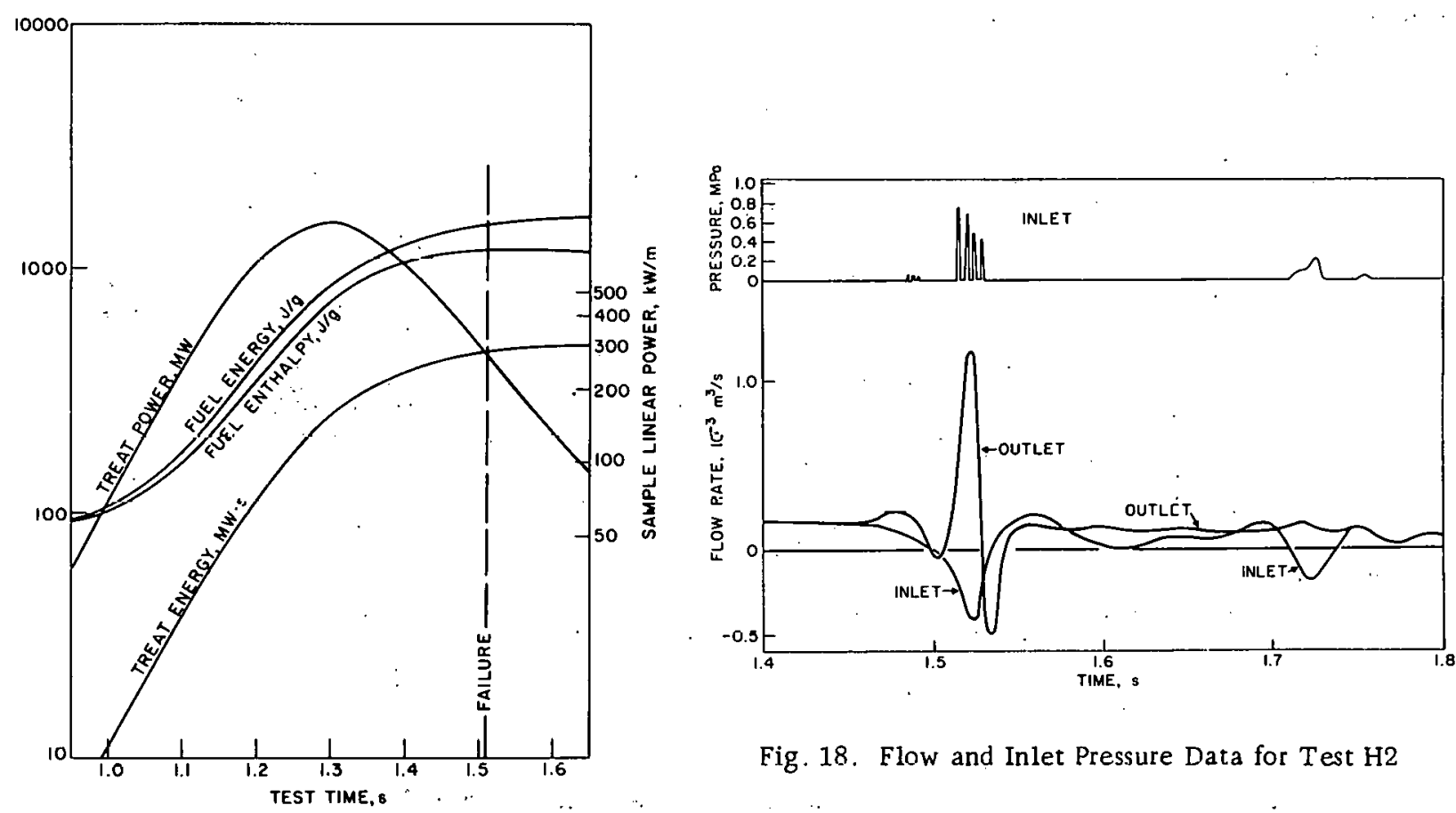

Fig. 18. Flow and Inlet Pressure Data for Test $\mathrm{H} 2$

Fig. 17: Power and Energy for Test H2 


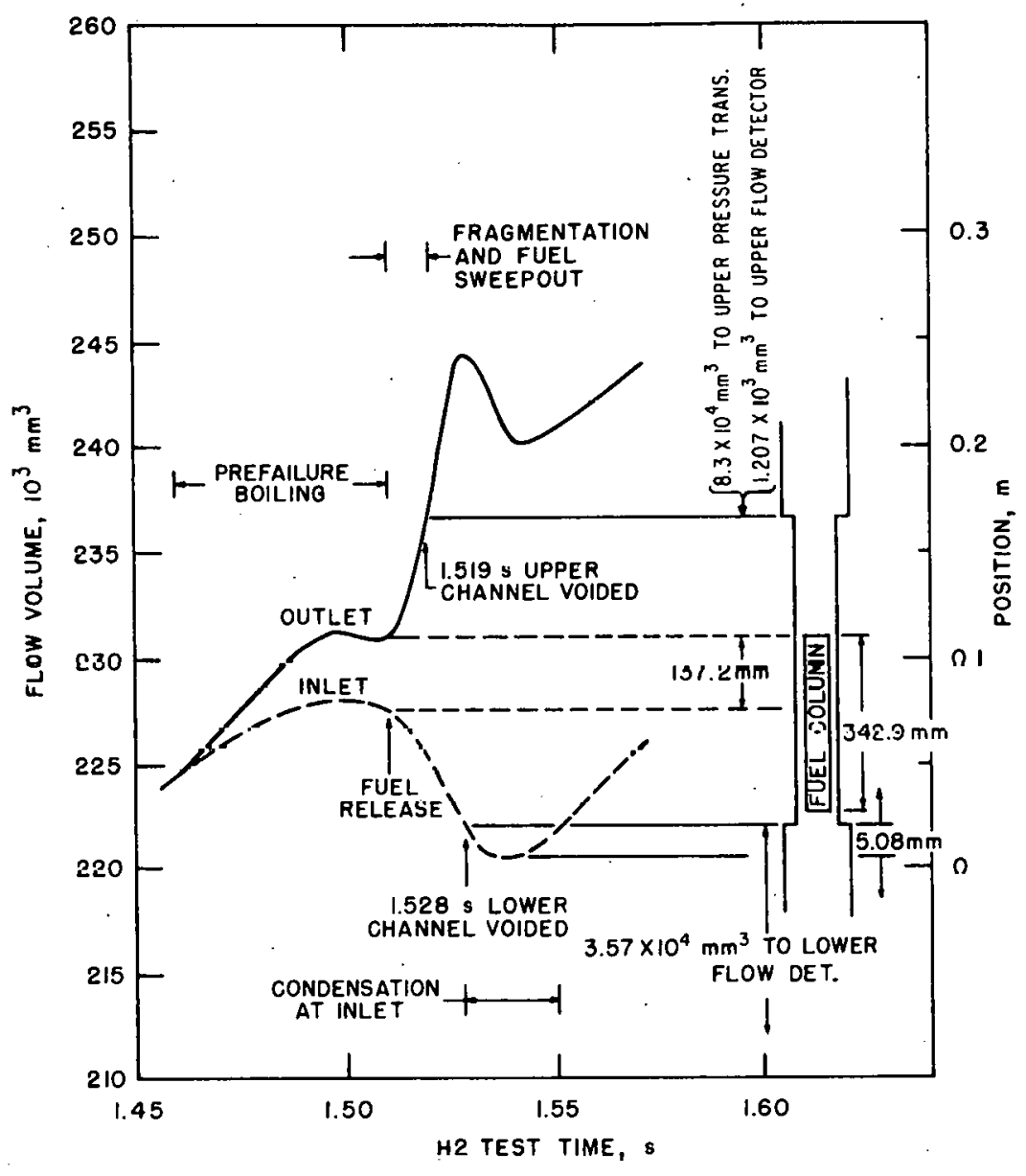

Fig. 19

Integrated Flow (Void History) in Test H2. The sketch and scale at the right side relate void volume to linear dimensions of the flow channel and fuel column. The 137.2-mm void section at failure is assumed to grow dnwnward from the top of the fuel column. Fuel release after 1.528 s woủld not be manifest in the fluw dynamics.

Calculated and measured coolant temperatures and calculated fuel temperatures are given in Fig. 20, along with an indication of some events of significance in the transient. Calculated areal fractions above the liquidus and solidus temperatures and the progression of melting are also shown in Fig. 20 for the hottest axial node.
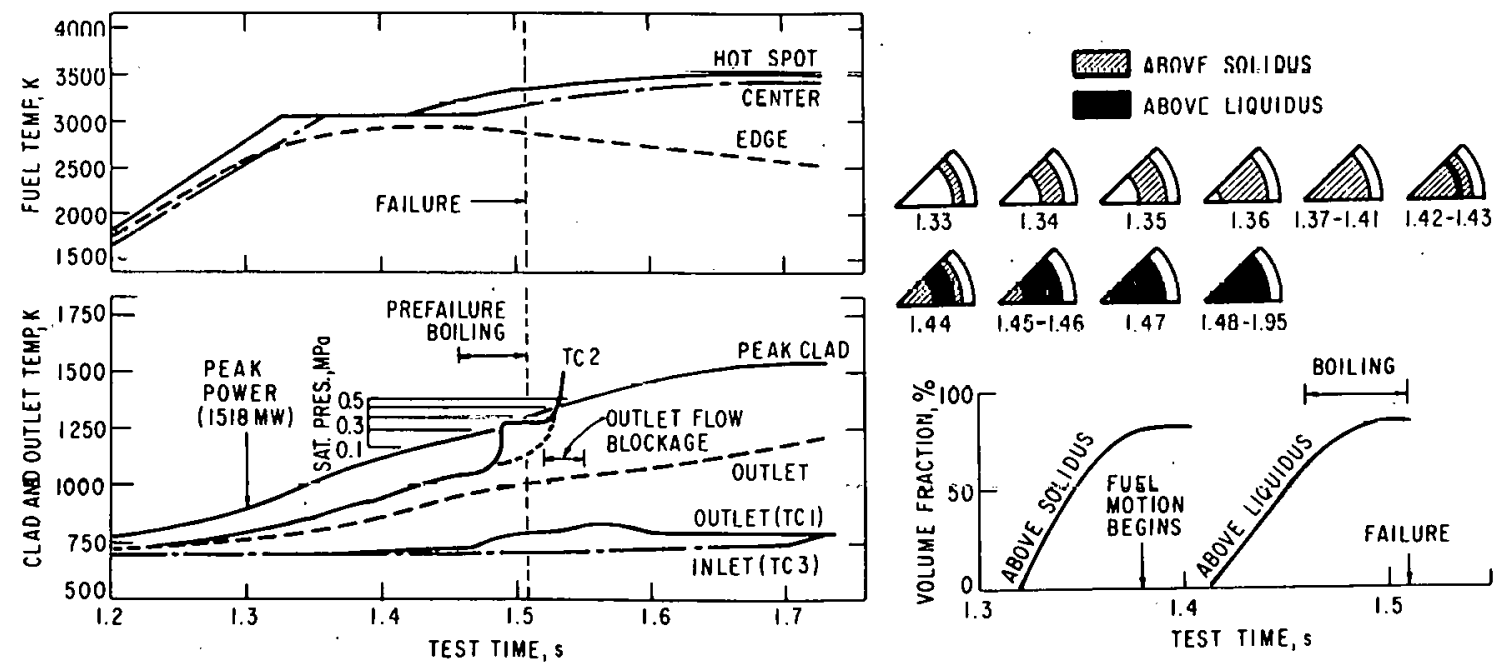

Fig. 20. Thermal History for Test H2. Calculated fuel temperatures are shown in the top left panel. Calculated cladding and coolant temperatures, and measured coolant temperatures, are shown in the lower left panel. The progression of fuel melting at the hottest axial node is at the right. 
The voiding curve shows that vapor generation began at about $1.46 \mathrm{~s}$, with about $3500 \mathrm{~mm}^{3}$ of vapor being formed by $1.50 \mathrm{~s}$. This vapor generation probably reflects local boiling under or just downstream of the spacer wire, which would account for the apparent upward motion of the void with the flow stream. Several very small pressure pulses $(69 \pm 69 \mathrm{kPa})$ were observed in the interval from 1.48 to $1.49 \mathrm{~s}$, probably corresponding to collapse of vapor bubbles in the channel above the fuel column. Void growth stopped at $1.50 \mathrm{~s}$, reflecting a balance between vapor production and condensation.

The temperature calculations indicate that peak cladding surface temperatures in the range of saturation at $0.1-0.2 \mathrm{MPa}$ existed by $1.46 \mathrm{~s}$, when vapor generation began. Thus, the calculations verify the presence of at least local boiling before failure. Note also that TC3, located near the top of the fuel column, oscillated in reading between saturation at about $0.25 \mathrm{MPa}$ and a lower value beginning at about $1.45 \mathrm{~s}$.

A sudden increase in the rate of void growth at $1.51 \mathrm{~s}$, accompanied by a series of four pressure pulses, marked the time of cladding failure and release of fuel into the partially voided channel. Thus, failure occurred 45$50 \mathrm{~ms}$ after boiling began. This interval is consistent with an estimate of the time required to dry out a liquid film adhering to the cladding tube.

At $1.522 \mathrm{~s}$, the acceleration of the upper sodium slug became negative, and reentry began $12 \mathrm{~ms}$ later. This flow reversal was due to reduction of pressure in the fuel region, probably due to condensation of vapor and rupture of the holder wall. Failure of the holder wall by melthrough was found in several spots--one very near the top of the fuel column--in posttest examination. Reentry of the upper slug terminated by $1.54 \mathrm{~s}$, without penetration of liquid back into the hot fuel zone. At about this same time, the inlet flow became positive and a period of quiescent behavior began.

The apparent steady flow in the interval between about 1.55 and $1.7 \mathrm{~s}$ suggests a certain amount of through flow, which would surely lead to interaction with hot fuel and production of pressure pulses and slug ejections. Neither of these phenomena was observed. The flow measurement at the inlet indicated reentry of $8000 \mathrm{~mm}^{3}$ of sodium between 1.58 and $1.7 \mathrm{~s}$. This is just enough to contact the lower $25 \mathrm{~mm}$ of the fuel column (assuming that the inner holder wall has ruptured), leading to the observed ejection at $1.71 \mathrm{~s}$.

Hodoscope data suggest an initial sharp bending of the pin near the top of the fuel column as early as $1.3 \mathrm{~s}$, with a general bowing over the entire length occurring by about $1.33 \mathrm{~s}$. This motion is coincidental with the initial approach to solidus temperatures in the fuel pin. A definite indication of upward fuel flow began at $1.36 \mathrm{~s}$ (150 ms before pin failure) and continued at a nearly constant $r$ ate for $\sim 200 \mathrm{~ms}$. Molten fuel appeared to move against or around the upper insulator pellets. Initial fuel motion was from the region about $25 \mathrm{~mm}$ below the top of the fuel column. Later fuel flow seemed to be 
from the lower into the upper regions of the pin. After failure, there was some slight evidence of fuel entering the flow channel. However the precise time of fuel release into the flow channel cannot be determined from the hodoscope data. (Due to the signal-to-noise ratio of the hodoscope, the threshold of detection for fuel addition is much larger than that for fuel depletion.)

There was no indication of fuel slumping or downward movement from the cladding-failure region; motion of fuel upwards out of the original fuel region was the predominant motion.

Posttest examination suggested that molten fuel from the lower region of the fuel column flowed upward through a tubular-shaped shell of fuel that never did melt. Sections of intact cladding tube were found over the bottom $25 \mathrm{~mm}$ of the pin, despite the presence of once-molten fuel and cladding that formed a porous flow-channel plug in that region. Most of the fuel was found frozen to the holder walls as large chunks, many of which could be easily broken lnto small pieces. Accumulation of frozen debris about $25 \mathrm{~mm}$ above and below the top of the fuel column caused a partial flow blockage at the outlet.

Both flow-channel blockages were relatively porous (about one-third void by volume) and consisted of mixtures of steel and fuel. The generally homogeneous nature of the fuel-steel mixture found on the holder wall suggests that hot or molten fuel melted the cladding and both moved as a mixture. An apparent propensity for increasing steel fractions in the lower region, especially in the lower plug, may be due to a small amount of cladding melting before fuel release, especially at the bottom of the pin. One example of molten cladding slumping downward was seen about $25 \mathrm{~mm}$ above the bottom of the fuel column, but the amount of material was small and did not seem. to significantly affect the formation of the lower plug.

All the sodium was flushed from the loop and reacted with alcohol in an attempt to reclaim any fuel fines that were expected to be swept out of the flow channel. Less than $5 \mathrm{~g}$ of debris was found, and most of this had a density of less than $4000 \mathrm{~kg} / \mathrm{m}^{3}$. No measurable quantity of fuel was found.

The test data do not clearly identify the initial failure point, the mechanisms that cause fuel to move, or the sequence of fuel motion after initial release. A sequence, not inconsistent with the data or available analytical models, includes prefailure upward flow of fuel inside the pin, leading to contact of the molten fuel with the cladding. Local loss of cooling due to local boiling allows the fuel to melt the cladding in the upper insulator region. Mixing of the fuel-cladding slush with the two-phase coolant initiates rapid vapor production and complete voiding of the channel. Vapor from prefailure boiling could account for the mild pressure pulses and low energy conversion.

Only that fuel released during the first $10-15 \mathrm{~ms}$ after failure can be swept out with the flow stream, since the channel is essentially voided afterwards. The outlet-channel plug apparently was formed during this interval, 
while the lower plug may have formed in two stages. Fuel released later than $\sim 15 \mathrm{~ms}$ after failure entered a completely voided channel and froze on the holder wall, with some melthrough. If the release rate remained constant, fuel motion should have been complete within $\sim 75 \mathrm{~ms}$.

A summary scenario for Test $\mathrm{H} 2$ is given in Table VI.

TABLE VI. Summary Scenario for Test $\mathrm{H} 2$

\begin{tabular}{|c|c|}
\hline TREAT Time, $s$ & Event and Evidence \\
\hline 1.32 & $\begin{array}{l}\text { Hottest axial fuel node (just above midheight) ap- } \\
\text { proaches solidus. }\end{array}$ \\
\hline 1.34 & Pin bowing at top noted by hodoscope. \\
\hline 1.36 & $\begin{array}{l}\text { Cladding gap closes at hot node. Maximum areal } \\
\text { fraction above solidus reached. Bowing over pin } \\
\text { length observed by hodoscope. }\end{array}$ \\
\hline 1.38 & Liquidus temperatures reached. \\
\hline 1.45 & $\begin{array}{l}\text { TC2 indicates higher-than-calculated coolant tem- } \\
\text { perature. Possible vapor formation. }\end{array}$ \\
\hline 1.46 & Vapor generation evident from flow and void data. \\
\hline $1.48-1.49$ & $\begin{array}{l}\text { Small inlet pressure pulses, believed due to vapor- } \\
\text { bubble collapse. }\end{array}$ \\
\hline $1.36-1.56$ & $\begin{array}{l}\text { Upward fuel motion at constant rate observed on } \\
\text { hodoscope. }\end{array}$ \\
\hline 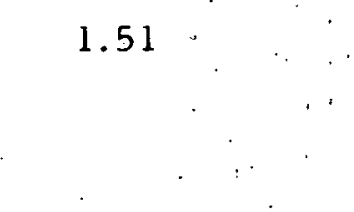 & $\begin{array}{l}\text { Pin failure; release of molten fuel into flow channel. } \\
\text { Sodium slugs ejected from both ends of flow channel } \\
\text { with } \sim 760-\mathrm{kPa} \text { pressure pulses at inlet. TC2 burn } \\
\text { out. }\end{array}$ \\
\hline $1.51-1.52^{\circ}$ & Liquid reentry from both ends of flow channel. \\
\hline $1.59-1.70$ & $\begin{array}{l}\text { Local boiling observed in flow data (small } \\
\text { oscillations). }\end{array}$ \\
\hline 1.72 & $\begin{array}{l}\text { Reentry FCI. Inlet slug ejection. Little correlated } \\
\text { activity at outlet suggests outlet blockage by fuel } \\
\text { plug. }\end{array}$ \\
\hline 1.9 & $\begin{array}{l}\text { End of available flow data. Tendency for slow de- } \\
\text { crease noted. Posttest examination suggests outlet } \\
\text { blockage. }\end{array}$ \\
\hline
\end{tabular}


B. Test E4

Geometrically, Test E4 was identical to Test H2. Pin PNL-17-43.

was used. A more energetic TREAT transient was specified. Figure 21 shows the reactor and fuel-pin power, as well as energy data. The flow and pressure data are plotted in Fig. 22. Note that the flow data between 1.97 and $2.01 \mathrm{~s}$ are

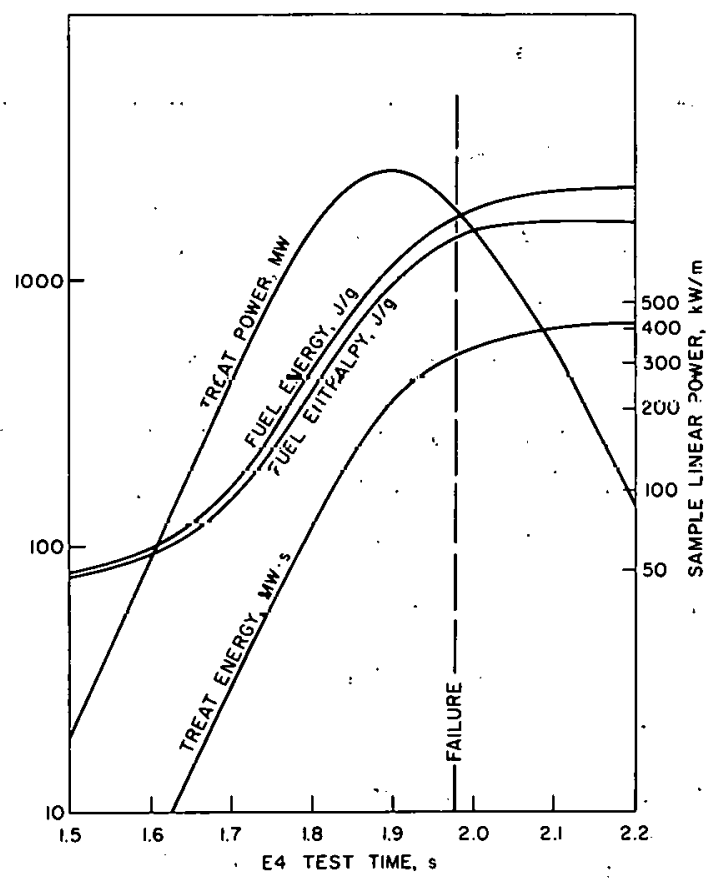

Fig. 21

Pöwer and Energy for 'I'est E4

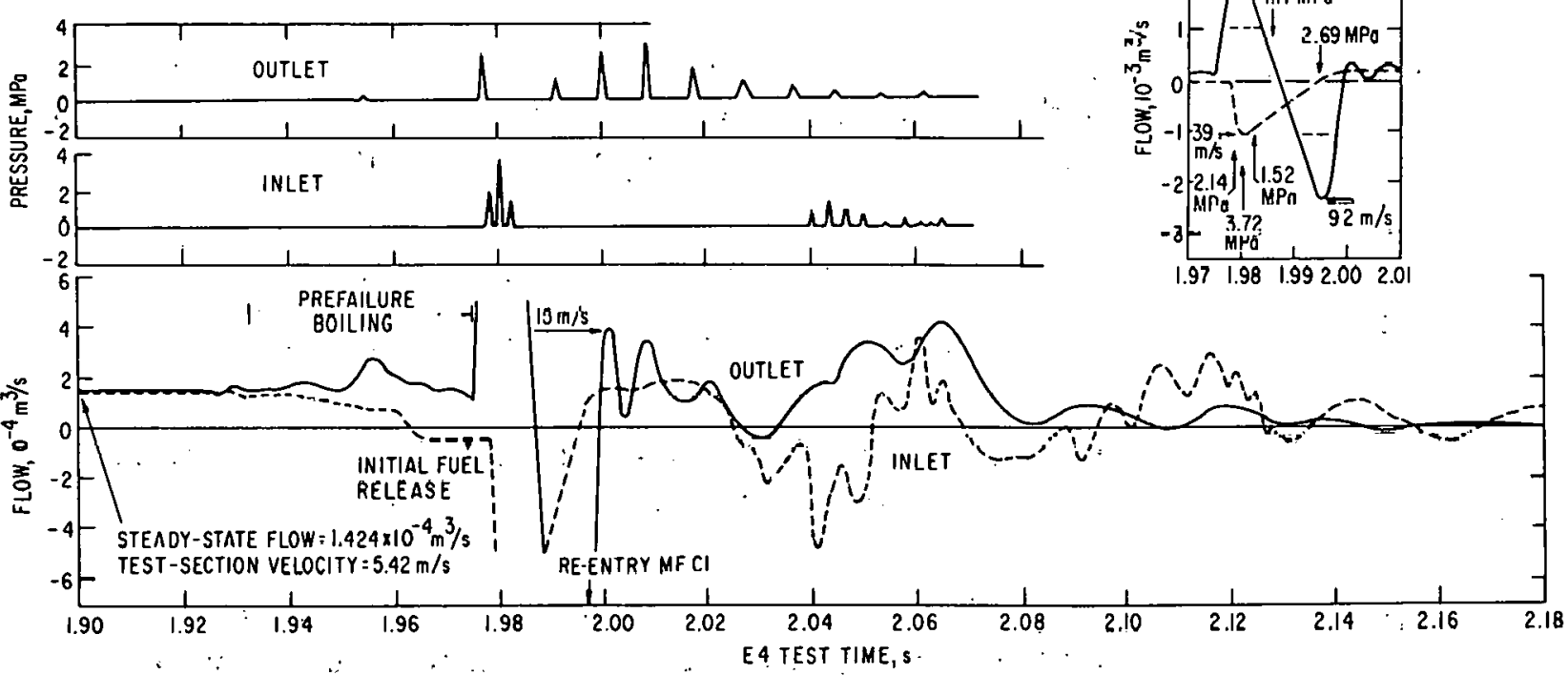

Fig. 22. Flow and Pressure Data for Test E4. The-insert shows the estimated flow with the time; the amplitudes measured inlet and outlet pressure pulses. Flowmeters went off-scale at $1000 \mathrm{~cm}^{3} / \mathrm{s}$ as indicated by dashed lines in the flow curve. The scale for pressure data after $2.0 \mathrm{~s}$ is half that shown. 
plotted separately. These results are estimated from the neighboring velocities and accelerations, since the flowmeters went off-scale during this interval. Integrated flow curves are shown in Fig. 23, along with the apparent void volume. Calculated and measured temperatures are given in Fig. 24, along with the areal fractions of fuel having temperatures in excess of solidus and liquidus temperatures.
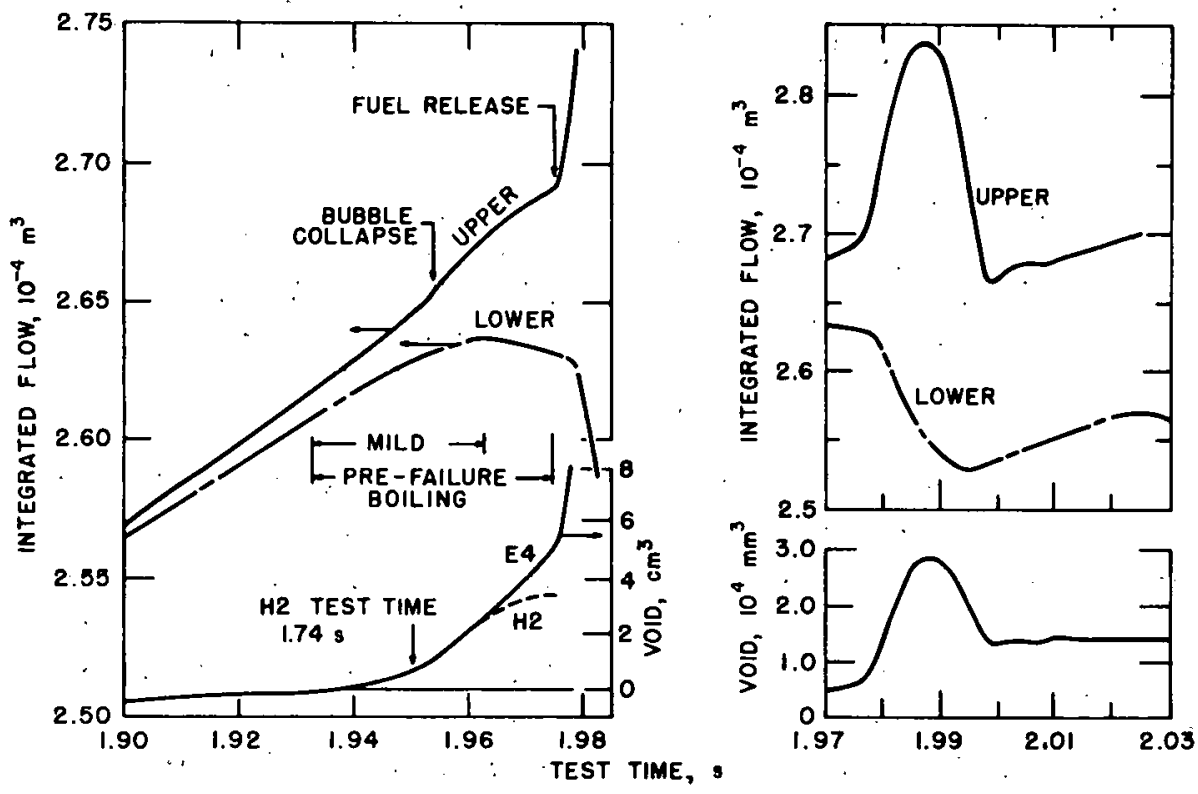

Fig. 23

Integrated Flow and Void Volume for Test E4. Void size during Test $\mathrm{H} 2$ is shown for comparison. The time during which the two void curves are identical (1.930-1.965 s) is referred to as mild boiling.
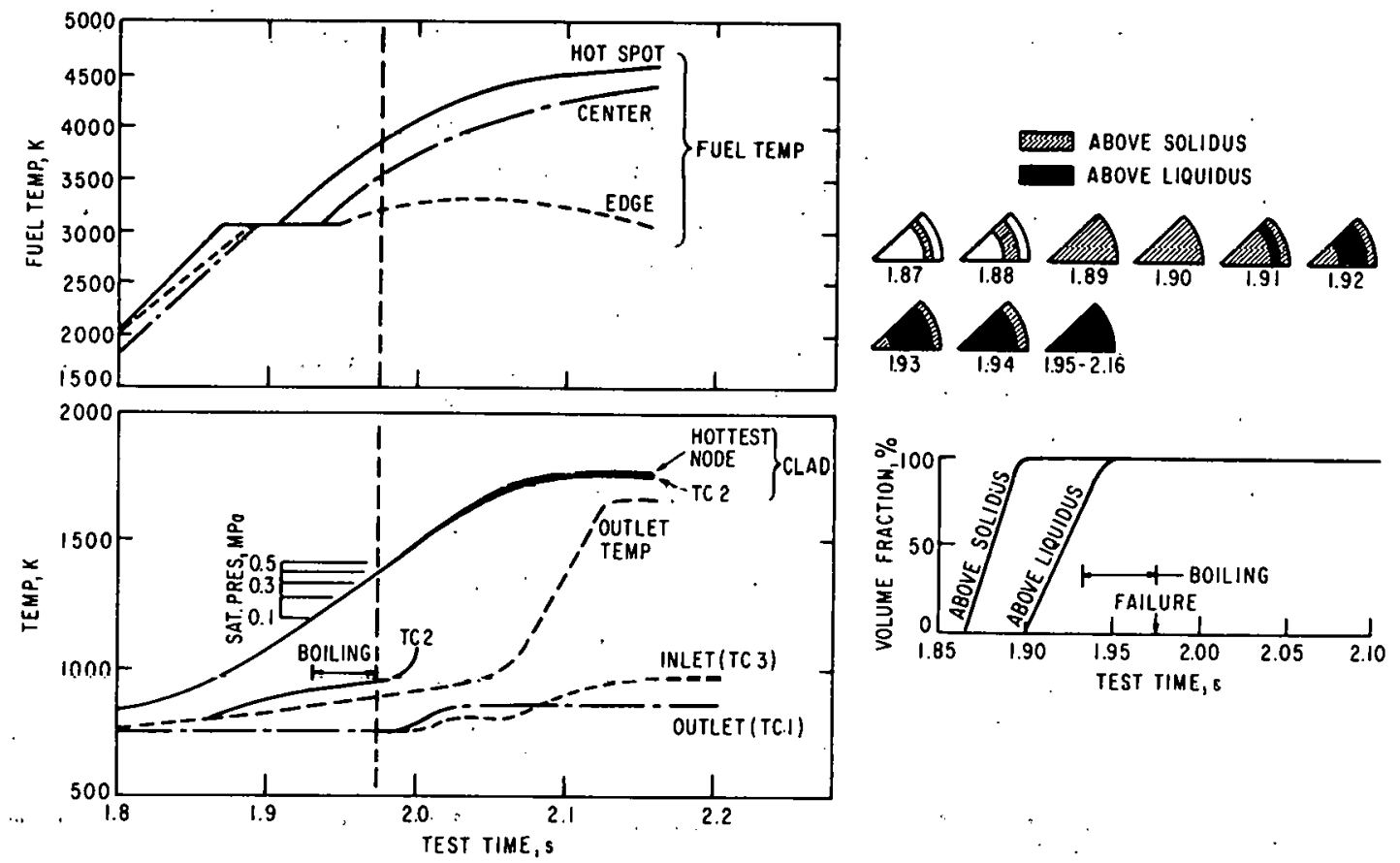

Fig. 24. Temperature History for Test E4. Calculated fuel temperatures are shown in the top left panel. Calculated cladding temperatures at the hottest axial node and at the location of TC2, and the outlct coolant temperaturc3, are shown in the lower left panel. Measured temperatures are also shown. Heating at the inlet at $2.05 \mathrm{~s}$ is due to cooling of the inlet blockage and some mixing of hot material with the inlet-plenum sodium. Propagation of the inlet front and fuel fraction above the solidus and liquidus temperatures are shown on the right. 
Failure of the cladding is thought to have occurred at $1.975 \mathrm{~s}$, preceded by about $45 \mathrm{~ms}$ during which mild boiling is apparent, and by about $17 \mathrm{~ms}$ during which the entire fuel cross section was calculated to have a temperature above liquidus. Figure 23 suggests that vapor production may have begun as early as $1.91 \mathrm{~s}$. A careful examination of the void-growth rate shows a defined break in slope at $1.93 \mathrm{~s}$, suggesting that the apparent void before this time was caused by thermal expansion of the fuel and flow-channel sodium as they were heated. The voiding after $1.93 \mathrm{~s}$ is believed to be due to true vapor production.

The entire channel opposite the fuel column appeared to be voided of sodium by $1.988 \mathrm{~s}$. Fuel released later deposited on the holder wall, causing extensive melting. The apparent reentry noted in $\mathrm{H} 2$ did not appear in $\mathrm{E} 4$, although the secondary ejection of sodium from the inlet was noted beginning at abuut $2.025 \mathrm{~s}$.

The sequence of failure events is very much like that in $\mathrm{H} 2$. Voiding was much more rapid than observed in $\mathrm{H2}$, with slug accelerations lasting for only about $5 \mathrm{~ms}$. Channel plugs were larger than those observed in H2, suggesting more rapid tuel release, with considerable release within $5 \mathrm{~ms}$ of failure. More fuel release was expected because of the higher fuel temperatures and larger melt fraction. In this case, temperatures in excess of fuel boiling were calculated, and fuel vapor may have contributed to fuel motion.

Posttest destructive examination indicated that the major point of failure was within. $50 \mathrm{~mm}$ of the top of the fuel column. Apparently, the steelfuel debris from the initial failure (thought to be due to cladding melthrough) caused a partial or complete plugging of the flow channel above the point of failure. 'L'he thermocouple near the top of the fuel column burned out within $10 \mathrm{~ms}$ of failure.

The top part of the upper plug showed signs of reacting with the pin cladding and holder wall. The lower region of the upper plug showed signs of material being compacted in place. Similar features were observed in the lower flow-channel plug, but with a lesser degree of cladding and end-cap melting. Both plugs had porosities and compositions similar to those found in Test H2. As much as three-quarters of the fuel was found frozen to the holder walls as large chunks or clinkers that did not break up as easily as those found in H2. Microphotographs show a very homogeneous mixture of $\sim 2-5-\mu \mathrm{m}$ steel globules through the chunks that were examined,

Most of the inner holder wall had been melted, accounting for the extensive volume fractions of steel found in some of the fuel. Globules of once-molten cladding (distinguished from holder steel by its molybdenum content) were found between the walls of the holder at the elevation of the upper spacer tube. A number of globules of fuel devoid of any steel were found scattered throughout the flow channel, suggesting the motion of some molten cladding had preceded that of fuel. 
The upper insulator pellet had undergone extensive melting and cracking. Chunks that broke off did not move far, perhaps because of their large size. Evidence of a burn hole in the cladding at and above the insulator suggests the prefailure upward fuel flow may have been the cause of initial burnthrough of the cladding and pin failure. Fuel was found in the spacer tube and frozen on several convolutions of the spring. Sodium vapor had condensed between the spring and the cladding tube as a thin layer. No evidence of liquid sodium was found in the pin plenum.

The lower insulator suffered extensive cracking and some inflow of molten steel, but no melting. The bottom fuel pellet may not have melted, but was broken up and scattered throughout the flow channel.

Despite the apparent high porosity of the fuel plugs, flow could not be established after the test for any setting of the sodium pump. The upper plug was $80 \mathrm{~mm}$ long; the lower one about $38 \mathrm{~mm}$. Together, they are believed to account for $\sim 25 \%$ of the total fuel inventory. About $5 \%$ of the fuel was distributed throughout the flow channel above the upper plug, and the remaining fuel was frozen to the outer holder walls. No measurable quantity was found in the main loop sodium.

There are no hodoscope data for this test, but the similarity in test data and posttest findings would indicate fuel movements were similar to those observed in $\mathrm{H} 2$.

A summary scenario for Test E4 is given in Table VII.

TABLE VI. Summary Scenario for Test E4

\begin{tabular}{|c|c|}
\hline Time, $s$ & Event and Evidence \\
\hline 1.868 & $\begin{array}{l}\text { Solidus temperature is approached near the outside edge of } \\
\text { the pellet. }\end{array}$ \\
\hline $\begin{array}{l}1.884 \\
\therefore\end{array}$ & $\begin{array}{l}\text { Liquidus temperatures are reached. Internal upward tlow is } \\
\text { expected to begin. }\end{array}$ \\
\hline 1.90 . & $\begin{array}{l}\text { Complete cross-sectional area of hottest axial node above } \\
\text { solidus temperature. }\end{array}$ \\
\hline 1.91 & Coolant and pin expansion due to heating noted in void data. \\
\hline 1.93 & Mild boiling begins. Void grows to $25000 \mathrm{~mm}^{3}$. \\
\hline $1.963-1.975$ & Some vapor collapse noted in outlet-flow data. \\
\hline 1.975 & $\begin{array}{l}\text { FAlLURE. Sodium slugs ejected out both ends of flow channel. } \\
\text { Pressure pulses of } 2.76-3.48 \mathrm{MPa} \text { measured. }\end{array}$ \\
\hline 1.99 & $\begin{array}{l}\text { TC2 located } 25 \mathrm{~mm} \text { below top of fuel column burns out. Outlet } \\
\text { blockage started. }\end{array}$ \\
\hline 2.02 & $\begin{array}{l}\text { Inlet and outlet flow correlation is small, indicating outlet } \\
\text { blockage complete. }\end{array}$ \\
\hline $2.0 .3-2.04$ & Minor reentry event noted at inlet. \\
\hline
\end{tabular}




\section{Test El}

Test El was the first experiment to use the Mark-IIA integral sodium loop. Consequently the test was planned to fall short of the regime of vigorous failures and extreme pressures. A single, fresh $\mathrm{UO}_{2}$ pin was tested. It was surrounded by a ring of six dummy pins (helium-filled, hollow-jacket tubes) to provide characteristic coolant channels. The test pin contained a $0.318-\mathrm{m}$ stack of $13 \%$-enriched unirradiated $\mathrm{UO}_{2}$ pellets within a $\mathrm{Type} 304 \mathrm{~L}$ stainless steel jacket, with $7.37-\mathrm{mm} O D$ and $0.508-\mathrm{mm}$ wall. The fuel-cladding diametral gap was $0.08 \mathrm{~mm}$, the fuel smeared density was $90 \% \mathrm{TD}$, and the pin plenum was helium-filled. Immediately above the fuel was a stainless steel coil spring used to resist pellet movements during pretest handling operations. The pin was wrapped with $1.4-\mathrm{mm}$ dia stainless steel wire at a $0.2-\mathrm{mm}$ pitch to separate it from the adjacent dummy pins.

The power transient is shown in Fig. 25. TREAT power and fuel linear power are read from the left- and right-hand scales, respectively. The radially averaged transient energy generated in the fuel is shown in Fig. 26. Calculations indicate that nearly all (95-100\%) of this energy was retained while the fuel column remained intact.

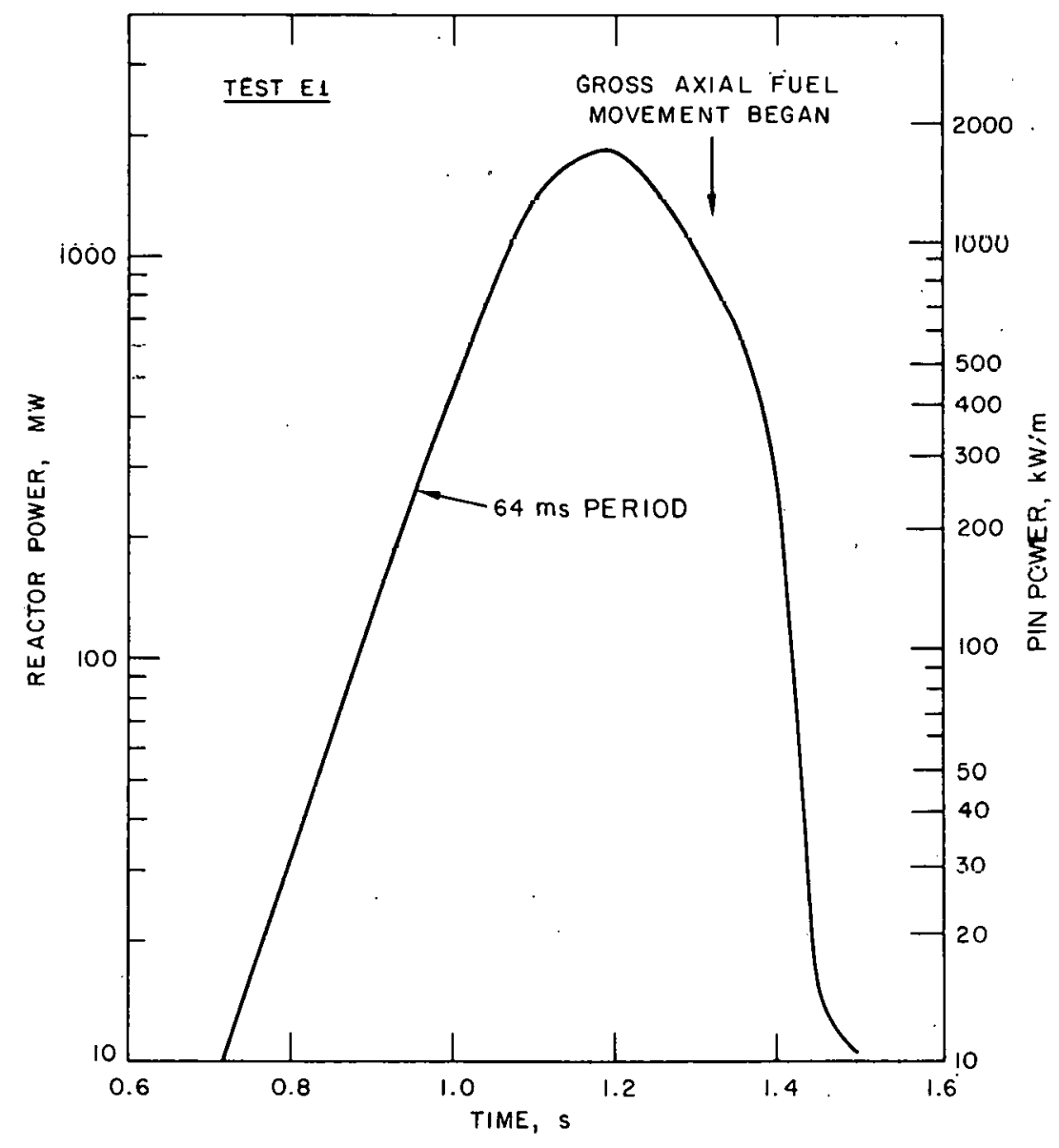

Fig. 25. Power 'l'ransient for Test E1 


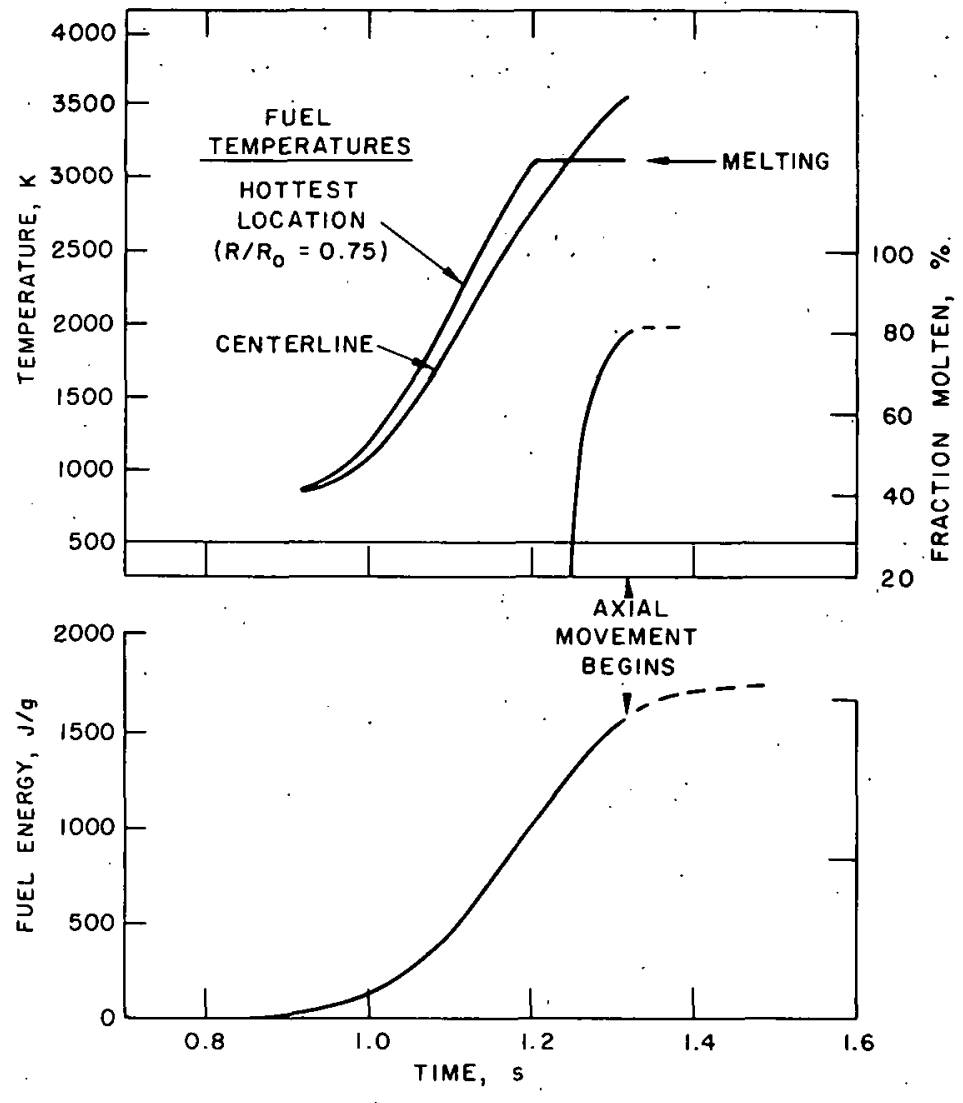

Fig. 26. Thermal History of Test E1
The hodoscope data showed that gross axial fuel movement within the pin began at $1.32 \mathrm{~s}, 140 \mathrm{~ms}$ after peak power. Calculations indicate that $80 \%$ of the fuel was molten and that the peak fuel temperature was $\sim 3550 \mathrm{~K}$ at that time (see Fig. 26). The absence of anomalies in the coolant flow and pressure records implied that cladding failure did not occur.

Postmortem examinations showed that, although molten $\mathrm{UO}_{2}$ had penetrated gaps in the solid oxide next to the cladding and frozen against the cladding, the cladding did not melt through, apparently due to the low sodium temperature (738.7 $\mathrm{K}$ maximum, radially averaged). Solidified fuel was found throughout the entire length of the inside of the cladding, with shrinkage voids distributcd along the pin. Mechanical loading of the cladding by the fuel was relieved by a large amount of molten fuel forced upward through the spring, apparently by the evolution of gas during melting, some fuel reaching the top of the $0.11-\mathrm{m}$-long plenum. The heat from the fuel partially melted the spring. The voids formed in the center of the fuel column. As a result of this, a rim of unmelted fuel about $0.33 \mathrm{~mm}$ thick was present in several locations, indicating that $80 \%$ of the cross section had melted, in good agreement with the calculated value. The measured maximum cladding (plastic) strain was $1.14 \%$, occurring at the fuel midplane. Calculations that did not consider axial fuel motion gave a cladding strain of about $1.2 \%$ at the onset of fuel melting and a final strain exceeding $3 \%$.

D. Test E2

Test E2, the second experiment using the Mark-IlA loop; was similar in design to Test El, but incorporated features designed to cause pin failure, Axial restraint was added to provide a more prototypic situation with respect to prefailure axial fuel movement than in Test El. A $13-\mathrm{mm}$-long depleted- $\mathrm{UO}_{2}$ pellet and $51-\mathrm{mm}-$ long $(12-\mathrm{g})$ stainless steel rod were placed on top of the $0.287-\mathrm{m}$ stack of $13 \%$-enriched $\mathrm{UO}_{2}$ fuel pellets. The steel rod just above the depleted pellet provided an inertial loading inhibiting gross axial fuel movement 
before cladding failure. A spring was used to hold the entire assembly in place within the cladding (the same type of cladding as in the El test pin).

The power transient for $\mathrm{E} 2$ is shown in Fig. 27, with TREAT power and fuel linear power read on the left-and right-hand scales, respectively. A higher-energy transient than that of $\mathrm{El}$ was used to ensure pin failure.

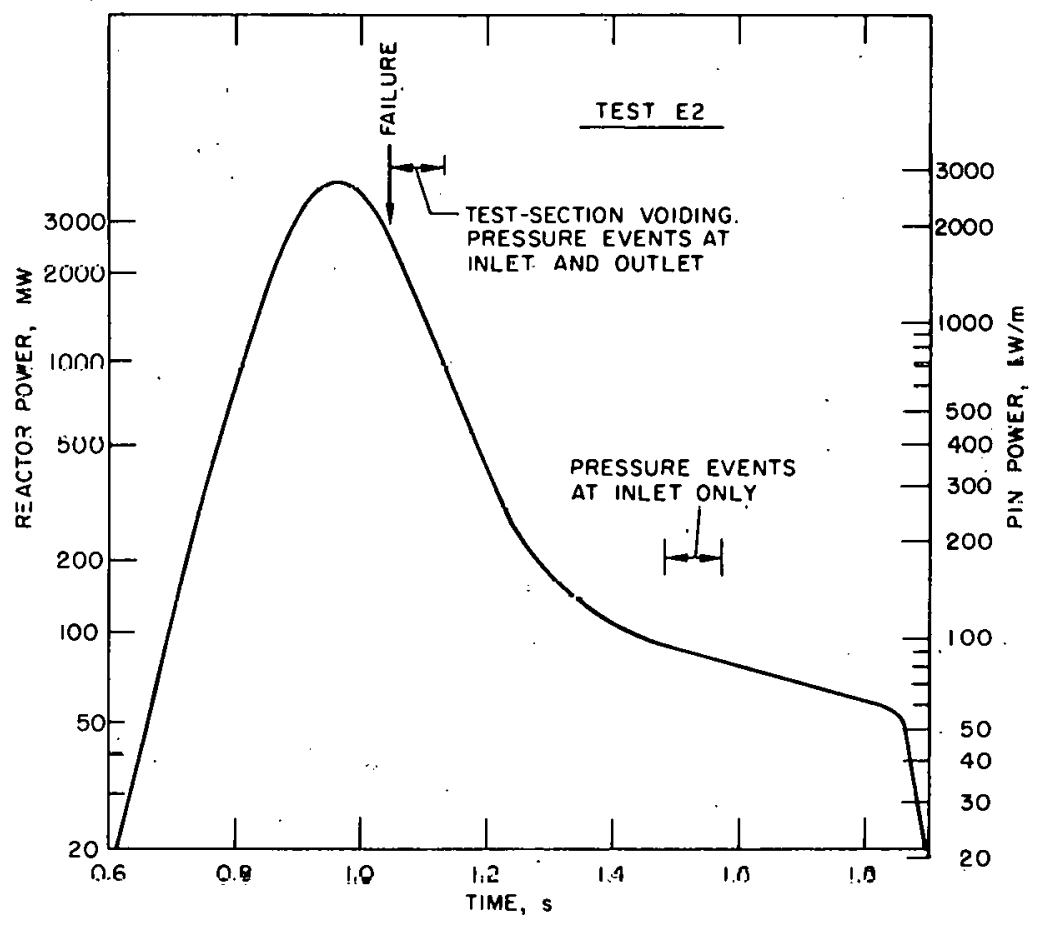

Fly. 27. Powèr T'ransient for T'est E2

Details of the pressure, flow, and temperatures recorded during the test are shown in Fig. 28. Voiding curves calculated from the flow measurements are also presented.

Pressure spikes, with peak values of $2.96 \mathrm{MPa}$ at the inlet and $2.21 \mathrm{MPa}$ at the outlet, and strong flow accelerations at both outlet and inlet, signified pin failure at $t=1.05 \mathrm{~s}, 80 \mathrm{~ms}$ after peak power, after $75 \%$ of the transient energy had been generated. Calculations made with the SASlA-ASH code indicate that, at pin failure. $90 \%$ of the fuel was molten, the peak fuel temperature. was $\sim 4200 \mathrm{~K}$, and the peak coolant temperature was $733 \mathrm{~K}$. The calculated fuel temperature and energy histories are shown in Fig. 29. Nearly a.ll (95-100\%) of the energy generated before failure was retained by the fuel. The initial series of pressure pulses continued for $80 \mathrm{~ms}$ until the fuel region was voided of coolant. Little or no reentry occurred at the outlet. A second series of pressure pulses occurred at the inlet (only), with maximum amplitude of $\sim 3.50 \mathrm{MPa}, 450 \mathrm{~ms}$ after failure when the void had passed beyond the upper pressure transducer. It is not clear that this second event was caused by inlet flow reentry. 


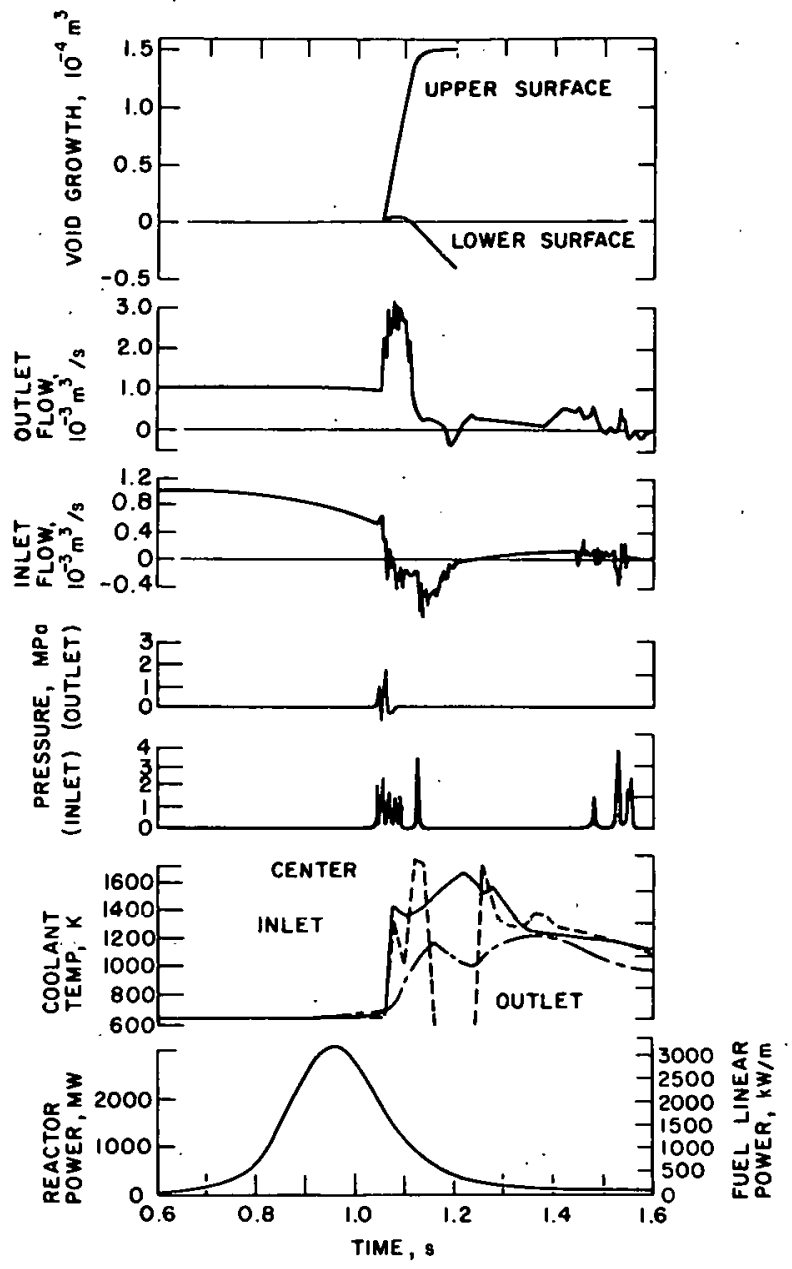

Fig. 28. Data for Test E2
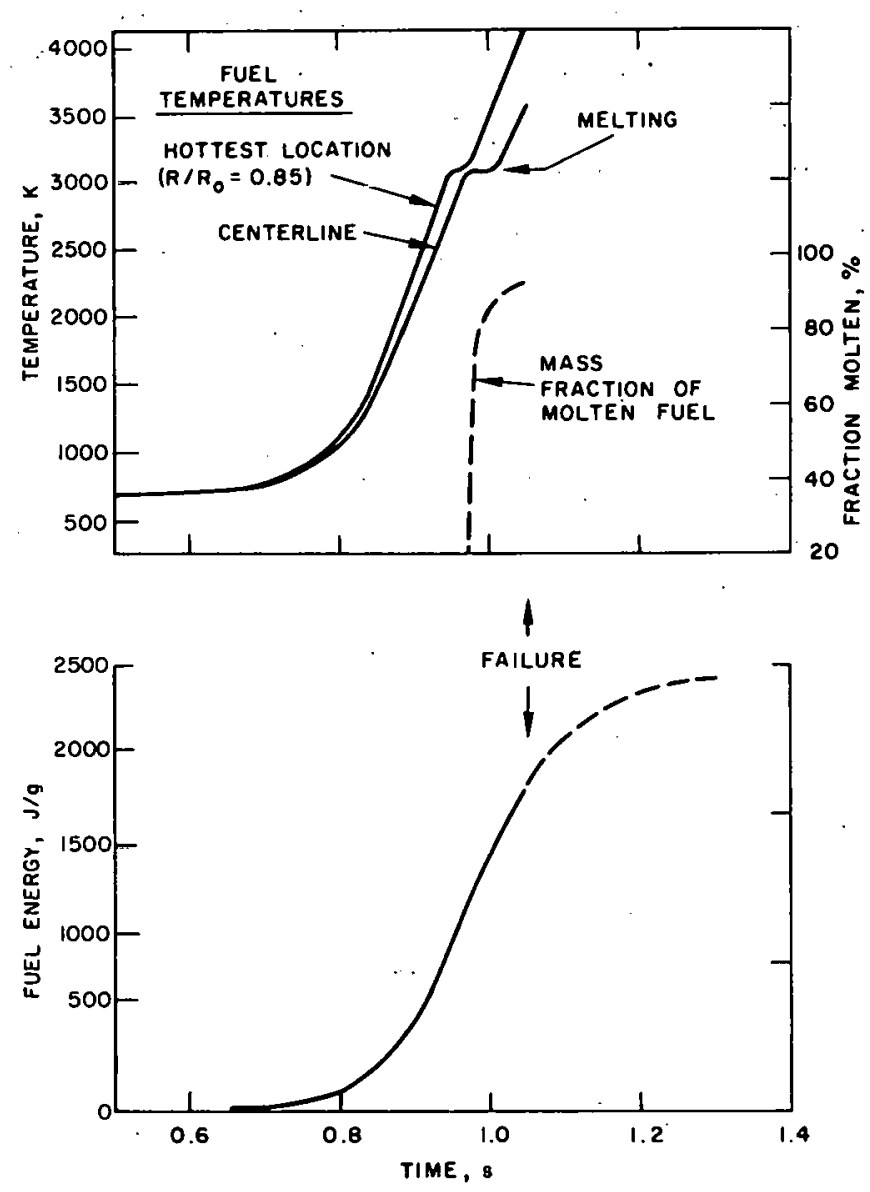

Fig. 29. Thermal History of Test E2

Posttest examination of the remains revealed that extensive cladding failure occurred over the top $41 \mathrm{~mm}$ of the fuel stack. The appearance of the cladding remains was consistent with failure by melthrough. To a lesser cxtcnt, the cladding also melted through beneath the downstream side of the spiral spacer wire, where heat transfer was reduced. The maximum measured cladding strain was $1.5 \%$. (Calculated plastic strain at the onset of fuel melting was $1.4 \%$, with about $5 \%$ calculated to occur at failure.) Fuel was extremely fragmented and extensively dispersed. Fines were found packed between the cladding tubes, causing nearly complete flow blockage.

During the transient, the steel restraining rod in the plenum above the fuel was forced upward, compressing the spring $8 . \mathrm{mm}$. (This is the most likely means of prefailure fuel-pressure relief, but could also occur during. gas-driven fuel expulsion from the cladding.) It is conjectured that the restraining-rod movement was caused by rapid thermal expansion of the fuel and its volume expansion on melting, and that the outer shell of unmelted fuel separated under tension, allowing molten fuel to contact and melt through the cladding. 
Microscopic examination of the small amount of fuel remaining inside the cladding supported the supposition that gas trapped in the fuel stack (smeared density of about $90 \%$ theoretical density) was forced toward the molten center of the pin, where it could expel fuel, rather than escaping up the fuel-cladding gap through local "chimneys."

The detailed structure of the fuel fines was typical of that for rapid quenching of molten oxide. The size of the fines followed a normal distribution, with $20 \%$ of the particles smaller than $40 \mu \mathrm{m}$ and $80 \%$ smaller than $500 \mu \mathrm{m}$. No evidence was found of "shot"-like particles, either solid or hollow, indicating that the fuel had cooled slowly. Intergranular fracture occurred, showing that the original particles were larger, although the original size cannot be deduced. No damaging fuel-coolant interaction was generated in E2, either upon failure or as a result of a failure-induced sequence of coolant ejection and reentry.

A scenario of the basic events during the test is given in Table VIII.

TABLE VIII. Summary Scenario for Test E2

\begin{tabular}{|c|c|}
\hline TREAT Time, $s$ & Event and Evidence \\
\hline 0.0 & Transient initiation. \\
\hline 0.95 & $\begin{array}{l}\text { Melting is calculated to start at hottest } \\
\text { location. }\end{array}$ \\
\hline 0.97 & $\begin{array}{l}\text { Melting is calculated to start at } \\
\text { centerline. }\end{array}$ \\
\hline 0.97 & Peak power attained. \\
\hline 1.05 & $\begin{array}{l}\text { Fuel-pin failure; pressure pulses at inlet } \\
\text { and outlet; flowmeters indicate voiding. }\end{array}$ \\
\hline 1.13 & First series of pressure puleos ondo. \\
\hline $1.48-1.57$ & $\begin{array}{l}\text { Second series of pressure pulses ob- } \\
\text { served at inlet only. }\end{array}$ \\
\hline
\end{tabular}

E. Test $\mathrm{H3}$

Test $\mathrm{H3}$ demonstrated the capability of an "intermediate-power, "lowburnup, ir radiated fuel pin to withstand a mild overpower transient terminated with fuel temperatures just short of the fuel solidus. An EBR-II-irradiated mixed-oxide pin, of 3.5 at. \% burnup and with no central void, was tested in flowing sodium as the central element in a seven-pin cluster. The six peripheral unirradiated pins were similar to the central pin, but with greater axial restraint. A fluted, stainless steel tube with $0.89-\mathrm{mm}$ wall served as holder for the pin bundle and boundary for the coolant flow. This tube was surrounded by, and in close mechanical contact with, a thick (2.54-mm wall) stainless steel outer wall. 
The power transient for the test is shown in Fig. 30 for the central (irradiated) pin and the hottest peripheral (fresh) pin. None of the pins failed during the excursion, and the test data show an absence of anomalous coolant behavior. Figure 30 also shows measured coolant temperatures at the inlet and outlet. The calculated temperatures at the top of the fuel (the hottest location) and at the outlet are shown for comparison.
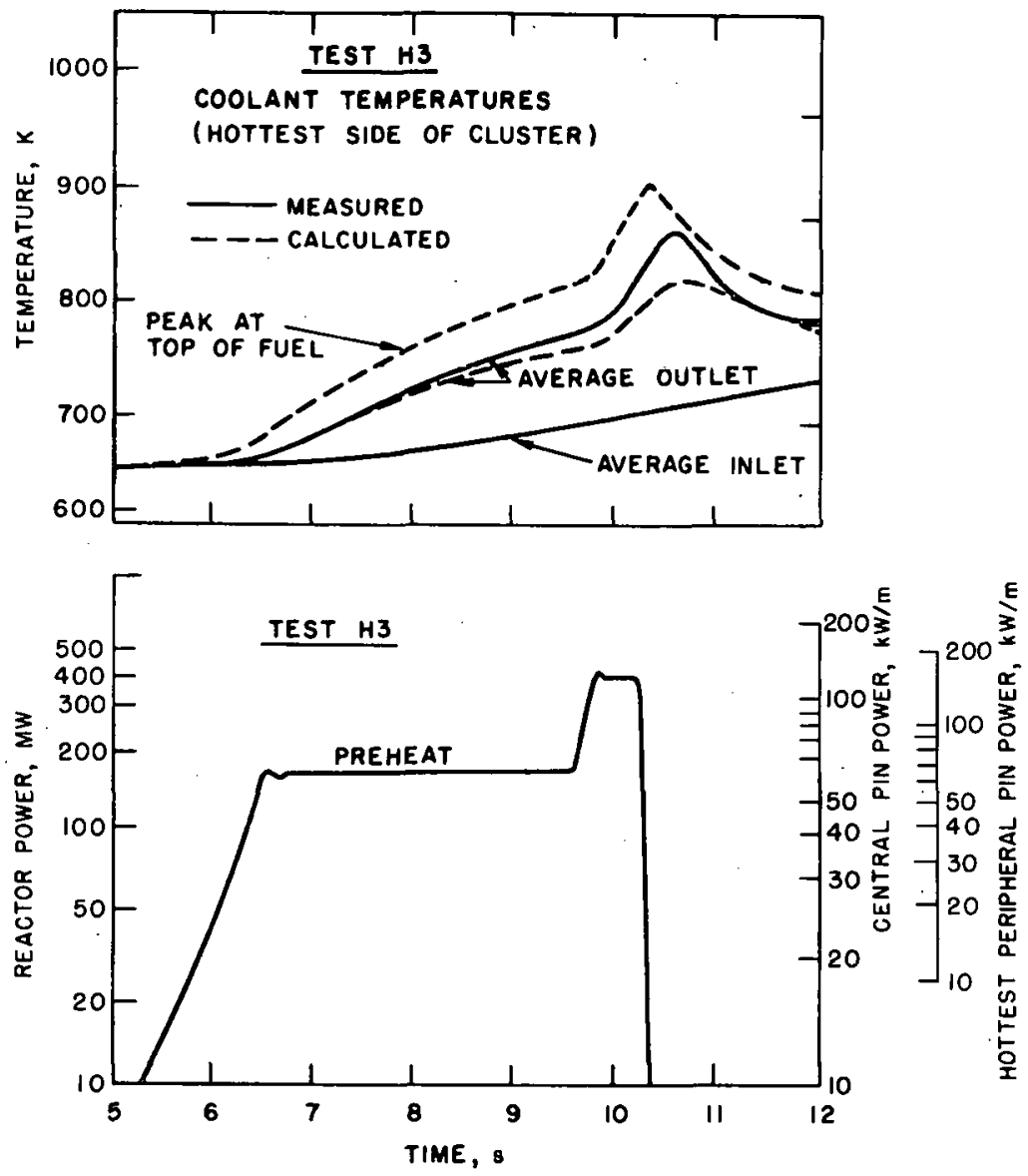

Fig. 30. Power and Temperatures for Test H3

Calculated thermal conditions in the fuel of the central and hottest peripheral pins are shown in Figs. 31 and 32. These curves apply at the axial location of maximum retained energy in the fuel, i.e., at a relative fuel height of 0.8 .

Posttest macroscopic observations and measurements revealed essentially no dimensional differences between the transient-tested central PNL-17 pin and an untested sibling pin. No transient fuel or cladding swelling occurred, as evidenced by profilometry and fuel-cladding gap-size measurements. Porosity, grain size, and grain structure were also essentially the same. Differences were found only in the quantity of released fission gas and the distribution and morphology of fission-gas bubbles; determined by sampling of the fission gas in the plenum replica electron fractography, and 

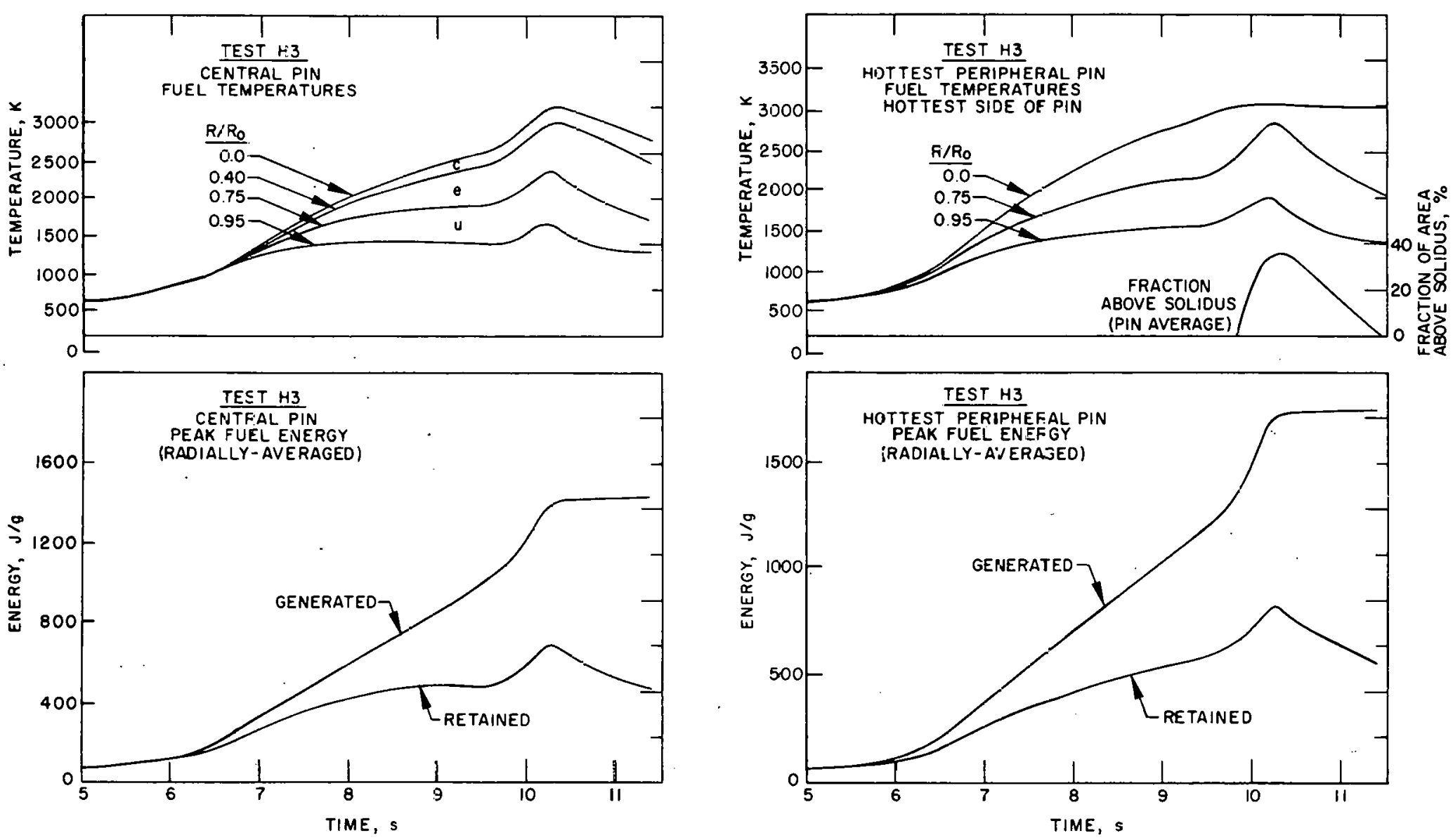

Fig. 31. Thermal History of Central Pin for Test H3 $(c=$ columnar; $e$ = equiaxed; $\mathrm{a}=$ unrestructure $\cdot$ )

Fig. 32. Thermal History of Hottest Peripheral Pin for Test H3 
laser gas sampling. As can be seen in Fig. 33, the gas released during the transient came principally from the cooler unrestructured regions by precipitation on boundaries and diffusion from cracks and pores, and to a lesser extent from migration from the hotter regions. The observed lack of melting in the central pin is consistent with the calculations. The calculated maximum plastic strain of $0.5 \%$ of the cladding is somewhat high; no strain was measured.

Up to $40 \%$ of the cross-sectional area of the fuel in the hottest peripheral pin melted during the transient, as discovered in the posttest examination; this is in close agreement with calculations. No permanent cladding deformation occurred. Molten-fuel movement consisted mainly of filling the voids between the dished ends of adjacent pellets. In one location where a gap existed between pellets, fuel was extruded out toward, but did not contact, the cladding.

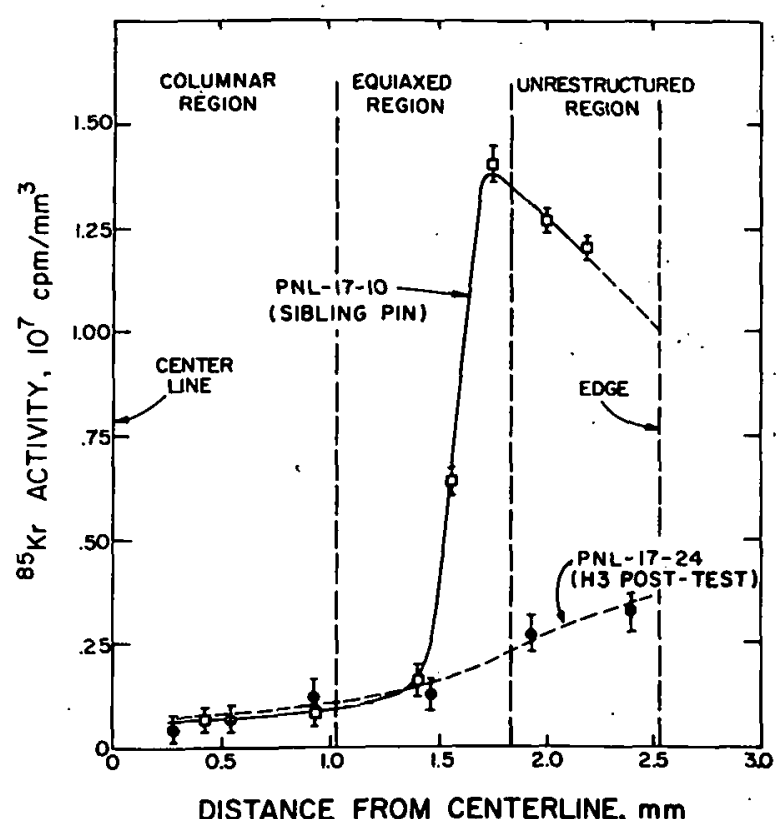

Fig. 33

Change in Fission-gas Distribution due to Test H3. ANL Neg. No. 900-3325 Rev. 2. 
F. Test $\mathrm{H4}$

A "high-power" irradiated fuel pin was subjected to a $50 \phi / \mathrm{s}$ overpoweraccident simulation in Test $\mathrm{H} 4$. The test is closely related to both Tests $\mathrm{H} 5$ and E6 as illustrated in Table I; i.e., the pin cluster and coolant-channel geometry were identical in all three tests, the only basic differences being the preirradiation characteristics of the central pin (H5 versus $\mathrm{H} 4$ ) and the rate of power input ( $\mathrm{E} 6$ versus $\mathrm{H4}$ ). A double-walled, gas-insulated pin holder was used in $\mathrm{H} 4$, as in the other two tests.

It was planned to carry the preirradiated element well into it s failure regime. However, the cladding ruptured sooner than expected, and considerable additional energy was generated before the reactor was scrammed. This is illustrated in Fig. 34. As a result, all pins suffered major damage, although not at the same time, with gross fucl rclocation within and slightly above the original fuel region. Several coolant expulsion and reentry events occurred. It appears that $0.3 \mathrm{~s}$ elapsed between the coolant flow disturbance due to the first pin failure and that due to the next pin failure. If the first pin to fail was the hottest peripheral pin, its neighboring peripheral pins, which contained

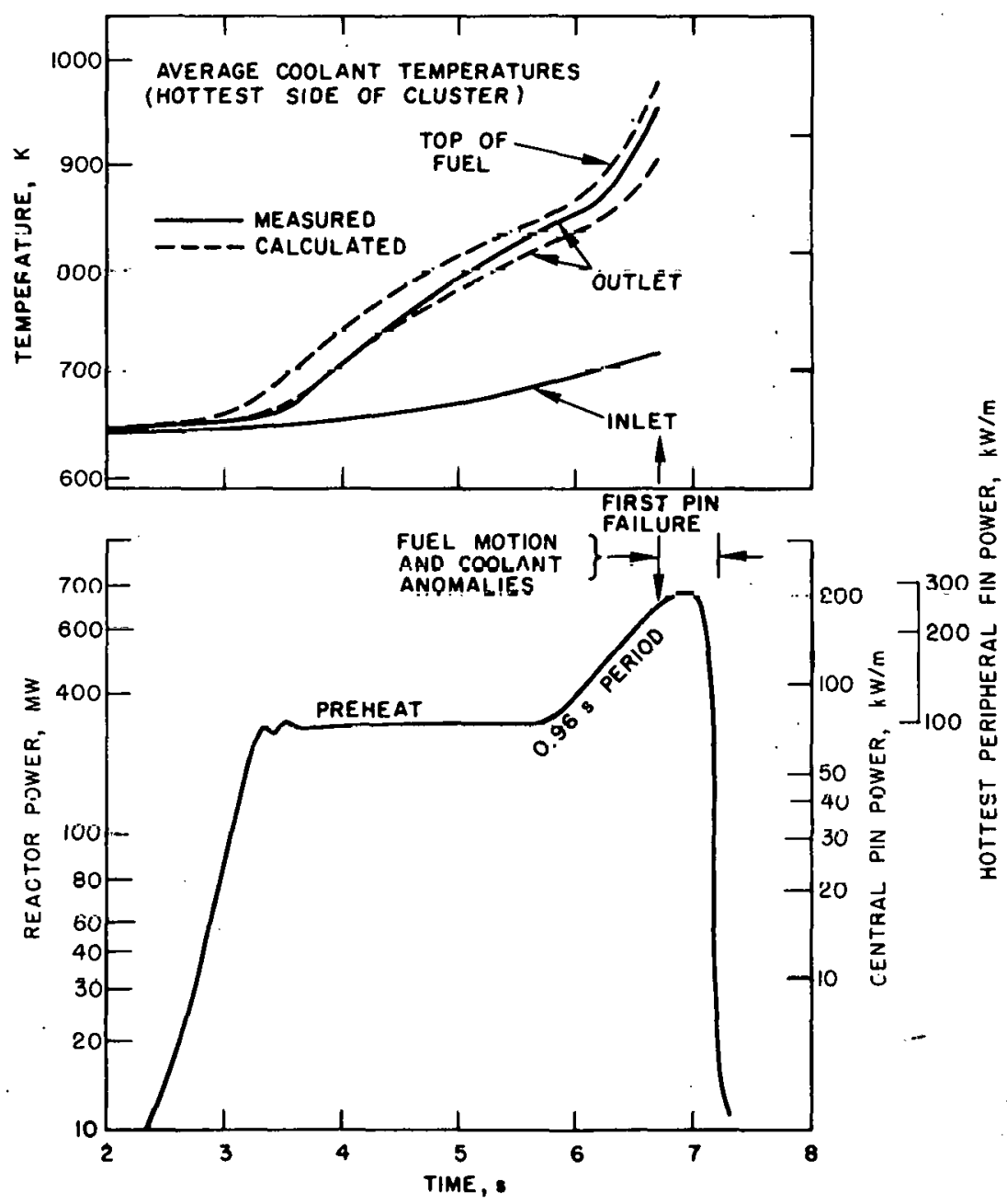

Fig. 34. Power and Temperatures for Test $\mathrm{H} 4$ 
about as much energy, would probably fail immediately thereafter. That this was not the case in H4 supports the belief that the central pin failed first.

The top of the fuel column apparently plugged with fuel and steel shortly after the initial failure, since subsequent coolant and pressure phenomena were observed principally at the inlet. The remainder of the events mainly appear to be a pin failure that voided the fuel region, subsequent pin failures and fuel expulsion into the voided region, and a final series of reentries and expulsions of sodium through the inlet. The first reentry-expulsion event in the series was very strong, with a narrow, 6.895-MPa leading pressure spike and rapid coolant expulsion. The pressures generated during the final series of reentries and expulsions apparently packed the fuel against the blockage that formed after the first pin failure at the top of the fuel region. The posttest neutron radiograph of the loop shows that the packed fuel mass is about $0.11 \mathrm{~m} \mathrm{high}$ and that a $0.22-\mathrm{m}$ region immediately below is largely devoid of fuel. The

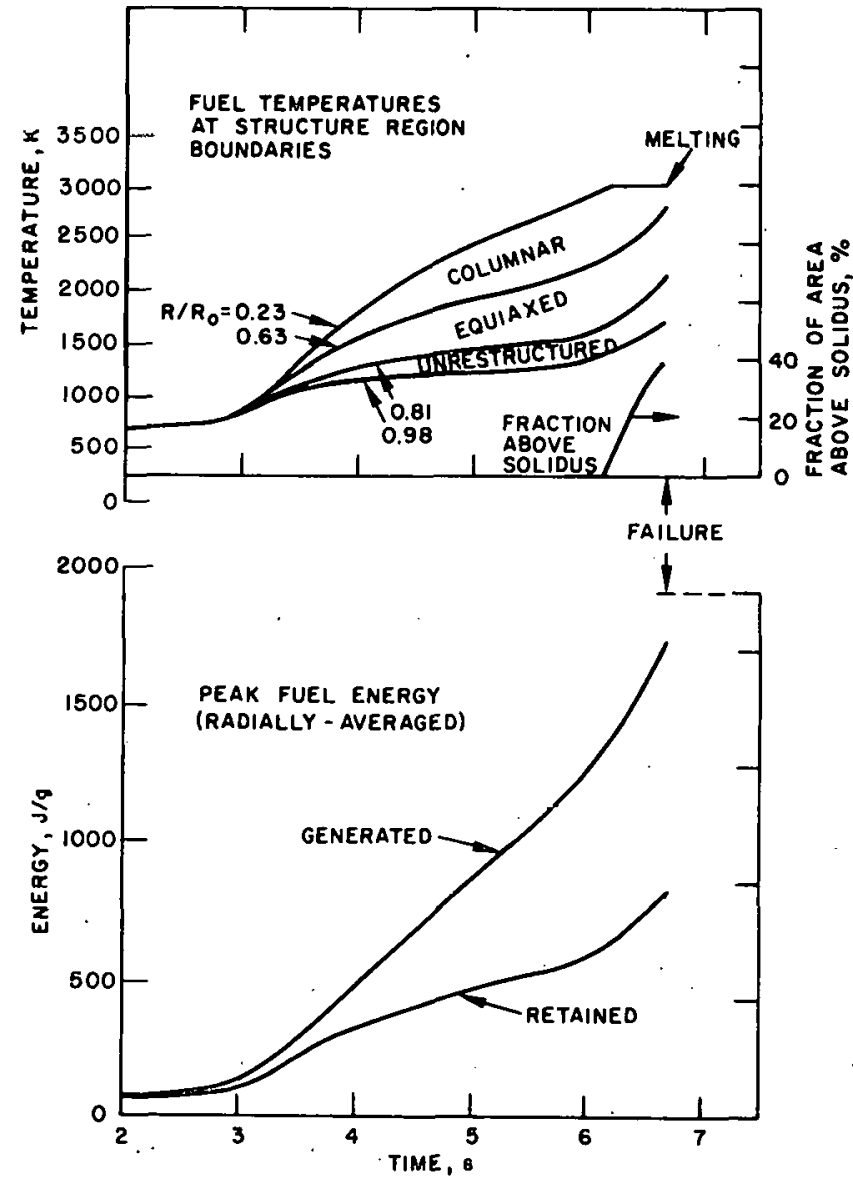

Fig. 35. Thermal History of Central Pin for Test H4 bottom $0.05 \mathrm{~m}$ of the fuel columns remained fairly intact. Some fuel was carried into the region adjacent to the pin plena, most likely during the initial expulsion at the outlet.

Measured and calculated coolant temperatures are shown in Fig. 34. The coolant was well below saturation everywhere when the first pin failed. Cladding temperatures were typically within $50 \mathrm{~K}$ of the coolant temperatures. Calculated fuel energies, temperatures, and amount of melting are shown in Fig. 35 for the central pin and in Fig. 36 for the hottest peripheral pin. The dashed lines in Fig. 36 indicate conditions that: would have occurred in the absence of initial pin failure.

As in Test H5 (see next section), the preirradiated pin seems to have failed when the solidus temperature front closely approached the region of high gas conlenl as that front moved radially outward.

A scenario of events during Test $\mathrm{H} 4$ is included as Table IX. The posttest neutron radiograph is included in Appendix D. 
TABLE IX. Summary Scenario for Test H4

\begin{tabular}{|c|c|}
\hline TREAT Time, s & Event and Evidence \\
\hline 0.0 & Transient initiation. \\
\hline 3.25 & Start of constant-power preheat. \\
\hline 5.75 & End of preheat; start of overpower excursion. \\
\hline 6.69 & $\begin{array}{l}\text { Pin failure (probably the central element only) evidenced by simultaneous pulses } \\
\text { from all pressure transducers and flowmeters. Maximum indicated pressures } \\
\text { were } 827 \mathrm{kPa} \text { (outlet) and } 1.17 \mathrm{MPa} \text { (inlet). Temperature-rise rate of holder wall } \\
\text { at fuel midplane increased. The inlet flow begandecelerating steadily for } 60 \mathrm{~ms} \\
\text { without reversing. The outlet flow rate began rising in an } 80-\mathrm{ms} \text {-wide peak, } \\
\text { reaching three times the initial value. }\end{array}$ \\
\hline 6.73 & $\begin{array}{l}\text { Events in the fuel region after this time were not detected by the outlet pressure } \\
\text { transducer, due to voiding and blockage of the channels near the top of the fuel } \\
\text { column. }\end{array}$ \\
\hline & $\begin{array}{l}\text { A small event caused weak pressure pulses at the inlot. (only) and gradually } \\
\text { accelerated the outlet flow. Thermocouple on the pin-holder wall at the fuel mid- } \\
\text { plane began behaving ahnnmally, s!ggesting wall molting. }\end{array}$ \\
\hline 6.86 & $\begin{array}{l}\text { Holder-wall thermocouple at the top of the fuel indicated boiling sodium. Inlet } \\
\text { therinocouple was melted by molten steel or hot fuel, possibly not at its tip. Outlet } \\
\text { thermocouple began cooling. }\end{array}$ \\
\hline 6.90 & $\begin{array}{l}\text { Inlet flow stopped for the first time. Coolant was strongly expelled through the } \\
\text { outlet. No accompanying pressure pulses occurred. }\end{array}$ \\
\hline 6.94 & Reactor power peaked. \\
\hline $6.97-7.01$ & $\begin{array}{l}\text { Pin-holder thermocouple indicaled melting of holder wall at top of fuel column. } \\
\text { Pin-holder thermocouple at the fuel midplane on the side facing the pump indicated } \\
1239 \mathrm{~K} \text { sodium ( } 200-\mathrm{kPa} \text { sat temp) }\end{array}$ \\
\hline 7.03 & $\begin{array}{l}\text { Probable additional pin failure(s) ncourred, with rapid flow reversal dild pressure } \\
\text { pulses reaching } 1,10 \mathrm{MPa} \text { at inlet. No ontlet flow or prooourc pulses wete } \\
\text { recorded. Erratic behavior of all pin-holder thermocouples began. }\end{array}$ \\
\hline $7.08-7.17$ & $\begin{array}{l}\text { Fuel region continued voiding. Momentary abnormal signal from inlet thermo- } \\
\text { couple posstbly indicated passage of hot fucl. Pin-holder therriocouple on the } \\
\text { colder sicle dl the fuel midplane melted. Fuel region began refilling from the inlet. }\end{array}$ \\
\hline 7.177 & $\begin{array}{l}\text { A very strong event caused expulsion of coolant out of the inlet, with a } 6.895-\mathrm{MPa} \\
\text { leading pressure pulse indicated. The peak expulsion rate was greater than twice } \\
\text { the initial positive flow. The entire fuel region voided within } 0.07 \mathrm{~s} \text {. The outlet } \\
\text { flow was nearly unafferted. Pin=holder thermooouples on thic hotler side at the top } \\
\text { of the fuel. and at the fuel midplane melted. }\end{array}$ \\
\hline 7.25 & $\begin{array}{l}\text { Fuel region began refilling from inlet. Other inlet thermocouple melted, probably } \\
\text { above its tip. }\end{array}$ \\
\hline $7.3-7.6$ & $\begin{array}{l}\text { Mild flow reversals at inlet occurred every } 0.1 \text { s with decreasing strength. Rapid } \\
\text { cooling of l'Cy at loop upper bend was halted, and the thermocouple was heated } \\
\text { slightly before beginning slow cooling. Cooling ratc of uutlet thermocouples } \\
\text { decreased. }\end{array}$ \\
\hline $7.6-9.0$ & Inlet flow steadied to $10 \%$ of its initial value. Outlet flow oscillated slowly. \\
\hline $9.0-12.0$ & $\begin{array}{l}\text { Flow oscillations at } 5.3 \mathrm{~s} \text { recorded by inlet and loop-plenum flowmeters, probably } \\
\text { caused by the coolant falling from the loop plenum and oscillating between gas } \\
\text { trapped in the fuel region and the plenum gas space. }\end{array}$ \\
\hline
\end{tabular}




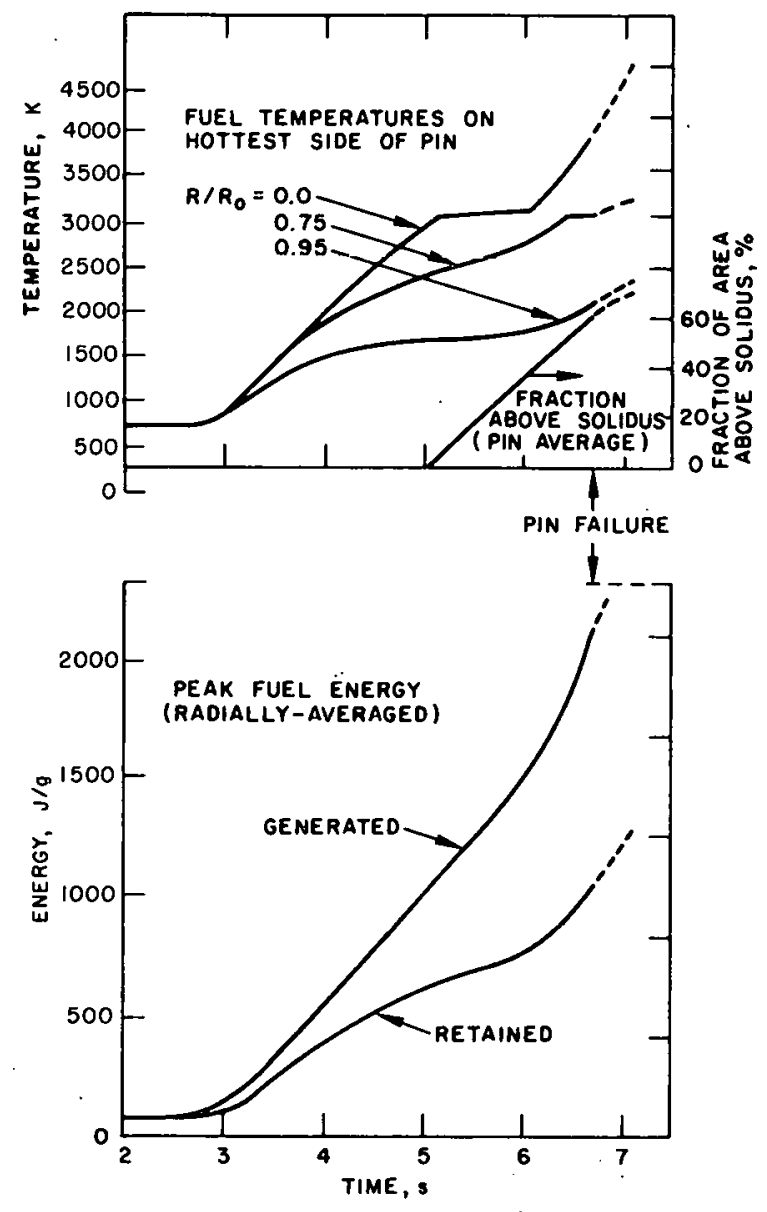

Fig. 36. Thermal History of Hottest Peripheral Pin for Test H4

\section{G. Test H5}

Test $\mathrm{H} 5$ was performed to study the behavior during failure of a fuel pin subjected to a simulated $50 \phi / \mathrm{s}$ overpower accident. The test pins and hardware were identical in type to those used in H3, except that the steel outer tube surrounding the $\mathrm{H} 3$ fluted pin holder was replaced by an annulus of helium, thereby making the holder wall essentially adiabatic. (In addition, five of the six peripheral pins used in $\mathrm{H} 5$ had been subjected to the $\mathrm{H} 3$ transient, resulting only in central void formation. The extent to which the radial redistribution of fuel in these pins altered the pin-to-pin flux distribution, or their failure characteristic s compared to completely fresh pins, is uncertain.) The power transient for H5 (see Fig. 37) had a lower preheat level than $\mathrm{H} 3$ and a more representative power excursion. The reactor scram was programmed to occur just after initial (central pin) failure was expected.

The test data (see Fig. 38) show that failure was first indicated at about

8.01 s. At $100 \mathrm{~ms}$ before failure, the signal from the outlet flowmeter unexplainedly decreased by $30 \%$ and remained at the reduced level for $60 \mathrm{~ms}$ before pin failure. Radiographic evidence (see Appendix D) and hodoscope data indicate that fuel was lost from both the central pin and the peripheral pins, but that most of the fuel remained within the pins. Destruction of the pin geometry was not extensive. Of the fuel that left the pins, some was carried upward and out of the original fuel region, but most appears to have lodged near the probable point of failure, about three-fourths of the way up the fuel column. Fuel and cladding debris blocking the flow channels allowed only $\sim 45 \%$ of the initial flowrate at the pretest pump-current setting. No violent molten-fuel/coolant interaction (MFCI) occurred; the maximum pressure recorded at the time of initial failure wàs $1.59 \mathrm{MPa}$.

Based on the pressure, flow, and hodoscope data, failure of and fuel movement from the central pin probably caused the first coolant anomaly. The hodoscope data alone show that fuel movement from the hottest peripheral pin began about $70 \mathrm{~ms}$ later, at the time of peak reactor power and concurrently. with further coolant flow and pressure events. Thus, apparently not all the original fuel region was voided of coolant at that time. ('The time behavior of voiding during the test cannot be determined with certainty due to malfunction of the inlet flowmeter.) The fluted tube $(0.89-\mathrm{mm}$ wall) was breached $0.1-0.2 \mathrm{~s}$ 


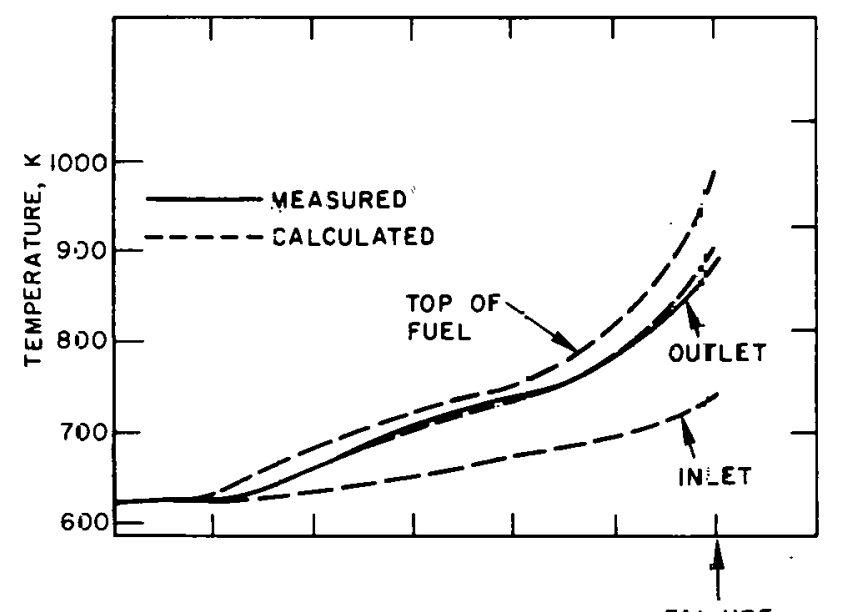

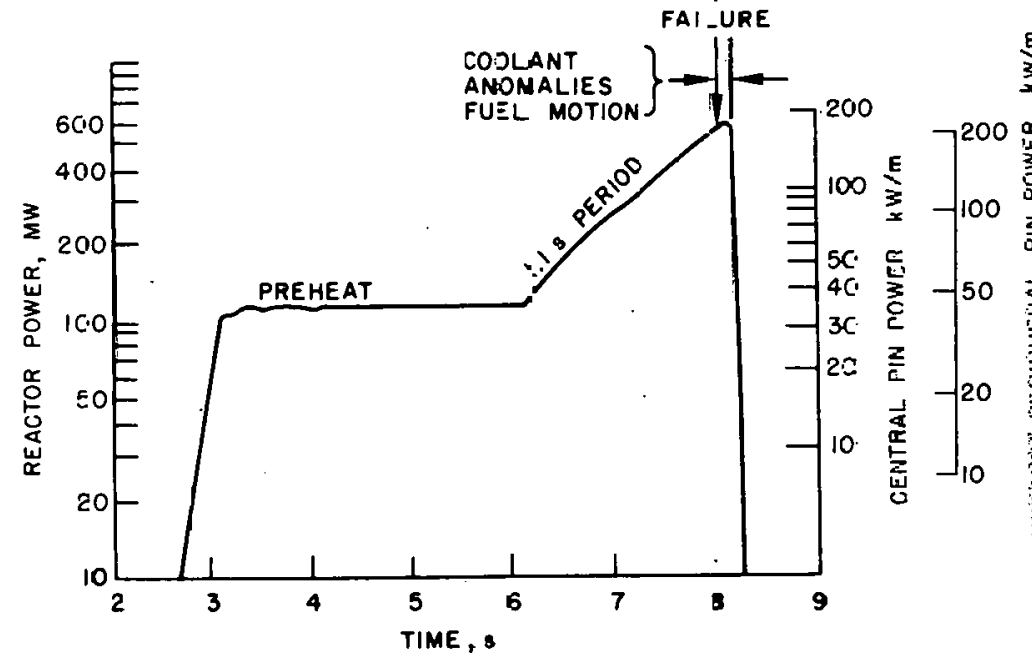

Fig. 37. Power and Temperatures jar Test Hळ
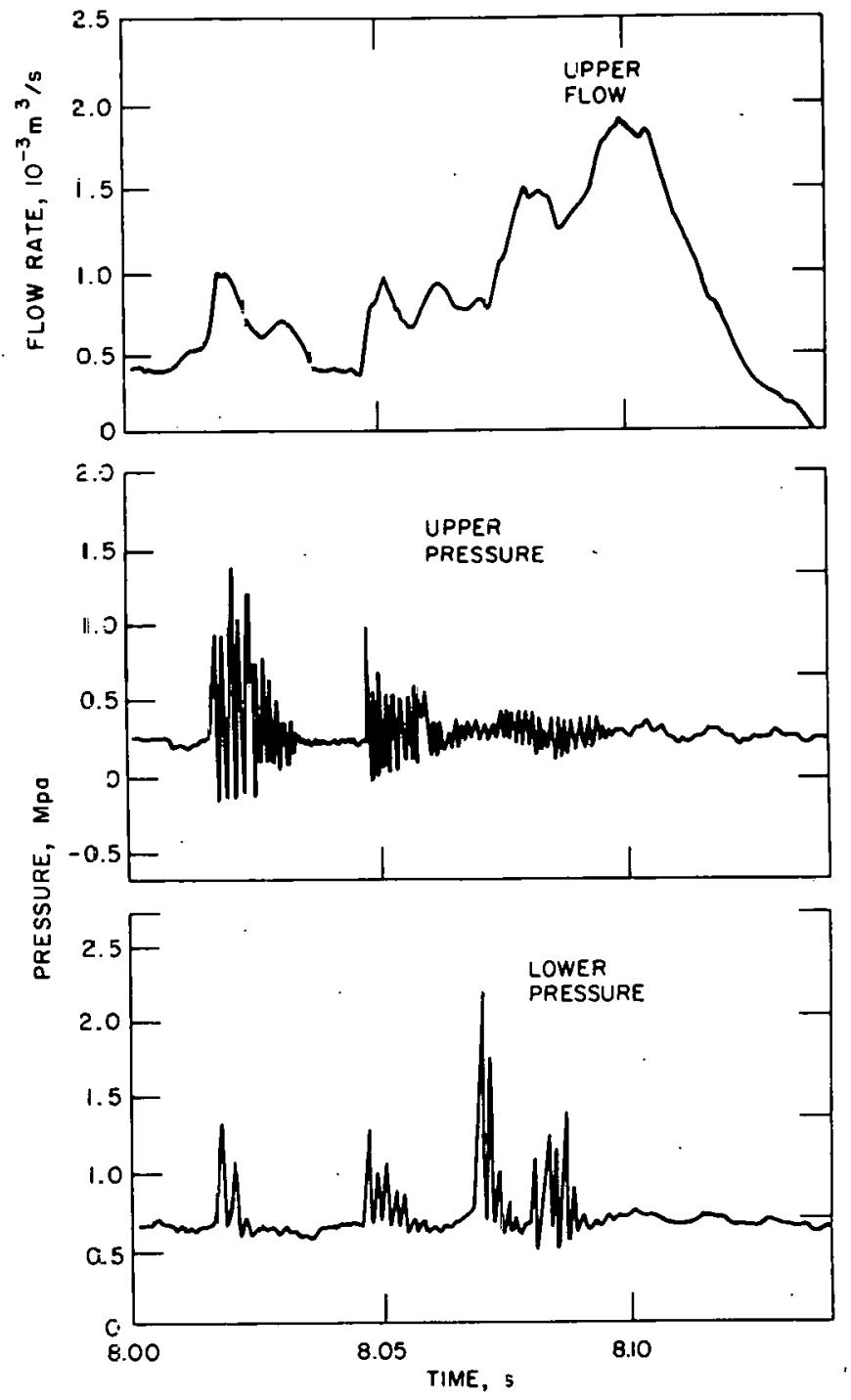

Fig. 38. Flcw and Pressure Data for Test H5 
after failure of the hottest peripheral pin adjacent to the probable location of the pin failure. Little, if any, fuel reached the loop wall.

The measured temperature history of coolant at the outlet is shown as the solid curve in Fig. 37. Calculated histories for coolant temperature at the top of the fuel (hottest axial location) and at the outlet are also given.

[All H5 calculations are based on an inlet coolant temperature history scaled from the measured coolant temperatures in the similar Test H3. Inlettemperature signals recorded during Test $\mathrm{H} 5$ were distorted by pickup from an adjacent signal channel (a redundant outlet thermocouple).] The coolant in the fuel region was always at least $167 \mathrm{~K}$ below saturation before pin failure, at the estimated loop pressure of $210 \mathrm{kPa}$.

Figures 39 and 40 show the calculated thermal conditions in the central and hottest peripheral pins at the axial location of the peak energy retained in the fuel (relative fuel-column height of 0.7 ). Conditions at the axial midplane were only slightly, e.g., $\sim 283 \mathrm{~K}$ and $8 \mathrm{~J} / \mathrm{g}$, below those shown.

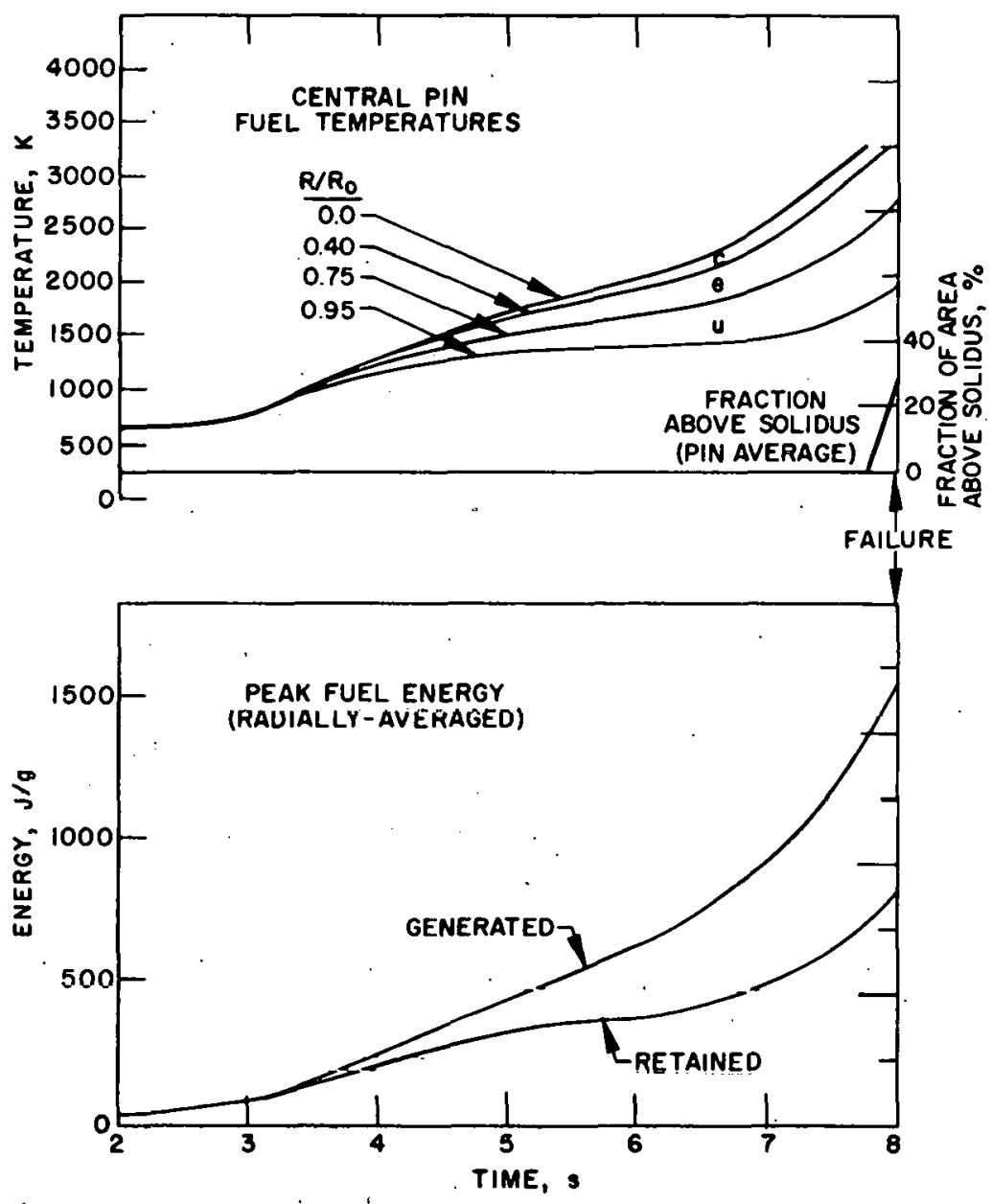

Fig. 39: Thermal History of Central Pin for Test H5 ( $c$ = columnar; $\mathrm{e}=$ equiaxed $\mathrm{u}=$ unrestructured $)$. 


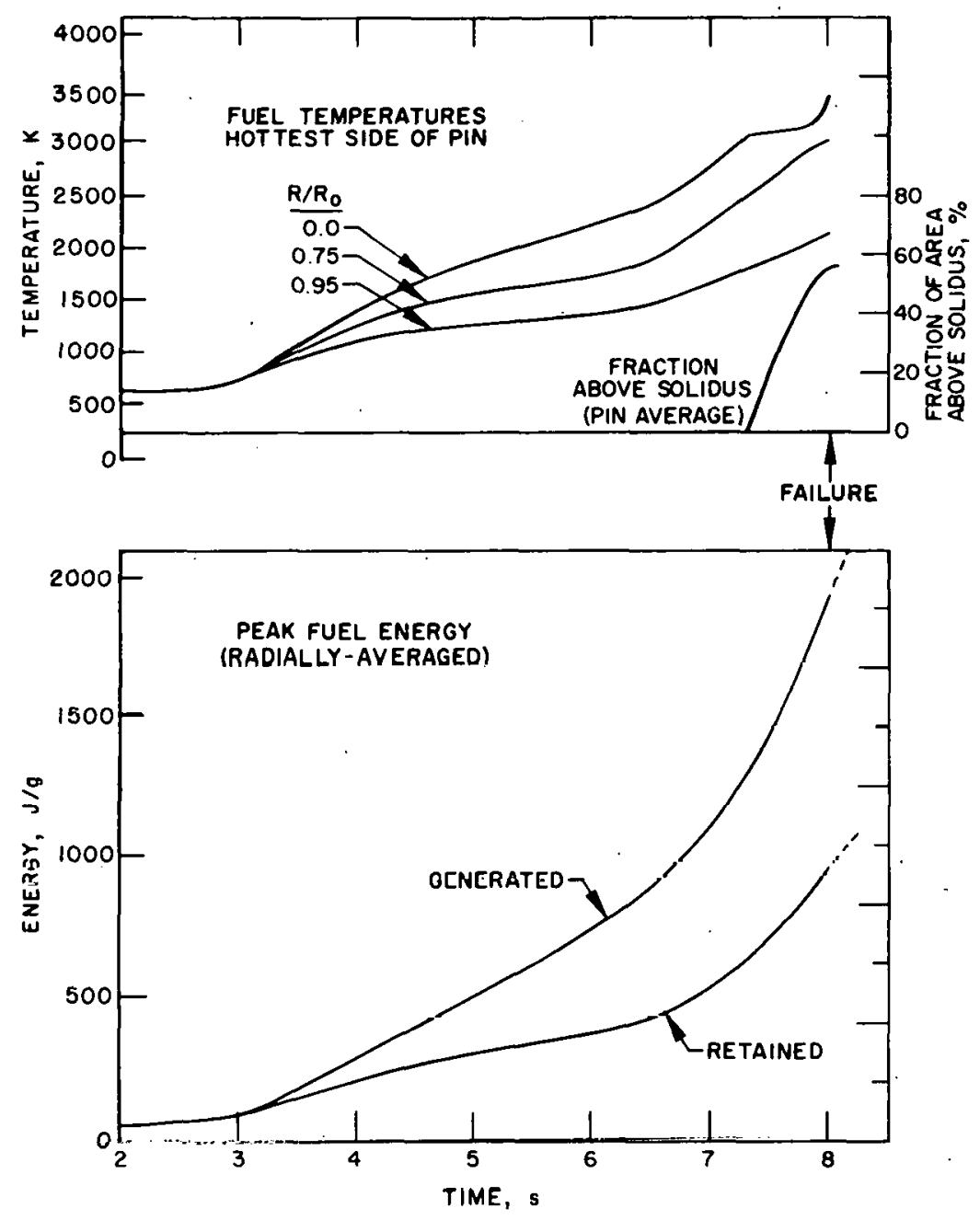

Fig. 40. Thermal History of Hottcat Pcripheral Fin for Test H5

At initial pin failure, about $25 \%$ of the fuel area was above the solidus. Measurements of the radial variation of the retained fission-gas concentration in a sibling PNL-17 irradiated pin showed that the gas density is low in the center within a radius enclosing $\sim 30 \%$ of the fuel, hut rapidly increases beyond that radius. Thus, central-pin failure in $H 5$ apparently occurred as fuel containing an appreciable quantity of gas approached the solidus and released its gas.

Table X gives a scenario of events for Test.H5, summarizing our understanding of the test data.

H. Test E6

Like Tests $\mathrm{H} 3$ and $\mathrm{H} 5$, Test E6 was performed using one central irradiated pin and six fresh peripheral pins. In contrast, the irradiated pin was from the NUMEC-F subassembly and had a distinct high-power microstructure. The peripheral pins were identical to those used in the previous seven-pintests. 
An H5-type "adiabatic" fuel holder was used. The power transient, shown in Fig. 4l, was designed to simulate a $3 \$ / \mathrm{s}$ ramp reactivity insertion following the preheat phase. Values of fission energy and fuel enthalpy are also shown in Fig. 41 for the central pin and the hottest edge pin. In this graph the values plotted are the maximum value along the pin axis of the radially and azimuthally averaged energy and enthalpy.

The flow and pressure transients derived from the data from Test E6 are plotted in Fig. 42. Only the inlet pressure has been plotted, since no pulses were observed at the outlet. Figure 43 shows the apparent motion of the interfaces between liquid and void derived from integration of the flowmeter data. Figure 44 shows the apparent void volume. The posttest neutron radiograph is shown in Appendix D.

TABLE X. Summary Scenario for Test H5

\begin{tabular}{|c|c|c|}
\hline TREAT Time, & s & Event and Evidence \\
\hline 0.0 & & Transient initiation. \\
\hline 3.1 & & Preheat power level attained. \\
\hline 6.1 & & Preheat ends; power transient begins. \\
\hline 7.3 & & Melting is calculated to begin in hottest peripheral pin. \\
\hline 7.75 & & $\begin{array}{l}\text { Melting is calculated to begin in central pin; } 0.40 \text { areal fraction above solidus } \\
\text { in hottest peripheral pin. }\end{array}$ \\
\hline 8.01 & & $\begin{array}{l}\text { First indications of failure; sharp rise in both pressure transducers, upper } \\
\text { flowmeter, and all thermocouples in the vicinity of the pin. }\end{array}$ \\
\hline $8.01-8.15$ & & $\begin{array}{l}\text { Major flow and pressure events; series of pressure pulses of } \sim 690 \mathrm{kPa} \text { spaced } \\
\text { at } \sim 20-\mathrm{ms} \text { intervals cause flow accelerations through the upper flowmeter and } \\
\text { probable partial voiding of the fueled region. }\end{array}$ \\
\hline $8.20-8.30$ & . & $\begin{array}{l}\text { Fluted tube breach; a. boiling sodium contacts thermocouple between walls of } \\
\text { fluted tubc at } 8.21 \mathrm{~s} ; \mathrm{b} \text {. flow stops at upper flowmeter; c. outlet thermo- } \\
\text { couples cool as hot sodium and fuel diverted to outside of fluted tube. }\end{array}$ \\
\hline $8.40-8.70$ & & $\begin{array}{l}\text { Upward flow acceleration; a. small sharp rise in flow through test-section } \\
\text { outlet as space around fluted tube is filled; b. upward flow through outlet, } \\
\text { peaking al } 8.60 \mathrm{~s} \text {; } \mathrm{c} \text {. inlct TC failc at } 8.57 \mathrm{~s} \text {; nne mitlet TC begins cooling; } \\
\text { d. TC between walls fails at } 8.69 \mathrm{~s} \text {; other outlet TC's begin cooling; e. outlet } \\
\text { flow ceases at } 8.7 \mathrm{~s} \text {. }\end{array}$ \\
\hline 8.90 & & First indication of possible downward flow at outlet. \\
\hline $9.40-9.50$ & & No outlet flow. \\
\hline $9.55-10.05$ & & $\begin{array}{l}\text { Additional possible downward flow pulses at outlet; marked rises in outputs of } \\
\text { outlet. TC's at } \sim 9.7 \text { and } \sim 10.0 \mathrm{~s} \text {. }\end{array}$ \\
\hline $10.1-10.5$ & & Little or no flow through outlet. \\
\hline $10.5-10.7$ & & $\begin{array}{l}\text { Upward flow through outlet; one outlet } \mathrm{TC} \text { reaches a broad temperature peak } \\
\text { near the sodium saturation temperature; all outlet thermocouples begin final } \\
\text { cooling. }\end{array}$ \\
\hline
\end{tabular}




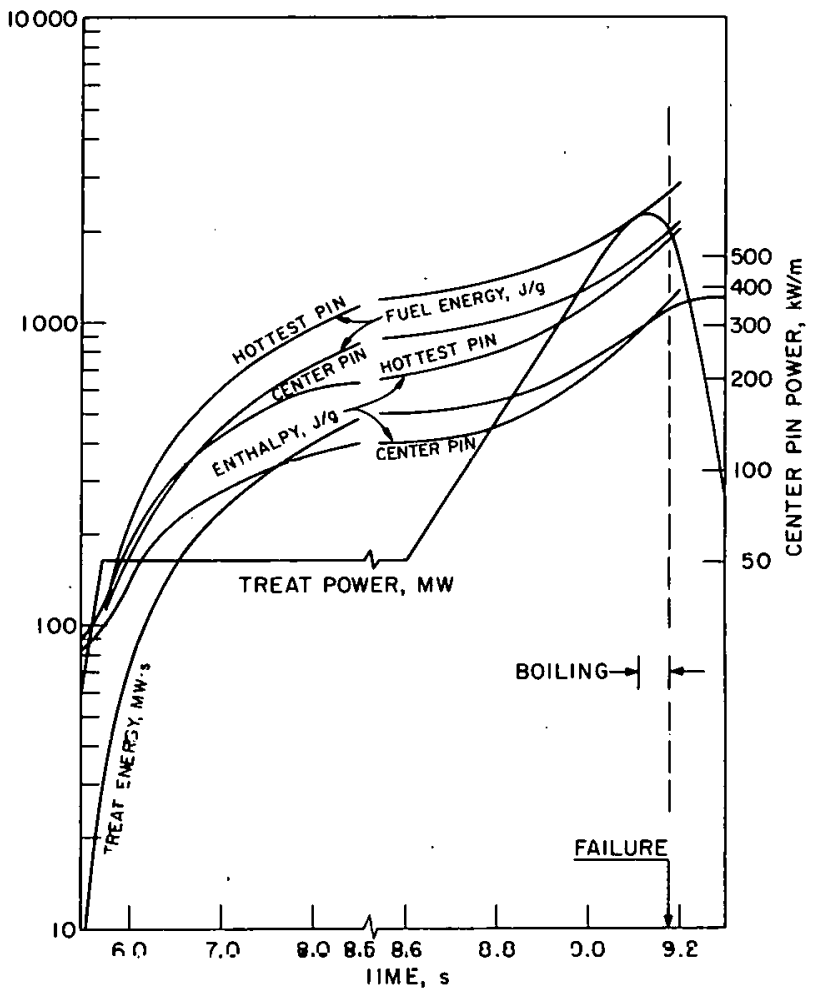

Fig. 41

Power and Energy for Test E6
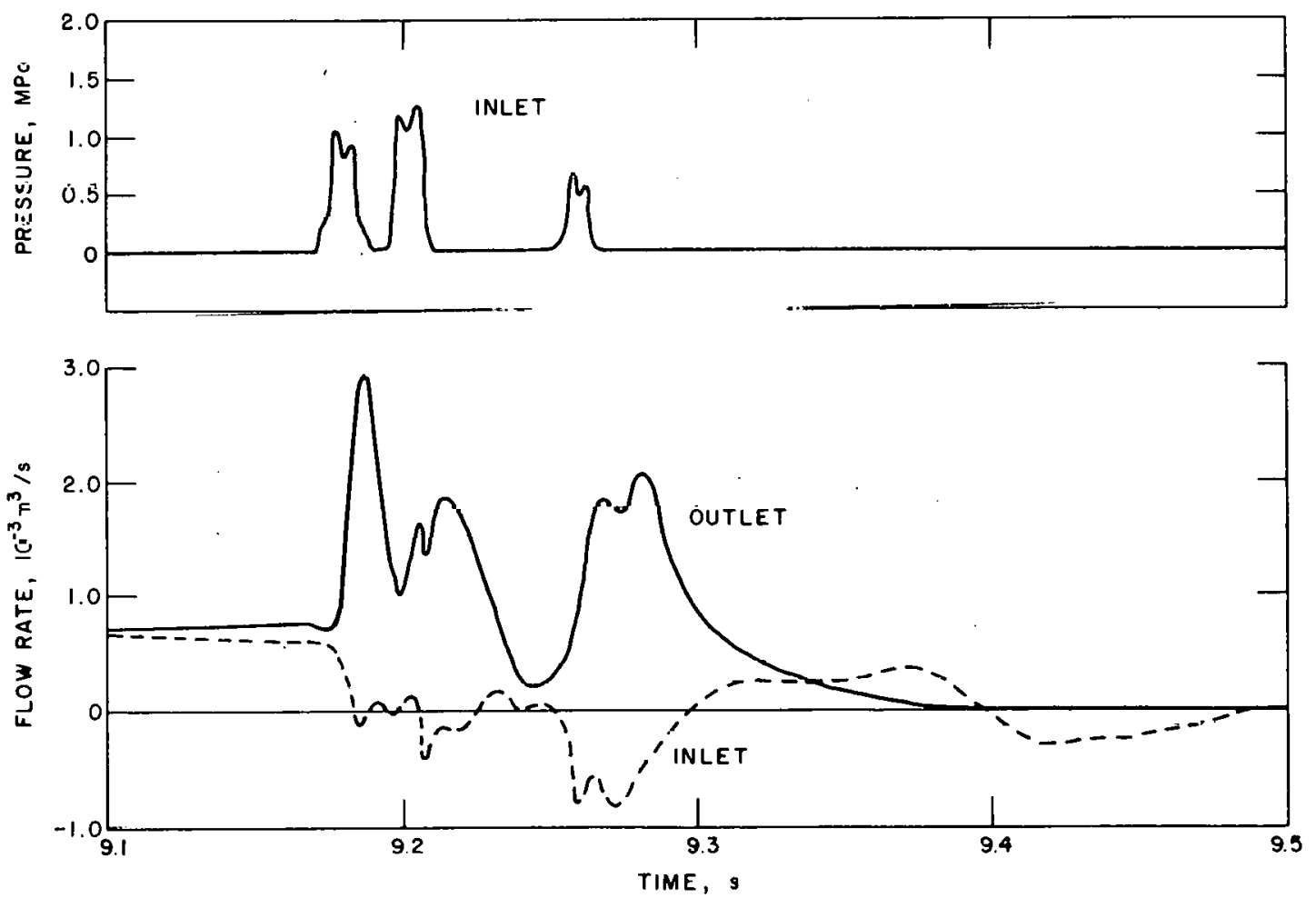

Fig. 42. Flow and Pressure Data for Test E6 


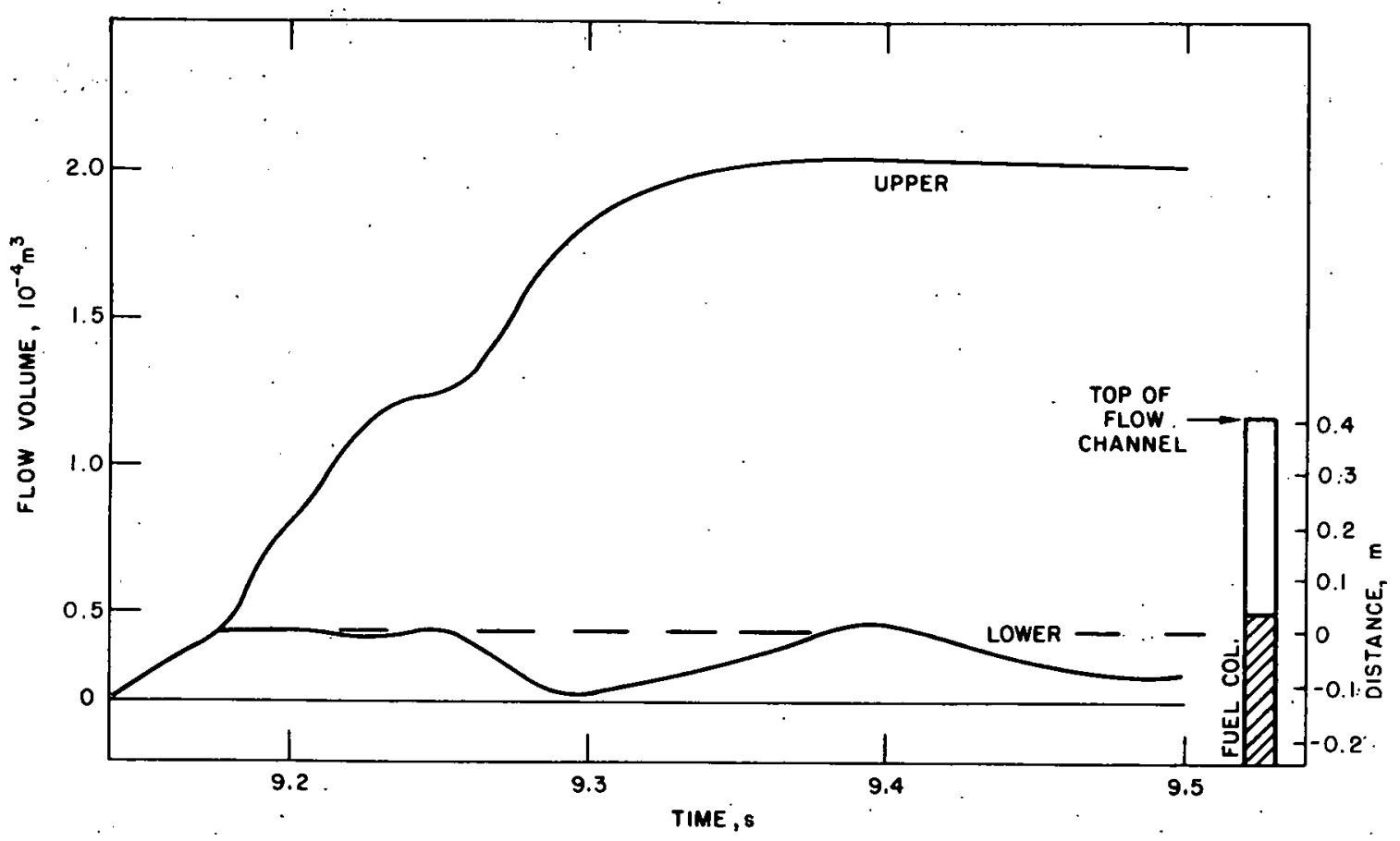

Fig. 43. Integrated Flow Volumes for Test E6

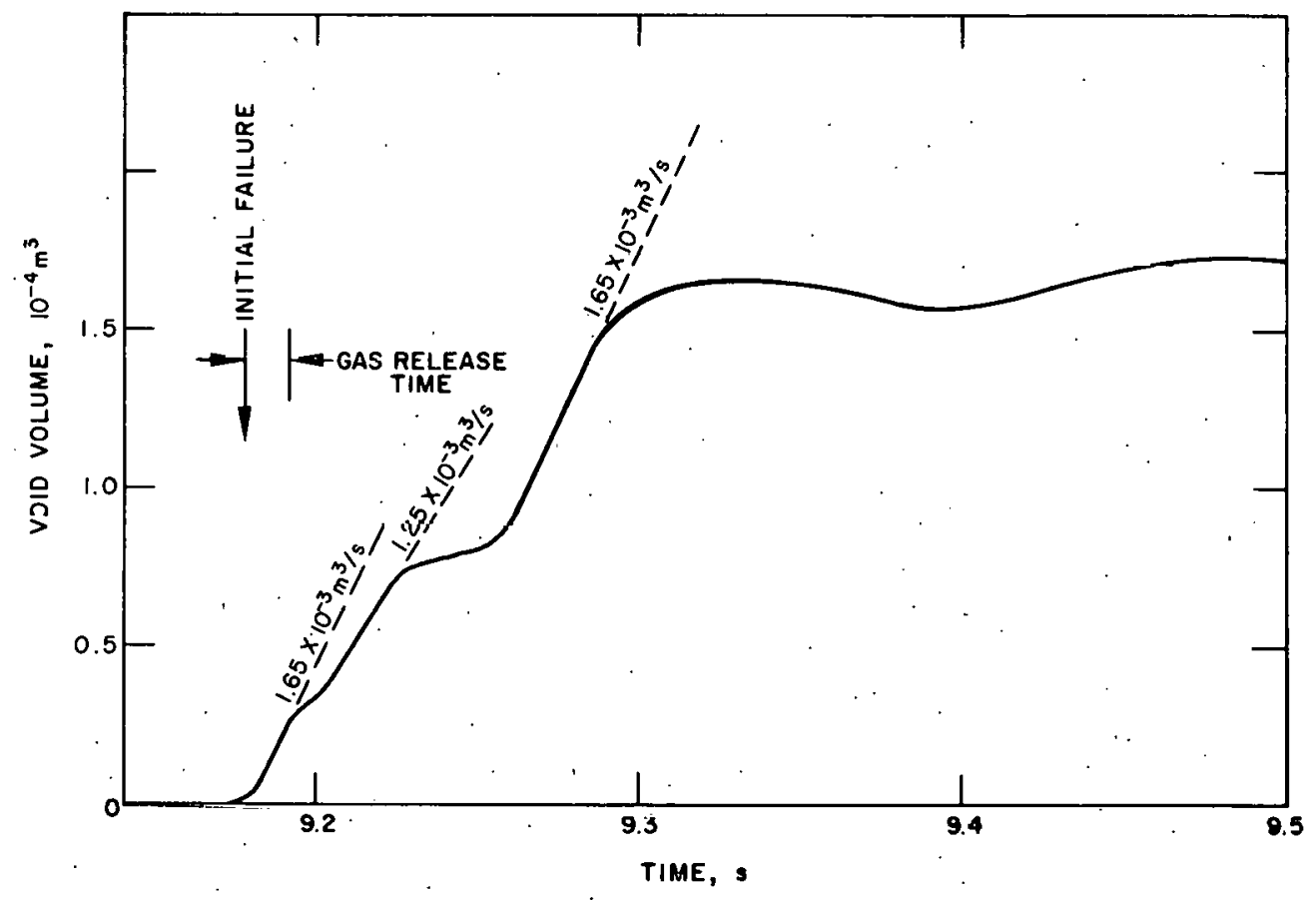

Fig. 44. Void Volume for Test E6 
Three failure-related events are apparent in the pressure and flow data (see Fig. 42) at 9.177, 9.205, and 9.258 s. Conditions at the first failure event are such that failure of one or more peripheral pins, as well as failure of the central pin, appears likely. Interpretation of the events surrounding failure is uncertain. This uncertainty is compounded by the lack of hodoscope results and posttest examination. In its general features, the flowmeter response to initial failure appears to be a rough superposition of fission-gas release (as characterized by the $\mathrm{E} 7 \mathrm{data}$ ) and fuel release (such as that occurring in $\mathrm{H} 2$ or E4). This observation leads one to believe that both gas and fuel may have been released in the initial failure. Simultaneous release of fuel and gas from the central pin is possible, but gas release from the central pin and fuel release from a peripheral pin are believed more likely. The later events may be failure of other pins or fuel release from already failed pins.
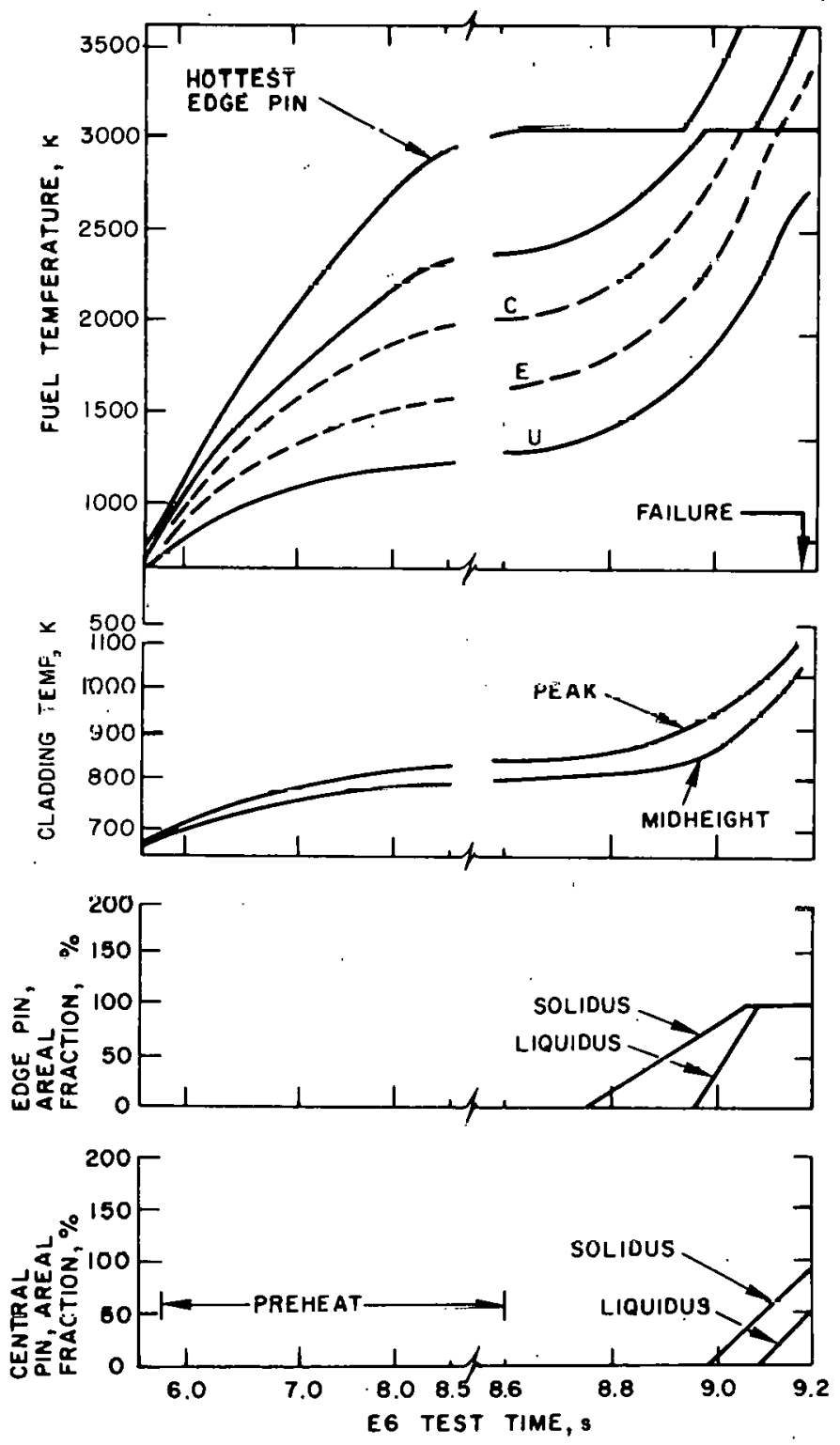

Fig. 45. Thermal History of Test E6 (C = columnar; $E=$ equiaxed: $U$ = unrestructured)

At $936 \div(180 \mathrm{me}$ aftcr failure), sodium-vapor temperatures were measured by the inlet thermocouple for about $150 \mathrm{~ms}$ before thermocouple failure. Inlet-flow data and the position of the lower liquid-vapor interface during this time suggest that the presence of hot dehris at the inlet, rather than of vapor from the mixing zone, would account for the obocrved inlet temperalures. Posllest metallographic examinations have not been performed, and the nature of an inlet blockage, if one exists, is nut known. Flow blockage is clearly indicated in the flow data, but its location is uncertain.

Thermal-hydraulic calculations for this test were made in two stages since the code used assumcs identical georretry for a.11 seven fuel pine. The first cal= culation best describes the central irradiated pin with a central void; the second best describes the solid fresh edge pins Results of the calculation for the central pin are shown in Figs. 45 and 46.

Areal melt fractions for the edge and central pins are shown in the lower portion of 

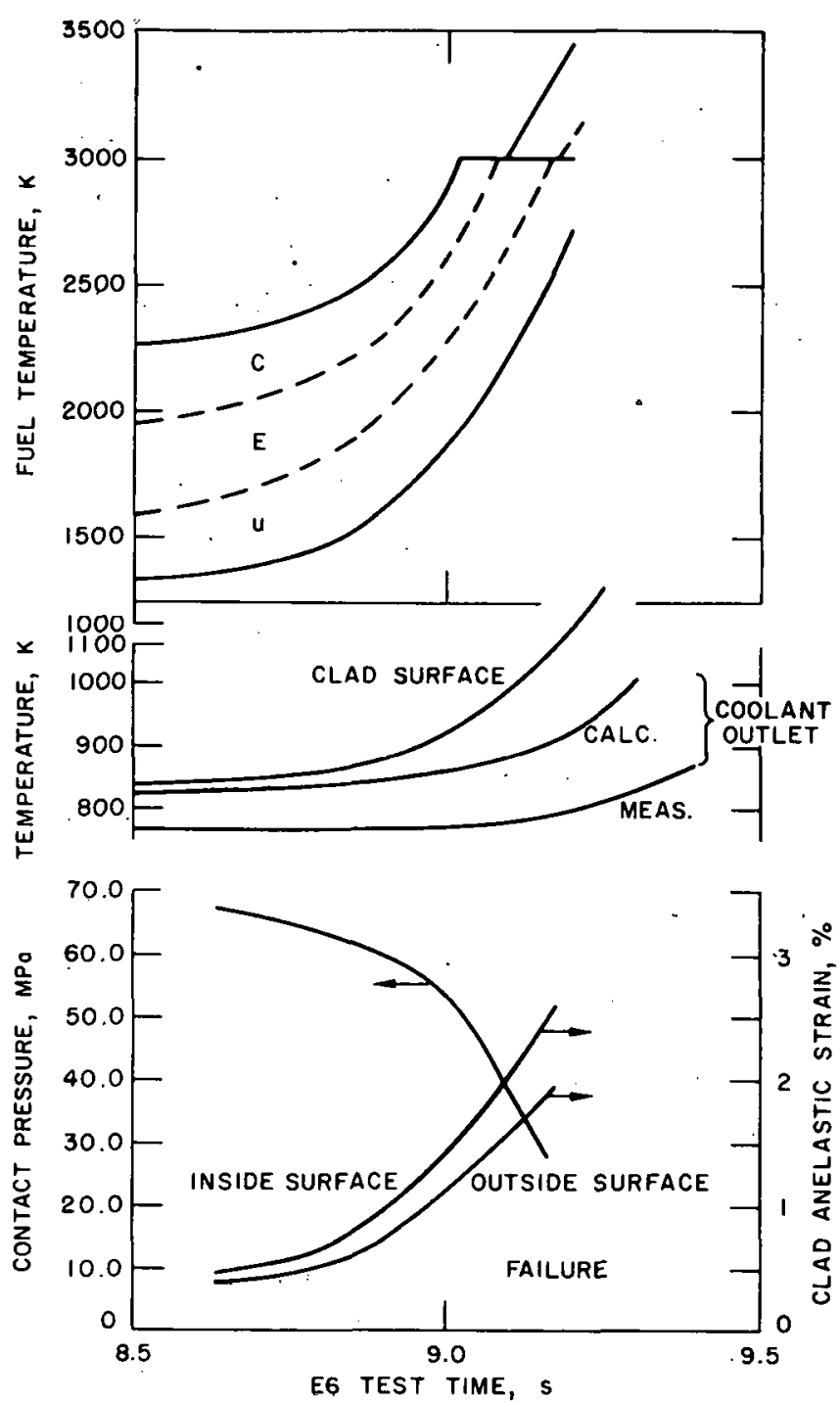

Fig. 46. Thermal-Mechanical History of Central Pin in Test $E 6(C=$ columnar; $E=$ equiaxed; $\mathrm{U}$ - uncostructured)
Fig. 45. All temperatures and melt fractions are at the central axial nodes of the fuel column. At the end of the preheat period, the top of the fuel column is the hottest node, but at the time of failure, the hottest point has moved downwards, since the axial power distribution had its power maximum at the center of the fuel column. Peak. temperatures of the hottest edge pin are also shown in Fig. 45.

Calculated cladding temperatures for the hottest edge pin into the hottest flow channel are $\sim 110 \mathrm{~K}$ higher than the central-pin results shown in Fig. 45. Prefailure boiling is most likely associated with an edge pin.

The contact pressure exerted by the fuel pellet on the cladding and the resulting cladding strain was also calculated. Results for the central pin are shown in Fig. 46. Examination of the posttest radiographs shows a major failure region from the top of the fuel column. The strain calculations shown in Fig. 46 are for this axial mode. Corresponding fuel and cladding temperatures are also shown.

Initial cladding failure at 9.177 s (as suming nearly simultaneous failure of the central pin to release fission gas, and an edge pin to release fuel) occurs at an inelastic strain of $0.7 \%$ and a cladding temperature of $1216 \mathrm{~K}$. At this time, melting has progressed well into the unrestructured region of the fuel pin. If we assume the fission-product gas to be in thermodynamic equilibrium with the edge of the fuel pellets $(\sim 2590 \mathrm{~K})$, the estimated gas pressure at failure is $12.2 \mathrm{MPa}$, that is, abnut. half of the total calculated contact pressure at failure.

Neither hodoscope nor posttest-examination results are available and the failure scenario, listed in Table XI, is based on flow and pressure data. The posttest neutron radiograph, shown in Appendix D, indicates a more extensive upward fuel sweepout than evident in either Test H5 or E7. Although the flow data indicate a flow blockage, neither its location nor its nature can be determined from the radiograph. 


\section{Test E7}

Test E7' is the only Fuel Dynamics TOP experiment to be conducted with seven irradiated fuel pins. Like Test E6, the irradiated pins were from the NUMEC-F subassembly and had a higher-power microstructure. The power transient simulated a $3 \$ / \mathrm{s}$ ramp-reactivity-addition accident; the reactor power and fuel enthalpy transients are shown in Fig. 47.

Flow data are shown in Fig. 48. There were no recorded pressure pulses during the test, and the time of initial failure is identified by departure of the flows from steady-state conditions. Beginning at $7.45 \mathrm{~s}$, the inlet flow gradually decelerated to zero in $100 \mathrm{~ms}$ and then reversed direction. Reverse

TABLE XI. Summary Scenario for Test E6

(Hodoscope data not included)

\begin{tabular}{|c|c|}
\hline TREAT Time, $s$ & Event and Evidence \\
\hline 9.110 & $\begin{array}{l}\text { Surface boiling begins } \\
\text { Peak cladding temperature: } \sim 1100 \mathrm{~K} \\
\text { Central pin } 63 \text { areal \% aluve solldus temperature } \\
\text { Edge pins } 80 \text { areal } \% \text { above solidus temperature } \\
\text { Vapor-production rate: } 5.4 \times 10^{4} \mathrm{~mm}^{3} / \mathrm{s} \\
\text { Fuel enthalpy rate of change near maximum: } 3180 \mathrm{~J} / \mathrm{g} \cdot \mathrm{s} \\
\text { Fuel enthalpy: } 1190 \mathrm{~J} / \mathrm{g} \text { for edge pin; } 988 \mathrm{~J} / \mathrm{g} \text { for central pin }\end{array}$ \\
\hline 9.177 & $\begin{array}{l}\text { Cladding rip or rupture; fission-gas release } \\
\text { rladding tcmperature }>1350 \mathrm{~K} \\
\text { TR.EAT powcr decredsing, p1n temperature equilibrating } \\
\text { Gas-release rate: } 2.2 \times 10^{-3} \mathrm{~m}^{3} / \mathrm{s} \text {; vapor volume: } \sim 3.5 \times 10^{3} \mathrm{~mm}^{3} \\
\text { Unrestructured region } \sim 50 \% \mathrm{molten} \\
\text { Peak edge fuel tcmperature: }-4150 \mathrm{~K} \\
\text { Pin-gas pressure estimated to be } 11.1 \text { to } 12.7 \mathrm{MPa} \\
\text { Fuel enthalpy: } 1490 \mathrm{~J} / \mathrm{g} \text { edge pin; } 1210 \mathrm{~J} / \mathrm{g} \text { central pin }\end{array}$ \\
\hline 9.182 & First fuel release \\
\hline . & 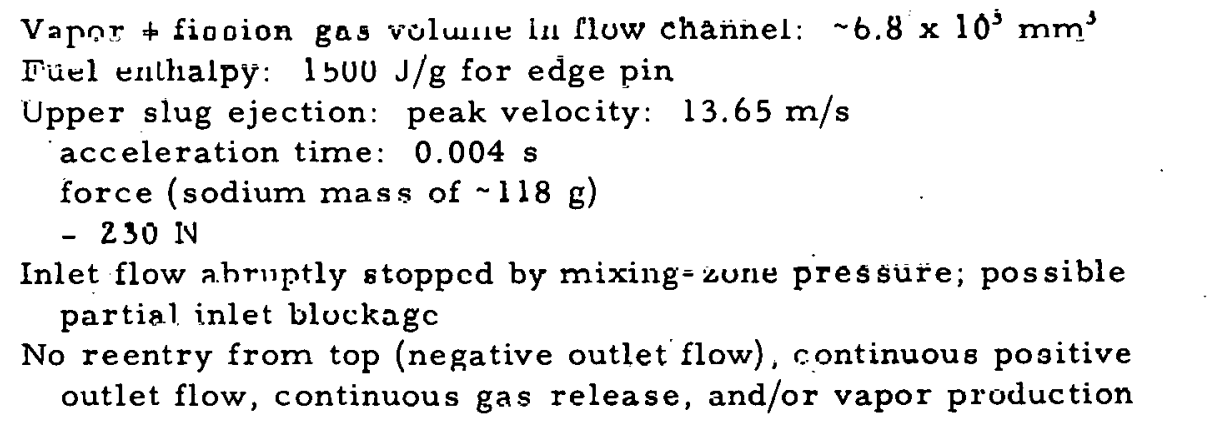 \\
\hline 9.205 & $\begin{array}{l}\text { Second fuel release } \\
\text { Flow channel above initial fuel-release point completely voided } \\
\text { Fuel enthalpy: } 1550 \mathrm{~J} / \mathrm{g} \text { edge pin; } \sim 1320 \mathrm{~J} / \mathrm{g} \text { central pin }\end{array}$ \\
\hline 9.258 & $\begin{array}{l}\text { Third fuel release } \\
\text { Fuel enthalpy near maximum }(\sim 1610 \mathrm{~J} / \mathrm{g}) \\
\text { Areal melt fraction maximum }(80 \% \text { edge pins, } 76 \% \text { central pin) }\end{array}$ \\
\hline
\end{tabular}




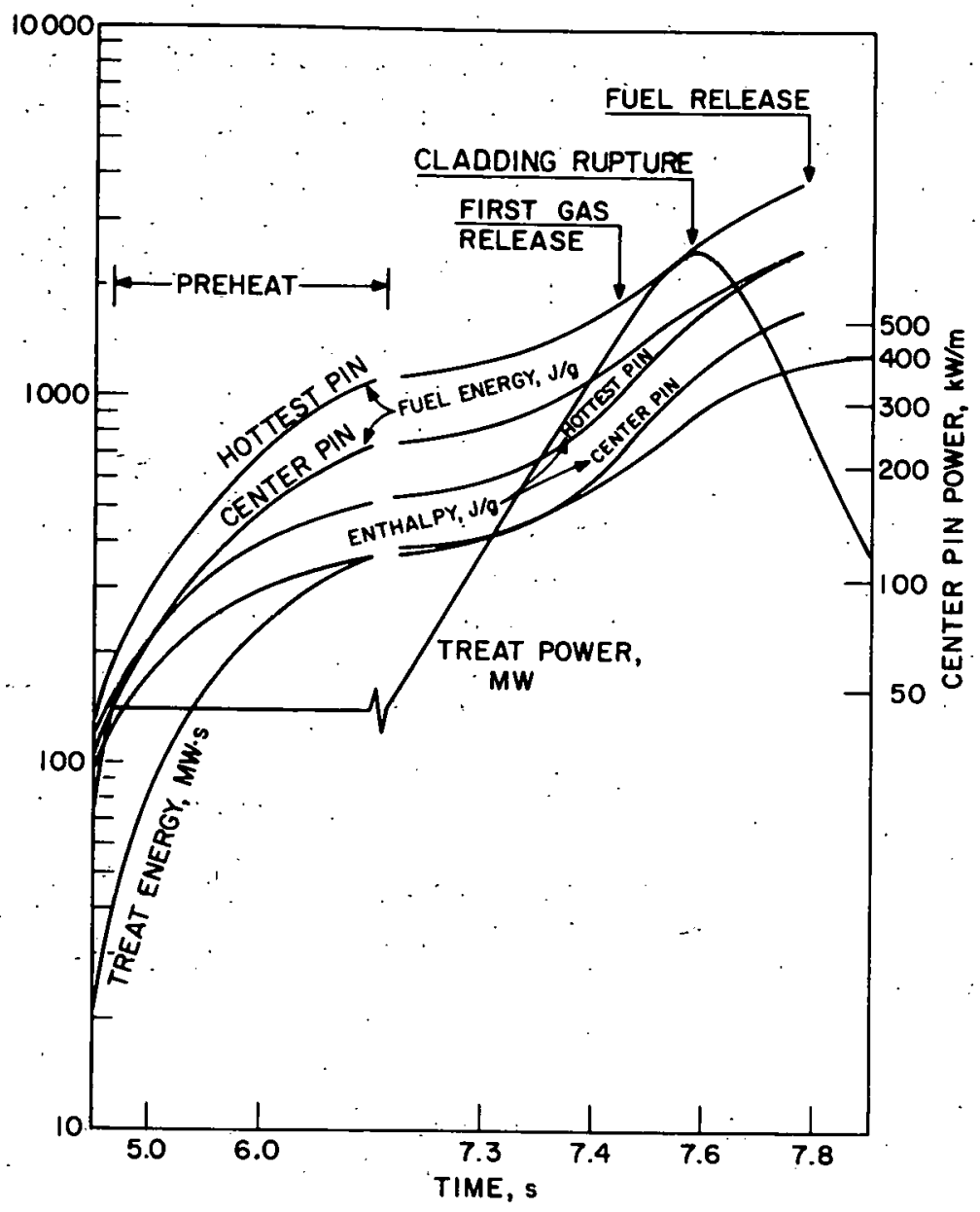

Fig. 47. Power and Energy for Test E7

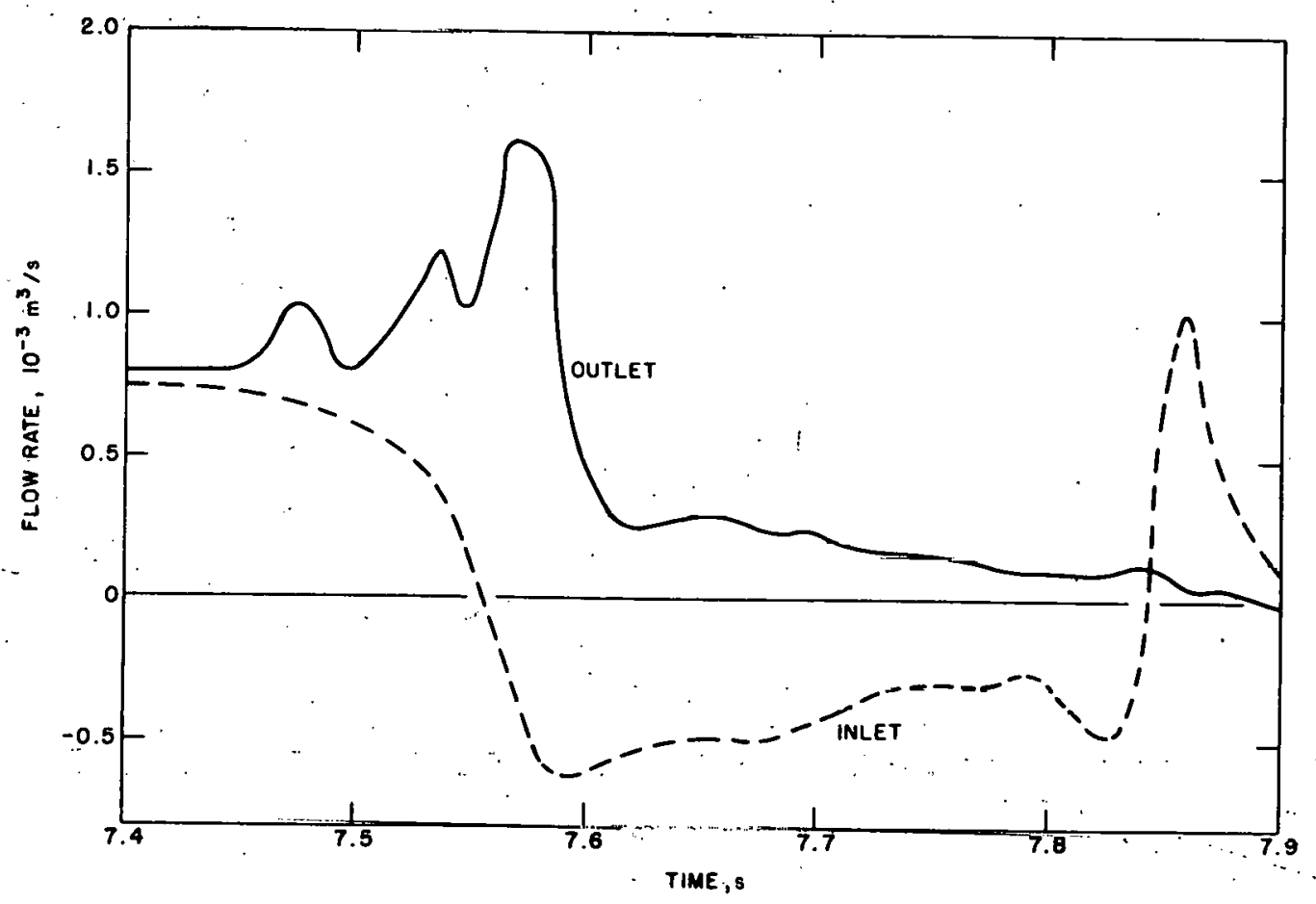

Fig. 48. Flow Data for Test E7 
inlet flow continued for the next $300 \mathrm{~ms}$, with volume flows varying from $\sim 2.25 \times 10^{-4}$ to $6.40 \times 10^{-4} \mathrm{~m}^{3} / \mathrm{s}$. There is a corresponding mild expulsion of outlet flow during the $50 \mathrm{~ms}$ after failure followed by a larger ejection during the next $70 \mathrm{~ms}$. After this ejection, the outlet flow slowly decreased to zero. A final positive inlet-flow surge beginning at $7.83 \mathrm{~s}$ terminated all flow activity.

The time-integrated flows past the upper and lower flowmeters are shown in Fig. 49 and the apparent void volume in Fig. 50. The initial void is believed to result from gas release from the fuel pin through a pin-hold crack, possibly along a grain boundary in the cladding, since other possibilities do not seem reasonable. Other possibilities include swelling or blistering of the cladding and coolant expansion by heating or boiling. However, cladding expansion before rupture or burst of about $5 \%$ in radius would account for less than $1000 \mathrm{mmr}^{3}$ of volume change, and rladding bliotcrs witluul ruplure that account for more than a frartion of $1000 \mathrm{~mm}^{3}$ of the dupdsent vold do not seem reasonable. Thus, gas release seems most probable.

In the initial stages, void growth was nearly linear (7.45-7.49 s), then tapered off to a lower rate. At about $7.51 \mathrm{~s}$, an exponential growth began, having a period of about $10 \mathrm{~ms}$, and lasted until about $7.58 \mathrm{~s}$. Apparently, the initial failure remained isolated until $7.51 \mathrm{~s}$, at which time the failure became larger, or more pins failed.

Since the initial failure appeared to result in gas release, it does not appear correct to interpret the data in Fig. 49 directly in terms of interface motion. The estimated interface motion is shown in Fig. 51. This graph was

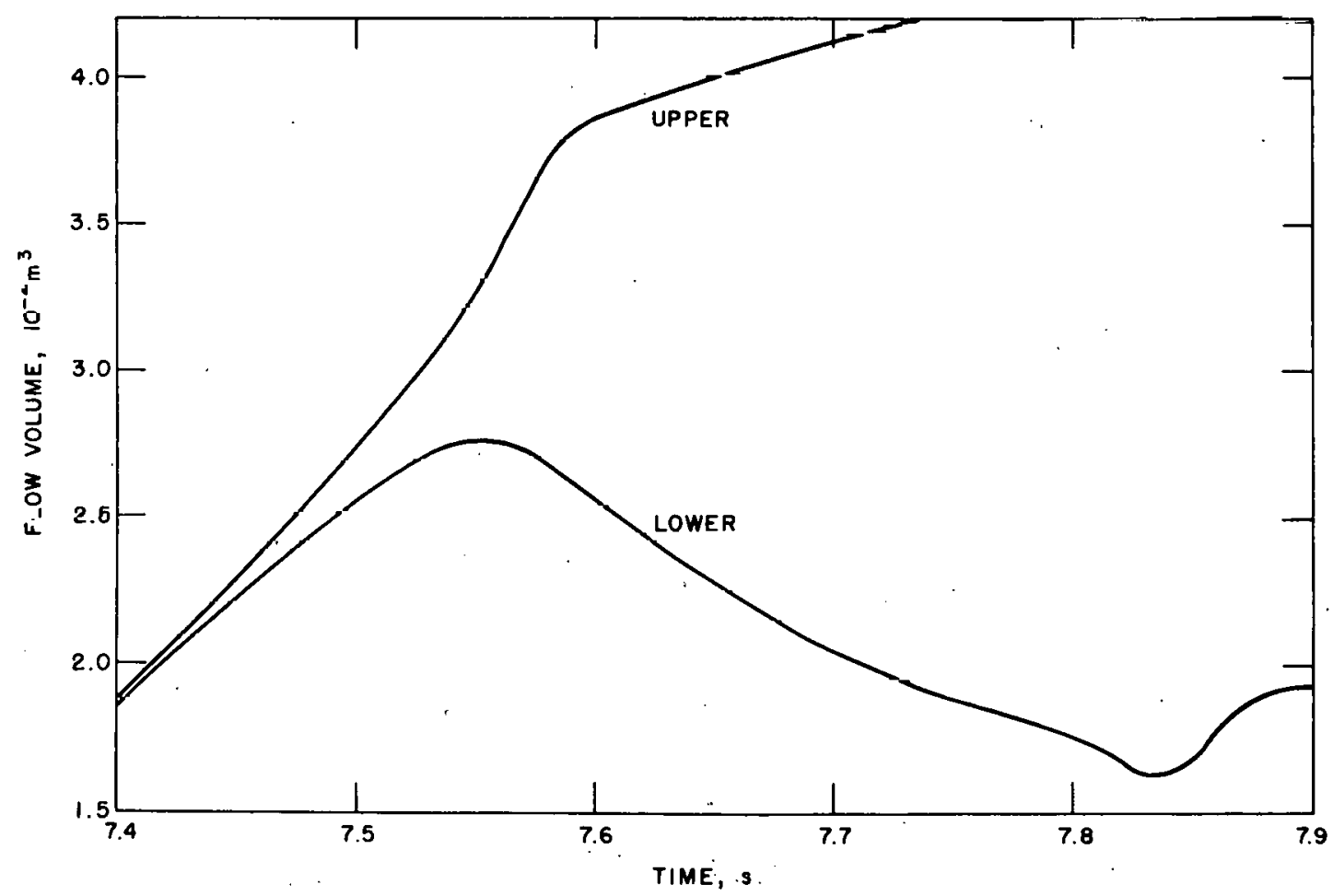

Fig. 49. Integrated Flow Volumes for Test E7 


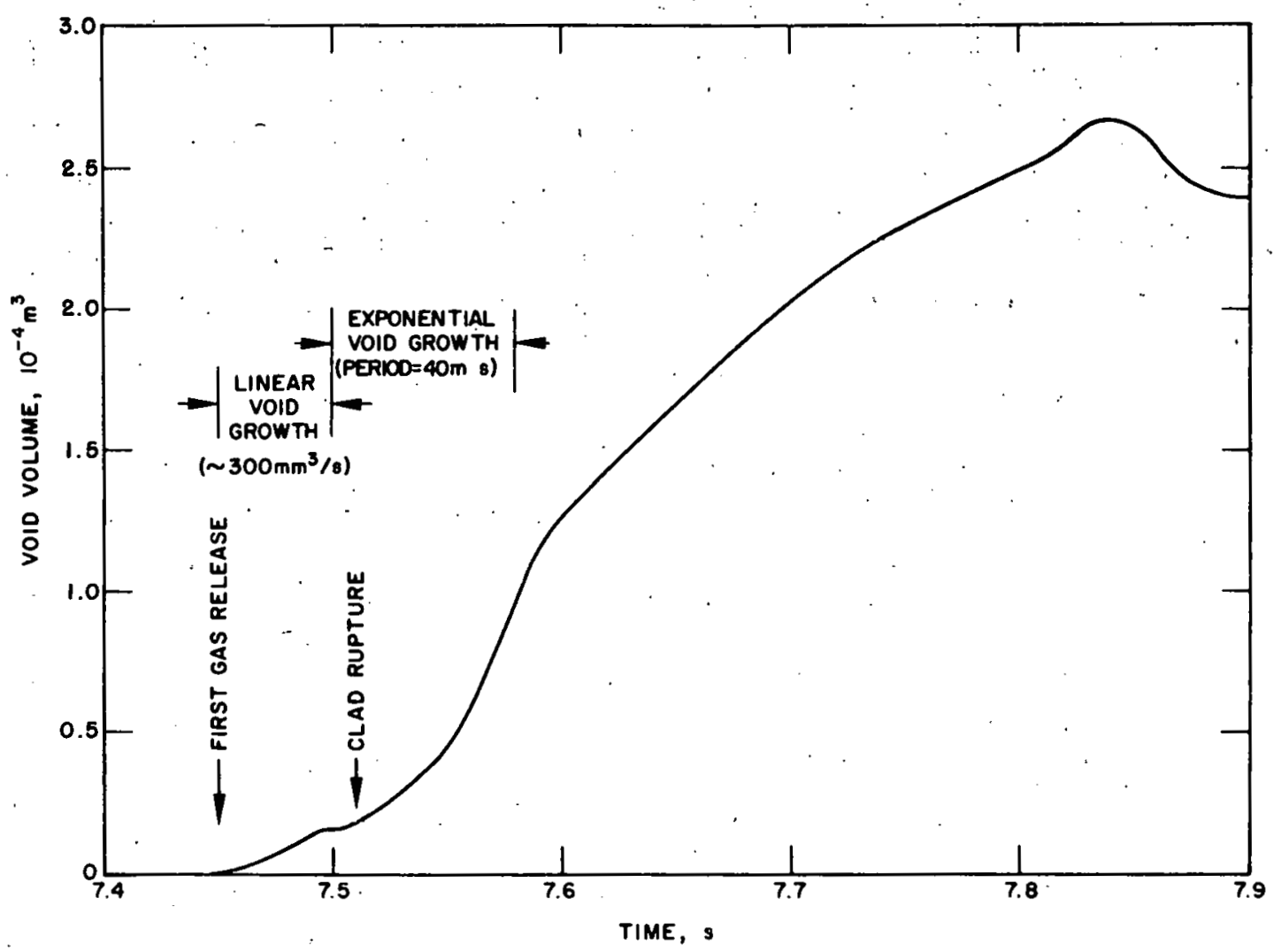

Fig. 50. Void Volume for Test E7

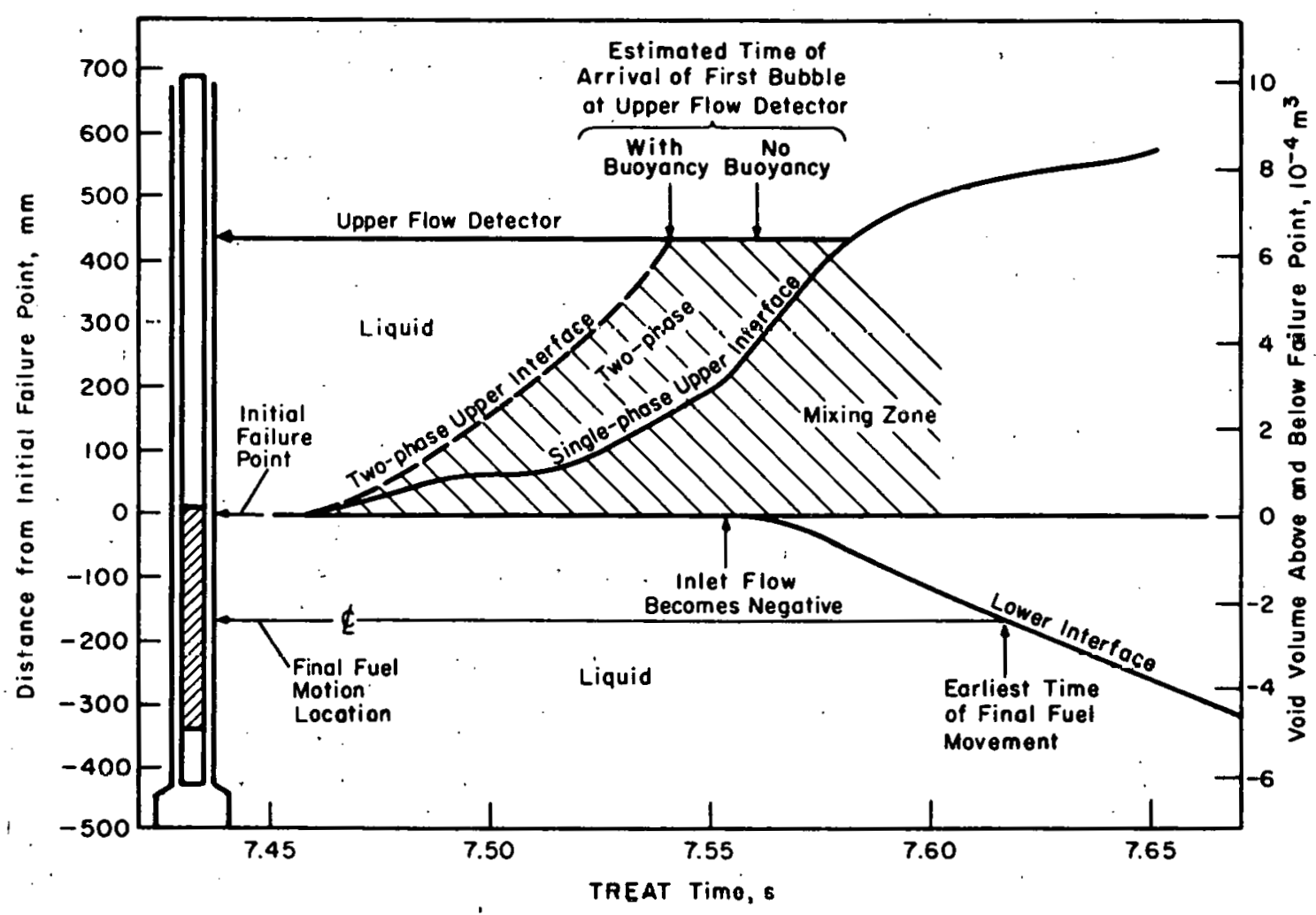

Fig. 51. Single- and Two-phase Flow Interfaces for Test E7 
constructed by assuming that the indicated void volume existed in a region downstream of the initial failure point (taken to be at the top of the fuel column) until flow reversal was indicated at the inlet. Not until this time $(7.551 \mathrm{~s})$ did the vapor-liquid interface move downward from the initial point of gas release. Some of the first gas bubbles to be released arrived at the upper flow detector within about $85 \mathrm{~ms}$ (as evidenced by the momentary drop in outlet flow beginning at $7.535 \mathrm{~s}$ ). In this case, there was no well-defined gas-liquid interface as usually defined by the integrated flows.

The posttest radiograph of the stripped loop (see Appendix D) shows that all fuel in the central $50-\mathrm{mm}$ region of the fuel column had been voided. This region was not vapor- or gas-blanketed until after $7.62 \mathrm{~s}$, suggesting little or no fuel movement from the axial center at this time. Destruction of the fucl pins was much more extensive than, in other seven-pin cluster tests.

Hodoscope data showed a linear depletion of fuel from the central region of the cluster beginning at $7.75 \pm 0.03 \mathrm{~s}$. The loss was gradual, almost imperceptible above fluctuations during the transient. Total motion lasted several seconds and ultimately reached a magnitude sufficient to void fully the central axial sestinn of the cluetcr. Note thal by the time the hodoscope first "sees" fuel movement, all major flow activity (except for a final inlet reentry at $7.85 \mathrm{~s}$ ) was essentially complete and the flow channel completely voided.

Upward driving forces for fuel movement may include sodium, steel, or fuel vapnr and releace of rctaincd fissiun gases, since most the fission gas initially retained in the fuel pin had been released relatively early in the transient. From the calculated peak temperatures at the time of the second gas release (7.51 s), fuel-vapor prcssures wete uf the order of $1 \mathrm{MHa}$. Hressures in excess of several 10.1 MPa were possible at the time of final fuel movements, but the fuel-temperature calculations on which these pressure estimates were made are not very reliable.

An estimate based on adiahatir heating from 7.6 to 7.7 s yielded a temperature increase of $1400 \mathrm{~K}$ and a fuel vapor pressure of $7.1 \mathrm{MPa}$. Evidence of continuous gas release and sodium-vapor generation after the initial gas release is based on the complete absence of any reentry from the inlet. At the lime of final fuel movement, about $3 \times 10^{4} \mathrm{~mm}^{3}$ of liquid did reenter from the bottom, but the absence of reejection and an associated pressure pulse would indicate that this reentry reflected vapor-bubble collapse near the inlet or holder-wall rupture.

Posttest metallographic examinations have not yet begun, but a preliminary gamma scan of the lower bend region of the loop indicates the potential presence of significant quantities of fuel in this region. If this is fuel that was swept out with the flow stream, it must have occurred as late as 300$500 \mathrm{~ms}$ after the failure accompanied by gas release. After this time, there 
was no measurable flow; before this time, no fuel motion was observed by the hodoscope. It is not possible to identify which pin failed first nor when fuel was first released.into the coolant channel. Clearly, something like a very mild interaction occurred at $7.79 \mathrm{~s}$ that led to a substantial inlet reentry at 7.83 s. Considerable fuel release probably occurred as early as $7.55 \mathrm{~s}$, but, because of extensive flow-channel voiding and possible holder-wall rupture, the characteristic slug ejections and pressure pulses were not produced.

Results of the thermal-hydraulic calculations are shown in Fig. 52 for the central pin and in Fig. 53 for the hottest edge pin. At the time of the initial pinhole leak $(7.45 \mathrm{~s})$, the inner columnar region of the central pin was approaching the solidus temperature, the peak cladding temperature was
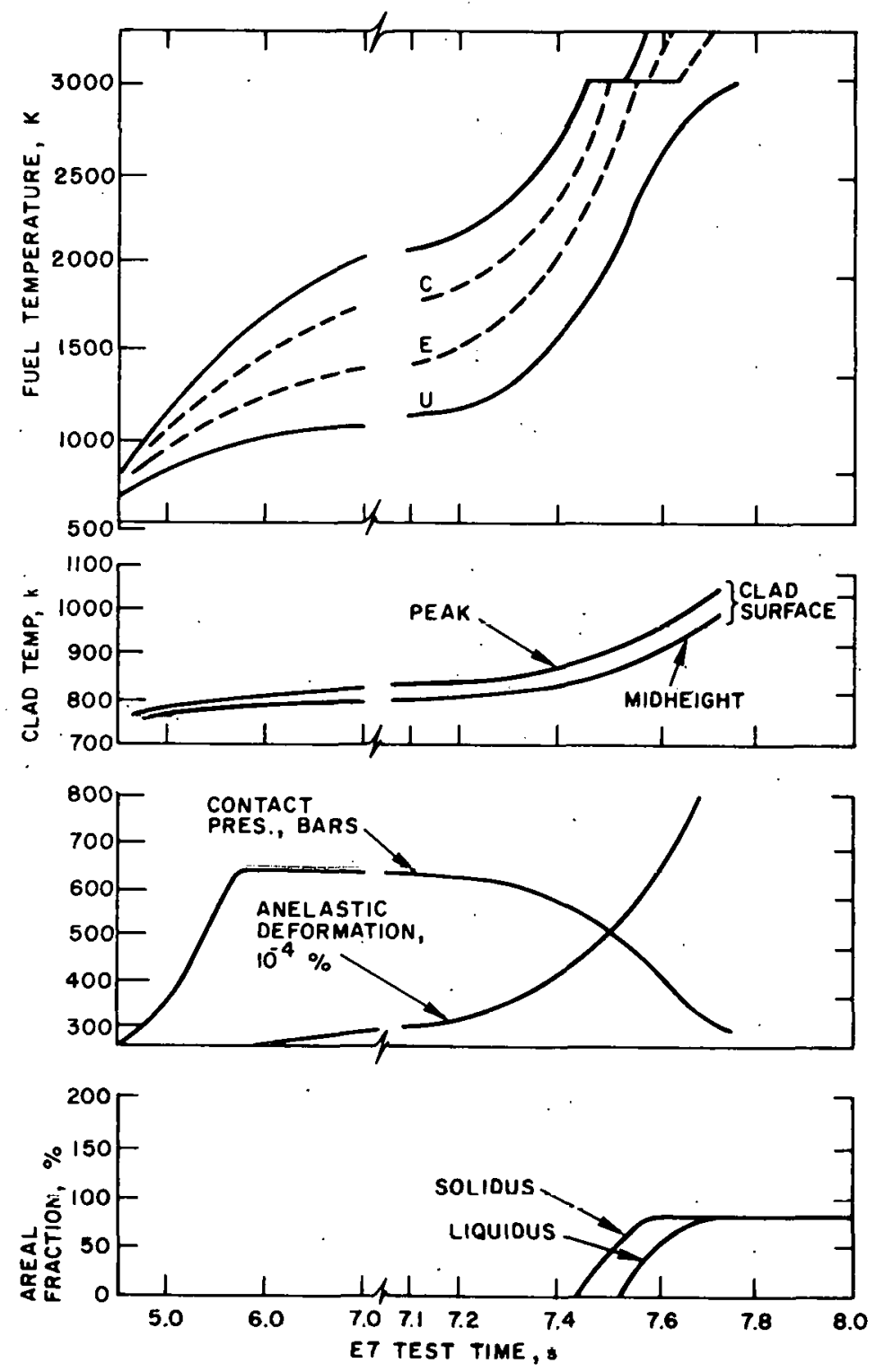

Fig. 52. Thermal-Mechanical History of Central Pin for Test E7 $(C$ - columnar; $E$ = equlaxed: $U$ - unrestructurcd)
$1005 \mathrm{~K}$, the fission-gas pressure inside the cladding was $\sim 6.6 \mathrm{MPa}$ (of the total $54.7-\mathrm{MPa}$ contact pressure), and the average cladding strain was $\sim 1.2 \%$. Although strain calculations have not been made for the edge pins, the hottest pin was $\sim 62 \%$ molten, and the unrestructured region approached the solidus temperature.

Despite the lower cladding temperature $(866.5 \mathrm{~K})$, the hottest edge pin was probably the first to rupture. A similar condition existed for the central pin at $7.57 \mathrm{~s}$, and it may have ruptured at $7.58 \mathrm{~s}$.

By $7.55 \mathrm{~s}$, the edge pin was $80 \%$ above the liquidus and very possibly released fuel into the flow channel. The event at $7.79 \mathrm{~s}$, identified as fuel release, may have been a substantial release of fuel from the flow channel into the loop sodium and could account for fuel believed to be deposited in lie lower bend.

The posttest neutron radiograph of E7 is shown in Appendix D. Considerably more general destruction of the fuel pins than seen in $\mathrm{H} 5$ 


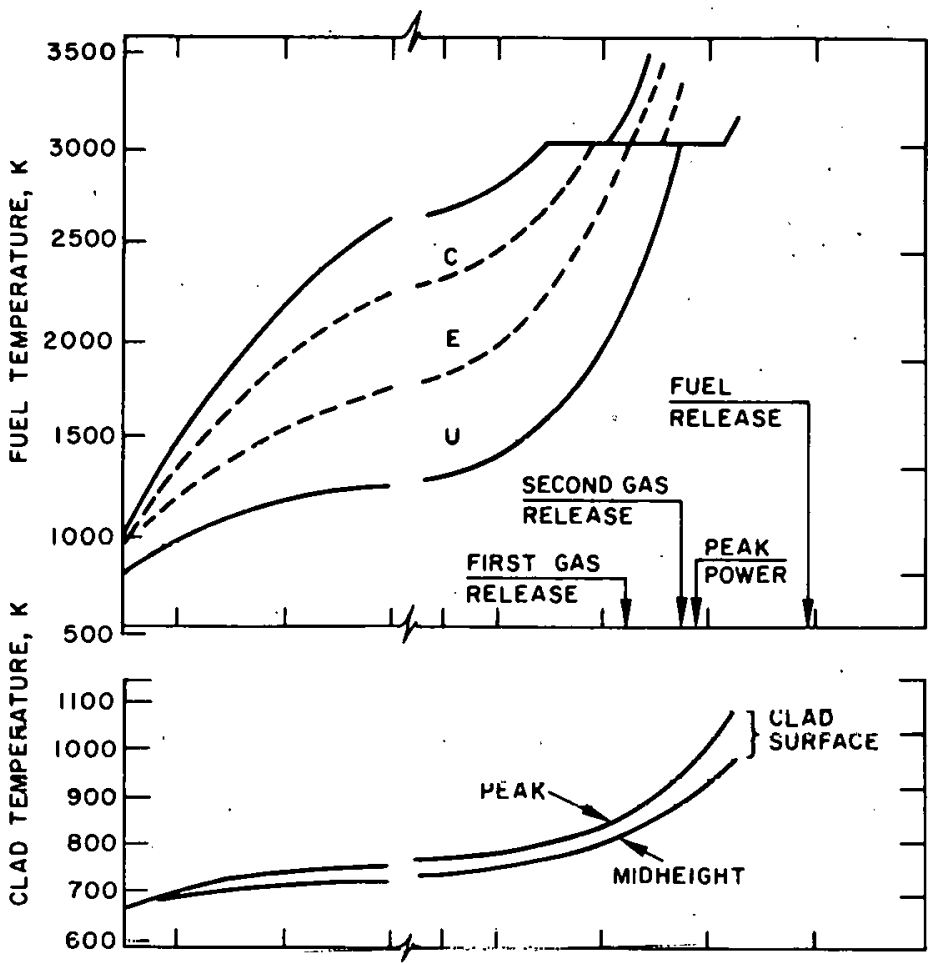

Fig. 53

Thermal History of Hottest Peripheral Pin for Test $\mathrm{E7}(\mathrm{C}=$ columnar; $\mathrm{F} \equiv$ equiaxed; $U$ = unrestructured)

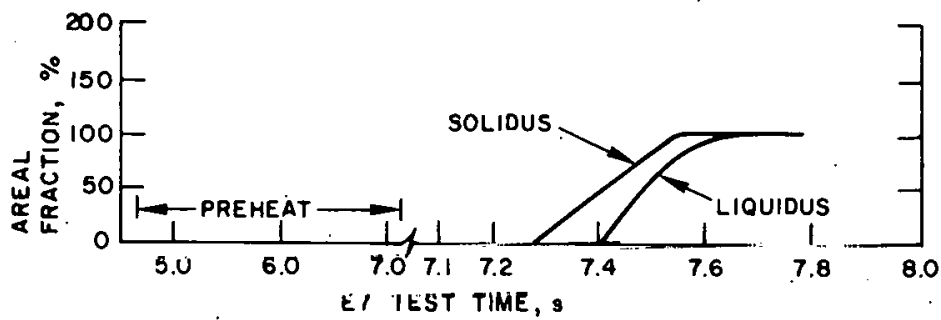

or E6 is evident. Some fuel removal beyond the original fuel culurnnts apparent, but the fuel does not appear to have moved as fir as in E6. 'The locations and nature of flow blockages are not apparent from the radiograph.

A summary scenario for Test E7 is given in Table XII.

TAB LE XII. Summary Scenario for Test E7

TREAT Time, s Event and Evidence

7.45

7.50

7.55

7. 58

7.62

7.75

7.79

Pinhole rupture developed in hottcst edge pin lo release $1.5 \times 10^{4} \mathrm{~mm}^{3}$ (at pressure and temperature) of fission gas during a 45-ms period. Cladding tenueralures are too low for this to be vapor production.

A larger rupture, perhaps in the central pin, released $-1.2 \times 10^{-4} \mathrm{~m}^{3}$ of gas during the ncxt $55127 \mathrm{~s}$.

Possible small local fuel release into voided region.

Lowcr mixisy-zulle Inierface begins to move downward, allowing more extensive cladding failure.

Axial center of fuel (hottest mode) becomes vapor-blanketed.

First indication of fuel motion by hodoscope. Fuel depletion occurs at center and is very slow, lasting several seconds.

Entire flow channel voided. Some hot debris released from flow channel into loop sodium. 


\section{J. Test E3}

Test E3 was the first simulation of a severe overpower transient using preirradiated oxide-fuel pins in the Mark-II loop. The goal of the test was to obtain an early indication of the severity of events resulting from failure of preirradiated fuel, particularly the effects-of fission gas on fuel fragmentation and mixing with the coolant. A three-pin cluster of MTR-irradiated $\mathrm{UO}_{2}$ fuel pins with short $(0.14-\mathrm{m})$ fuel columns, annealed Type 304 stainless steel cladding, and no axial restraint was used. The initial power level during MTR irradiation was about $2.5 \mathrm{GW} / \mathrm{m}^{3}$ (equivalent to $\sim 46.6 \mathrm{~kW} / \mathrm{m}$ in an FTR pin). The pins therefore developed a high-power structure with a central void along the full length of the fuel column. Nominal burnup of the test pins was 6 at. $\%$.

The fuel was quite "gassy," with only $23 \%$ release of fission gases from a sibling pin. Estimated initial plenum pressure was $940 \mathrm{kPa}$. The fuel holder simulated the hydraulic environment of a larger cluster, but was not "adiabatic". by design. Since no gas space was present opposite the fuel column, the environment was "harder" than that of any other test in which failure occurred. A natural TREAT transient of particularly short period ( $35 \mathrm{~ms}$ ) and high peak power (6500 MW) was used. The resulting energy generation and fuel enthalpy at the hottest location are shown in Fig. 54. No thermal-neutron filter was used in this test.

Flow and pressure data for Test E3 are shown in Fig. 55, and the integrated flow is shown in Fig. 56. Failure occurred at $0.668 \mathrm{~s}$, as indicated by sharp pressure pulses and sodium-slug ejections from the flow channel.

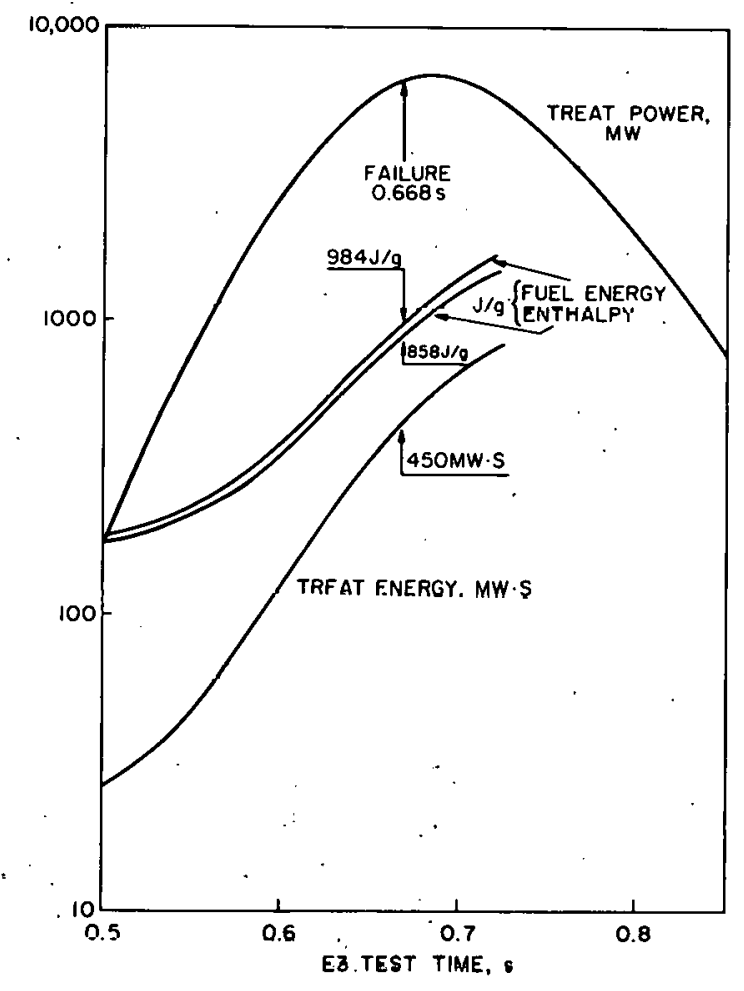

Fig. 54. Power and Energy for Test E3
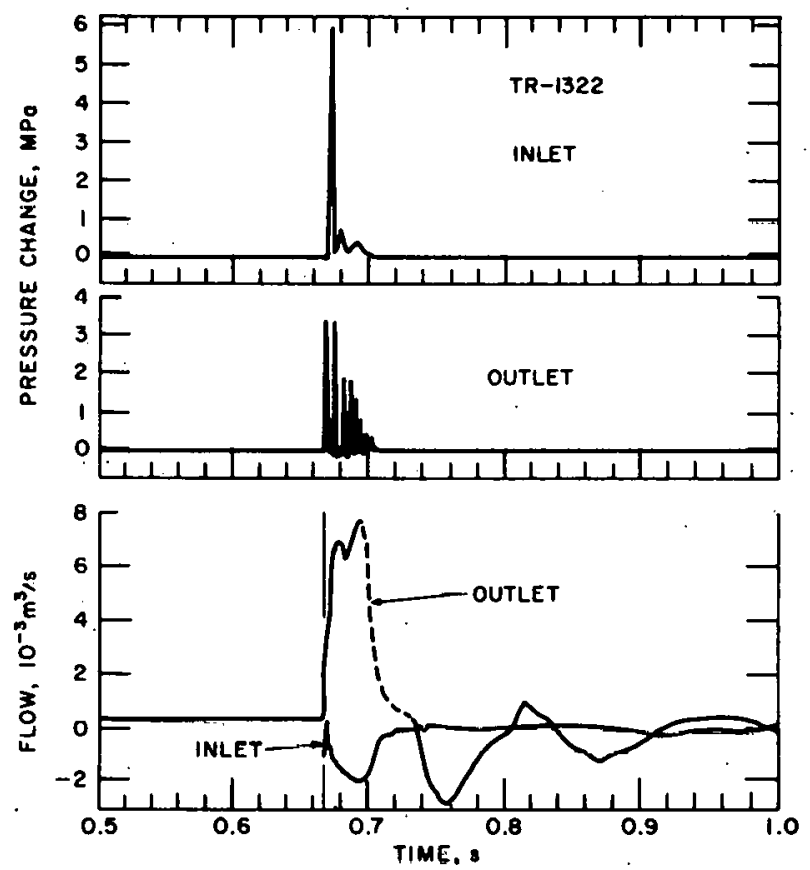

Fig. 55. Flows and Pressures for Test E3 


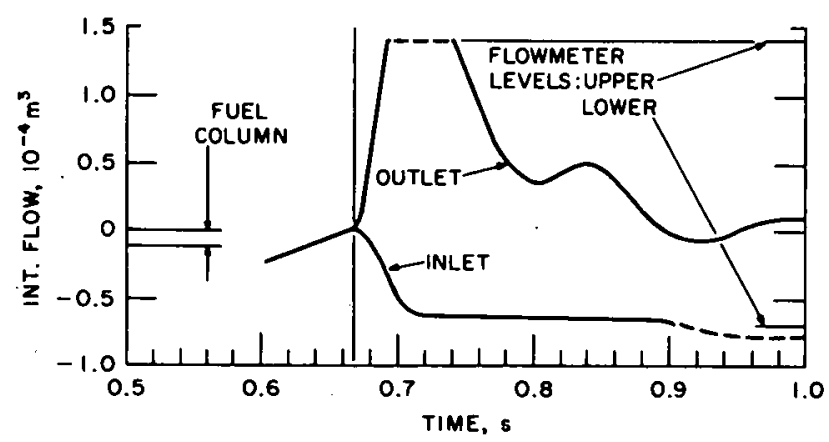

Fig. 56. Integrated Flow for Test E3

The series of outlet pressure pulses seen. in Fig. 55 was probably the characteristic response of the pressure transducer to a single sharp pulse. The maximum growth rate of void volume was the largest ever recorded in a loop test, although the interface velocity (on a one-dimensional basis) was comparable to that observed in Test E4. Two peaks are seen in the outlet flow curve (at 0.673 and $0.694 \mathrm{~s}$ ), which suggests a second failure within about $25 \mathrm{~ms}$ of the first. Because of voiding of the test section, possible isolated failure of a third pin may not be seen in the flow and pressure data.

The absupt nature of the pressure and flow transients implies that failure of at least one pin was brittle in nature, rather than gradual gas release believed to be the case in Test E7. The Type 304 cladding of the E3 pins likely suffered embrittlement during the high-fluence thermal preirradiation. The pressure spike recorded at the outlet was of the same order of magnitude as the estimated gas pressure inside the pins, while that at the inlet was somewhat higher. The integrated flows, given in Fig. 56, show that the sodiurn was rapidly expelled from the test section after failure and that the test section remained generally voided with a few subsequent weak reentry-expulsion events at the top of the test scction. Voiding of the fuel region was complete within about $12 \mathrm{~ms}$ of failure. At sorne time after failure, the flow channel became completely blocked.

Posttoat examination revealed essentially complete removal of fuel from the fuel-column region. Highly fragmented fuel remains wcre piled up against the thermocouple holder located above the fuel pins. This concentration of fines evidently caused flow blockage, but not until-more than two-thirds of the fuel had escaped into the loop.

Hodoscope results for E3 have a fairly large uncertainty with respect to beginning of fuel motion, due to the high power level of the transient and failurc before the peak. Fuel motion began within a $\sim 30-\mathrm{ms}$ period after failure, but the time cannot be determined more precisely. Motion out of the original fuel region was essentially complete in about $100 \mathrm{~ms}$. The character of the indicated motion is that of gradual fuel removal upwards, rather than a particular identifiable motion.

Calculated thermal-history data are given in Fig. 57. Note that, while melting had not yet occurred by $0.668 \mathrm{~s}$, it would begin in another $5 \mathrm{~ms}$. Thus, melting of fuel likely occurred at about the time at which motion began. The mechanical history is given in Fig. 58 . 

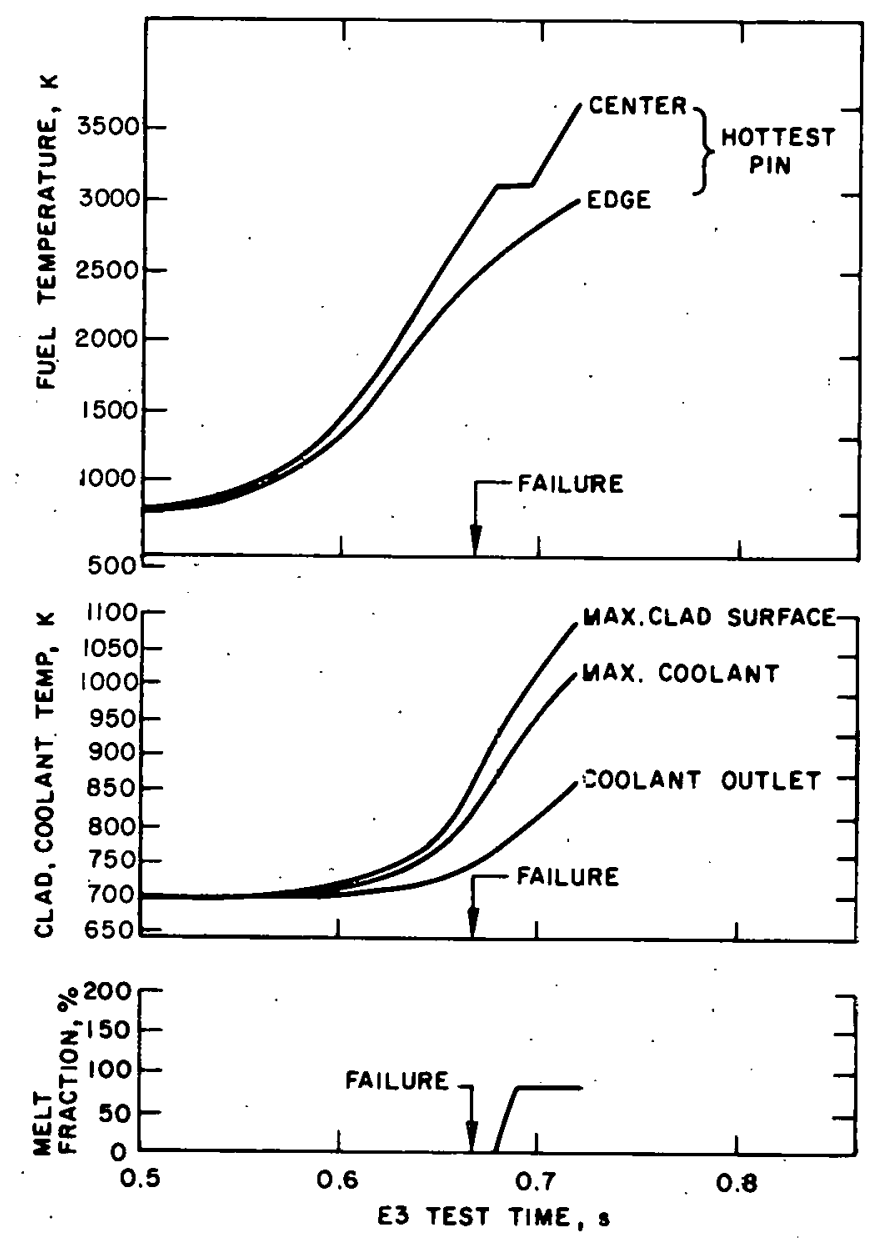

Fig. 57. Thermal History of Test E3
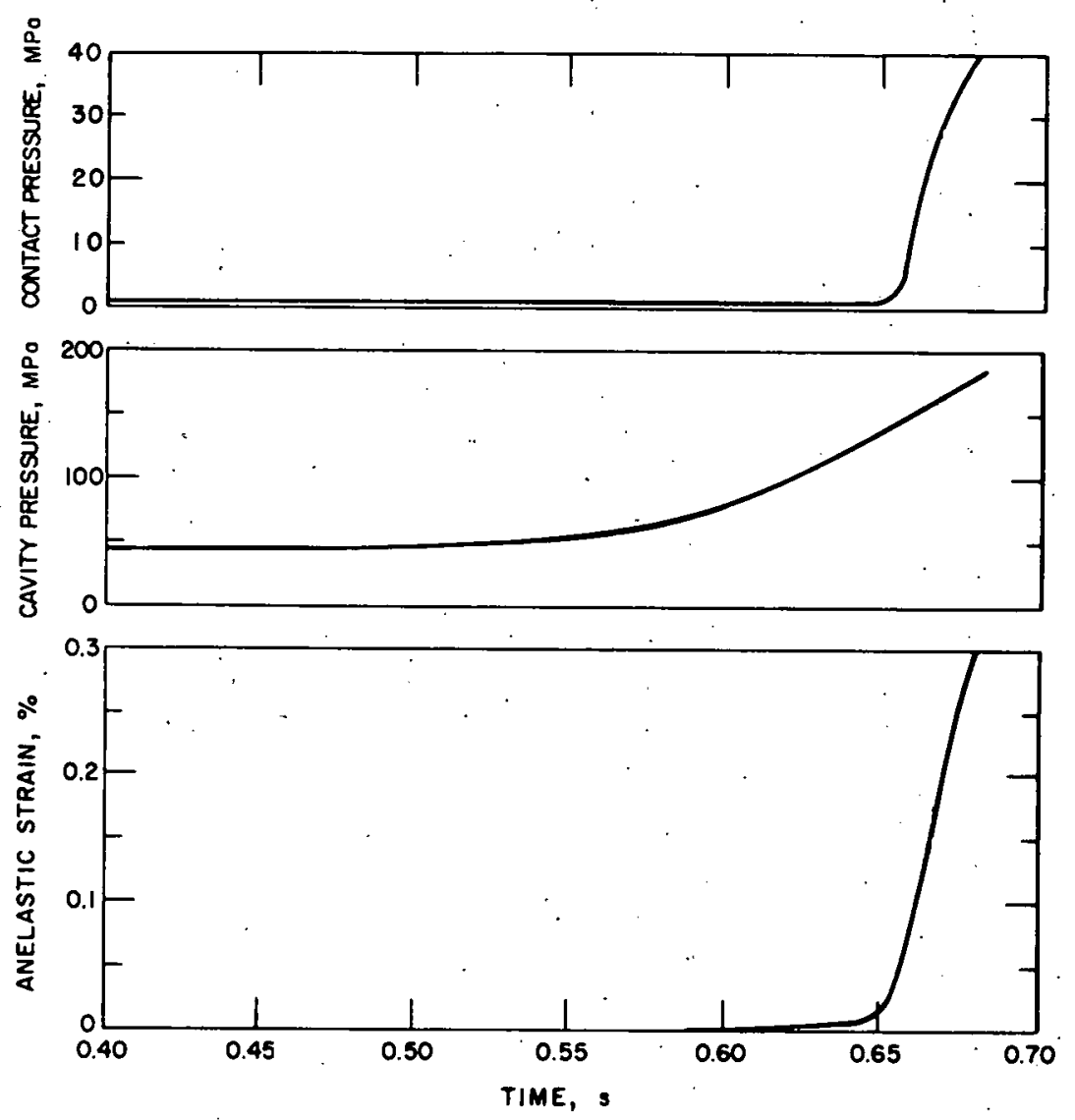

Fig. 58. Mechanical History for Test E3 


\section{SUMMARY, INTERPRETATIONS, AND COMPARISONS}

A. Failure Characterization

'In this section, the character of fuel-pin failure, as apparent from test results, is discussed. Included is a discussion of the failure criteria, the location of failure, and the apparent nature of initial failure.

\section{Failure Criteria}

Accurate prediction of the time and location of fuel-pin failure during a reactor accident depends upon application of failure criteria derived from experiments and/or analysis. Several quantities havc been suggested for use as failure criteria, including fuel enthalpy. fucl melt fraction (fraction having temperature in excess of the solidus temperature for the fuel material). cladding strain (total or plastic), and fuel-cladding contact pressure. The threshold values may additionally depend upon the rate of enthalpy increase, cladding temperature, the rate of increase of cladding temperature, claddingstrain rate, and fuel microstructure, among others. Basically, the independent variables treated in the test program are the transient rate and fuel microstructure. For a given rate, fresh fuel is thought to have the highest failure threshold, followed in order by high-power-, intermediate-power-, and lowpower-irradiated fuel.

Table XIII and Figs. 59 and 60 summarize the results of the Mark-II loop TOP experiments considered in this report. The valies of the various parameters reported are based on COBRA-DEFORM calculations described in.

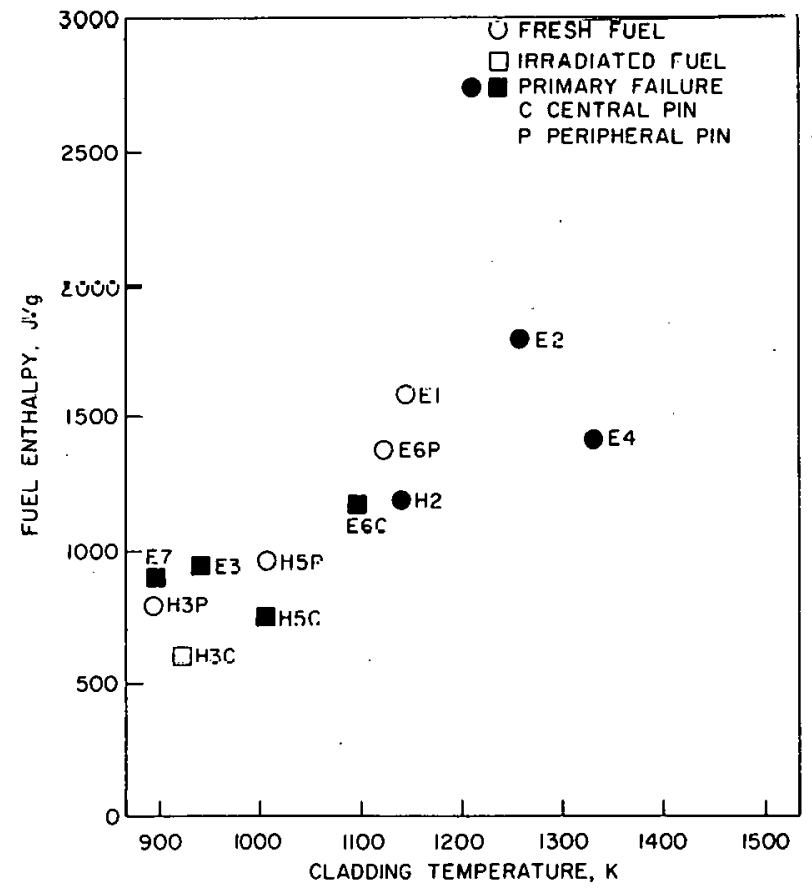

Fig. 59. Results for Failure Threshold

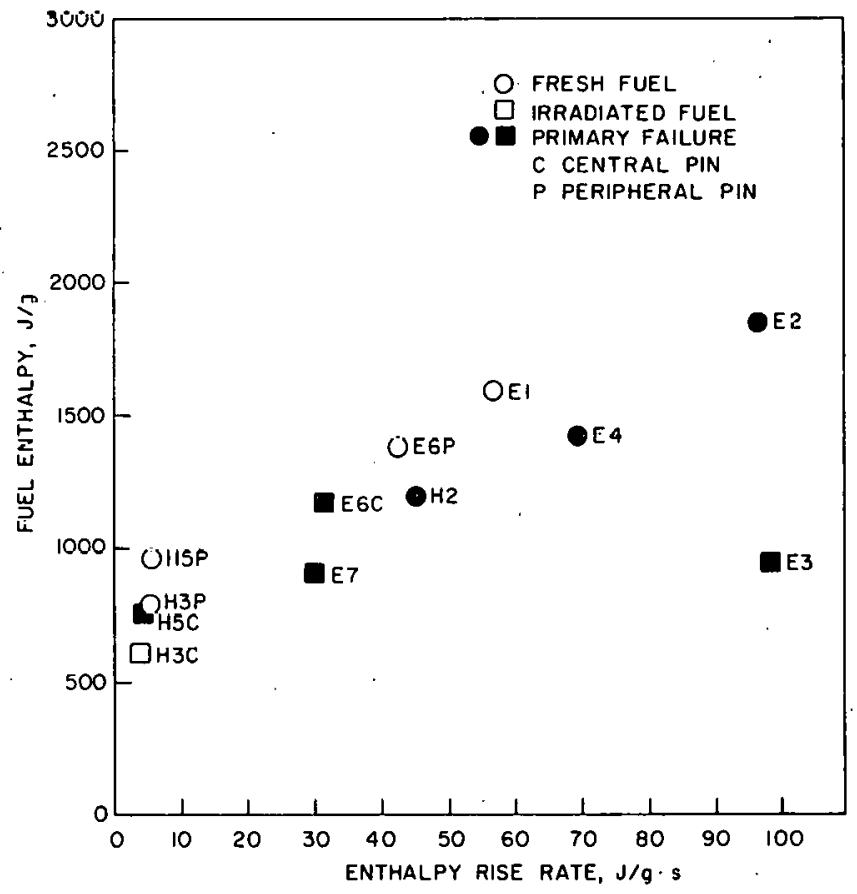

Fig. 60. Rate Effect on Failure Threshold 
TABLE XIII. Thermal Conditions in Fuel Dynamics Tests

\begin{tabular}{|c|c|c|c|c|c|c|c|c|c|c|c|c|}
\hline \multirow[b]{2}{*}{$\begin{array}{c}\text { Test } \\
\text { Designation }\end{array}$} & \multirow{2}{*}{$\begin{array}{l}\text { Time for Which } \\
\text { Results } \\
\text { Are Quoted }\end{array}$} & \multirow[b]{2}{*}{$\begin{array}{l}\text { Pin for Which } \\
\text { Results } \\
\text { Are Quoled }\end{array}$} & \multicolumn{5}{|c|}{ At Elevation of Maximum Fuel Enthalpy } & \multicolumn{3}{|c|}{. } & \multirow[b]{2}{*}{$\begin{array}{l}\text { Cladding-strain } \\
\text { Rate (Max } \\
\text { prior to Failure), } \\
\$ / \mathrm{s}\end{array}$} & \multirow{2}{*}{$\begin{array}{l}\text { Fuel-cladding } \\
\text { Contact Pres } \\
\text { (Max or at Time } \\
\text { and Location of } \\
\text {-Failure). MPa }\end{array}$} \\
\hline & & & $\begin{array}{l}\text { Radial Avg Fuel } \\
\text { Enthalpy (Relative to } \\
\text { - Room Templ. } \\
\mathrm{J} / \mathrm{gm}\end{array}$ & $\begin{array}{l}\text { Radial Avg Fuel } \\
\text { Enthalpy (Relative to } \\
\text { End of Preheatl. } \\
\mathrm{J} / \mathrm{gm}\end{array}$ & $\begin{array}{c}\text { Rate of Rise of } \\
\text { Radial Avg Fuel } \\
\text { Enthalpy (Max } \\
\text { prior to Timel. } \\
\mathrm{J} / \mathrm{gm} / \mathrm{s}\end{array}$ & $\begin{array}{l}\text { Cladding Midradius } \\
\text { Temp, K }\end{array}$ & $\begin{array}{c}\text { Rate of Rise of } \\
\text { Clad Midradius. } \\
\text { Temp (Max } \\
\text { prior to Timel. } \\
\mathrm{K} / \mathrm{s}\end{array}$ & $\begin{array}{l}\text { Max. Bulk. } \\
\text { Coolant } \\
\text { Temp. K }\end{array}$ & $\begin{array}{l}\text { Portion of } \\
\text { Fuel Cross- } \\
\text { sectional Area } \\
\text { at or above } \\
\text { Solidus (Max) }\end{array}$ & $\begin{array}{l}\text { Permanent } \\
\text { (Anelastic) } \\
\text { Cladding Strain } \\
\text { (Max or at } \\
\text { Failure) }\end{array}$ & & \\
\hline El & $\begin{array}{l}\text { Gross internal } \\
\text { fuel motion } \\
\text { (1.32 s) }\end{array}$ & . & 1590 & $N A^{a}$ & 5652 & 1145 & 2170 & 730 & 80 & 3 & 1.3 & $N A^{a}$ \\
\hline$E 2$ & $\begin{array}{l}\text { Failure } \\
(1.05 \mathrm{~s})\end{array}$ & & 1800 & NA & 9630 & 1255 & 3110 & 730 & 92 & 5 & 3.6 & $N A^{a}$ \\
\hline$H_{\bar{c}}$ & Failure & & 1190 & NA & 4522 & 1140 & 2090 & 1070 & 76 & $\mathrm{NC}^{\mathrm{b}}$ & $N C^{b}$ & $N C^{b}$ \\
\hline E4. & Failure & . & 1420 & NA & 6908 & 1330 & 4790 & 1220 & .100 & $N C^{b}$ & $N C^{b}$ & $\mathrm{NC}^{\mathrm{b}}$ \\
\hline HE: & $\begin{array}{l}\text { Max fuel } \\
\text { enthalpy } \\
(10.6 \mathrm{~s})\end{array}$ & Central & 607. & 170 & 380 & 920 & 190 & .950 & 0 & 0.45 & 0.9 . & 74 \\
\hline H3 & $\begin{array}{l}\text { Same } \\
(10.6 \mathrm{~s})\end{array}$ & $\begin{array}{l}\text { Hottest } \\
\text { peripheral }\end{array}$ & 795 & 230 & 523 & 895 & 190 & 950 & 40 & $\therefore 0$ & 0.07 & 0 \\
\hline H5 & $\begin{array}{l}\text { First } \\
\text { anomaly } \\
(8.015)\end{array}$ & Central & 754 & 400 & 419 & 1005 & 230 & 1060 & 25 & $\cdot$ & & \\
\hline H5 & $\begin{array}{l}. \text { Same } \\
(8.01 \mathrm{~s})\end{array}$ & $\begin{array}{l}\text { Hottest } \\
\text { Deripheral }\end{array}$ & 963 & .565 & 544 & 1005 & 270 & 1060 & 55 & & . & \\
\hline E6 & $\begin{array}{l}\text { First } \\
\text { anomaly } \\
(9.18 \mathrm{~s})\end{array}$ & Central & 1170 & 775 & 3140 & 1095 & $\$ 170$ & 1230 & 80 & 2.5 & 11.5 & 22 \\
\hline EG & $\begin{array}{l}\text { Same } \\
(9.18 \mathrm{~s})\end{array}$ & $\begin{array}{l}\text { Hottest } \\
\text { periphe-al }\end{array}$ & 1380 & 921 & 4229 & 1120 & 1280 & 1230 & 100 & $N A^{a}$ & $N A^{a}$ & $N \mathrm{~A}^{\mathrm{a}}$ \\
\hline$E$ & $\begin{array}{l}\text { First } \\
\text { anomaly } \\
(7.45 \mathrm{~s})\end{array}$ & $\begin{array}{l}\text { Hottest } \\
\text { peripheral }\end{array}$ & 900 & 461 & 2970 & 895 & 720 & $960^{\circ}$ & 65 & 1.5 & 3.0 & 46 \\
\hline $\boldsymbol{E}$ & $\begin{array}{l}\text { Failure } \\
(0.668 \mathrm{~s})\end{array}$ & Hottest & 942 & NA & 9797 & 940 & 3720 & 840 & 0 & 0.22 & 8.6 & 44 \\
\hline $1+4$ & $\begin{array}{l}\text { First } \\
\text { anomaly } \\
(6.96 \mathrm{~s})\end{array}$ & Central & 795 & 250 & 461 & 990 & 270 & 1030 & 35 & & & \\
\hline Eq & $\begin{array}{l}\text { Same } \\
(6.96 \mathrm{~s})\end{array}$ & $\begin{array}{l}\text { Hottest } \\
\text { peripheral }\end{array}$ & 1040 & 310 & 494 & 980 & 220 & 1010 & 57 & & & \\
\hline
\end{tabular}

âNat applicable.

DOEFCRM calculations not performed due to melting beginning at radius $/ 0$. 
Appendix B. Figure 59 gives the calculated fuel enthalpy at failure as a function of cladding temperature at the time of failure. Values given for tests in which no failure occurred are the maximum values attained during the transient. For peripheral pins, the values are averaged circumferentially. Darkened symbols indicate primary failure, that is, the initial failure occurring in a test according to the present interpretation. Similar data are given in Fig. 60, with the rate of increase of fuel enthalpy as the independent variable. This plot illustrates the rate dependence of results. All data plotted were taken at the elevation of the maximum radially averaged fuel enthalpy.

a. Fresh Pins. Fresh fuel pins were tested alone in Tests H2, E4, E1, and E2. 'l'he former two tests used prototypic fuel; the latter two did not. Failure resulted in all tests except El. In addition, fresh, prototypic; peripheral pins were used in cluster Tests $\mathrm{H} 3, \mathrm{H} 4, \mathrm{H} 5$, and E6. These pins are not thought to have undergone primary failure, but failed due to failure of the irradiated central pins. However, data related to these pins are useful in considerations of failure criteria.

Tests $\mathrm{H} 2$ and E4 provide a comparison of the failure thresholds for identical fresh pins tested in identical genmetry at different trancicnt ratc3. Additionally, the coolant flow at failure and the coolant temperature differed, leading to higher cladding temperatures for $E 4$ than for $H 2$. The rate of enthalpy increase was substantially greater for $\mathrm{E} 4$ than for $\mathrm{H} 2$, and the enthalpy at failure was also substantially higher. Both tests exhibited a high melt fraction at failure (75-100\%). Because of the radial power depression in these pins, melting did not begin at. the renterline. The significancc of this fact to the results is not clear, but it would probably reduce the failure threshold, since the temperature of fuel in proximity to the cladding would he higher than would be the case if melting had starter at the centerline.

Both Tests $\mathrm{H} 2$ and $\mathrm{E} 4$ appear to have produced pin failure following a period of 40-50 ms during which local boiling was occurring, probably at the contact point between spacer wire and cladding, where a region of stagnant sodium may exist. Local loss of cooling may be required for failure of the type of pin tested in $\mathrm{H} 2$ and $\mathrm{E} 4$, in which axial movement of molten fuel appeared to have occurred. So long as cooling by liquid sodium is maintained, even contact of molten fuel with the inner cladding surface does not appear to produce failure, since an insulating shell of frozen fuel will form. Presence of such a shell was seen in the El posttest examination, and also appeared on the wall of the adiabatic holder from $\mathrm{H} 2$ and E4. Axial motion of molten fuel effectively relieves cladding strain due to fuel-cladding mechanical interaction, and the gas pressure obtained with fresh fuel is small compared to that expected in irradiated pins.

The observation that boiling initiation precedes failure by about the same time in both tests is consistent with the time required for evaporation of a sodium film, which is a function primarily of the heat-input rate. A dependence of enthalpy at failure on the rate of increase of enthalpy 
would be expected, reflecting the increase of fuel enthalpy during the dryout time. However, little correlation with average cladding temperature or bulk coolant temperature would be expected. It would also appear that very high melt fractions could be sustained at failure, so that melt fraction would not necessarily be a good predictor of failure.

Relative to Tests $\mathrm{H} 2$ and E4, Tests El and E2 subjected the fuel pins to higher enthalpies, but failure was realized only in E2. This result probably is illustrative of the effect of axial restraint on failure threshold. The mechanism of failure in $\mathrm{E} 2$ is not as clearly identified as that in $\mathrm{H} 2$ and E4, although posttest examination showed evidence of cladding melting under the spacer wire, which is consistent with the results for Tests $\mathrm{H} 2$ and E4. Because of the low temperatures of the bulk sodium and the high sodium volume, boiling cannot be identified in the flow data, and calculations are not sufficiently detailed to identify an inception.

Other data points for fresh fuel pins are plotted in Figs. 59 and 60 , representing the conditions calculated for the hottest peripheral pins in Tests $\mathrm{H} 3, \mathrm{H} 4, \mathrm{H} 5$, and $\mathrm{E} 6$ at the time of failure for the test in question (or most severe conditions in $\mathrm{H} 3$ ). The points are plotted as "nonfailure" points, because failure probably occurred in the central, preirradiated pins first. The point for Test E6 is of particular interest because of the very high enthalpy and melt fraction calculated. In this case, failure of the peripheral pin probably occurred essentially coincidentally with that of the central pin. The fact that failure did not occur before attainment of the indicated conditions is testimony to the high resistance to failure of fresh fuel so long as cooling of the cladding is maintained.

On the other hand, damage to the peripheral pins in $\mathrm{H} 4$ and H5 occurred, in spite of the less severe conditions attained at the time of initial failure. In these cases, failure of the central, preirradiated pin probably caused a cooling loss which led to failure of the peripheral pins. Therefore, these points should be regarded as "no-failure" points.

b. Irradiated Pins. It is of interest to compare the conditions at failure in fresh-fuel tests with those in tests including irradiated fuel. Since Tests H2, E4, and E2 were performed using "natural" TREAT transients, direct one-to-one comparison with later Tests $\mathrm{H} 4, \mathrm{H} 5, \mathrm{E} 6$, and $\mathrm{E} 7$ involves some uncertainty. In general terms, the failure threshold can be compared, bearing in mind that some transient shape effect may be operative. Table XIII indicates that the initial failure in Test $\mathrm{H} 5$ occurred with a melt fraction in the central preirradiated pin that was substantially lower than that in the hottest fresh peripheral pin and that at failure in $\mathrm{H} 2$ and $\mathrm{E} 4$. . Likewise, the fuel enthalpy is lower. Thus, the relative failure thresholds postulated for fresh and low-power preirradiated fuel are qualitatively verified. The results of H5 suggest a failure threshold based on a fuel-melting front advancing to fuel containing large amounts of fission-product gas. Based on the sibling-pin data 
given in Fig. 4, there apparently is a marked increase in gas content of the PNL-17 pins at about the half-radius or slightly beyond. The calculated melting front in the $\mathrm{H} 5$ central pin had advanced to about this radius when failure occurred.

Preliminary results of Test $\mathrm{H} 4$ indicate a failure threshold that is close to that of $\mathrm{H} 5$ in terms of fuel enthalpy, cladding temperature, and thermal rates. The calculated melt fraction is only slightly higher. Thus, for a given ramp rate, only a very small difference between high-power (H4) and low-power (HS) fuel is indicated. The difference is probably not significant in view of the uncertainties in the calculations. Failure in $\mathrm{H} 4$ is indicated with a melt radius bearing about the same relation to the inner boundary of high-gas-content fuel as is apparent in H5. Thus, failure in H4 appears to have occurred about as would be expected from $\mathrm{H} 5$ results.

By contrast, indication of pin failure in E6 came at a fuel enthalpy about 50\% higher than that indicated in either $\mathrm{H} 4$ or $\mathrm{H} 5$. The fuel melt fraction was also considerably higher. A considerable ramp-rate effect on failure of high-power fuel is implied. In fact, one sees by comparison of the results of Tests E6 and $\mathrm{H} 2$ (Figs. 59 and 60) that high-power irradiatcd fuel can sustain as high an energy at failure as fresh fuel under some conditions. Note that coolant boiling before failure is a distinct possibility in Test E6, as well as in E4 and H2, with the implication that the meshanism of failure may be common to the three tests.

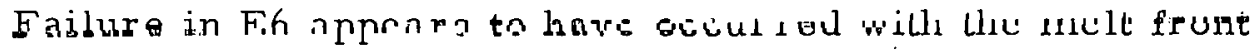
well into the zone of high gas content. Since release of gas from fuel and resultant pressurization of the cladding may have some time-dependent as pects, it is consistent that melting could progress further in the rapid E6 transient than in the much slower $\mathrm{H} 4$ transient before the loading of the cladding could cause failure. In fact, the basic failure mechanism in E6 was probably a melthrough rather than a pressure-induced failure.

Test E7 is the only 'I'UP test run using seven preir radiater fuel pins. All were high-power pins similar to that usedin E6; the transient was also similar to that of E6. Initial failure in E7 occurred at a slightly lower enthalpy and melt fraction than was observed in E6. If it be presumed that failuse vicurred in the hottest peripheral pin first, the failure enthalpy in $E 7$ was about $85 \%$ of that of the central pin in E6. The extent of melting was likewise less in E7 than in E6, but melting still extended into the fuel having high gas concentration. In general, both E6 and E7 indicate a failure threshold for high-power-irradiated fuel that is intermediate between those of fresh and intermediate-power fuels.

Test E3 exhibited a very low failure threshold. The thermally irradiated low-enrichment fuel had a high-power structure (central void, columnar grains, etc.) but a very high gas retention due to reduction in powe $r$ 
during irradiation. Failure just before melting was observed, with correspondingly low fuel enthalpy. This fuel was probably as representative as any tested in a loop to date of very low-power irradiated FTR fuel because of its gas retention.

c. Nonprototypicalities. Caution must be exercised in direct interpretation of the failure-threshold data, since a number of nonprototypic conditions existed in each test. In the single-pin tests, the radial power distribution was such that melting did not begin at the centerline, which introduces an unknown (but probably reducing) effect on the failure threshold. In addition, the pins tested in $\mathrm{H} 2$ and $\mathrm{E} 4$ had little axial restraint compared to a typical reactor pin. Thus, axial motion acting to relieve cladding strain was more probable than is likely in a reactor pin.

In the seven-pin tests, the power distribution in the central pin was flatter than was in the single-pin tests, but the distribution in the peripheral pins was neither uniform radially nor axisymmetric. Therefore, the peripheral pins were subject to axisymmetric temperature distributions. An azimuthal dependence probably existed in the power distributions for the central pins, which is not now taken into account. The effect of nonaxisymmetric temperature distributions on failure threshold remains to be investigated.

d. Conclusions. The results of Tests $\mathrm{H} 2, \mathrm{E} 4$, and $\mathrm{E} 2$ indicate that, of all the pins tested, fresh fuel pins can withstand the highest fuel enthalpies and cladding temperatures before failure. However, these tests were run at higher thermal rates than any of the other tests, save E3. For a given enthalpy rise rate, comparison of the enthalpy at failure between fresh and irradiated fuel can only be made on the basis of $\mathrm{H} 4$ and $\mathrm{H} 5$ results. The ir radiated pins probably failed first in these tests, but this result is not conclusive.

Failure of fresh fuel pins appears to follow a period of local boiling and resultant loss of cooling and meltthrough of cladding. At least for the higher ramp rates, very large melt fractions can be sustained so long as cooling is maintained. Due to lack of data on fresh pins at low ramp rates, it is not clear what rate effect may be operative.

Based on $\mathrm{H} 4$ and $\mathrm{H} 5$ results, there is no significant difference in failure threshold between NUMEC-F and PNL-17 pins for low rates of increase of enthalpy and low cladding temperature. At the higher enthalpy rise rate, both the enthalpy and cladding temperature at failure in E6 exceed the corresponding values at failure in E7, a result that seems contrary to what would be expected. Effects not considered here, perhaps involving the cladding, may be operative in the NUMEC-F pins. At present, a mechanism for failure cannot clearly be identified from the ir radiated-pin data.

The limited number of data points herein are not the sole data base for failure-threshold correlation. Other data from capsule tests 
are also available. A considerable spread in failure-threshold data will probably appear, especially for irradiated fuel, so that differences like those between E6 and E7 may not be unrealistic.

\section{Location and Nature of Failure}

Consideration of the location and nature of cladding failure is necessary to describe the response of fuel pins to transient reactivity insertion. The location of the failure is of particular importance to modeling of the reactor accident because of its strong effect on the reactivity feedback from subsequent fuel motion. The nature, of failure as observed in experiments is the key to correct modeling of failure for a particular type and condition of fuel pin. Separation of discussion of the nature of failure from that of failure criteria is somewhat arbitrary.

Information on the location and nature of cladding failure in Fuel Dynamics experiments is obtained from fast-neutron hodoscope data, posttest examinations of remains, and posttest neutron radiography, and by inference from pressure, temperature, and flow measurements. The quality of data from these various sources is variable from test to test, and in some cases, no data are currently available.

Hodoscope results normally take the form of an assessment of fuel motion, so that escape of fuel from the cladding is the effect seen. The spatial resolution of the data is generally good for single-pin tests ( $\mathrm{E} 2, \mathrm{H} 2$, and $E 4$ ), but is less satisfactory for multipin tests in which single-pin effects tend to be at the lower limit of sensitivity of the instrument.

Both posttest physical examination and neutron radiography provide information on the final disposition of fuel and cladding. In many cases, information on the location and nature of failure can be inferred, especially when substantial parts of the test assembly remain intact. This situation appears to apply in Tests $\mathrm{H} 5$ and E6, for example.

Inference from pressure and flow data is a more uncertain process, which must be used when other sources of information are unavailable or inconclusive. Such inferences have been drawn in connection with several tests, such as E3 and E7, in which other sources have not provided the requisite data.

a. Fresh Pins. Tests $\mathrm{H} 2$ and E4 both are thought to have failed by meltthrough of the cladding at an axial location within about $50 \mathrm{~mm}$ of the top of the fuel column, based largely on posttest examination results and hodoscope data for $\mathrm{H} 2$. Coolant boiling was clearly indicated by loop instruments and verified by calculation to have started about $40-50 \mathrm{~ms}$ before failure in both tests. In both cases, extensive melting of cladding and fuel occurred after failure. 
The other experiment on fresh fuel, E2, also appears to have failed by meltthrough within about $50 \mathrm{~mm}$ of the top of the fuel column. Considerably more intact cladding was found in posttest examination than was found in either $\mathrm{H} 2$ or E4. The cladding showed clear evidence of melthrough along the spacer wire in the upper portions of the pin.

In this discussion, failure refers to the initial breach of the cladding. A considerable difference appears among the three fresh-fuel tests in the extent of destruction of the pins. In Tests $\mathrm{H} 2$ and E4, melting and destruction of the cladding were extensive following initial failure, with almost all the cladding opposite the fuel column destroyed. By contrast, much of the bottom portion of the cladding was substantially intact following Test E2. The low bulk coolant temperature and large coolant volume of E2 probably contributed to cooling the cladding, but voiding of the coolant channel following failure in $\mathrm{H} 2$ and $\mathrm{E} 4$ resulted in loss of cooling and more extensive melting.

Failure of fresh fuel by meltthrough is independent of the bulk coolant temperature at failure, since these temperatures for $\mathrm{E} 2, \mathrm{H} 2$, and E4 were quite different. Thus, the failure may be triggered by local phenomena, such as boiling behind spacer wires. However, the bulk coolant conditions may well determine the postfailure events to a significant degree. The indicated failure location agrees with one's intuitive feeling that failure should occur where the cladding is hottest.

b. Irradiated Pins. Tests $\mathrm{H} 5$ and E6 resulted in failures that left the peripheral (fresh) pins in the seven-pin clusters with substantially intact cladding over much of their length below the failure point, but with loss of fuel easily visible in posttest neutron radiographs. We infer that the elevation at which damage to the peripheral pins is indicated is also the elevation of failure in the central pin, although the condition of the central pin cannot be determined with any assurance from the radiographs. The location of failure appears to be about the same in both tests, 64-140 mm below the top of the fuel column. The nature of the failures is uncertain.

In E6, the data have been interpreted to mean that the initial failure was a small leak in the cladding of the central pin, which resulted in fuel and gas release, the amount of fuel release being uncertain. More extensive failure ensued due to voiding of the channel by the gas. Recent calculations, summarized in Sec. III.H, suggest that coolant boiling was present to some degree in the channels adjoining the central pin before failure. Such boiling could account for the flow decrease just before failure noted in the data. However, boiling alone probably could not account for the rapid reversal of inlet flow without sorne contribution from gas escape. No hodoscope or posttest examination data are available at this time, so confirmation of the above interpretation is lacking.

Data and calculations for Test H5 suggest that failure may be of the more "normal" sort in which rapid cladding pressurization due to 
fission-gas release leads to rupture of the cladding and release of fuel into the coolant. (Two equally probable times for the beginning of fuel motion. can be derived from the hodoscope data. The earlier of these times correlates well with the pressure pulses and flow perturbation observed. The later time does not correlate well with any other signals.) There appears to be a good correlation between the time of apparent failure (pressure pulses) and marked flow accelerations and advance of the melting front to the radius at which the gas content of the fuel shows a marked increase. Radiographs of Test $\mathrm{H} 5$ indicate that the fuel pins may be substantially intact, so that particularly good posttest examination results are expected.

Based on the similarity in the character of the pressure signals accompanying failure, the nature of failure in Test $\mathrm{H} 4$ appears similar to that in $\mathrm{H} 5$. In both cases, the pressure signals showed a rapid rise, followed by distinct oscillations. Such behavior suggests that the initial wave seen by the pressure sensor had a short risetime compared to the natural period of the sensor system. Such pulses would be associated with an abrupt pressurization of the failure zone, either due to fuel-coolant interaction or sudden gas release. In contrast, the pressure pulses in E6 did not exhibit the same behavior, suggesting slower rise times. A slowly rising pressure would be consistent with introduction of gas into the coolant due to a leak as opposed to a rupture. Posttest neutron radiographs of Test $\mathrm{H} 4$ indicate large-scale destruction of the pins, so little additional information is expected on the nature of failure. Similarly, hodoscope results on the location of failure are not yet available.

Like Test E6, initial failure in 'l'est E'/ was probably a small leak releasing fission gas from the pin into the coolant. The location of this leak cannot be definitively determined from the experimental data, but it is thought to have occurred within about $25 \mathrm{~mm}$ of the original top of the fuel column. 'I'he initial leak appears to have resulted in an approximately linear gas-release rate for about $130 \mathrm{~ms}$, followed by an exponentially increasing release. This suggested failure of additional pins, enlargement of the initial failure, or release of additional gas from the fuel. Hodoscope data did not show fuel escape from the pins at the time of gas release, and no pressure or flow signature of fuel release into coolant was seen. Posttest neutron radiographs indicated large-scale destruction of the fuel pins; it is therefore unlikely that posttest examination will yield better information on the failure.

The remaining test in which failure occurred, E3, does not appear to fit either the $\mathrm{H} 2 / \mathrm{E} 4 / \mathrm{E} 2$ or the $\mathrm{H} 5 / \mathrm{E} 6 / \mathrm{E} 7 \mathrm{category}$. The transient was rapid, and the fuel pins had a "high-power" structure (fully developed central void) with high gas retention $(75 \%)$. Failure occurred abruptly, early in the transient, just as fuel melting started. Since the Type 304 stainless steel cladding had been irradiated in a thermal flux, a high degree of embrittlement is probable. The abrupt nature of the failure appears consistent with a brittle failure, probably simultaneously over essentially the entire length of the pins. 
c. Nonprototypicalities. Several nonprototypic effects may influence the nature and location of failure as observed in these tests. The nature of failure and extent of pin damage will be influenced by the metallurgical condition of the cladding. One would intuitively expect relatively brittle cladding to exhibit abrupt failure, whereas more ductile cladding would fail more gradually, perhaps with leakage of gas before a large-scale cladding breach. Most of the pins tested in this program have had prototypic cladding material and were fast-flux irradiated, but had a low fluence-toburnup ratio. The effect of this condition is unknown.

The extent of damage to fuel pins is also influenced by the coolant temperatures and voiding patterns. Voiding rates in these tests relative to those in the FTR are discussed below. Especially in H2, E4, and E7; voiding of the heated zone would tend to proceed more rapidly in the tests than in a reactor subassembly, so that coolant is removed from more the heat-transfer surface in the test than in the subassembly. Therefore, more extensive damage would be expected in these cases. In E2, the large volume of sodium compared to that of fuel, a nonprototypic condition, would minimize damage.

With respect to location of failure, it should be recognized that the pins tested are representative of only a portion. of the FTR pin. Initial failure in the FTR pin will be governed by the minimum failure threshold of the fuel types present in the particular pin, and will occur at the corresponding location.

d. Conclusions. Based on the results of Tests $\mathrm{H} 2, \mathrm{E} 4$, and $\mathrm{E} 2$, failure of fresh fuel pins appears to result from melthrough of the cladding due to boiling and loss of cooling. The location of failure appears to be near the top of the fuel column. Extensive damage to the test pin occurred in both $\mathrm{H} 2$ and E4, with less extensive damage in E2, probably due to better cooling. Data related to the peripheral pins in Tests $\mathrm{H} 4, \mathrm{H} 5$, and E6 are consistent with these conclusions, but are not conclusive because failure of the irradiated pins is thought to have occurred first.

Failure of ir radiated fuel subjected to low enthalpy rise rate (H4 and H5) appears to be abrupt in nature, implying failure due to cladding strain rather than a gas leak. Failure in $\mathrm{H} 5$ appears to have occurred in the top quarter of the fuel column. The location in $\mathrm{H} 4$ is unknown. By contrast, the high-thermal-rate tests of high-power fuel (E6 and E7) exhibit more gradual failures, suggesting gas release. Thus, a possible rate effect on nature of failure is suggested, but more study of the point is needed. Inferences from available data suggest failure in the top half of the pin in these cases.

\section{B. Fuel Motion}

The previous section considered the character of fuel-pin failure; this section discusses the fuel motion resulting from failure. 'l'his motion of 
fuel determines the reactivity course of the accident and the potential for kinetic-energy generation during the transient. Direct observation of fuel motion in Fuel Dynamics tests is possible with the fast-neutron hodoscope. Additional fuel-motion information can be inferred from temperature, pressure, and flow data as well as from posttest radiographs and the results of metallographic examinations. For convenience, the discussion is divided into sections on prefailure and postfailure motion.

\section{Prefailure Criteria}

a. Discussion. Fuel motion within the cladding before pin failure is possible during accident transients if the conditions are favorable. If axial expansion occurs, significant reactivity decreases may accompany the motion, resulting in early accident termination, perhaps before pin failurc. Factors that promote axial fuel motion include thermal expansion and melting of tuel, pressure due to fuel vapor or gases that move molten or solid fucl, and lack of mechanical resistances to motion. On the other hand, upward motion of molten fuel may be retarded by mechanical interaction between fuel and cladding, and by mechanical restraint due to features of the pin design.

Extensive prefailure axial motion appears to have occurred in Tests El, H2, and possibly E4. Such motion is clearly indicated in the hodoscope data for the first two tests. Results of posttest examination are consistent with prefailure motion in $E 4$, but direct evidence is not available. No data are available for $\mathrm{E} 2$, due to hodoscope difficulties and extensive melting of the upper portion of the cladding.

The three tests in which axial motion is probable share several features. First, each was a fresh fuel pin and attained a very high ( $75-$ $100 \%$ ) areal fraction of fuel above solidus. Second, each test had a very rapir power rise. (without preheat) and a substantially uniform axial power distribution, which led to fairly uniform melting. Third, expansion space for molten fuel was easily available, and axial inertial restraint was lacking in the pins; in $\mathrm{E} 1$, nothing separated the fucl and the plenum, whereas in $\mathrm{H} 2$ and $\mathrm{E} 4$ only $10 \mathrm{~mm}$ of insulator peliets provided separation. None of these conditions exist in the FTR pins.

Of the remaining tests, none have produced data suggesting prefailure axial motion. However, in some cases the results are either in. conclusive or not yet available. In Test $\mathrm{H} 3$, no fuel motion was seen by the hodoscope, either in the PNL-17 preirradiated central pin or in the fresh peripheral pins. No melting occurred in the central pin, so no motion was expected; however, up to $40 \%$ melting was present in the peripheral pins, so some motion might be expected. No motion was observed, probably since, in Test H3 (and succeeding tests as well) the fresh pins had spring-loaded Inconel reflector rods on top of the insulator pellets that provided inertial restraint and limited the expansion volume available to the fuel. In addition, the axial power distribution was not uniform, but was more nearly cosine-shaped, leading to less melting at the ends of the pins. 
No indications of prefailure movement have been obtained from the hodoscope data for Tests H5, E6, and E7. Similarly, no data on prefailure motion were obtained for Test E3.

b. Conclusions. Prefailure fuel motion occurred in tests of fresh fuel that involved certain nonprototypic features tending to promote such motion. Prefailure motion was not observed in tests having preirradiated fuel and more prototypic features, although the results were not completely conclusive. The present experimental results, therefore, cannot support the assumption of extensive prefailure axial motion in accident analysis.

2. Postfailure Motion and Final Fuel Disposition

The description of postfailure fuel motion and the final disposition of fuel is necessary to complete the analysis of the TOP accident. Motion of fuel from regions of high reactivity worth to regions of lower reactivity worth is the mechanism by which shutdown of the reactor is postulated to occur. Permanent subcriticality and coolability of the fuel following the accident depend upon the final disposition of the fuel.

With few exceptions, Fuel Dynamics experiments have been planned to produce fuel failure, regardless of the energy input required. Also, the fuel samples have had essentially uniform structure axially, so that the failure threshold observed is that of the structure tested. The possibility exists, therefore, that the samples may be subjected to energy input in excess of that which would be realized in similar fuel in the reactor accident. Moreover, the experiments are generally planned with some energy margin above expected failure. Reference to Sec. III shows that failure occurred in some cases with significant fractions of the transient energy still remaining to be generated. Also, failure in all these tests (except E3) occurred with large melt fractions. Thus, the observed fuel motion is that to be expected when large amounts of molten fuel are available. No data on prototypic pins that failed with low melt fraction (such as postulated for true low-power fuel) are available.

Due to the variety of test geometries and conditions made necessary by fuel pin, test vehicle, and facility availability, it is difficult to establish qualitative trends in fuel-motion behavior. However, certain features can be identified: A result common to all tests performed thus far in which failure occurred is the formation of a flow blockage at some point in the transient. Only in Tests $\mathrm{H} 2$ and $\mathrm{H} 5$ was significant flow rate obtained after the test, and even in these cases, only about half the initial flow was possible. Varying degrees of fuel removal from the original fuel region of the test have been observed. In general, the fuel was removed from the original fuel column onto the holder walls, with significant amounts entering into the region immediately above; but to date, evidence exists only in two cases (E2 and E3), supporting removal of a substantial amount of fuel beyond the pin bundle into the loop. A preliminary gamma scan of the lower bend suggests some fuel escape in Test E7. 
a. Fresh Fuel. Fresh-fuel Tests $\mathrm{H} 2$ and $\mathrm{E} 4$ had identical geometry and differed primarily in the heating rates realized. Boiling occurred before failure in both tests, but $E 4$ had a higher melt fraction at failure than did $\mathrm{H} 2$. The pins had reached their maximum melt fraction in both cases. The flow and pressure data were similar for both tests, as was the posttest condition of the test section. Careful analysis of the hodoscope data for $\mathrm{H} 2$ suggests that the initial fuel movement was an upward flow inside the cladding that began as early as $150 \mathrm{~ms}$ before failure. Observed fuel removal from the pin occurred in a linear (with time) manner and existed for as long as about $40 \mathrm{~ms}$ following failure. This fuel loss occurred initially in the upper third of the pin, was primarily upward in direction, and amounted to $\sim 10 \%$ of the total fuel inventory.

Following initial cladding failure, available data could be interpreted as reflecting a general pin failure, spreading from the top to the bottom, with fuel motion essentially radially and with little evidence of further axial motion. The entire postfailure fuel release lasted for $30-40 \mathrm{~ms}$. Apparently, the fuel froze on the wall of the "adiabatic" holder. Note that the coolant had been effectively voided from the channel before large-scale failure, so that no FCI or hydraulic sweeping of fuel could occur after the initial release. Indeed, no measurable quantity of fuel fines were recovered from the loop sodium. The fuel that did escape from the fuel region plated out on the plenum structure and did not get out into the loop.

No hodoscope data were obtained for $\mathrm{E} 4$, but the other evidence suggests a behavior similar to that of $\mathrm{H} 2$. One difference is that failure in $\mathrm{E} 4$ resulted in porous fuel-clad plugs several inches lnng at both onde of the fucl column, with essentially no fuel movement beyond these plugs, except within the cladding (which was probably prefailure movement). Much shorter plugs, especially at the inlet and of the same general composition, were found in $\mathrm{H} 2$, suggesting that the higher $r$ ate (or total energy) produced more extensive cladding melting and motion coincident with initial failure that prevented measurable amounts of fuel escape from the flow channel.

Compared to Tests $\mathrm{H} 2$ and E4, the third fresh-fuel-failure test, E2, had a higher enthalpy rise rate. It did, however, have a very low bulk coolant temperature due to the presence of six dummy pins surrounding the single fuel-bearing pin. Hodoscope data were not available to give a complete picture of fuel motion, but the posttest examination indicatcd cxtensive removal of fuel from the pin and extensive removal of the fuel out into the loop. Fuel fines were found throughout the loop, with about $27 \%$ of the original fuel inventory found in the loop cleanup. The flow blockage that resulted was principally made up of fines packed in the coolant. channels several inches downstream from the apparent site of failure. A similar packing, but less. extensive in amount, was noted in $\mathrm{H} 2$, and even less in E4.

The geometric parameters given in Table XV (later) show that $E 2$ had the lowest ratio of fuel cross-sectional area to flow area and the 
largest hydraulic diameter of any test. It would seem that these parameters, as well as heating rate, reflect favorable conditions for hydraulic sweepout of fuel. Likewise, the presence of cold coolant compared to $\mathrm{H} 2$ and E4 could suggest greater capability for sweepout. In fact, E2 did show a greater sweepout than any other fresh-pin test, but eventual plugging was not avoided.

b. Irradiated Fuel. Results from tests of irradiated fuel are not so easily compared, since geometrical, fuel-type, and rate differences exist among all the tests for which results are available. The qualitative features of the fuel motion in $\mathrm{H} 5$ and E6, as ascertained from radiographs, are similar, differing largely in degree. The results of E7 and E3 likewise bear some similarity, but are also quite different in respect to their flow dynamics at failure. Also, their behavior differs markedly from that of $\mathrm{H} 5$ and E6.

In Tests $\mathrm{H} 5$ and $\mathrm{E} 6$, one irradiated pin was surrounded by six fresh peripheral pins. In $\mathrm{H} 5$, failure of the central pin appears to have occurred first, with failure of the peripheral pins following, whereas simultaneous failure may have occurred in E6. Radiographic and hodoscope evidence from $\mathrm{H} 5$ indicates removal of fuel from the central pin. This movement started at a time coincident with the first pressure pulse and proceeded irregularly, as if in response to changing pressures in the channel. Removal of fuel from. peripheral pins occurred somewhat later ( 70 ms). The hodoscope did not show fuel motion past the top of the original fuel region, because of sensitivity limitations.

Presence of a small amount of fuel in the plenum region of the pins is indicated in the radiographs. The quantity of this fuel and its source cannot be determined at this time. Fuel removal from the central pin is suggested by the radiographs of Test E6 as well; however, the extent of fuel motion into the plenum region was apparently much greater than seen in $\mathrm{H} 5$. The data for E6 suggest that major fuel motion did not occur until 60-70 ms after the initial failure, but details of the motion are not established. According to radiographs, in both $\mathrm{H} 5$ and $\mathrm{E} 6$, the peripheral pins seem to be substantially intact, with more disturbance evident in $\mathrm{E} 6$. ' ' 'he se two tests do seem to fit the general picture of fuel removal from a failed pin and sweepout into the plenum region without extensive destruction of the pin geometry. However, at least partial plugging appears in both tests.

Note also that the one ir radiated-six-fresh-pin configuration practically guarantees a different fuel-motion behavior among the pins. Although the central pin may fail and eject fuel in a manner typical of that type of pin, the resulting void formation will lead to failure of the peripheral pins. These peripheral pins will have a higher melt fraction than the central pin and will fail in a different node. Thus, the fuel-motion situation may be quite different in the test than it would in the reactor, where neighboring pins might fail at about the same time and in the same manner. The possibility exists that fuel from the first pin that fails in the test may be swept out through welldefined channels, with plugging resulting from fuel released from the peripheral pins. 
Test E7 is the only TOP experiment run thus far using seven ir radiated fuel pins. Its results are also unlike those of any other test. Rather than fuel motion being associated with discrete failure of one pin or a few pins, the motion indicated by the hodoscope involves the entire cluster and does not begin until some $300 \mathrm{~ms}$ after the initial indication of failure. The motion observed was slow and involved a loss of fuel from essentially the entire cluster. Radiographs suggest a motion of fuel out of most of the cluster, with a concentration straddling the original top of the fuel column and extending about $50 \mathrm{~mm}$ in either direction. A complete fuel void is indicated over about $50 \mathrm{~mm}$ at the original axial midplane. The reason for the marked difference between the behavior of E7 and that of other tests is thought to be a large-scale gas release in E7 leading to voiding of the coolant before fuel motion. Following this voiding, the behavior is thought to be like a loss-of-flow accident, with cladding melting and relocation and finally fuel motion under the impetus of forces due to fuel or cladding vapor pressure.

Test $E 3$ is the other experiment in which all fuel pins were irradiated. The fuel motion apparent in this test was not unlike that in E7. Due to hodoscope difficulties, the picture of fuel motion was not very clear, but fuel motion probably began within about $30 \mathrm{~ms}$ afte $x$ initial failure and continued for about 100-130 ms, with fuel removal being complete about $130 \mathrm{~ms}$ after failure. Fuel motion was exclusively upward and involved essentially the entire cluster, although there was some preferential removal from one side of the cluster. Fuel removal appears to have occurred well after complete voiding of sodium from the fuel region, so the motion could not be ascribed to an FCI. Fuel removal from the original fuel region was complete, and only about $20 \%$ of the fuel failed to escape into the loop. This fuel, along with some cladding debris, backed up behind the thermocouple positioning rake and caused a flow blockage.

Due to the highly nonprototypic geometry and pin design of E3, relating the results of this test to reactor conditions is difficult. It does suggest that fuel motion need not be tied to an FCI, at least for gassy, irradiated fuel, and that fuel removal can be quite complete under the right circumstances. However, a blockage did eventually form, and this behavior seems typical for these experiments.

c. Conclusions. A feature of the results of the Fuel Dynamics tests in which failure occurred is at least partial phugging of the flow channels. In tests of fresh fuel, in which failure occurred with large melt fractions, extensive sweepout of fuel only occurred with a large excess of coolant relative to fuel (E2). Plugging followed sweepout. In Tests H2 and E4, with failure into a limited amount of nearly boiling sodium, sweepout was limited. Some degree. of sweepout occurred in irradiated-fuel Tests $\mathrm{H} 4, \mathrm{H} 5, \mathrm{E} 6$, and E7, possibly before plugging. Available evidence indicates initial fuel removal from the central irradiated pin in $\mathrm{H} 5$ before motion of fuel from the peripheral pins, with motion beginning essentially at the time of failure. By contrast, the 
motion in E7 is a more general depletion of fuel from the central portion of the cluster occurring somewhat after failure. A similar behavior is indicated for E3.

Overall, motion of fuel is generally away from the center of the test clusters, with some clear tendency toward upward motion in the irradiated-fuel tests. Fuel swept out beyond the boundaries of the original fuel column generally did not move beyond the boundaries of the pin bundle. Only in Tests E2 and E3 was large-scale fuel motion beyond the pin bundle indicated, although some removal in E7 is suspected.

Some relationship between the extent of plugging and the severity of conditions at failure is implied by comparison of the results of H5 and E6; that is, failure at lower melt fraction (or fuel enthalpy) seems to result in less complete plugging. However, the relationship between the amount of molten fuel and the amount of fuel swept out is not known.

\section{Fuel-Coolant Interaction}

Interest in the general area of fuel-coolant interactions during TOP accidents arises in two connections. First, if a fuel-coolant interaction could result in a vapor explosion, a large fractional conversion of energy stored in the fuel to mechanical work on the coolant and to coolant kinetic energy could be realized. It is this coolant kinetic energy against which the containment capability of the primary-system structure must be measured. Second, the fuel-coolant-interaction pressures play an important role in determining the rate of flow of molten fuel out of a ruptured pin and the resultant voiding of the coolant channel. Motion of fuel within the channel is probably related to motion of the boundaries of the voided region.

An extensive series of both in- and out-of-pile experiments have been conducted to measure the pressures and energy-transfer aspects of fuelcoolant interaction. These tests are discussed in Ref. 7. Fuel Dynamics TOP tests, although not designed specifically to determine FCI-related quantities, do provide some information of interest.

Data related to coolant dynamics and fuel-coolant interactions are summarized in Table XIV. The second and third columns indicate the presence of prefailure coolant boiling and the mode of initial pin failure. The presence of either sodium vapor from boiling or noncondensible gases due to a gas release from the cladding can greatly reduce pressure buildup and transmission of pulses, since a compliant volume is introduced. Note that, although abrupt failure is indicated for Tests H5 and E3, the presence of gas in the mixing zone is likely in these cases as well.

The next two columns list the maximum pressure values indicated by the upper (outlet) and lower.(inlet) pressure transducers, respectively. The 
transducers are located on the loop, as indicated in Fig. A.2. Neither transducer measures mixing-zone pressure directly; each is separated from the probable zone of initial failure by several centimeters of flow path. Attenuation of pressure waves at flow area changes between the pressure source and the transducer, and attenuation due to gases or vapor will lead to reduced pressure-pulse amplitudes at the transducers relative to those in the mixing zone.

TABLE XIV. Quantities Related to Coolant Dynamics and Fuel-Coolant Interactions

\begin{tabular}{|c|c|c|c|c|c|c|c|c|c|c|c|}
\hline \multirow[b]{2}{*}{ Test } & \multirow{2}{*}{$\begin{array}{l}\text { Profailure } \\
\text { Boiling }\end{array}$} & \multirow{2}{*}{$\begin{array}{l}\text { Mode of } \\
\text { Initial Pin } \\
\text { Failure }\end{array}$} & \multicolumn{2}{|c|}{$\begin{array}{c}\text { Max Measured } \\
\text { Pressure Pulses, } \\
\text { MPa }\end{array}$} & \multicolumn{3}{|c|}{$\begin{array}{c}\text { Max Voiding } \\
\text { Rate }\end{array}$} & \multicolumn{2}{|c|}{$\begin{array}{l}\text { Max Calc } \\
\text { Bubble } \\
\text { Pressure, } \\
\mathrm{MPa}\end{array}$} & \multicolumn{2}{|c|}{$\begin{array}{l}\text { Calc Work } \\
\text { Done }\end{array}$} \\
\hline & & & Upper & Lower & $10^{-3} \mathrm{~m}^{3} / \mathrm{s}^{\mathrm{a}}$ & & $\mathrm{m} / \mathrm{s}$ & Upper & Lower & $(J)^{a}$ & $(\mathrm{~J} / \mathrm{g})$ \\
\hline E2 & $\begin{array}{l}\text { Probduly at } \\
\text { spacer wire }\end{array}$ & Meltthrough & 1.38 & 2.76 & 3.050 & & 11 & 0.689 & 2.07 & 85 & 0.95 \\
\hline $\mathrm{H} 2$ & Yes & Meltthrough & 0.689 & Inoperative & 1.600 & & $\cdots 61$ & 1.03 & 1.03 & 10 & 0.15 \\
\hline E⿺辶் & Yes & Meltthrough & 2.76 & 345 & 3.150 & & 120 & 6.21 & 14.48 & 55 & 0.85 \\
\hline H5 & No & $\begin{array}{l}\text { Abrupt } \\
\text { mechanical } \\
\text { failure }\end{array}$ & 1.03 & $17 ?$ & $1.900^{b}$ & & $10^{b}$ & 0.689 & - & $40^{\mathrm{b}}$ & 0.088 \\
\hline E6 & Yes & $\begin{array}{l}\text { Gas release } \\
\text { through } \\
\text { pinhole }\end{array}$ & None & 1.38 & 3.000 & & 17 & 1.38 & 2.07 & 80 & 0.18 \\
\hline E7 & No & $\begin{array}{l}\text { Gas release } \\
\text { through } \\
\text { pinhole }\end{array}$ & None & None & 2.100 & & 15 & 1.72 & 1.03 & $140^{C}$ & 0.31 \\
\hline E3 & No & $\begin{array}{l}\text { Abrupt } \\
\text { mechanical } \\
\text { failure }\end{array}$ & 3.45 & 5.86 & $9.750^{d}$ & & 118 & 4.48 & 11.72 & $150^{d}$ & $3^{d}$ \\
\hline $\mathrm{H4}$ & No & $\begin{array}{l}\text { Abrupt } \\
\text { mechanical } \\
\text { failuí }\end{array}$ & 0.827 & 6.895 & 1.800 & & 10 & - & - & & \\
\hline
\end{tabular}

avoiding rates and work donc quoted to nearest $5.0 \times 10^{-9} \mathrm{~m}^{3} / \mathrm{s}$, and $5 \mathrm{~J}$, respectively.

bupper slug only; no. lower flow data.

rat cnd of initial roid growth $17.02 \mathrm{~s})$.

dAt time of upper flowmeter voiding.

On the other hand, the transducer system (transducer and NaK-filled standoff tube) will behave as a mass-spring-dashpot system. If such a system is excited by a pulse, it may overshoot by as much as a factor of 2 . This effect opcrates in the opposite direction to the attenuation effects discussed above. 'L'he conclusion to be drawn is that there is considerable uncertainty. in the relationship of measured pressure amplitude and actual pressure in the mixing zone. However, this uncertainty probably is of the order of $2-5$, nor one of 10 or greater.

The maximum recorded pulses exceeded $3.45 \mathrm{MPa}$ in only two cases, Tests $E 3$ and $H 4$. In E3, the maximum pulse accompanied the initial failure, whereas in $\mathrm{H} 4$, it was a delayed pulse accompanying a reentry. A smaller pulse (1.2 M.Pa) was observed at the time of failure. In the other tests, the maximum pulses, or pulses of nearly the maximum amplitude, accompanied the initial failure. In fact, pressure indications are used as markers of failure. In all.cases, the pulses observed at the inlet exceeded those at the outlet. This result may reflect the pressure rise associated with reversal of the inlet momentum. 
The next column in Table XIV gives the maximum voiding rates observed in the various tests. All the values, except that for E3, fall in the same range, with about a factor of two separating the low and the high rates. Also tabulated are the voiding velocities, indicating the separation rate of boundaries of a void in the pin.bundle occupying the entire flow area. These values are indices to the relative vigor of the coolant ejection. In terms of the voiding velocities; three cases stand out: Tests $\mathrm{H} 2, \mathrm{E} 4$, and $\mathrm{E} 3$. These tests all had high thermal rates and underwent a coherent failure rather than failure of one pin followed by another, etc., or failure into a large amount of cold sodium. For E3, the quoted velocity is somewhat artificial, since the maximum velocity occurs well after voiding of the pin bundle. The results illustrate the importance of coherent failure on voiding velocity.

The next two columns give the results of calculations of the pressure at the interface between the expanding mixing zone and the loop sodium based on one-dimensional, incompressible, isothermal, hydraulics using the loop geometrical data given in Appendix $A$ and assuming an initial loop-plenum pressure of $2.4 \mathrm{MPa}$. Essentially, the pressures represent those values required to produce the accelerations observed in the flow data. Tests E3 and E4 stand out in these results, with calculated pressures in the range of 13.80 $\mathrm{MPa}$; the calculated values exceed those measured by a factor of $\sim 2$ in E3 and $\sim 4$ in E4. The significant result is that the estimated pressures do not exceed about $14.48 \mathrm{MPa}$. If higher pressures did occur during the transient, they were not maintained long enough to produce measurable accelerations.

The final column in Table XIV gives the total work done by the expanding mixing zone on the coolant. It is the maximum value of the sum of the work done in increasing the fluid kinetic energy, overcoming friction and minor losses, increasing the elevation of the fluid, and overcoming the pump pressure. The value reflects the maximum void size and the rate of growth of the void, but does not differentiate between work done due to gas expansion and that due to sodium vaporization. The greatest total work done appears in Test E3, with a nearly equal value in E7. However, since there was almost 10 times as much fuel in E7 as in E3, the work done per gram of fuel is much greater in E3. In fact, the work done per gram in E3, $3 \mathrm{~J} / \mathrm{g}$, exceeds the next greatest value by a factor of about 3. Compared to the energy at failure, in E3 the indicated work done represents an energy conversion of something less than $0.5 \%$. Values for other tests are lower.

On the basis of the observations and calculations discussed in the previous paragraphs, we can conclude that the highly energetic sort of fuelcoolant interactions in which the thermodynamic limit of energy conversion is approached did not occur in any of the Fuel Dynamics TOP tests, and that the pressures produced did not approach the critical pressure of sodium. 


\section{RELATION OF TESTS TO THE FTR}

\section{A. Fuel Pins}

The fuel pins used in most Fuel Dynamics tests are prototypic of FTR pins in some respects, but differ markedly in others. Clearly, the fuel pins used in early Tests El, E2, and E3 are very nonprototypic of the FTR pins, since the fuel material was $\mathrm{UO}_{2}$ instead of mixed oxide and the cladding material was Type 304 stainless steel. Mixed-oxide fuel with Type 316 stainless steel cladding, $20 \%$ cold-worked was used in the other TOP tests, and was prototypic in these respects.

All pins tested had fuel-column lengths of $0.343 \mathrm{~m}$ or shorter, compared to the $0.91-\mathrm{m}$-long FTR fuel column. The shorts. 1fngth was distaled by the length of the EBR-II core, in which pins used in the Fuel Dynamics program have been irradiated. A contributing factor is the overall. capacity of the Mark-IIA loop for pin length. Because of the short fuel-column length and the relatively flat axial power distribution of EBR-II, the irradiated fuel pins used in Fuel Dynamics tests had a microstructure that was essentially uniform over the length of the fuel. By contrast, FTR pins will typically have a gradation in microstructure from the ends toward the midplane. Likewise, the short length means that one cannot duplicate either the axial temperature gradient or the sodium temperature rise across the fuel column. These conditions mean that a given test can only produce conditions representative of one segment of the FTR fuel pin. As shown in Sec. II.F above, a reasonable match was obtained for core-centerline conditions in the later tests using shaped transients.

In the absence of data on full-length fuel pins with graded microstructures typical of the F'lR, it is necessary to apply data from tests of short pins, each having a particular microstructure, to determination of failure in the FTR pin on a region-by-region basis.

All mixed-oxide pins tested thus far have had uranium enrichment greater than natural. For fresh fuel pins, this fact probably makes little difference, but for irradiated pins, a low cladding-fluence-to-burnup ratio results. This effect cannot be quantified from available data. since burnup and fluanco were not investigated in the Fuel Dynamics program. All the fresh pins tested have been "green" (except for the peripheral pins reused in H5 after IH3). That is, they were used as-fabricated with no exposure to irradiation before transient testing. Again it is difficult to identify any consequence of this condition from the test results. Naturally, all FTR fuel will exist in this condition at the start of operation, as will the fresh subassemblies at the beginning of a cycle. Restructuring takes place within a short time (days). A third characteristic of the test discussed here that cannot be quantified from the data is that of preconditioning. Preconditioning refers to operating at steady-state conditions long enough to heal any startup or shutdown cracks resulting from 
thermal cycles. Such cracks are certainly present in the test fuel and may not be healed during the transients. In the absence of experimental data, an analytical treatment of these effects must suffice.

As mentioned in Sec. II, the internal structure of the test pins varied greatly from test to test. Only the special fresh pins used as peripheral pins in $\mathrm{H} 3, \mathrm{H} 5$, and $\mathrm{E} 6$ are nearly prototypic of FT.R in this respect. A $13-\mathrm{mm}$ insulator-pellet stack and a $150-\mathrm{mm}$-long Inconel reflector were on top of the fuel column in the special pins. In the PNL-17 pins used as central pins in $\mathrm{H} 3$ and $\mathrm{H} 5$, and in Tests $\mathrm{H} 2$ and $\mathrm{E} 4$, the reflector was replaced by a spacer tube. As a result, the inertial restraint was less than prototypic, and the volume into which molten fuel could move within the cladding was greatly increased. Thus, the conditions appear favorable for prefailure axial motion of molten fuel. The heat capacity of the tube was also less than that of the corresponding reflector, but due to the low cladding-gap conductance expected, this is probably not a matter of consequence. On the other hand, NUMEC-F pins tested in E6 and E7 had greater than prototypic axial restraint, due to the long column of insulator pellets. However, the results do not make it obvious that this effect is important. For the reason given above, the increased heat capacity is probably unimportant as well.

\section{B. Test-section Characteristics}

The characteristics of the test section, including the fuel holder and its associated structure, are most important in establishing the similarity of test conditions and reactor conditions. Cross-section views of the various design used for Fuel Dynamics tests are shown in Fig. 5. Other data are provided in Table XV in an attempt to quantify the similarity. The manifestations

TABLE XV. Geometric Parameters of Test Sectionsa

\begin{tabular}{|c|c|c|c|c|c|c|c|}
\hline Parameter & $\mathrm{H} 2 / \mathrm{E} 4$ & $\mathrm{H} 3 / \mathrm{H} 5$ & $\mathrm{E} 6 / \mathrm{H} 4$ & E7 & $\mathrm{El} / \mathrm{E} 2$ & E3 & FTR \\
\hline Flow Area, $\mathrm{mm}^{2}$ & 26.3 & 181 & 181 & 144 & 279 & 82.6 & 4340 \\
\hline Flow Area per pin, $\mathrm{mm}^{2}$ & $\begin{array}{r}26.3 \\
-\end{array}$ & $\begin{array}{l}25.8 \\
16.7\end{array}$ & $\begin{array}{l}25.9 \\
17.1\end{array}$ & $\begin{array}{l}20.6 \\
13.1\end{array}$ & $\begin{array}{l}279 \\
22.8\end{array}$ & $\begin{array}{l}27.7 \\
11.2\end{array}$ & $\begin{array}{l}20.0 \\
17.2\end{array}$ \\
\hline Fuel Area & 0.770 & 0.785 & 0.783 & 0.985 & 0.110 & 0.420 & $\cdot 1.02$ \\
\hline$\overline{\text { Flow Area }}$ & - & 1.21 & 1.18 & 1.55 & 1.35 & - & 1.18 \\
\hline Heated Perimeter & 0.386 & 0.536 & 0.539 & 0.565 & 0.236 & 0.351 & 0.748 \\
\hline Wetted Perimeter & - & 0.810 & 0.830 & 0.852 & 0.837 & - & 0.805 \\
\hline Hydraulic Diameter, mm & $\begin{array}{c}2.2 \\
-\end{array}$ & $\begin{array}{l}3.02 \\
2.95\end{array}$ & $\begin{array}{l}3.05 \\
3.10\end{array}$ & $\begin{array}{l}2.54 \\
2.43\end{array}$ & $\begin{array}{l}3.38 \\
3.30\end{array}$ & $\begin{array}{c}2.79 \\
-\end{array}$ & $\begin{array}{l}3.25 \\
3.02\end{array}$ \\
\hline Steel Cross-sectional Area & 1.06 & $0.707^{c}$ & 0.703 & 0.820 & 0.923 & 0.953 & 0.680 \\
\hline Flow Area & - & 0.479 & 0.449 & 0.561 & 0.552 & - & 0.472 \\
\hline Upper Inertial Length, m & 0.226 & 0.414 & 0.378 & 0.625 & 0.381 & 0.272 & 2.28 \\
\hline Lowcr Inertial Lègth, $m$ & 0.577 & 1.47 & 1.46 & 1.10 & 1.96 & 0.698 & 2.718 \\
\hline
\end{tabular}

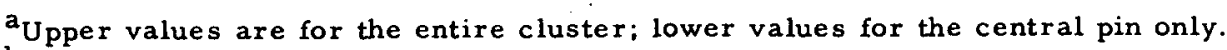

b Includes cladding, spacer wire, and flow tube in contact with flowing sodium.

$c_{\mathrm{H} 5}$ only.
} 
of test-section design are probably most important in the area of fuel movement, since failure threshold and location of failure appear to be primarily functions of quantities related to the pin and coolant conditions alone.

Several quantities are tabulated for each test and for the FTR in Table XV. Where two values are given, the upper value is for the entire cross section of the flow path, including the total flow area and the entire fuel cross section; the lower value pertains only to a central fuel pin away from the cluster boundary. For seven-pin tests, this is the central pin; for the FTR. it is any pin not in the outer row. The central-pin values were obtained by drawing a hexagonal cell around the fuel pin.

The ratio of the fuel cross-sectional area to the flow area is tabulated in Table XV. This ratio reflects the amount of fuel in the test section (or cluster) relative to the area available through which it could move. A high value of this ratio would probably not enhance chances for sweepout of fuel through the channels. When the entire-cluster values are considered, Tests El$\mathrm{E} 3 \mathrm{had}$ the most favorable ratios: $\mathrm{H} 2, \mathrm{E} 4, \mathrm{H} 3, \mathrm{H} 5, \mathrm{H} 4$, and $\mathrm{E} 6$ had less favorable values; E7 was the least favorable. At least in trend, the extent of sweepout tends to follow the ratios. On this basis, all the tests appear to have at least slightly better chances for sweepout than does the cluster. On the basis of single-pin ratios, Tests $\mathrm{H} 3, \mathrm{H} 5, \mathrm{E} 6$, and $\mathrm{H} 4$ provide a good mockup of the FTR. Test E7 shows less favorable conditions.

Within the fuel-column height, the ratio of heated perimeter to wetted perimeter may bc important. The heated perimeter includes only the cladding, not the spacer wires. It is not clear what effect the values of this ratio would have on fuel motion. One could argue that. fuel is more likely to $s$ tick, or plate out, on unheated surfaces than on heated surfaces, since the $r$ ate of heat. lransfer would be larger. On the other hand, the heated surfaces would be at higher temperatures when contacted by fuel, which may stick more readily to the higher-temperature surface. Especially if the heated surface has dried out after voiding while the unheated surface retains a sodium film, fuel will be more likely to stick to the heated surface. Taken nn a rentral=pin basis, all the seven-pin tests provide a good match of this ratio to the reactor. However, on a cluster basis, there is clearly too little heated surface in the tests.

The hydraulic diameter reflects the relative availability of flow area through which fuel can move to surface area on which fuel might stick or plate out. A high value would seem to be relatively favorable for fuel motion. In general, the seven-pin tests all provide a reasonable approximation to the FTR values. The smallest values were for Tests $\mathrm{H} 2$ and $\mathrm{F} 4$, with $\mathrm{E} 7$ also having a small value. Note that there is little difference between entire-cluster hydraulic diameters and those for the central pin above. In all the tests (and the reactor), hydraulic diameters were about $3 \mathrm{~mm}$, indicating a very constricted flow path. Sweepout of fuel from the top of the fuel column past the top of the cluster would require passage through a length of about $110-115$ hydraulic diameters in $\mathrm{H} 3, \mathrm{H} 4, \mathrm{H} 5$, or E6; about 255 diameters in E7; and about 380 diameters for the FTR pin bundle. 
The ratio of the steel cross-sectional area to the flow area is an index to the heat capacity of the structure, which tends to promote low temperatures in the plenum region of the clusters, compared to the flow area through which fuel can move and through which energy transport occurs. For the reasons discussed above in connection with the ratio of heated perimeter to wetted perimeter, the effect of a high heat capacity on sweepout is not clear. In general, a larger proportion of steel was used in the tests than the FTR.

\section{Loop Characteristics}

In addition to comparisons of fuel pins and test-section designs, the dynamic behavior of the Mark-II loop is important in relating test results to the FTR. Areas of interest include loop pressurization, inlet-temperature variation, and voiding dynamics.

Loop pressurization will occur as voiding progresses, since the volume of cover gas in the loop plenum is relatively small. This is probably not important, at least in the early stages of failure and fuel motion. The plenumgas volume is in excess of $5 \times 10^{-4} \mathrm{~m}^{3}$. Voiding of the entire pin bundle in an $\mathrm{H} 5 / \mathrm{E} 6 / \mathrm{H} 4$-type test section would reduce this volume to about $3.5 \times 10^{-4} \mathrm{~m}^{3}$, with a corresponding pressure increase (adiabatic compression). If an initial pressure of $0.25 \mathrm{MPa}$ is assumed, the increase in saturation temperature is only about $83.3 \mathrm{~K}$ for this rather extreme case. Release of all the gas from seven NUMEC-F irradiated pins into the plenum will result in a smaller rise in saturation temperature.

A rise in the inlet temperature will occur during a loop experiment, due to the limited sodium inventory and lack of a heat exchanger. In transients of duration greater than the recirculation time through the loop (about 0.5-1 s at normal flow rates), the sodium temperature at the inlet will begin to rise as heated sodium is recirculated. This rise can be handled in a straightforward manner in analysis.

The coolant-voiding dynamics of the tests are probably of considerable importance in determining the extent of damage to fuel pins and the fuel motion following failure. This importance arises because cooling of the cladding away from the failure point and motion of the fuel within the fuel-coolant mixing zone are both related to the motion of the interface between liquid sodium and the expanding vapor-fuel mixture in the mixing zone. If pressurization of the mixing zone results in reversal of the inlet flow (downward voiding), hot cladding will be uncovered, with accompanying loss of cooling. Thus, spread of damage is expected. 'Likewise, reversal of inlet flow implies downward expansion of the mixing zone. Upward voiding does not tend to spread damage to the same extent because failure is usually near the top of the pin, so there is less active fuel length to uncover. To the extent that fuel really travels with the expanding mixing-zone boundaries, rapid upward voiding provides a favorable condition for fuel sweepout. 
Some quantitative comparison between the voiding dynamics of the loop tests and that of an FTR subassembly can be given by comparing the inertia lengths tabulated in Table XV. To a first approximation, the coolant dynamic behavior of a loop experiment can be described by one-dimensional hydrodynamics, assuming isothermal conditions. Early in a transient, the motion of a planar interface between an expanding mixing zone and a liquid slug can be approximated by

$$
\frac{d v}{d t}= \pm \frac{1}{\rho L^{*}}\left(P_{m}-P_{0}\right)
$$

in which friction, area changes, and elevation are ignored; here

$$
\begin{aligned}
\mathrm{v} & =\text { interface velocity } \\
\rho & =\text { sodium density } \\
L^{*} & =\text { inertia length } \\
\mathrm{P}_{\mathrm{m}} & =\text { mixing-zone pressure, } \\
\Gamma_{0} & =\text { rctarding prcoourc, }
\end{aligned}
$$

and the positive sign applies to the upper slug and the negative sign applies to the lower slug. The inertia length is calculated from

$$
L^{*}=A_{b} \sum \frac{L_{i}}{A_{i}}
$$

where

$$
\begin{aligned}
A_{b} & =\text { pin-bundle area } \\
L_{i} & =\text { length of the ith segment of flow path },
\end{aligned}
$$

and

$$
A_{i}=\text { area of the ith segment of flow path. }
$$

The values given in Table XV for the tests were calculated from the data in Appendix $A$, using the $U$ and $L$ sections, respectively, and ignoring the $C$ sections. Values for the F'TR were calculated trom data supplied by Chawla. ${ }^{8}$

Two observations are apparent from the inertia-length data and the above discussion. First, the accelerations to be expected, being inversely proportional to the inertia lengths, will be greater in the tests than in the reactor for a given set of driving and retarding pressures. Second, the ratio of lower-to-upper inertia lengths is roughly 1.2 in the reactor, whereas it varies from about 1.8 to about 5.2 for the tests. Values for $\mathrm{H} 5, \mathrm{E} 6 / \mathrm{H} 4$, and E7 were, respectively, 3.6, 3.9, and 1.8. The higher the value of this ratio, the greater the tendency to void upward rather than downward. 
The following comments appear to be in order with respect to comparison of test to reactor-voiding behavior. Tests $\mathrm{H} 2$ and $\mathrm{E} 4$ tended to show fairly symmetric voiding (for the tests), with generally more rapid downward voiding than in the FTR. Generally similar behavior would be expected in E7, which would show the most symmetric voiding of all the tests. Upward voiding in $\mathrm{E} 7$ would be markedly slower than that in $\mathrm{H} 2$; downward voiding would be slower than in $\mathrm{H} 2 / \mathrm{E} 4$, but by a lesser difference. Voiding in both directions would be more rapid in E7 than in the FTR. These expected voiding patterns are consistent with the test results, which revealed extensive damage to the fuel pins in each case, with loss of cooling a reasonable cause for the damage. The rapid upward voiding did not seem to be reflected in large sweepout, however. Note that E3, which would behave like $\mathrm{H} 2$ and E4 in voiding, exhibited extensive sweepout; lack of direct correlation of sweepout solely with voiding is suggested.

The remaining tests--H4, H5, E6, and E2--showed large ratios of inertia lengths. This result implies a great preference for upward voiding. In fact, the upward voiding is so effective in relieving the mixing-zone pressures that little downward voiding is expected. Again; this expectation is reflccted in the test results, at least in $\mathrm{H} 5, \mathrm{E} 6$, and $\mathrm{E2}$, for which destruction of the pins below the failure location was not complete, with the implication that cooling was maintained. Some sweepout was observed in these tests, but it is hard to correlate definitely with voiding rates. Compared to the FTR, the upward voiding was more rapid in the tests, and the downward voiding was about the same, or slower, in the tests.

D. Summary

Fuel pins tested in Fuel Dynamics experiments were representative of only a portion of the full-length FTR pin, so that the indicated failure threshold is that for only the particular microstructure. Relation to the FTR situation requires application of the data on a region-by-region basis. All of the pins tested had a low fluence-to-burnup ratio compared to FTR driver fuel and were not preconditioned to heal cracks prior to testing. These effects must be handled analytically. Structural differences between test pins and FTR pins exist, but their importance is thought to be minimal.

Several quantities have been identified indicating the degree of similarity between the test-section geometry and that in the FTR. The significance of each quantity is not clear at this time. Based on current knowledge, we cannot say that the conditions in the tests were more or less favorable for fuel motion (sweepout) than would be the case under reactor conditions.

Coolant voiding dynamics for the loop tests reflect the geometry of the test section and loop. In general, voiding in the tests is expected to be more rapid and more preferentially upward than in the reactor. Tests $\mathrm{H} 4$, H5, Eh, and E2 would be expected to exhibit aboul lle sarne or even less downward voiding than would the reactor. The expectations appear consistent with the test results in qualitative terms. Again, we cannot say that the voiding dynamics are euch as to produce nirure ur less sweepout than would occur in the reactor. 


\section{APPENDIX A}

Test Hardware

\section{TREAT}

The Transient Reactor Test (TREAT) Facility ${ }^{9}$ is a graphite-moderated, $\mathrm{UO}_{2}$-fueled thermal reactor, designed, built, and operated by Argonne National Laboratory to provide a capability for safely conducting experiments involving destruction of fuel samples related to the U. S. fast-reactor-safety programs. Although there is a limited air-cooling capability, TREAT is basically a "heat-capacity" facility. Under the current $837 \mathrm{~K}$ maximum core-temperature limit, the reactor has produced bursts up to $2150 \mathrm{MJ}$. $^{10}$ The reactor is shown in Fig. A. 1.

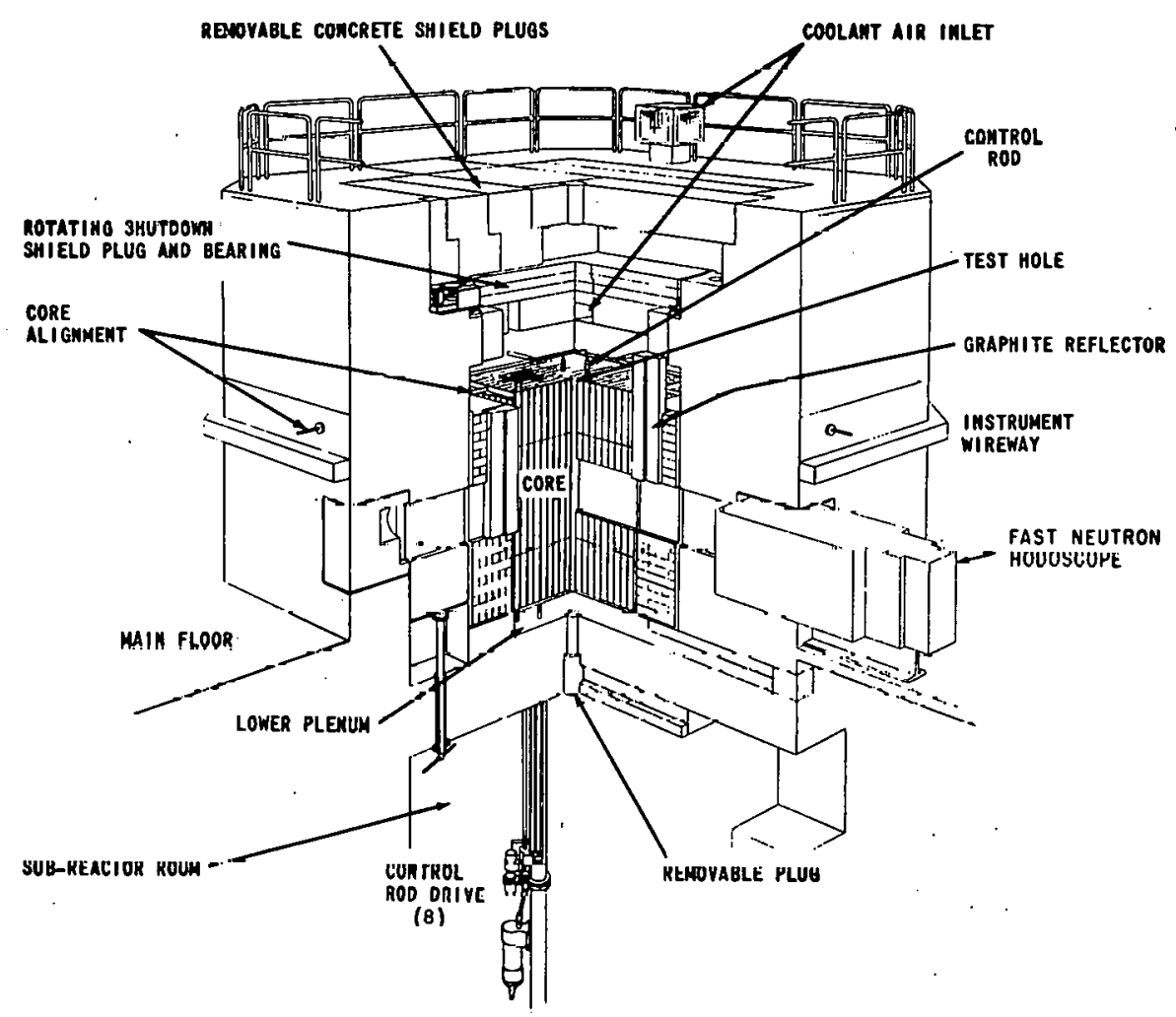

Fig. A.1. TREAT Facility. ANL Neg. No. 900-2776.

TREAT fuel is a homogeneous mixture of graphite and fully enriched urania ( $\mathrm{C}: \mathrm{U}$ ratio $=10,000)$. Each fuel element has a $1-\mathrm{m}$-long fuel section with $0.6-\mathrm{m}$-long graphite reflector sections at top and bottom. The fuel section is clad in Zircaloy-2. Special elements with the center $0.6 \mathrm{~m}$ of fuel removed are available to provide a slot through the core for optical photography or for the neutron hodoscope. The slotted elements and hodoscope are shown in Fig. A.1. A maximum core size of $19 \times 19$ elements can be accommodated. 
Experiments are performed in self-contained capsules that replace one or two central fuel elements. The recent addition of a computer control to the transient control rods allows extensive latitude in specifying transient shapes within the limitations of fuel temperature, available reactivity, and rod speed.

2. The Mark-IIA Loop

All the Fuel Dynamics tests were conducted in the Mark-IIA loop, ${ }^{11}$ shown in Fig. A.2. This loop provides the flowing-sodium environment required

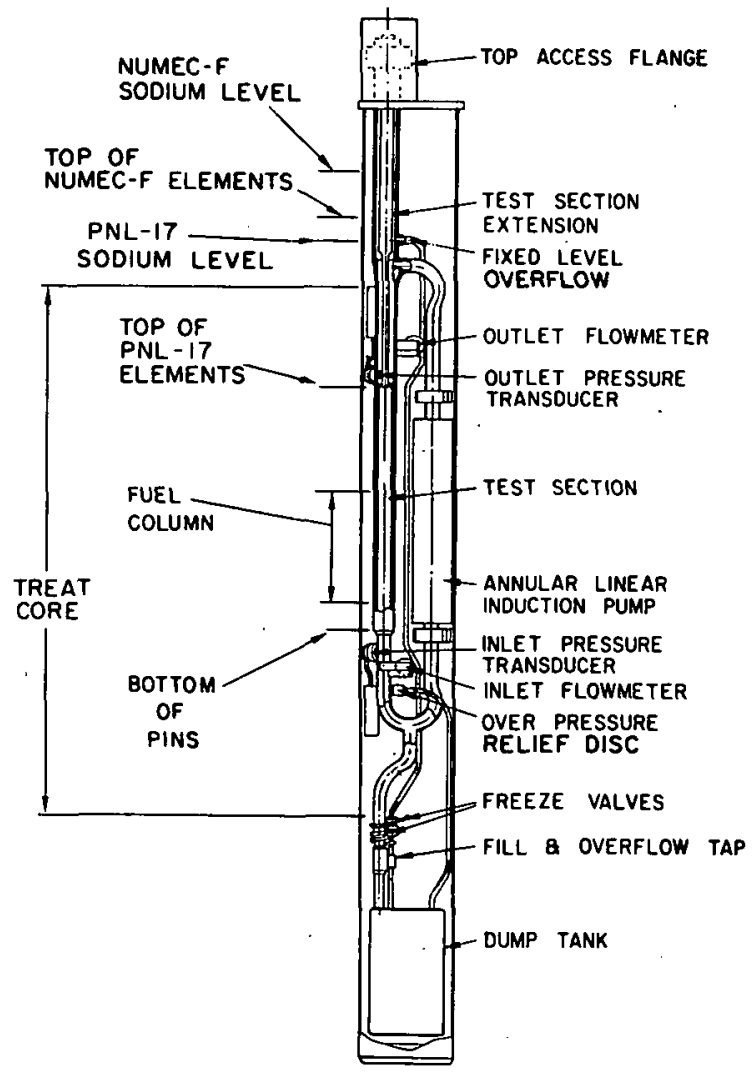

Fig. A.2

Mark-II Loop. ANL Neg.

No. 900-2777 Rev. 1. for mockup of reactor conditions as well as containment of the experiment. Sufficient heat capacity is available in the loop body to absorb the energy generated in a test without excessive heating of the loop or the neighboring TREAT fuel elements. Sodium is circulated through the loop by an annular linear induction pump (ALIP), which can be controlled by varying the power input. ${ }^{12}$ There is no reject heat exchanger; therefore the loop is limited to transient operation only. A gas-filled plenum above the sodium limits pressure changes during experiments.

The structural design of the loop is based on a steady-state pressuretemperature rating of $34.47 \mathrm{MPa}$ at $810.9 \mathrm{~K}$. Material used is Type 316 stainless steel, except for the pump tube, which is Inconel X-750. Use of Inconel reduces the magnetic air gap in the ALIP to the minimum possible. A rupture disk is provided in the loop in the event of a pressure exceeding the rating. The outlet of the rupture disk is piped to a dump tank having a volume of about $1.9 \times 10^{-3} \mathrm{~m}^{3}$

Operational thermocouple instrumentation is provided on the loop body at several places of interest. The outputs of these thermocouples are monitored on a slow recording system, but are not generally monitored on fast recorders during a transient. These instruments provide temperature data necessary during loop heatup and cooldown, and for establishing initial conditions for a test.

The test firel pins are positioned in the loop by a fuel holder and positioning structure such as shown below. Tests have been run using up to 
seven fuel pins with lengths up to $1.1 \mathrm{~m}$. The fuel holder and associated structure help determine the hydraulic properties of the test, since the pinbundle flow path is defined by the fuel holder and the positioning structure influences the flow above the pin bundle to a significant degree. Hydraulic properties of the downcomer and pump are solely determined by the loop and are common to all tests. The only variations of consequence are in the pump power setting and in the region at the entrance to the pump leg of the loop. In the latter region, the presence of the pin bundle opposite the entrance in longpin $(1.1-m)$ tests influences the hydraulics of the loop.

\section{Hodoscope}

The fast-neutron hodoscope is used for the direct observation of fuel and its motion during a TREAT test. ${ }^{13}$ Figure A. 1 shows the location of the hodoscope in the TREAT reactor. The hodoscope operates by collecting the fission neutrons originating from the test fuel. Slots in special TREAT elements allow a clear path between the test section and the hodoscope. These high-energy (over $0.3 \mathrm{pJ}$ ) neutrons easily penetrate the coolant and structural materials of the test section. The hodoscope has 334 individual collimators with a fast-neutron detector at the receiving end of each. The detectors are focused on a rectangular plane, $0.0571 \times 0.51 \mathrm{~m}$, which intersects the test section.

The information on fuel motion carried by the collected neutrons is rendered in two different forms. First, graphs of the normalized count rate as a function of time can be prepared for most of the 334 channels. Second, an image sequence can be reconstructured using the display tube of a computer. The reconstruction can be examined dynamically at various speeds, and motion pictures can be prepared in real time or in slow motion.

\section{Test Section and Loop Diagrams}

This section includes diagrams of the test sections used in the tests reported here, along with hydraulic data pertaining to each assembly. Figure A. 3 includes the loop-plenum section which is common to Tests E2, E3, E4, H2, and H5. The diagram shows the "bayonet subassembly" installed inside the loop plenum. Also included are the test sections for Tests H?, E4, and H5. Figure A. 4 shows the pump leg of the loop which is common to all tests. 'I'he test section and loop-plenum sections for Tests E 6 and F.7 are shown in Figs. A. 5 and A.6, respectively.

In each case, the loop is divided into three main parts, called the common, upper, and lower legs. The common leg includes essentially that portion of the loop through which no net flow moves in normal operation. The upper leg includes that portion of the flow path between the top of the fuel column and the entrance to the common leg (the tee, in most cases). The lower leg includes the piping between the junction (tee) and the top of the fuel column through the pump and pin bundle inlet. 

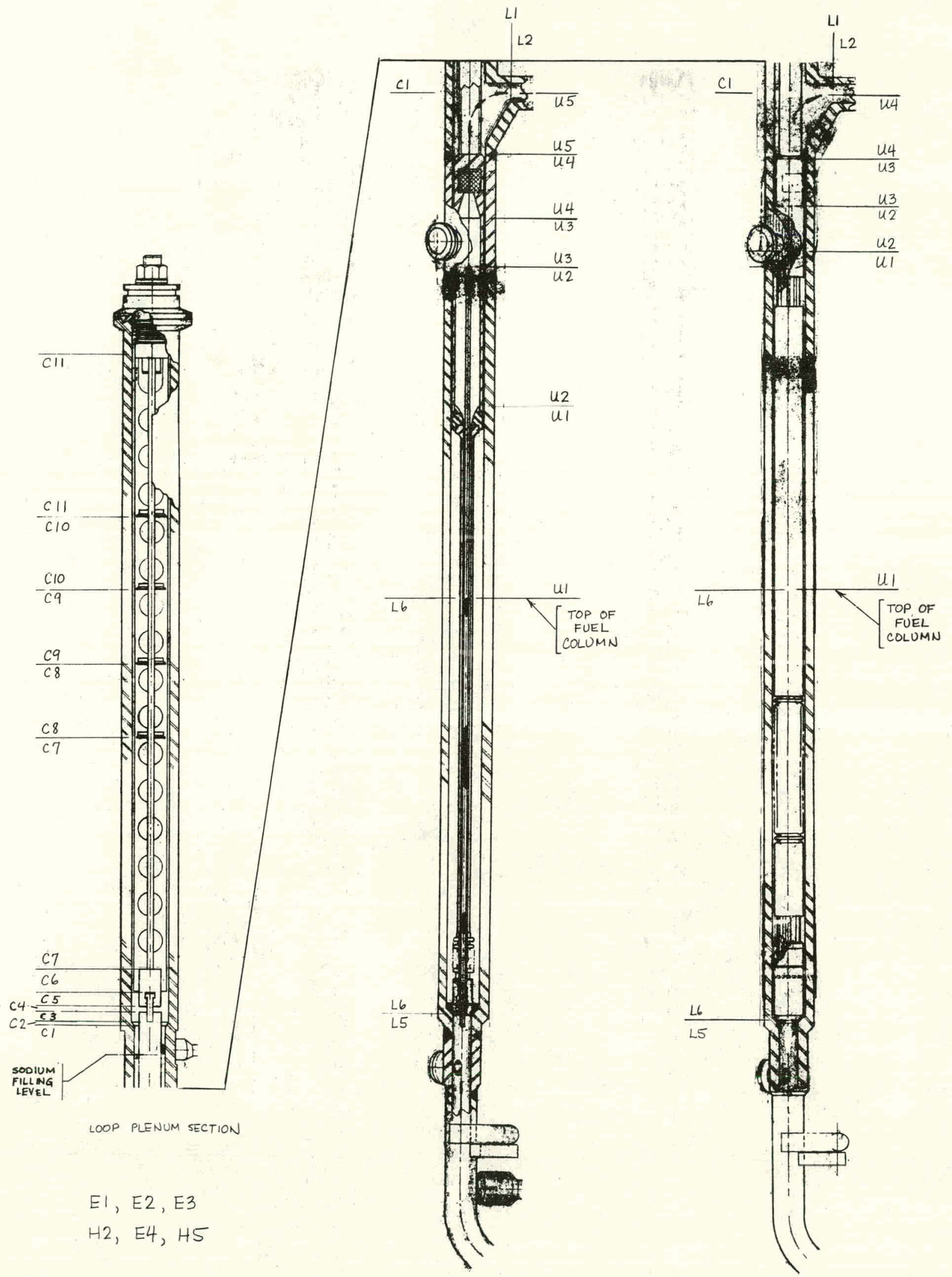

TEST SECTION
H2, E4

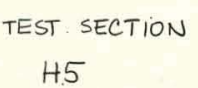

Fig. A.3. Loop-plenum Section and Test Sections for Tests H2, E4, and H5 

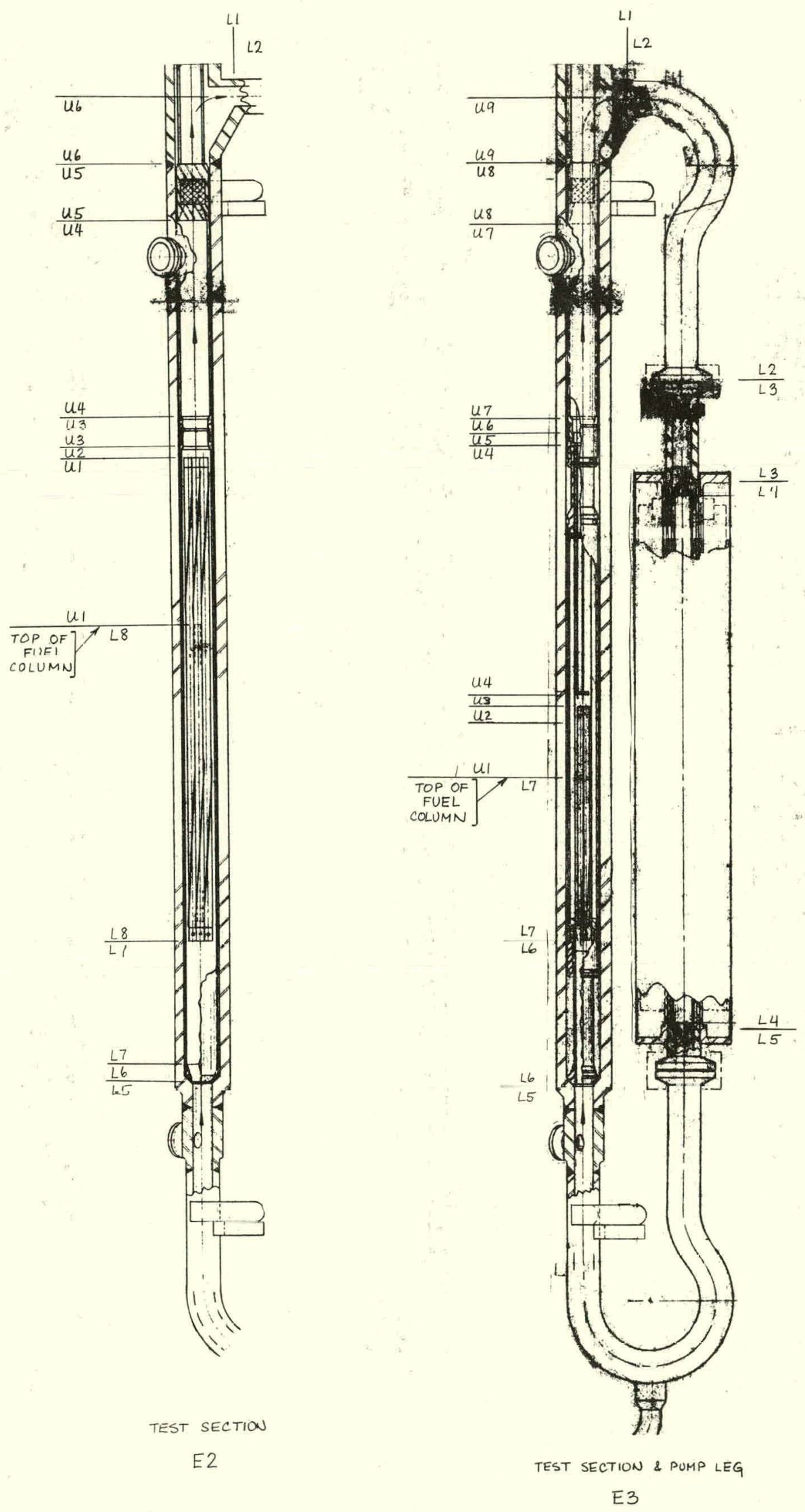

Fig. A.4. Test Sections for Tests E2 and E3 and Pump Leg of Loop 


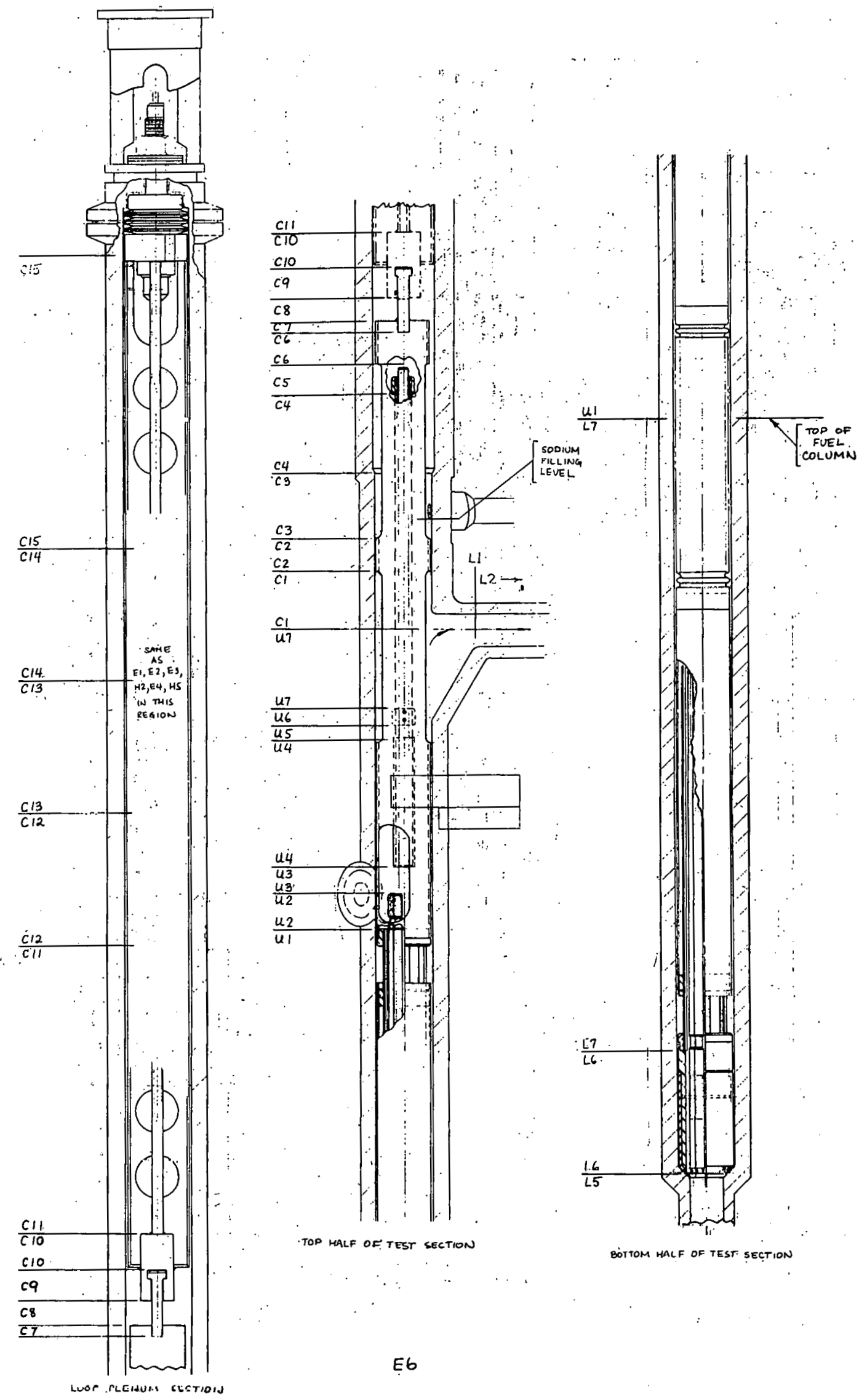

Fig. A.5. Loop-plenum Section and Test Section for Test E6 


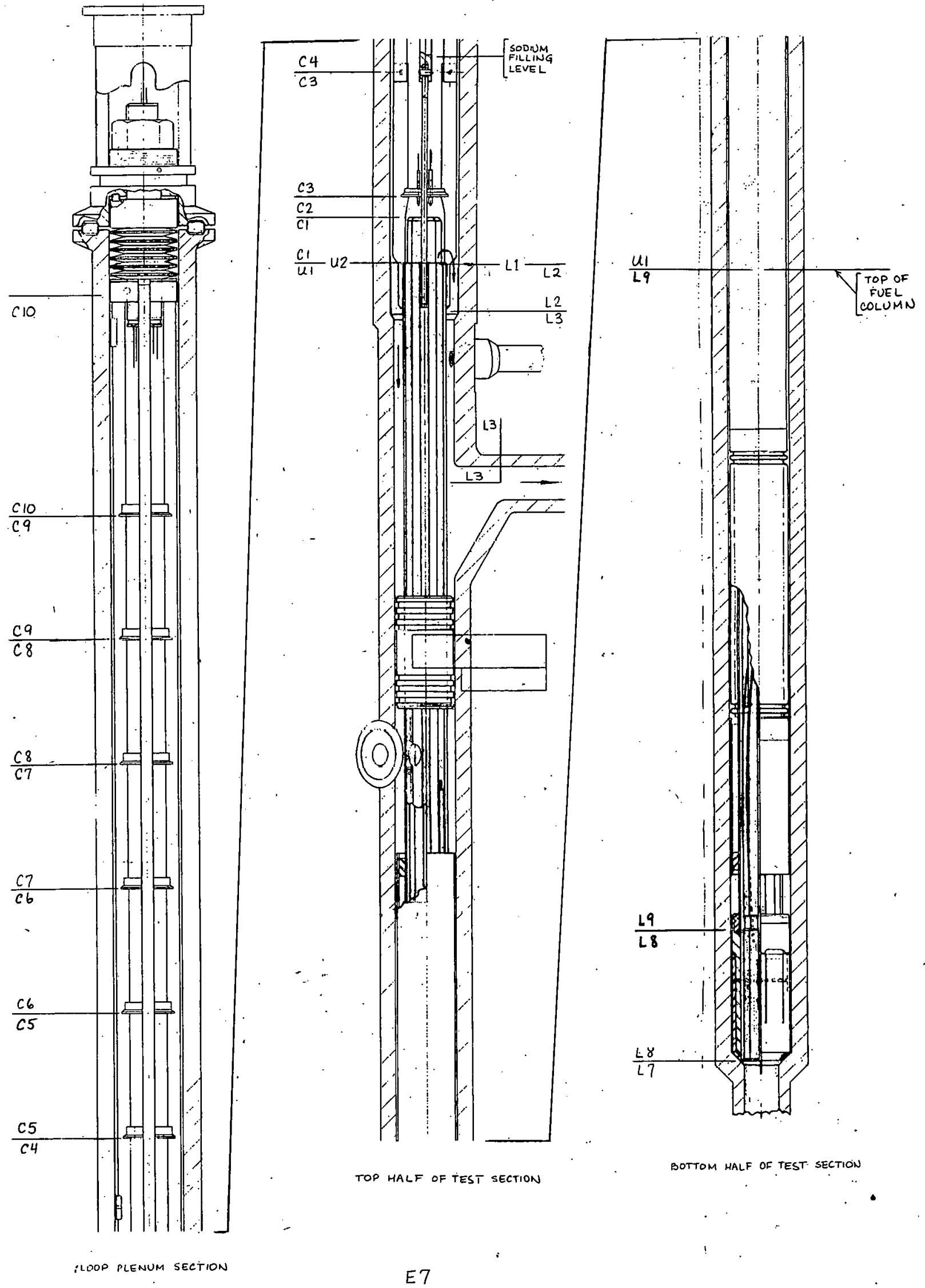

Fig. A.6. Loop-plenum Section and Test Section for Test E7 
Each leg is subdivided into a number of constant-area sections, each characterized by a length, flow area, hydraulic diameter, and unrecoverable loss coefficient. Positive flow is in the direction of increasing section number (i.e., L2 to $\mathrm{L} 3, \mathrm{U} 1$ to $\mathrm{U} 2$, etc.). The boundaries and identification letters are indicated in the figures. Note that some boundaries are chosen at obstructions in the flow path such as baffles.

The hydraulic data are given in Tables A.1-A.6. Loss coefficients are associated with the inlet to a particular section (i.e., the boundary between sections $n$ and $n-1)$. Expansion and contraction losses are calculated from ${ }^{14}$

$$
\mathrm{K}_{\exp }=\left[1-\left(\mathrm{A}_{2} / \mathrm{A}_{1}\right)\right]^{2}
$$

and

$$
\mathrm{K}_{\text {con }}=\left[\left(1 / C_{c}\right)-1\right]^{2},
$$

where $K_{\exp }$ is the loss coefficient for an expansion, $K_{c o n}$ is the loss coefficient, for a contractor, $A_{2}$ and $A_{1}$ are the flow areas $\left(A_{2}<A_{1}\right)$, and $C_{c}$ is a function of $A_{2} / A_{1}$ given in Ref. 14 (p. 188). These coefficients are applied in

$$
\Delta \mathrm{p}=\mathrm{K}_{\mathrm{xxx}} \frac{\rho \mathrm{V}_{2}^{2}}{2}
$$

where $V_{2}$ is the average coolant velocity in the smaller area, $\rho$ is the fluid density, $\Delta \mathrm{p}$ is the pressure drop, and $\mathrm{K}_{\mathrm{xxx}}=\dot{\mathrm{K}}_{\exp }$ or $\mathrm{K}_{\mathrm{con}}$ as appropriate.

TABLE A.1. Loop Flow Parameters for Test E2

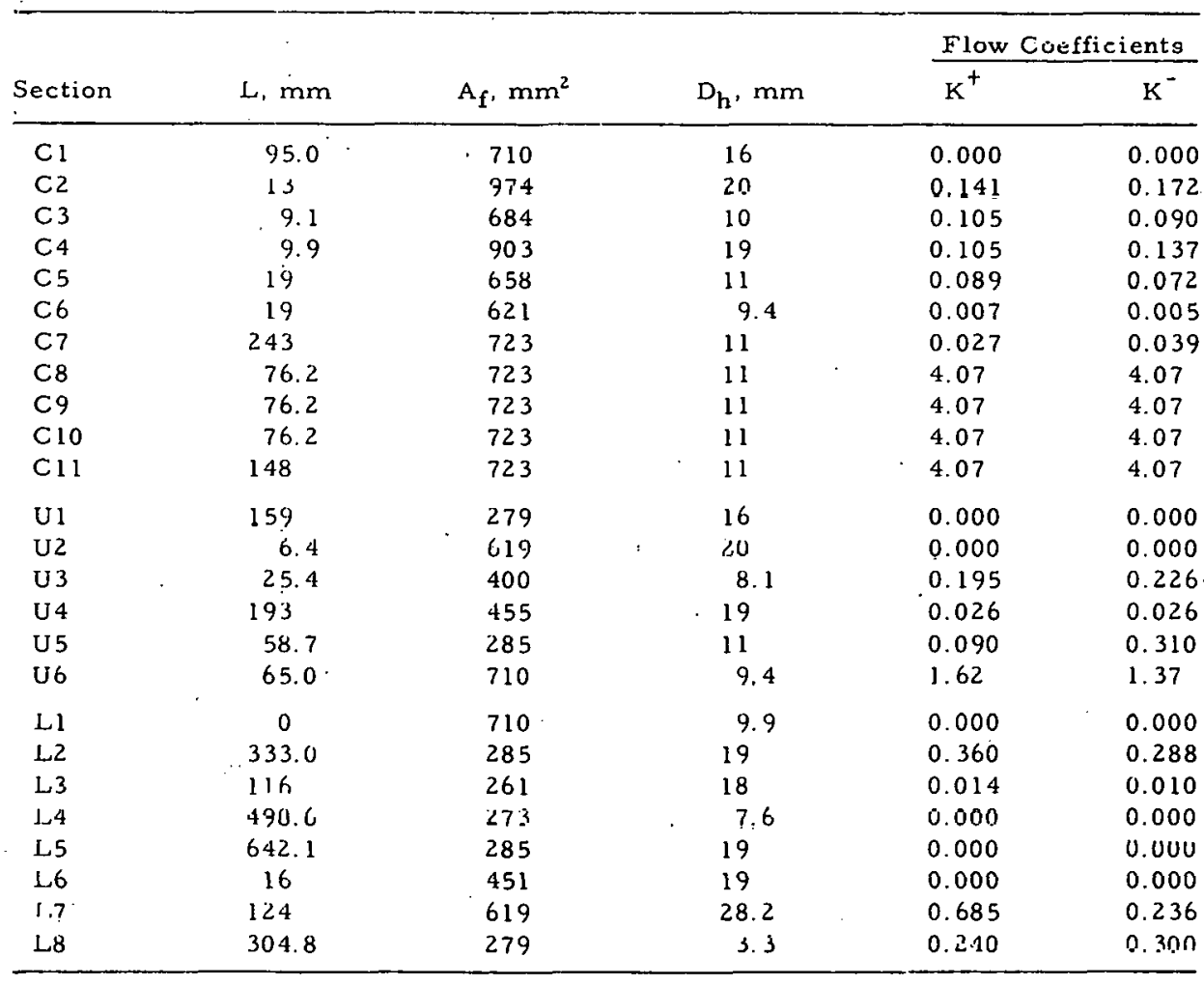


TABLE A.2. Loop Flow Parameters for Tests H2 and E4

\begin{tabular}{|c|c|c|c|c|c|}
\hline \multirow[b]{2}{*}{ Section } & \multirow[b]{2}{*}{$\mathrm{L}, \mathrm{mm}$} & \multirow[b]{2}{*}{$\mathrm{A}_{\mathrm{f}}, \mathrm{mm}^{2}$} & \multirow[b]{2}{*}{$\mathrm{D}_{\mathrm{h}}, \mathrm{mm}$} & \multicolumn{2}{|c|}{ Flow Coefficients } \\
\hline & & & & $\mathrm{K}^{+}$ & $\mathrm{K}^{-}$ \\
\hline $\mathrm{Cl}_{1}$ & 95.0 & 710 & 16 & 0.000 & 0.000 \\
\hline $\mathrm{C} 2$ & 13 & 974 & 20 & 0.141 & 0.172 \\
\hline $\mathrm{C} 3$ & 9.1 & 684 & 10 & 0.105 & 0.090 \\
\hline $\mathrm{C} 4$ & 9.9 & 903 & 19 & 0.105 & 0.137 \\
\hline $\mathrm{C}_{5}$ & 19 & 658 & 11 & 0.089 & 0.072 \\
\hline $\mathrm{C} 6$ & 19 & 620 & 9.4 & 0.007 & 0.005 \\
\hline $\mathrm{C} 7$ & 243 & 723 & 11 & 0.027 & 0.039 \\
\hline $\mathrm{C} 8$ & 76.2 & 723 & 11 & 4.07 & 4.07 \\
\hline C9 & 76.2 & 723 & 11 & 4.07 & 4.07 \\
\hline $\mathrm{C} 10$ & 76.2 & 723 & 11 & 4.07 & 4.07 \\
\hline Cll & 148 & 723 & 11 & 4.07 & 4.07 \\
\hline U & 200 & 27 & 2 & 0.000 & 0.000 \\
\hline $\mathrm{U} 2$ & 142 & 425 & 18 & 247 & 103 \\
\hline U3 & 50.0 & 461 & 24 & u. 000 & 0.000 \\
\hline$\cup 4$ & 58.7 & 285 & 11 & 0.090 & 0.310 \\
\hline U5 & 65.0 & 710 & 16 & 1.62 & 1.37 \\
\hline Ll & 0 & 710 & 9.9 & 0.000 & 0.000 \\
\hline $\mathrm{L} 2$ & 333.0 & 285 & 19 & 0.360 & 0.288 \\
\hline L3 & 116 & 261 & 18 & 0.014 & n.nin \\
\hline $\mathrm{L} 4$ & 498.6 & 273 & 7.6 & 0.000 & 0.000 \\
\hline$L S$ & 642.1 & 285 & .19 & 0.000 & 0.000 \\
\hline L6 & 427.0 & 27 & 2 & 0.365 & 0.820 \\
\hline
\end{tabular}

TABLE A. 3. Loop Flow Parameters for Test E3

\begin{tabular}{|c|c|c|c|c|c|}
\hline \multirow[b]{2}{*}{ Section } & \multirow[b]{2}{*}{$\mathrm{I}, \mathrm{mm}$. } & \multirow[b]{2}{*}{$A_{ \pm 1} \min _{2}^{2}$} & \multirow[b]{2}{*}{$\mathrm{L}_{11}, \mathrm{~mm}$} & \multicolumn{2}{|c|}{ Fluw Cuefificients } \\
\hline & & & & $\overline{\mathrm{K}}$ & $K^{-}$ \\
\hline $\mathrm{Cl}$ & 95.0 & 710 & 16 & 0.000 & 0.000 \\
\hline $\mathrm{C} 2$ & 13 & 771 & 20 & 0.111 & 0.172 \\
\hline C3 & 9.1 & hR 4 & 10 & 0.105 & 0.090 \\
\hline $\mathrm{C}_{4}$ & 9.9 & 903 & 19 & 0.105 & 0.137 \\
\hline C 5 & 19 & 658 & 11 & 0.089 & 0.072 \\
\hline $\mathrm{C} 6$ & 19 & 620 & 9.4 & 0.007 & 0.005 \\
\hline $\mathrm{C}_{7}$ & 243 & 723 & 11 & 0.027 & $0: 039$ \\
\hline $\mathrm{C} 8$ & 76.2 & 72.3 & 11 & 4.07 & 4.07 \\
\hline $\mathrm{Cy}$ & 76.2 & 723 & 11 & 4.07 & 4.07 \\
\hline$C_{10}$ & 76.2 & 723 & 11. & 4.07 & 4.07 \\
\hline C11 & 148 & 723 & 11 & 4.07 & 4.07 \\
\hline U I I & 57.1 & 82.6 & 2.8 & 0.000 & 0.000 \\
\hline U2 & 6.4 & 86.5 & . 3.3 & 0.000 & 0.000 \\
\hline U3 & 6.4 & 150 & 14 & 0.55 & 0.55 \\
\hline $\mathrm{U} 4$ & 246 & 145 & 8.6 & 0.54 & 0.89 \\
\hline U 5 & 4.6 & 198 & 16 & 1.05 & 1.65 \\
\hline U6 & 9.4 & 284 & 19 & 0.197 & 0.226 \\
\hline U7 & 193 & 455 & 24 & 0.317 & 0.344 \\
\hline U8 & 58.7 & 285 & 11 & 0.090 & 0.310 \\
\hline U9 & 65.0 & 710 & 1.6 & 1.62 & 1.37 \\
\hline Ll & 0 & 710 & 9.9 & 0.000 & 0.000 \\
\hline L2 & 333.0 & 285 & 19 & 0.360 & 0.288 \\
\hline 13 & 116 & 261 & 18 & 0.014 & 0.010 \\
\hline L4 & 498.6 & 274 & 7.6 & 0.000 & 0.000 \\
\hline L5 & 642.1 & 274 & 19 & 0.000 & 0.000 \\
\hline L6 & 143 & 152 & 14 & 0.200 & 0.218 \\
\hline $\mathrm{L} 7$ & 152 & 82.6 & 2.8 & 0.196 & 0.205 \\
\hline
\end{tabular}


TABLE A.4. Loop Flow Parameters for Test H5

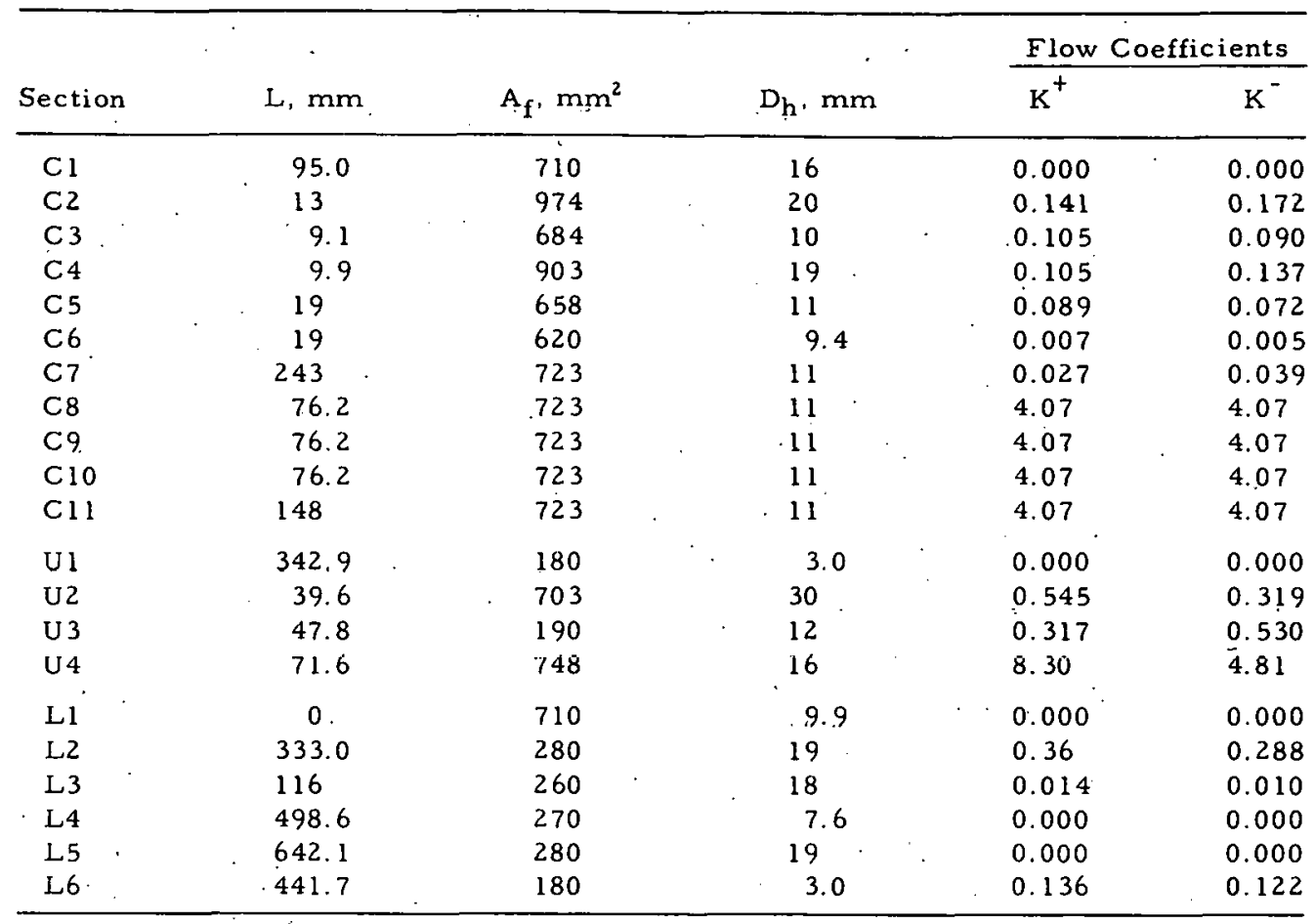

TABLE A. 5. Loop Flow Parameters for Test E6

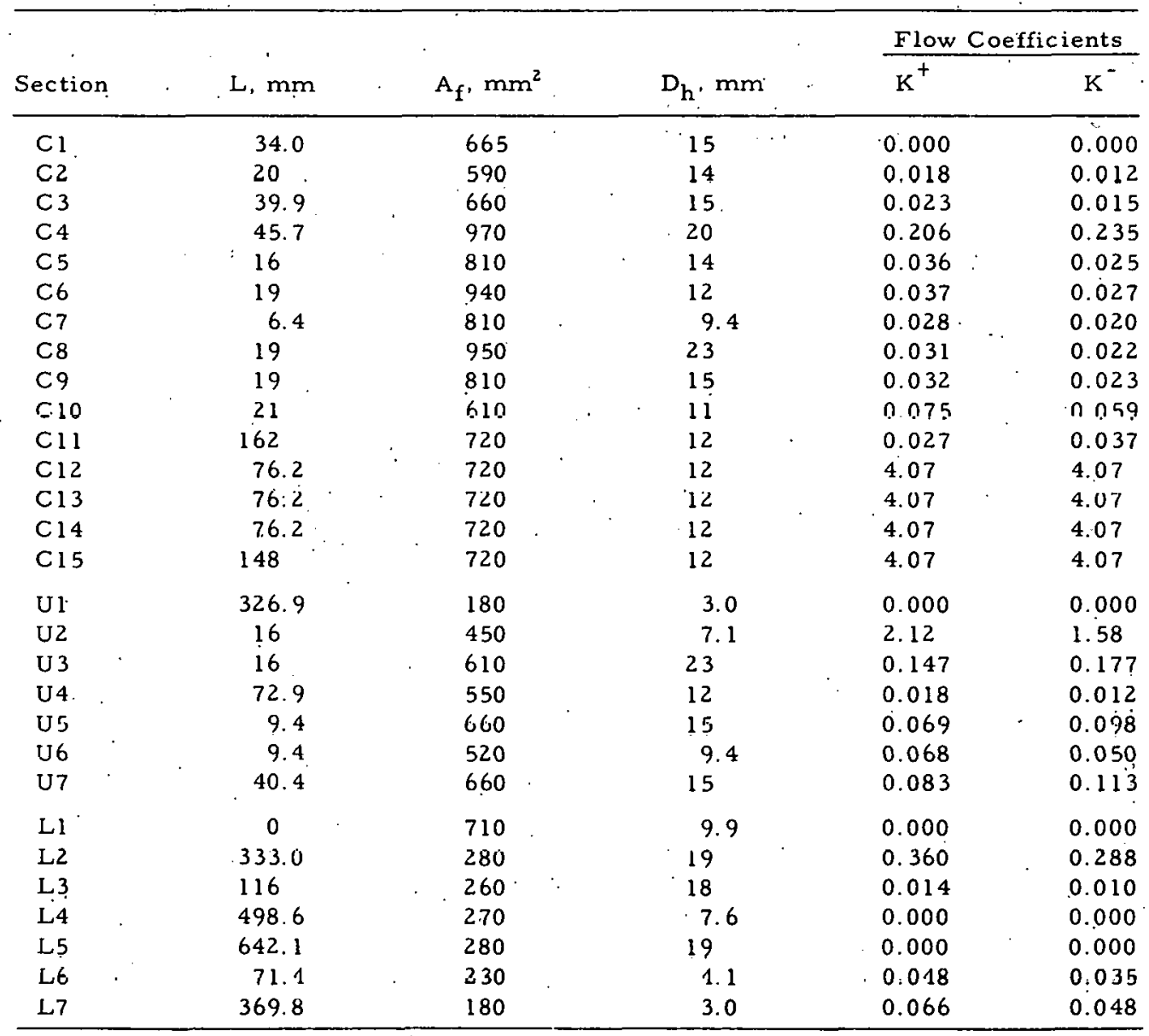


TABLE A.6. Loop Flow Parameters for Test E?

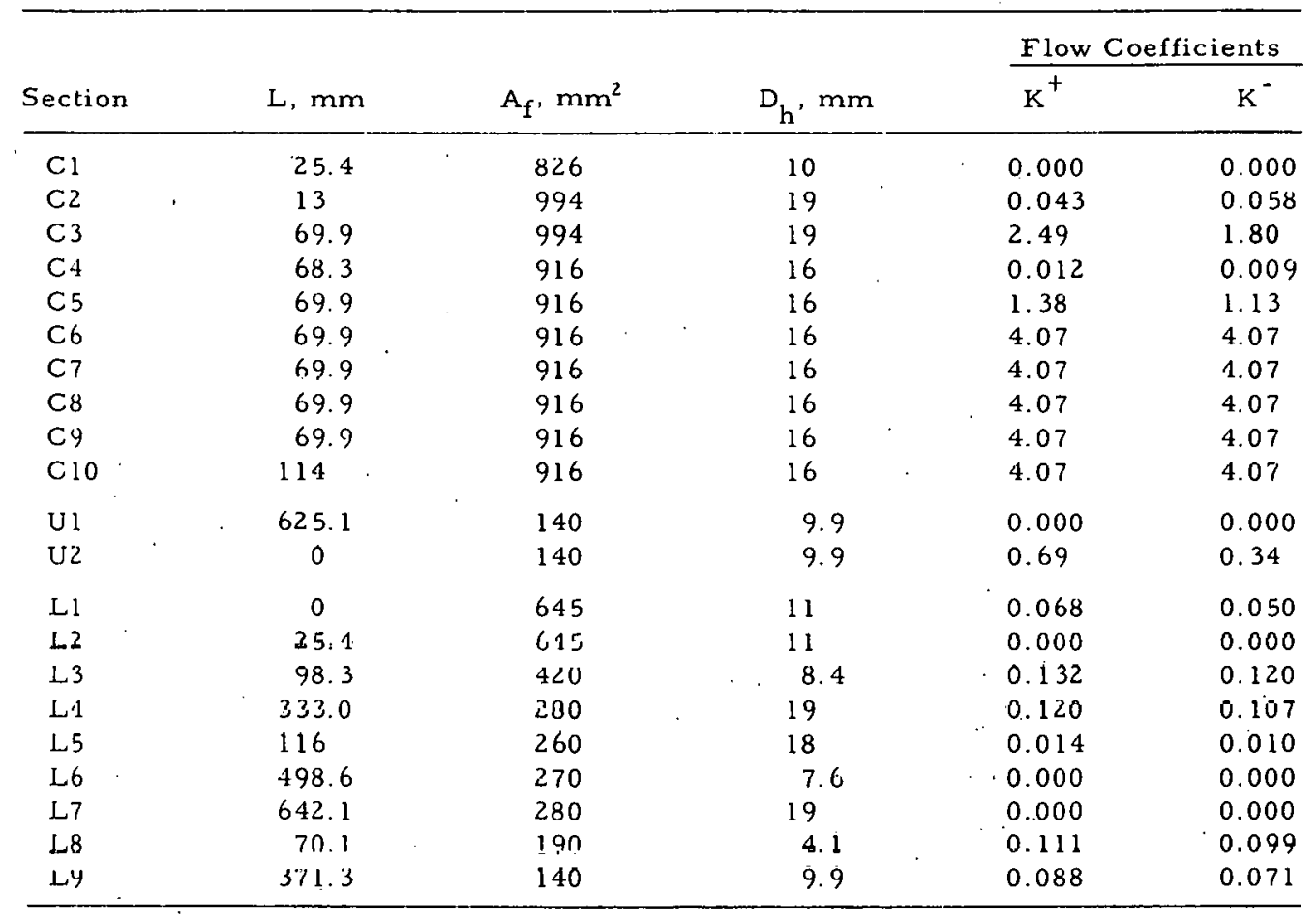

Passage of fluid past an obstruction is treated as passage through an orifice having an area ratio equal to that at the obstruction. The associated loss is taken to be that associated with expansion from the vena-contracta area, $\mathrm{CA}_{2}$, to the free-stream area, $\mathrm{A}_{1}$. Values of $\mathrm{C}$ are taken from Ref. 14, p. 321 , as suming high Reynolds number.

Friction pressure drops may be treated in the normal manner using the data given along with a friction-factor correlation such as

$$
f=0.316 \mathrm{Re}^{-0.25} \text {, }
$$

where $R e$ is the Reynolds number. Basically, this approach is consistent with the approach used in deriving the data presented in the tables. That is, the loop is treated as a piping system using data applicable for flow in pipes. This approach, although imprecise, is thought to be adequate for most calculations involving loop hydraulics. 


\section{APPENDIX B}

Thermal-Hydraulic and Stress-Strain Calculations

Computer simulations of the behavior during a transient of the coolant, fuel pins, and test-section wall are used to supplement the test data. Since most of the instrumentation is located so as to record the gross flow conditions within the inlet and outlet of the fuel-pin bundle, detailed conditions within the pin bundle must be estimated through calculations. In fact, most of the numbers given in Table XIII on conditions at the estimated time of failure were calculated rather than measured directly. Certain aspects of the computer simulations (such as the fuel-pin heat conduction and the sodium hydraulics up to saturation temperature) have been widely studied, but other important aspects of the calculations (such as fuel-cladding gap conductance and transient fission-gas-driven fuel swelling) are not so well known. The calculations presented in this report were done with modified versions of the computer codes COBRA-IIIM ${ }^{15}$ and DEFORM-II, ${ }^{16}$ and yield plausible results up to the time of flow reversal or loss of intact geometry (fuel-pin failure).

The COBRA-IIIM thermal-hydraulic computer code is an ANL-modified version of the COBRA-IIIB computer program. ${ }^{17}$ This program computes the flow and enthalpy in rod-bundle nuclear-fuel-element subchannels during both steady-state and transient conditions. Both turbulent mixing between adjacent subchannels and diversion crossflow due to pressure gradients and the helical wire wrap are considered. The wire-wrap diversion model was not used in calculations of the present tests. The inlet and outlet boundary conditions on the flow. subchannels require specification of the inlet enthalpy, inlet mass velocity, and exit pressure. Thus flow reversal cannot be calculated. At ANL, fuel pin and test-section duct-wall heat-transfer subroutines were added to COBRA. The fuel-pin model, which considered radial heat transfer only, permitted calculation of fuel and cladding temperatures as function of radius, pin azimuthal sector, and axial location for a specified transient, spatially dependent fission-energy-generation rate.

Recently, COBRA-IIIM has been modified further to improve the suitability of the code for analysis of the tests evaluated in this report. The most significant of these modifications are changes in the calculation of the fuel-cladding gap conductance and a link-up of the DEFORM-II stress-strain code to COBRA. In previous versions of COBRA, the gap conductance is assumed to be inversely proportional to the gap size $\Delta \mathrm{r}$; i.e.,

$$
h_{\text {gap }}=h_{\text {gap }} \frac{\Delta r_{0}}{\Delta r}
$$

where $\mathrm{h}_{\mathrm{gap}}$ is the gap conductance corresponding to the initial gap size $\Delta \mathbf{r}_{0}$ measured at room temperature. The modified fuel-cladding gap conductance is similar to that used in current FTR steady-state analysis. As before, the conductance is assumed to be inversely proportional to the gap size, but takes 
into account (1) the small gap remaining when the fuel and cladding are in contact under internal pin pressure and (2) the mechanics of energy transfer between the gas in the gap and the solid materials bounding the gap, i.e.,

$$
h_{\text {gap }}=\frac{k}{c+\Delta r}
$$

where $\mathrm{k}$ is the conductivity of the gas in the gap, $\mathrm{c}$ is a parameter reflecting the residual gap (of the order of $0.01 \mathrm{~mm}$ ), and $\Delta \mathrm{r}$ is the time-dependent gap calculated from differential thermal expansion between fuel and cladding. In both cases, the value of the gap conductance is limited so that $\mathrm{h}_{\mathrm{g} a \mathrm{p}}$ does not exceed a specified value ( $\left.h_{\text {gap }}\right)_{\text {max. }}$. To account for the use of both fresh and preirradiated pins in the same test, the COBRA input was extended to permit different parameter values for each pin in the pin bundle.

Deformation of the fuel and cladding during the transient is calculated by the DEFORM-II code using fuel and cladding temperatures calculated by COBRA-III. The cladding is loaded on the inside by the differential thermal expansion between the fuel and cladding once they are in contact. After the inner portion of the fuel pin melts, the loading of the solid outer shell of fuel due to fission- or bond-gas expansion is calculated. However, fuel swelling or cracking is not taken into account. All materials are assumed to be isotopic, and zonewise homogeneous, and to obey elastic-viscoplastic stressstrain relationships. The plane-strain approximation is used with axisymmetry, and shear stresses are neglected, except for an approximate treatment of friction between fuel and cladding. No motion of molten fuel is allowed. DEF URM was originally written to be used with the SAS code, and for this reason DEFORM cannot account for temperature variations in the azimuthal direction. Thus, temperatures calculated by COBRA are averaged azimuthally before being supplied to the DEFORM program, which then operates in the same manner as when it is obtaining its input from SAS. At present, there is no feedback from DEFORM to COBRA. A simplified flow diagram illustrating the linkage is shown in Fig. B. 1.

Other recent modifications to COBRA-IIIM include the calculation of various subsidiary results, such as average fuel energy density and average coolant outlet temperature, and the facility to change the computational time step at a predetermined point of the transient. A fairly large time step was found adequate during the preheat stage of the TREAT transient. However, during the subsequent burst, a time step smaller by an order of magnitude is needed to follow the rapid changes in temperature and stress. The COBRA-IIIM code generally uses backward time and space differences with associated errors in evaluation of material properties and forcing functions. Several places in the code have been modified to use more accurate average values. One limitation in COBRA-IIIM is that the latent heat of fusion is not adequately taken into account. The temperature of a melting-fuel zone is allowed to rise without allowing for the latent heat sink. Thus the heat transfer out of a partially molten zone to its neighbor is too large. Temperatures are adjusted at the output stage to partially correct the results but the heat-transfer error is not corrected. 


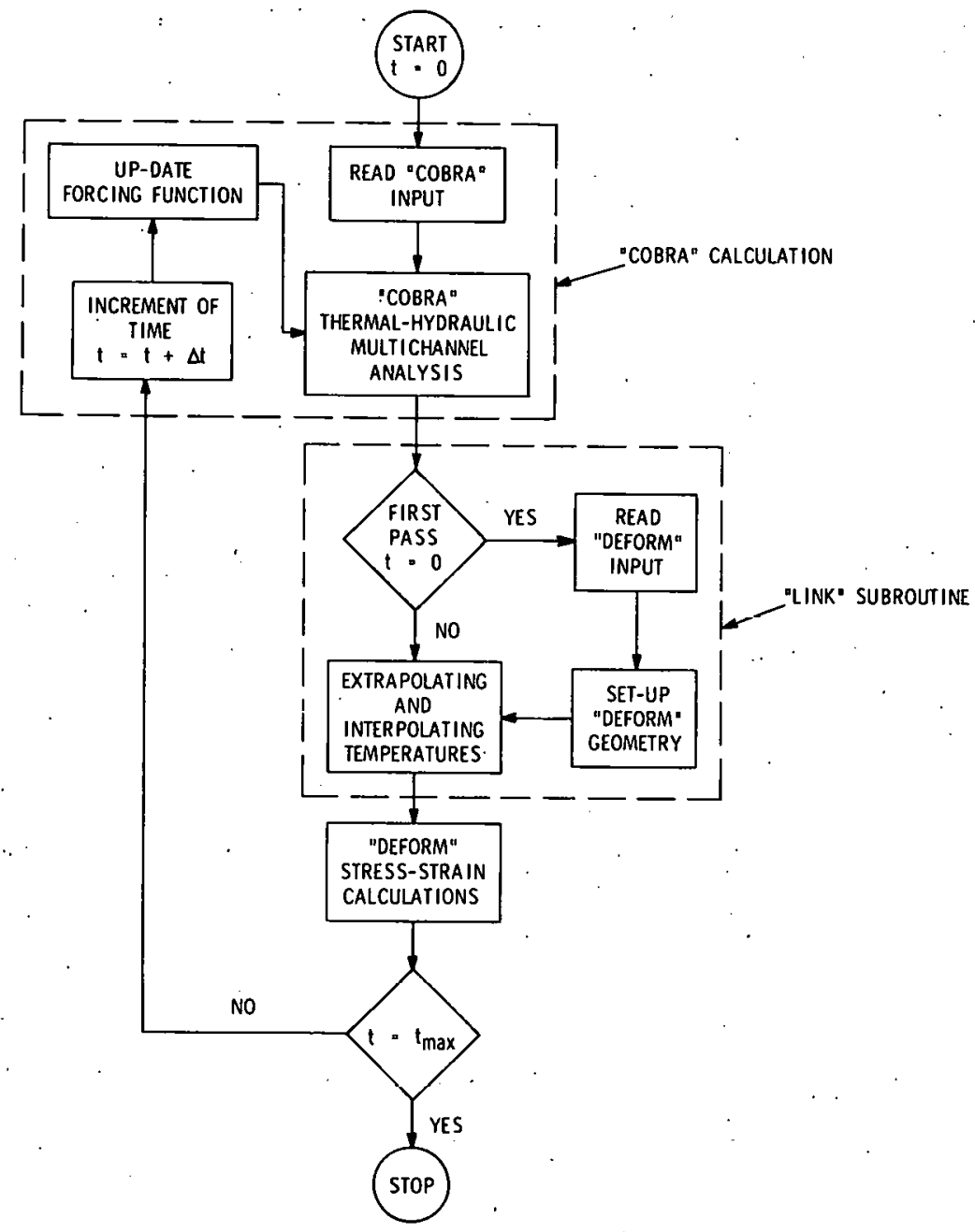

Fig. B.1. Simplified Flow Diagram of COBRA/DEFORM Linkage 


\section{APPENDIX C}

\section{Input Data for COBRA Thermal-Hydraulic Calculations}

This appendix contains the input data for the COBRA thermal-hydraulic calculations, the results of which are presented throughout the rest of this report. An attempt has been made to have a uniform consistent set of input data whenever the TOP tests have features in common. The data are not presented in a form similar to the actual COBRA input format, but are presented in numerous, largely self-explanatory tables in order to emphasize the common features.

Table C.l contains properties of sodium taken from Golden and Tokar. ${ }^{18}$ Table C. 2 contains cladding and fuel properties. In COBRA the duct wall is assumed to have the same thermal conductivity and specific heat as the cladding. Table C. 3 contains hydraulic parameters common to all calculations. The system pressure of $2.07 \mathrm{MPa}$ is used to suppress boiling for as long as convenient, since the boiling correlations in the present version of COBRA are not adequate to handle sodium boiling. When interpreting the computed results, we assume boiling occurs whenever the temperature in any subchannel cell reaches the saturation temperature for the actual system pressure.

TABLE C.l. Sodium Properties

\begin{tabular}{|c|c|c|c|c|c|c|c|c|}
\hline $\begin{array}{c}\text { Pressure } \\
\text { kPa }\end{array}$ & $\begin{array}{c}\text { Temp } \\
\qquad K\end{array}$ & $\begin{array}{c}\text { Liquid } \\
\text { Specific } \\
\text { Volume } \\
\mathrm{m}^{3} / \mathrm{kg}\end{array}$ & $\begin{array}{l}\text { Vapor } \\
\text { Specific } \\
\text { Volume, } \\
\mathrm{m}^{3} / \mathrm{kg}\end{array}$ & $\begin{array}{c}\text { Liquid } \\
\text { Enthalpy, } \\
\mathrm{J} / \mathrm{g}\end{array}$ & $\begin{array}{c}\text { Vapor } \\
\text { Enthalpy, } \\
\mathrm{J} / \mathrm{g}\end{array}$ & $\begin{array}{l}\text { Liquid } \\
\text { Viscosity, } \\
\mathrm{kg} / \mathrm{h} \cdot \mathrm{m}\end{array}$ & $\begin{array}{c}\text { Tiquid } \\
\text { Thermal } \\
\text { Conductivity, } \\
\mathrm{J} / \mathrm{mm} \cdot \mathrm{K}\end{array}$ & $\begin{array}{c}\text { Iiquid } \\
\text { Surface } \\
\text { Tension, } \\
\mathrm{kg} / \mathrm{m}\end{array}$ \\
\hline 0.000 & 583.15 & 0.001139 & 62427.901 .53 & 772.00 & 5164.93 & 1.2118 & 273.8 .369 & 0.01792 \\
\hline 0.007 & 616.48 & 0.001150 & 25587.09988 & 815.24 & 5181.35 & 1.1248 & 267.7932 & 0.01758 \\
\hline 0.02 & 644.26 & 0.001159 & 11119.7938 & 851.04 & 5196.59 & 1.0623 & 262.8086 & 0.01729 \\
\hline .0 .048 & 672.04 & 0.001167 & 5187.88866 & 886.65 & 5210.66 & 1.0070 & 257.8864 & 0.01701 \\
\hline 0.097 & 699.82 & 0.001177 & 2576.15236 & 922.10 & 5223.66 & 0.95793 & 253.0888 & 0.01673 \\
\hline 0.17 & 722.04 & 0.001184 & 1531.54524 & 950.36 & 5233.36 & 0.92236 & 249.2258 & 0.01650 \\
\hline 0.28 & 744.26 & 0.001192 & 940.16514 & 978.53 & 5242.50 & 0.88992 & 245.4251 & 0.01628 \\
\hline 0.45 & 766.48 & 0.001199 & 594.25179 & 1006.6 & 5251.11 & 0.85941 & 241.6867 & 0.01604 \\
\hline 0.57 & 777.59 & 0.001203 & 477.26178 & 1020.6 & 5255.25 & 0.84572 & 239.8799 & 0.01594 \\
\hline 0.689 & 788.71 & 0.001207 & 385.80482 & 1034.7 & 5259.30 & 0.83218 & 238.0107 & 0.01582 \\
\hline 0.896 & 799.82 & 0.001211 & 313.76295 & 1048.7 & 5263.23 & 0.81909 & 236.2037 & 0.01572 \\
\hline 1.10 & 810.928 & 0.001215 & 256.64136 & 1062.7 & 5267.09 & 0.80644 & 234.3346 & 0.01560 \\
\hline 1.38 & 822.039 & 0.001219 & 211.13137 & 1076.6 & 5270.86 & 0.79438 & 233.1508 & 0.01548 \\
\hline 1.65 & 833.150 & 0.001223 & 174.67344 & 1090.6 & 5274.55 & 0.78263 & 230.7208 & 0.01537 \\
\hline 2.00 & 844.261 & 0.001227 & $145.20744^{\circ}$ & 1104.6 & 5278.21 & 0.77132 & 228.9139 & 0.01525 \\
\hline 2.41 & 855.372 & 0.001230 & 121.35996 & 1118.5 & 5281.76 & 0.76045 & 227.1693 & 0.01513 \\
\hline 3.24 & 866.483 & 0.001235 & 101.88244 & 1132.5 & 5285.30 & 0.74989 & 225.3625 & 0.01503 \\
\hline 3.72 & 877.594 & 0.001239 & 85.90088 & 1146.4 & 5288.77 & 0.73962 & 223.6179 & 0.01491 \\
\hline 4.21 & 888.706 & 0.001243 & 72.79101 & 1160.4 & 5292.21 & 0.72980 & 221.8732 & 0.0148 \\
\hline 4.96 & 899.817 & 0.001247 & 61.92854 & 1174.3 & 5295.60 & 0.72027 & 220.1286 & 0.0147 \\
\hline 5.86 & 910.928 & 0.001252 & 52.87649 & 1188.3 & 5298.98 & 0.71104 & 218.3841 & 0.0146 \\
\hline 6.895 & 922.039 & 0.001255 & 45.38513 & 1202.2 & 5302.35 & 0.70197 & 216.7019 & 0.0145 \\
\hline 14.48 & 977.594 & 0.001277 & 72.22436 & 1272.0 & 5318.91 & 0.66104 & 208.2282 & 0.0139 \\
\hline 28.96 & 1033.15 & 0.001300 & 11.80513 & 1342.0 & 5335.52 & 0.62562 & 200.0660 & 0.0133 \\
\hline 53.78 & 1088.71 & 0.001323 & 6.70476 & 1412.4 & 5352.36 & 0.59452 & 192.1531 & 0.0128 \\
\hline 96.527 & 1144.26 & 0.001347 & 4.03472 & 1483.3 & 5369.50 & 0.56714 & 184.4894 & 0.0122 \\
\hline 151.68 & 1199.82 & 0.001372 & 2.57515 & 1554.9 & 5389.23 & 0.54273 & 177.0749 & 0.0116 \\
\hline 234.42 & 1255.37 & 0.001397 & 1.71053 & .1627 .4 & 5408.51 & 0.52101 & 169.9096 & 0.0111 \\
\hline 351.63 & 1310.93 & 0.001424 & 1.17802 & 1700.9 & 5427.44 & 0.50121 & 163.0560 & 0.0105 \\
\hline .2206 .32 & 1644.26 & 0.001608 & 0.21475 & 2172.0 & 5516.95 & 0.41445 & 127.2298 & 0.00708 \\
\hline
\end{tabular}


.TABLE C.2. Fuel and Cladding Properties

\begin{tabular}{|c|c|c|c|c|}
\hline Temp, $\mathrm{K}$ & 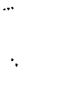 & $\begin{array}{r}\text { Thermal Condu } \\
\mathrm{J} / \mathrm{h} \cdot \mathrm{mm} \cdot \mathrm{I}\end{array}$ & $\begin{array}{l}\text { Ictivity, } \\
\text { K }\end{array}$ & $\begin{array}{c}\text { Specific Heat, } \\
\text { J.kg.K }\end{array}$ \\
\hline$\cdot$ & & Cladding and & Duct Wall & . \\
\hline 294.0 & & 51.8 & . & 28.7 \\
\hline 422.0 & & $: 58.3 \cdot$ & & 31.9 \\
\hline 588.7 & 。 & 66.67 & & 34.0 \\
\hline 644.3 & ${ }^{\circ}$ & 69.47 & 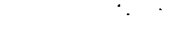 & 34.6 \\
\hline 699.8 & & 72.28 & & 35.1 \\
\hline 755.4 & & 75.08 & & 35.6 \\
\hline 810.93 & & 77.88 & & 36.4 \\
\hline 866.48 & & 80.69 & & 37.0 \\
\hline 922.04 & $\therefore$ & 83.49 & & 37.5 \\
\hline 977.59 & & 86.29 & & 38.3 \\
\hline 1033.2 & & 89.10 &. & 39.1 \\
\hline 1644.3 & & 89.10 & & 39.1 \\
\hline
\end{tabular}

Cladding-expansion Coeff $=0.8462 \times 10^{-5}+\left(0.2106 \times 10^{-8}\right) \mathrm{T}[\mathrm{K}]$

Fuel (Tcst E3 - UO

$\begin{array}{ccc}298.0 & 26.9 & \\ 473.2 & 21.1 & 20.9 \\ 673.2 & 17.0 & 20.2 \\ 873.15 & 14.1 & 19.6 \\ 1073.2 & 12.2 & 19.4 \\ 1273.2 & 10.7 & 19.5 \\ 1473.2 & 9.66 & 19.9 \\ 1673.2 & 8.97 & 20.6 \\ 1873.2 & 8.41 & 21.7 \\ 2073.2 & 7.98 & 23.1 \\ 2273.2 & 7.66 & 24.7 \\ 3113.2 & 7.66 & 26.73 \\ 3113.7 & 7.66 & 42.25 \\ 5255.4 & 7.66 & 31.89 \\ \end{array}$

Fuel-expansion Coeff $=0.33081 \times 10^{-5}+\left(0.16092 \times 10^{-8}\right) \mathrm{T}[\mathrm{K}]$

Fuel (Mixed-oxide Tests $\mathrm{H} 2, \mathrm{H} 3, \mathrm{H} 4, \mathrm{H} 5, \mathrm{E} 4, \mathrm{E} 6, \mathrm{E} 7$ )

$\begin{array}{rcl}298.0 & 25.6 & 11.1 \\ 699.8 & 13.0 & 15.2 \\ 1099.8 & 8.85 & 18.8 \\ 1399.8 & 7.35 & 21.2 \\ 1799.8 & 6.42 & 24.0 \\ 2199.8 & 617 & 26.3 \\ 2499.8 & 6.42 & 27.80 \\ 2699.8 & 6.79 & 28.65 \\ 2899.8 & 7.29 & 29.39 \\ 3033.2 & 7.66 & 29.82 \\ 3088.7 & 9.35 & 31.89 \\ 4699.8 & 9.35 & 31.89\end{array}$

Fuel-expansion Coeff $=0.33434 \times 10^{-5}+\left(0.1647 \times 10^{-8}\right) \mathrm{T}[\mathrm{K}]$

TABLE C.3. Hydraulic Parameters Common to All Tésts

\begin{tabular}{ll}
\hline System pressure & $2.07 \mathrm{MPa}$ \\
Friction factor & $0.316 \mathrm{Re}^{-0.25}$ \\
Crossfluw resistance & 0.5 \\
Momentum turbulent factor & 0 \\
Turbulent mixing factor $(\beta)$ & 0.0125 \\
ConducLion! geometry factor & 2.0 \\
Subcooled void correlation & $\mathrm{Not} \mathrm{Used}$ \\
Film-coefficient correlation & $\mathrm{Nu}=5.87+0.021 \mathrm{Pe}^{0.8}$ \\
\hline
\end{tabular}


Tables C. 4 and C.5 show the input and results of a limited sensitivity study on the choice of some of the parameter values in Table C.3. The calculations were performed using a set of input data for Test H5 somewhat different from the data in this appendix. The results are generally not very sensitive to the choice of these hydraulic parameters, but the results are sensitive to the size of the heat sink provided by the duct wall. Although this sensitivity study is not extensive, it shows that some freedom is available in the choice of parameters. This is especially important since there have not been any extensive hydraulic tests of the Mark-II loop with which to calibrate COBRA calculations.

TABLE C.4. Input Parameters for Sensitivity Calculations

\begin{tabular}{|c|c|c|c|c|c|c|}
\hline Case No. & $\begin{array}{c}\text { Turbulent } \\
\text { Crossflow, } \\
\beta\end{array}$ & $\begin{array}{l}\text { Conduction } \\
\text { Geometry } \\
\text { Factor, Kg }\end{array}$ & $\begin{array}{l}\text { Turbulent } \\
\text { Momentum } \\
\text { Factur, } f_{t}\end{array}$ & $\begin{array}{l}\text { Crossflow } \\
\text { Resiotanco }\end{array}$ & $\begin{array}{c}\text { Duct-wall } \\
\text { Thickness, } \\
\text { mm }\end{array}$ & $\begin{array}{c}\text { Heat-transfer } \\
\text { Coefficient } \\
\text { to Bypass, } \\
\left(\mathrm{T} / \mathrm{h} \cdot \mathrm{mm}^{2} \cdot \mathrm{K}\right)\end{array}$ \\
\hline 1 (Ref.) & 0.0125 & 2 & 0 & 0.5 & 0.89 & 0.20 \\
\hline 2 & 0.00625 & $2^{\circ}$ & 0 & 0.5 & 0.89 & 0.20 \\
\hline 3 & 0.025 & 2 & 0 & 0.5 & 0.89 & 0.20 \\
\hline 4 & 0.0125 & 0 & 0 & 0.5 & 0.89 & 0.20 \\
\hline 5 & 0.0125 & 4 & 0 & 0.5 & 0.89 & 0.20 \\
\hline 6 & 0.0125 & 2 & 0.5 & 0.5 & 0.89 & 0.20 \\
\hline 7 & 0.0125 & 2 & 1.0 & 0.5 & 0.89 & 0.20 \\
\hline 8 & 0.0125 & 2 & 0 & 0.25 & 0.89 & 0.20 \\
\hline 9 & 0.0125 & 2 & 0 & 1.0 & 0.89 & 0.20 \\
\hline 10 & 0.0125 & 2 & 0 & 0.5 & 1 & 0.20 \\
\hline 11 & 0.0125 & 2 & 0 & 0.5 & 2.5 & 0.20 \\
\hline 12 & 0.0125 & 2 & 0 & 0.5 & 0.89 & 0.02 \\
\hline 13 & 0.0125 & .2 & 0 & 0.5 & $\dot{0} .89$ & 2.04 \\
\hline
\end{tabular}

IABLE C.5. Resulls Crum Seirsitivity Calculatione

(Test $\mathrm{H} 5$ at approximate time of failure)

\begin{tabular}{|c|c|c|c|c|c|c|}
\hline \multirow[b]{2}{*}{ Case No. } & \multirow{2}{*}{$\begin{array}{c}\text { Max Fuel } \\
\text { Enthalpy at } \\
\text { Central Pin, } \\
\mathrm{J} / \mathrm{g}\end{array}$} & \multirow{2}{*}{$\begin{array}{c}\text { Midcladding } \\
\text { Temp, } \mathrm{K} \\
\text { (Central } \\
\text { pin at top } \\
\text { of fuel } \\
\text { column) }\end{array}$} & \multirow{2}{*}{$\begin{array}{c}\text { Avg Uutlet } \\
\text { Temp, } \\
\text { K }\end{array}$} & \multicolumn{3}{|c|}{ Dutlet Temp, K } \\
\hline & & & & Channel 1 & Channel 2 & Channel 3 \\
\hline 1 (Ref.) & 770.0 & 1092.1 & 904.32 & 931.82 & 899.54 & 884.21 \\
\hline 2 & 771.2 & 1099.4 & 903.09 & 944.37 & 897.15 & 878.37 \\
\hline 3 & 767.9 & 1080.5 & 902.09 & 919.26 & 901.15 & 890.43 \\
\hline 4 & 771.6 & 1102.8 & 903.71 & 951.32 & 904.26 & 869.32 \\
\hline 5 & 768.3 & 1083.7 & 902.15 & 922.21 & 899.48 & 889.87 \\
\hline 6 & 770.0 & 1092.1 & 902.59 & 932.09 & 899.21 & 884.48 \\
\hline 7 & 770.0 & 1092.3 & 902.54 & 932.15 & 899.04 & 884.59 \\
\hline 8 & 770.0 & 1092.1 & 902.65. & 931.82 & 899.54 & 884.21 \\
\hline 9 & 770.0 & 1092.1 & 902.65 & 931.82 & 894.54 & 884.21 \\
\hline 10 & 769.5 & 1089.3 & 876.93 & 916.26 & 872.32 & 852.59 \\
\hline 11 & 768.7 & 1080.4 & 810.9 & 872.76 & 802.4 & 774.0 \\
\hline 12 & 770.0 & 1092.1 & 903.65 & 932.37 & 900.59 & 885.43 \\
\hline 13 & 770.0 & 1091.2 & 893.54 & 926.59 & 176.4 & 872.71 \\
\hline
\end{tabular}


Figures C.1-C.4 are schematic diagrams of the fuel-pin and subchannel layout illustrating the nomenclature used in Tables C.6 and C.8. The relevant dimensions required by COBRA are shown in Tables C.6 and C.7. The heat-flux distribution from pin to pin is shown in Table C.8 and within each pin sector in Tables C.9 and C.10. Table C.1l contains miscellaneous input data on the fuel pins, duct wall, and sodium flow. The initial inlet temperatures and inlet mass flow are taken from the actual test data, and the heat transfer to bypass sink is assumed to remain at the initial inlet temperature. Tables C.12 and C.13 contain the forcing functions for TREAT power and inlet enthalpy taken from the test data. The inlet mass flow is assumed to remain at its initial value.

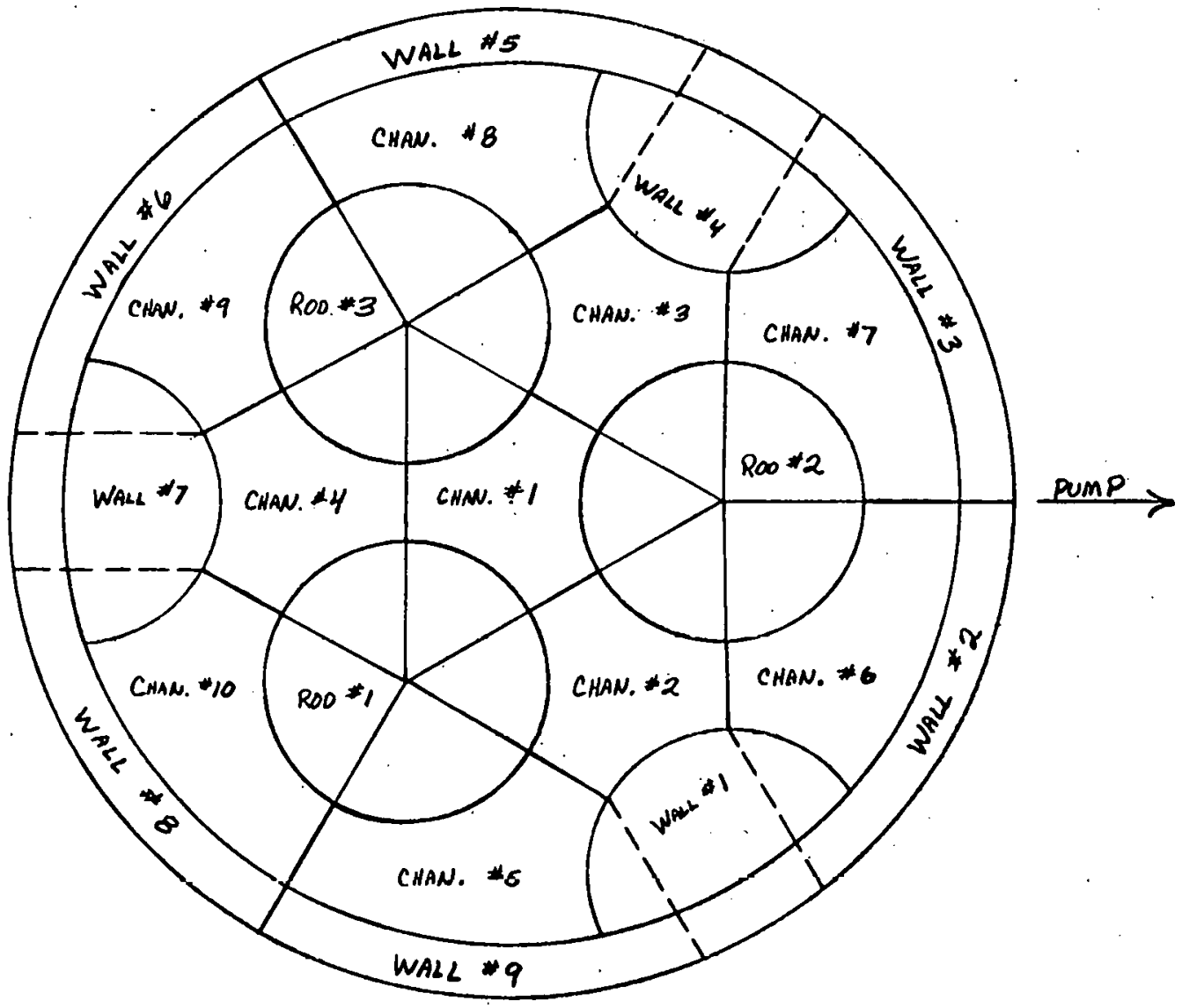

Fig. C.1. Rod and Channel Layout Used in COBRA Calculations for Test E3 (Not to scale)

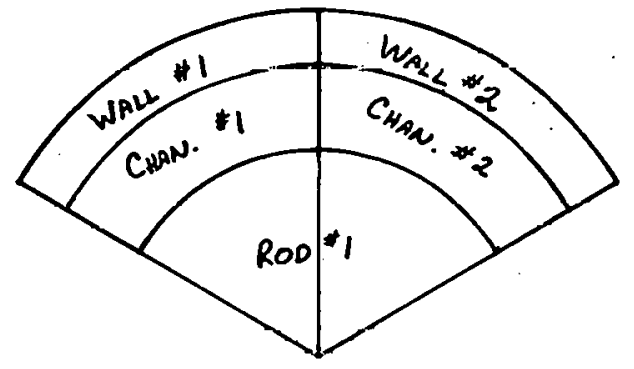

Fig. C.2

Rod and Channel Layout Used in COBRA Calculations for Tests $\mathrm{H} 2$ and $\mathrm{E} 4$ (Not to scale) 


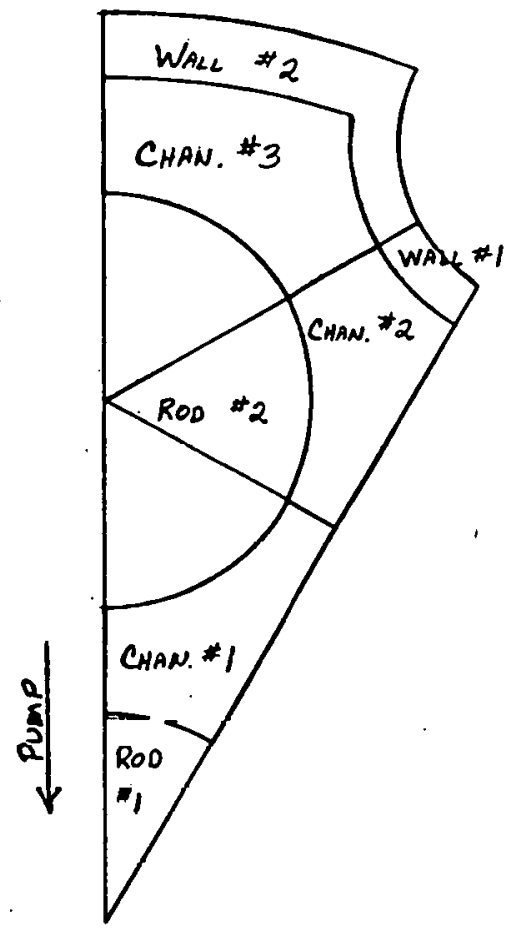

Fig. C.3

Rod and Channel Layout Used

in COBRA Calculations for

Tests H3 and H5 (Not to scale)

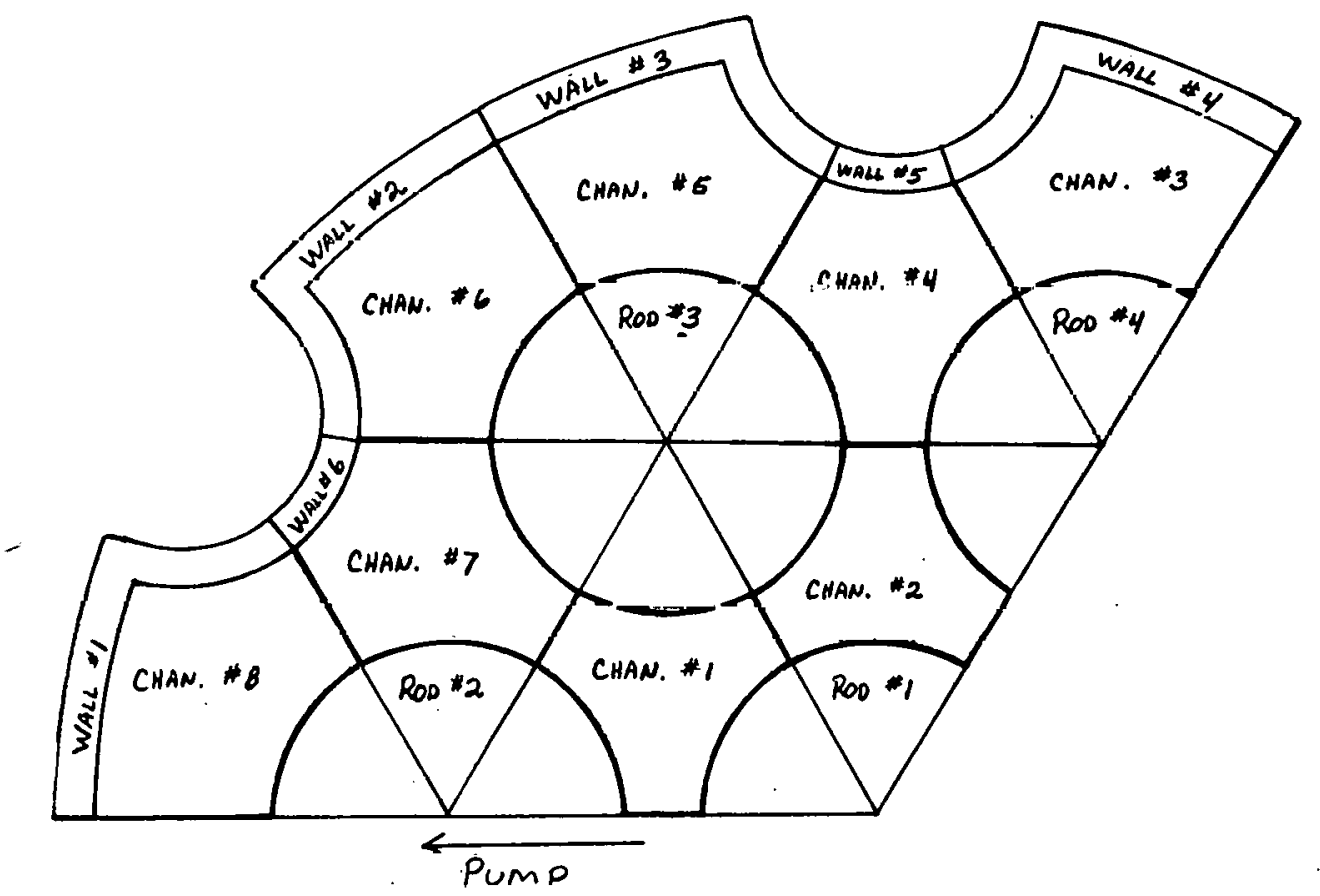

Fig. C.4. Rod and Channel Layout Used in COBRA Calculations for Tests E6 and E7 (Not to scale) 
TABLE C.6. Subchannel Input Data

\begin{tabular}{|c|c|c|c|c|c|}
\hline Test $(s)$ & $\begin{array}{c}\text { Channel } \\
\text { No. }\end{array}$ & $\begin{array}{c}\text { Area, } \\
\mathrm{mm}^{2}\end{array}$ & $\begin{array}{c}\text { Wetted } \\
\text { Perimeter } \\
\text { mm }\end{array}$ & $\begin{array}{c}\text { Heated } \\
\text { Perimeter, } \\
\text { mm }\end{array}$ & $\begin{array}{c}\text { Hydraulic } \\
\text { Diameter, } \\
\text { mm }\end{array}$ \\
\hline $\mathrm{H} 2$ and $\mathrm{E} 4$ & $\begin{array}{l}1 \\
2\end{array}$ & $\begin{array}{l}4.4 \\
4.4\end{array}$ & $\begin{array}{l}7.927 \\
7.927\end{array}$ & $\begin{array}{l}3.058 \\
3.058\end{array}$ & $\begin{array}{l}2.21 \\
2.21\end{array}$ \\
\hline $\mathrm{H} 3$ and $\mathrm{H} 5$ & $\begin{array}{l}1 \\
2 \\
3\end{array}$ & $\begin{array}{l}4.2 \\
4.5 \\
6.4\end{array}$ & $\begin{array}{l}5.66 \\
5.33 \\
8.94\end{array}$ & $\begin{array}{l}4.60 \\
3.07 \\
3.05\end{array}$ & $\begin{array}{l}2.959 \\
3.386 \\
2.858\end{array}$ \\
\hline E3 & $\begin{array}{r}1 \\
2 \\
3 \\
4 \\
5 \\
6 \\
7 \\
8 \\
9 \\
10\end{array}$ & $\begin{array}{l}7.03 \\
7.23 \\
7.23 \\
7.23 \\
8.97 \\
8.97 \\
8.97 \\
8.97 \\
8.97 \\
8.97\end{array}$ & $\begin{array}{l}8.89 \\
8.26 \\
8.26 \\
8.26 \\
11.8 \\
11.8 \\
11.8 \\
11.8 \\
11.8 \\
11.8\end{array}$ & $\begin{array}{l}6.942 \\
4.628 \\
4.628 \\
4.628 \\
3.472 \\
3.472 \\
3.472 \\
3.472 \\
3.472 \\
3.472\end{array}$ & $\begin{array}{l}3.162 \\
3.500 \\
3.500 \\
3.500 \\
3.035 \\
3.035 \\
3.035 \\
3.035 \\
3.035 \\
3.035\end{array}$ \\
\hline E6 & $\begin{array}{l}1 \\
2 \\
3 \\
4 \\
5 \\
6 \\
7 \\
8\end{array}$ & $\begin{array}{l}8.39 \\
8.39 \\
6.32 \\
8.71 \\
6.3 \\
6.3 \\
8.71 \\
6.32\end{array}$ & $\begin{array}{c}11.33 \\
11.33 \\
9.380 \\
10.61 \\
9.380 \\
9.380 \\
10.61 \\
9.380\end{array}$ & $\begin{array}{l}9.177 \\
9.177 \\
3.058 \\
6.116 \\
3.058 \\
3.058 \\
6.116 \\
3.058\end{array}$ & $\begin{array}{l}2.959 \\
2.959 \\
2.695 \\
3.282 \\
2.695 \\
2.695 \\
3.282 \\
2.695\end{array}$ \\
\hline E7 & $\begin{array}{l}1 \\
2 \\
3 \\
4 \\
5 \\
6 \\
7 \\
8\end{array}$ & $\begin{array}{l}6.58 \\
6.58 \\
6.52 \\
7.29 \\
6.52 \\
6.52 \\
7.29 \\
6.52\end{array}$ & $\begin{array}{c}10.77 \\
10.77 \\
8.7 .30 \\
9.167 \\
8.730 \\
8.730 \\
9.167 \\
8.730\end{array}$ & $\begin{array}{l}9.177 \\
9.177 \\
3.058 \\
6.116 \\
3.058 \\
3.058 \\
6.116 \\
3.058\end{array}$ & $\begin{array}{l}2.44 \\
2.44 \\
2.985 \\
3.180 \\
2.985 \\
2.985 \\
3.180 \\
2.985\end{array}$ \\
\hline
\end{tabular}

TABLE C.7. Duct-wall Lengths of Contact ( $\mathrm{mm}$ )

\begin{tabular}{cccccccc}
\hline Segment No. & E3 & E4 & H2 & H3 & H5 & E6 & E7 \\
\hline 1 & 2.31 & 0.36 & 0.36 & 1.5 & 1.5 & 0.16 & 0.43 \\
$亡$ & 7.338 & 0.36 & 0.36 & 5.18 & 5.18 & 0.46 & 0.43 \\
3 & 7.338 & - & - & - & - & 0.46 & 0.43 \\
4 & 2.31 & - & - & - & - & 0.46 & 0.43 \\
5 & 7.338 & - & - & - & - & 0.25 & 0.25 \\
6 & 7.338 & - & - & - & - & 0.25 & 0.25 \\
7 & 2.31 & - & - & - & - & - & - \\
8 & 7.338 & - & - & - & - & - & - \\
$y$ & 7.338 & - & - & - & - & - & - \\
\hline
\end{tabular}


TABLE C.8. Radial Power Factors (Calibration constant)

\begin{tabular}{|c|c|c|c|c|c|c|c|}
\hline Pin No. & E3 & E4 & $\mathrm{H} 2$ & $\mathrm{H} 3$ & H5 & $\mathrm{E} 6$ & E7 \\
\hline 1 & 1.83 & 3.135 & 3.135 & 1.52 & 1.52 & 1.634 & 1.634 \\
\hline 2 & 1.57 & $\therefore$ & - & 2.05 & 2.05 & 1.586 & 1.672 \\
\hline 3 & 1.87 & - & - & - & - & 1.871 & 1.995 \\
\hline 4 & - . & - & - & - & - & 2.052 & 2.194 \\
\hline
\end{tabular}

TABLE C.9. Axial Distribution of Heat Flux

\begin{tabular}{|c|c|c|c|c|c|}
\hline \multicolumn{2}{|c|}{ Test E3 } & \multicolumn{2}{|c|}{ Tests $\mathrm{H} 2$ and $\mathrm{E} 4$} & \multicolumn{2}{|c|}{$\begin{array}{c}\text { Tests } \mathrm{H} 3, \mathrm{H} 5, \\
\mathrm{E} 6, \text { and } \mathrm{E} 7\end{array}$} \\
\hline $\mathrm{X} / \mathrm{L}$ & $\begin{array}{l}\text { Relative } \\
\text { Flux }\end{array}$ & $\mathrm{X} / \mathrm{L}$ & $\begin{array}{l}\text { Relative } \\
\text { Flux }\end{array}$ & $\mathrm{X} / \mathrm{L}$ & $\begin{array}{l}\text { Rclative } \\
\text { Flux }\end{array}$ \\
\hline 0 & $1: 039$ & 0 & 0.849 & 0 & 0.810 \\
\hline 0.067 & 1.022 & 0.071 & 0.925 & 0.071 & 0.950 \\
\hline 0.133 & 1.000 & 0.143 & $0 . \dot{9} 75$ & 0.143 & 0.990 \\
\hline 02.00 & 0.977 & 0.214 & 1.000 & 0.214 & 1.000 \\
\hline 0.267 & 0.967 & 0.286 & 1.012 & 0.286 & 0.990 \\
\hline 0.333 & 0.965 & 0.357 & 1.031 & 0.357 & 0.960 \\
\hline 0.400 & 0.995 & 0.429 & 0.997 & 0.429 . & 0.820 \\
\hline 0.467 & 1.008 & 0.500 & 0 & 0.500 & 0 \\
\hline 0.533 & 1.020 & 1. & 0 & 1. & 0 \\
\hline 0.600 & 1.039 & & & & \\
\hline 0.667 & 0 & & & & \\
\hline 1. & 0 & & & & \\
\hline
\end{tabular}


TABLE C.10. Radial Power Distribution in Fuel

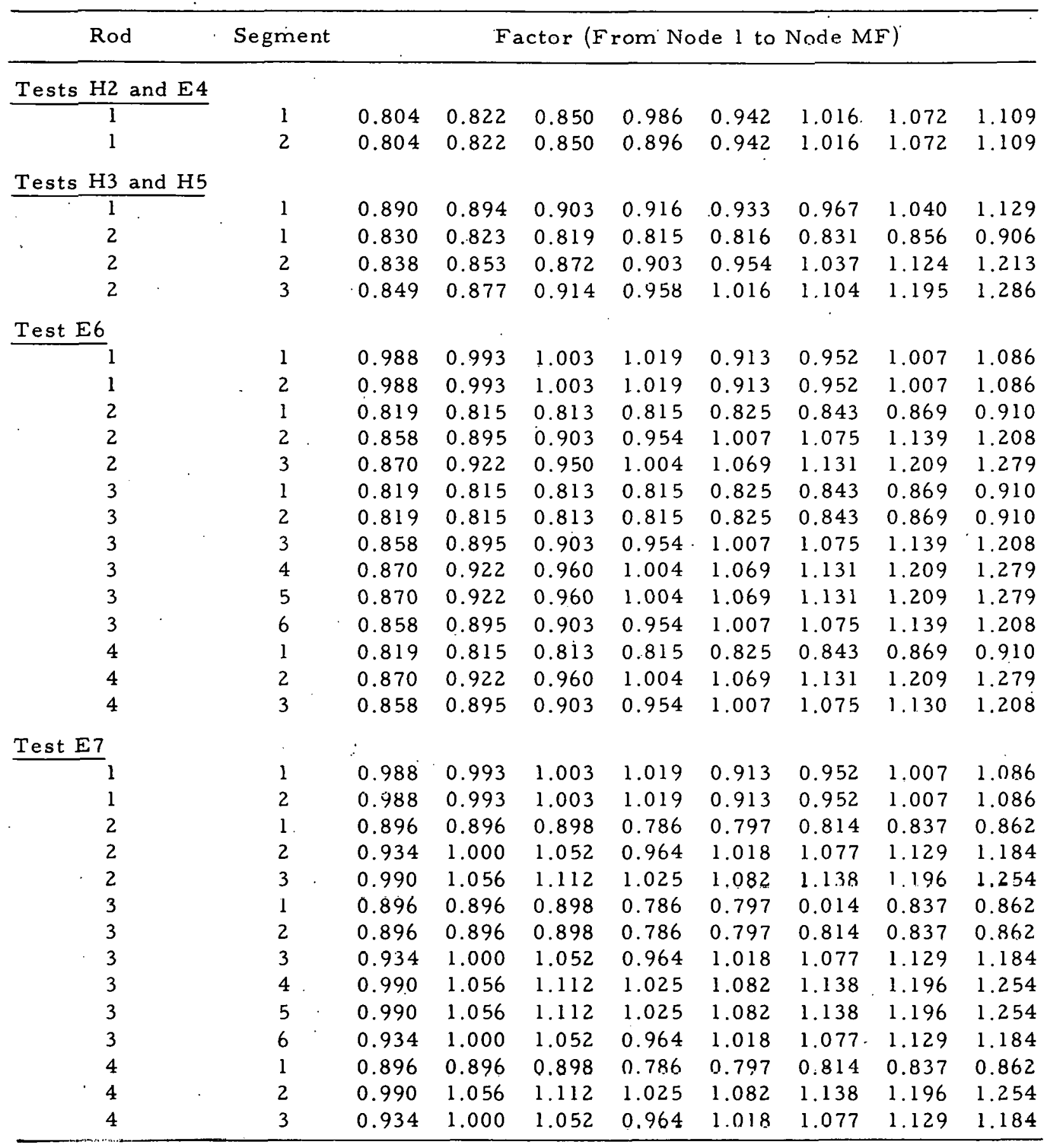


TABLE C.1l. Miscellaneous Input Data

\begin{tabular}{|c|c|c|c|c|c|c|c|}
\hline Fuel Pin & E3 & E4 & $\mathrm{H} 2$ & $\mathrm{H3}$ & $\mathrm{H} 5$ & E6 & E7 \\
\hline $\begin{aligned} \text { Diameter: } & \text { Fuel } O D=\text { Cladding } 10, \mathrm{~mm} \\
& \text { Central void, } \mathrm{mm} \\
& \text { Cladding } O D, \mathrm{~mm}\end{aligned}$ & $\begin{array}{l}3.96 \\
0.51 \\
4.42\end{array}$ & $\begin{array}{l}5.08 \\
0.0 \\
5.84\end{array}$ & $\begin{array}{l}5.08 \\
0.0 \\
5.84\end{array}$ & $\begin{array}{l}5.08 \\
0.0 \\
5.84\end{array}$ & $\begin{array}{l}5.08 \\
0.0 \\
5.84\end{array}$ & $\begin{array}{l}5.08 \\
1.2 \\
5.84\end{array}$ & $\begin{array}{l}5.08 \\
1.2 \\
5.84\end{array}$ \\
\hline $\begin{array}{l}\text { Density: Fuel, } \mathrm{kg} / \mathrm{m}^{3} \\
\text { Cladding, } \mathrm{kg} / \mathrm{m}^{3}\end{array}$ & $\begin{array}{l}9500 \\
7980\end{array}$ & $\begin{array}{l}9770 \\
7980\end{array}$ & $\begin{array}{l}9770 \\
7980\end{array}$ & $\begin{array}{l}9770 \\
7980\end{array}$ & $\begin{array}{l}9770 \\
7980\end{array}$ & $\begin{array}{l}9770 \\
7980\end{array}$ & $\begin{array}{l}9770 \\
7980\end{array}$ \\
\hline $\begin{array}{ll}\text { Radial nodes: } & \text { Number in fuel } \\
& \text { Fuel-node type } \\
& \text { Numbcr in cladding } \\
& \text { Cladding-node type }\end{array}$ & $\begin{array}{l}8 \\
\text { Equal } \Delta r \\
6 \\
\text { Equal } \Delta r\end{array}$ & $\begin{array}{c}8 \\
\text { Equal } \Delta r \\
5 \\
\text { Equal } \Delta r\end{array}$ & $\begin{array}{l}8 \\
\text { Equal } \Delta r \\
5 \\
\text { Equal } \Delta r\end{array}$ & $\begin{array}{l}8 \\
\text { Equal } \Delta r \\
5 \\
\text { Equal } \Delta r\end{array}$ & $\begin{array}{c}8 \\
\text { Equal } \Delta r \\
5 \\
\text { Equal } \Delta r\end{array}$ & $\begin{array}{l}8 \\
\text { Equal } \Delta r \\
5 \\
\text { Equal } \Delta r\end{array}$ & $\begin{array}{c}8 \\
\text { Equal } \Delta r \\
5 \\
\text { Equal } \Delta r\end{array}$ \\
\hline Fuel-column length, m & 0.14 & 0.343 & 0.343 & 0.343 & 0.343 & 0.343 & 0.343 \\
\hline Number of axial nodes in fuel & 10 & 7 & 1 & $T$ & 7 & 7 & 7 \\
\hline$T$ sulidus, $K$ & 3058 & $3 n 33$ & 3033 & 3033 & 3033 & 3033 & 3033 \\
\hline$T$ liquidus, $K$ & 3058 & 3089 & 3089 & 3033 & 3033 & 3033 & 3033 \\
\hline Heat of fusion, $\mathrm{J} / \mathrm{g}$ & 274 & 274 & 274 & 274 & 274 & 274 & 274 \\
\hline Specific heat during fusion, $\mathrm{J} / \mathrm{kg} \cdot \mathrm{K}$ & 0.5033 & 0.5033 & 0.5033 & 0.5033 & 0.5033 & 0.5033 & 0.5033 \\
\hline $\begin{array}{l}\text { Initial radial-gap sizes, mm } \\
\text { Central pin } \\
\text { Edge pin }\end{array}$ & $\begin{array}{l}0.04 \mathrm{l} \\
-\end{array}$ & $\begin{array}{c}0.08 \\
-\end{array}$ & 0.08 & $\begin{array}{l}0.019 \\
0.08\end{array}$ & $\begin{array}{l}0.019 \\
0.08\end{array}$ & $\begin{array}{l}0.08 \\
0.08\end{array}$ & $\begin{array}{l}0.08 \\
0.08\end{array}$ \\
\hline $\begin{array}{l}\text { Radial jump distance, } \mathrm{mm} \\
\text { Central pin } \\
\text { Edge pin }\end{array}$ & 0.008 & $\begin{array}{l}0.02 \\
-\end{array}$ & $\begin{array}{c}0.02 \\
-\end{array}$ & $\begin{array}{l}0.008 \\
0.02\end{array}$ & $\begin{array}{l}0.008 \\
0.02\end{array}$ & $\begin{array}{l}0.008 \\
0.02\end{array}$ & $\begin{array}{l}0.008 \\
0.000\end{array}$ \\
\hline $\begin{array}{l}\text { Initial gap conductance, } \mathrm{J} / \mathrm{h} \cdot \mathrm{nm}^{2} \cdot \mathrm{K} \\
\text { Comfral pin } \\
\text { Edqu pin }\end{array}$ & 10.6 & $\begin{array}{c}15.3 \\
-\end{array}$ & $\begin{array}{c}15.3 \\
-\end{array}$ & $\begin{array}{l}5.72 \\
13.3\end{array}$ & $\begin{array}{l}5.72 \\
15.3\end{array}$ & $\begin{array}{l}9.20 \\
15.3\end{array}$ & $\begin{array}{l}9.20 \\
9.20\end{array}$ \\
\hline $\begin{array}{l}\text { Max gap conductance, } \mathrm{J} / \mathrm{h} \cdot \mathrm{mm}^{2} \cdot \mathrm{K} \\
\text { Ccntrol pin } \\
\text { Fige pin }\end{array}$ & 87.89 & $\begin{array}{c}112.4 \\
-\end{array}$ & $\begin{array}{c}112.4 \\
-\end{array}$ & $\begin{array}{l}40.47 \\
112.4\end{array}$ & $\begin{array}{l}40.47 \\
112.4\end{array}$ & $\begin{array}{l}38.84 \\
112.4\end{array}$ & $\begin{array}{l}38.84 \\
38.8\end{array}$ \\
\hline Duct Wall & & & & & & & \\
\hline $\begin{array}{l}\text { Thickness, } \mathrm{mm} \\
\text { Density, } \mathrm{kg} / \mathrm{m}^{3} \\
\text { HTC to bypass, } \mathrm{J} / \mathrm{h} \cdot \mathrm{mm}^{2} \cdot \mathrm{K} \\
\text { Bypass temp, } \mathrm{K} \\
\text { Gamma heating }\end{array}$ & $\begin{array}{c}1 \\
7980 \\
13.3 \\
679 \\
\text { Nune }\end{array}$ & $\begin{array}{c}0.79 \\
7980 \\
2.04 \\
729 \\
\text { None }\end{array}$ & $\begin{array}{c}0.79 \\
7980 \\
2.04 \\
697 \\
\text { None }\end{array}$ & $\begin{array}{c}0.89 \\
7980 \\
10.2 \\
651 \\
\text { None }\end{array}$ & $\begin{array}{c}0.89 \\
7980 \\
0.41 \\
627 \\
\text { None. }\end{array}$ & $\begin{array}{c}0.89 \\
7980 \\
0.41 \\
655 \\
\text { None }\end{array}$ & $\begin{array}{c}0.89 \\
7980 \\
0.41 \\
655 \\
\text { None }\end{array}$ \\
\hline $\begin{aligned} & \text { Hydraulic Details: } \text { Channel length, } m \\
& \text { Number of nodes }\end{aligned}$ & $\begin{array}{l}0.217 \\
15\end{array}$ & 0.686 & $\begin{array}{l}0.686 \\
14\end{array}$ & $\begin{array}{l}0.680^{\circ} \\
14\end{array}$ & 14 & 0.600 & $\begin{array}{l}0.626 \\
14\end{array}$ \\
\hline Initial inlet temp, $K$ & 679 & 729 & 697 & 651 & 627 & 655 & 655 \\
\hline Initial inlet flow. $\mathrm{Kq} / \mathrm{h} \cdot \mathrm{mm}^{2}$ & 13.7 & 15.0 & 19.1 & 12.24 & 11.6 & 10.8 & 13.8 \\
\hline Avg heat flux from pin, J/h.mm² & 29.9. & 38.0 & 38.0 & 38.0 & 38.0 & 38.0 & 38.0 \\
\hline System pressure. MPa & 2.07 & 2.07 & 2.07 & 2.01 & 2.07 & 2.07 & 2.07 \\
\hline
\end{tabular}


TABLE C.12. Forcing Functions for E-series Tests

\begin{tabular}{|c|c|c|c|c|c|c|c|}
\hline \multicolumn{2}{|c|}{ Test E3 } & \multicolumn{2}{|c|}{ Test E4 } & \multicolumn{2}{|c|}{ Test E6 } & \multicolumn{2}{|c|}{ Test E7 } \\
\hline Time, $s$ & Factor & Time, $s$ & Factor & Time, s & Factor & Time, s & Factor \\
\hline \multicolumn{8}{|c|}{ Forcing Function for Power } \\
\hline 0.400 & 1 & 1.43 & 1 & 5.25 & 1 & 3.80 & 1 \\
\hline 0.500 & 166 & 1.50 & 20 & 6.00 & 165 & 4.50 & 79 \\
\hline 0.510 & 223 & 1.54 & 36 & 8.59 & 165 & 4.60 & 142 \\
\hline 0.520 & 325 & 1.58 & 64 & 8.72 & 309 & 7.00 & 142 \\
\hline 0.540 & 568 & 1.61 & 100 & 8.77 & 406 & 7.10 & 215 \\
\hline 0.560 & 972 & 1.65 & 198 & 8.84 & 591 & 7.20 & 384 \\
\hline 0.580 & 1602 & 1.68 & 311 & 8.88 & 731 & 7.28 & 581 \\
\hline 0.600 & 2532 & 1.72 & 568 & 8.94 & 1024 & 7.36 & 933 \\
\hline 0.620 & 3671 & 1.75 & 870 & 9.00 & 1407 & 7.42 & 1293 \\
\hline 0.640 & 4943 & 1.79 & 1425 & 9.08 & 2036 & 7.48 & 1753 \\
\hline 0.660 & 5997 & 1.85 & 2315 & 9.11 & 2223 & 7.54 & 2283 \\
\hline 0.670 & 6321 & 1.87 & 2511 & 9.12 & 2550 & 7.56 & 2416 \\
\hline 0.680 & 6483 & 1.88 & 2559 & 9.13 & 2550 & 7.58 & 2468 \\
\hline \multirow[t]{2}{*}{0.685} & 6500 & 1.89 & 2584 & 9.14 & 2237 & 7.60 & 2422 \\
\hline & & 1.90 & 2571 & 9.15 & 2194 & 7.62 & 2306 \\
\hline \multirow{11}{*}{ r } & . & 1.91 & 2543 & 9.17 & 2011 & 7.70 & 1610 \\
\hline & & 1.92 & 2493 & 9.22 & 1199 & 7.74 & 1217 \\
\hline & & 1.94 & 2318 & 9.26 & 585 & 7.78 & 894 \\
\hline & & 1.97 & 1932 & 9.29 & 317 & 7.82 & 661 \\
\hline & & 2.02 & 1264 & 9.32 & 169 & 7.86 & 489 \\
\hline & & 2.05 & 934 & 9.35 & 95 & 7.90 & 373 \\
\hline & & 2.10 & 552 & 9.40 & 52 & 8.00 & 238 \\
\hline & & 2.19 & 142 & 9.50 & 3 & 8.10 & 186 \\
\hline & & 2.22 & 53 & & & 8.50 & 124 \\
\hline & & 2.24 & 27 & & & 8.60 & 121 \\
\hline & & 2.50 & 15 & & & 8.80 & 9 \\
\hline \multicolumn{8}{|c|}{ Forcing Function for Inlet Enthalpy } \\
\hline 0.400 & 1.00 & 1.430 & 1.00 & 5.000 & 1.012 & 3.80 & 1.000 \\
\hline \multirow{16}{*}{0.685} & $1: 03$ & 1.980 & 1.00 & 7.000 & 1.019 & 6.00 & 1.021 \\
\hline & & 2.020 & 1.19 & 8.000 & 1.043 & 7.00 & 1.036 \\
\hline & & 2.066 & 1.19 & 9.000 & 1.083 & 7.10 & 1.043 \\
\hline & & 2.090 & 1.25 & 9.321 & 1.105 & 7.60 & 1.070 \\
\hline & & 2.200 & 1.25 & 9.354 & 1.390 & 7.61 & 1.117 \\
\hline & & & & 9.356 & 1.719 & 7.63 & 1.169 \\
\hline & & & & 9.358 & 2.058 & 7.66 & 1.268 \\
\hline & & & & 9.360 & 2.142 & 7.67 & 1.425 \\
\hline & & & & 9.362 & 2.195 & 7.68 & 1.646 \\
\hline & & & & 9.364 & 2.210 & $7.69^{\circ}$ & 1.812 \\
\hline & & & & 9.400 & 2.600 & 7.70 & 1.951 \\
\hline & & & & 9.500 & 2.956 & 7.72 & 2.194 \\
\hline & & & & & & 7.74 & 2.377 \\
\hline & ${ }^{\circ}$ & & & . & & 7.76 & 2.486 \\
\hline & & . & & & & 7.77 & 2.558 \\
\hline & & & & & & 7.78 & 2.655 \\
\hline
\end{tabular}


TABLE C.13. Forcing Functions for H-series Tests

\begin{tabular}{|c|c|c|c|c|c|}
\hline \multicolumn{2}{|c|}{ Test $\mathrm{H} 2$} & \multicolumn{2}{|c|}{ Test $\mathrm{H} 3$} & \multicolumn{2}{|c|}{ Test $\mathrm{H} 5$} \\
\hline Time, s & Factor & Time, s & Factor & Time, s & Factor \\
\hline \multicolumn{6}{|c|}{ Forcing Function for Power } \\
\hline 0.60 & 1 & 4.00 & 1 & 2.00 & 1 \\
\hline 0.88 & 23 & $5.00^{\circ}$ & 6 & 2.50 & 3 \\
\hline 0.97 & 74 & 6.00 & 45 & 2.70 & 9 \\
\hline 1.00 & 108 & 6.20 & 75 & 2.90 & 34 \\
\hline 1.03 & 159 & 6.60 & 165 & 3.00 & 62 \\
\hline 1.06 & 236 & 7.70 & 161 & 3.10 & 104 \\
\hline 1.09 & 339 & 9.58 & 167 & 3.20 & 107 \\
\hline 1.13 & 541 & 9.60 & 170 & 3.10 & 111 \\
\hline 1.18 & 880 & 9.70 & 264 & 6.10. & 114 \\
\hline 1.20 & 1043 & 9.84 & 427 & 6.90 & 251 \\
\hline 1.23 & 1267 & 9.90 & 403 & 7.10 & 285 \\
\hline 1.24 & 1334 & 9.92 & 399 & 7.30 & 333 \\
\hline 1.26 & 1435 & 9.94 & 398 & 7.50 & 395 \\
\hline 1.28 & 1504 & 10.04 & 409 & 7.70 & 465 \\
\hline 1.30 & 1518 & 10.20 & 400 & 7.90 & 536 \\
\hline 1.31 & 1506 & 10.22 & 387 & 8.00 & 569 \\
\hline 1.33 & 1459 & 10.24 & 354 & 8.10 & 605 \\
\hline 1.34 & 1422 & 10.26 & 295 & 8.12 & 573 \\
\hline 1.36 & 1315 & 10.28 & 213 & 8.20 & 233 \\
\hline 1.45 & 725 & 10.30 & 129 & 8.25 & $5 \%$ \\
\hline 1.49 & 515 & 10.32 & 57 & $8: 30$ & 15 \\
\hline 1.51 & 435 & 10.34 & 2.1 & & \\
\hline 1.54 & 334 & 10.36 & 9 & & \\
\hline 1.59 & 226 & 14.00 & 1 & & \\
\hline 1.69 & 36 & & & & \\
\hline 1.72 & 15 & & & & \\
\hline \multicolumn{6}{|c|}{ Forcing Function for Inlet Einthalpy } \\
\hline 0.600 & 1.000 & 4 & 1.000 & 2.0 & 1.000 \\
\hline 1.500 & 1.000 & 6 & 1.000 & 3.5 & 1.005 \\
\hline 1.585 & 1.068 & 7 & 1.008 & 4.0 & 1.010 \\
\hline 1.700 & 1.068 & 8 & 1.017 & 4.5 & 1.015 \\
\hline 1.720 & 1.143 & 9 & 1.047 & 5.0 & 1.025 \\
\hline 1.750 & 1.178 & 10 & 1.075 & 5.5 & 1.033 \\
\hline \multirow[t]{4}{*}{2.000} & 1.178 & 11 & 1.106 & 6.0 & 1.047 \\
\hline & & 12 & 1.139 & 7.0 & 1.068 \\
\hline & & 13 & 1.153 & 8.0 & 1.120 \\
\hline & & & & 9.0 & 1.195 \\
\hline
\end{tabular}




\section{APPENDIX D}

\section{$\underline{\text { Posttest Neutron Radiographs }}$}

Figures D.1-D.4 are posttest neutron radiographs showing the condition of Tests $\mathrm{H} 4, \mathrm{H} 5, \mathrm{E} 6$, and $\mathrm{E} 7$ after the TREAT transient and after stripping of the loop outfitting material from the loop. In these radiographs, the neutron-absorbing filter material and as much other extraneous material as possible have been removed. The composite pictures presented here are made up from a number of smaller pictures printed from the radiograph negatives. Some variation in density is noted.

Descriptive captions have been placed on the pictures to aid in interpretation. The darkness of the image reflects the neutron-absorbing property of the material through which the collimated neutron beam passed. Thus, fuel shows up as a black image, while stainless steel and Inconel show up as grey, with darkness depending on the thickness. 


\section{LEGEND}

A. Lower End Plugs and Insulator Pellets w: th a Small Amount of Fuel in the Channels.

B. Concentration of Fuel Near the 3ottom of the Fuel Column

C. Region Substantially Void of Fuel Except for a Few Sem-intact Pin Segrrents.

D. Concentration of Fuel near the Top of the Fuel Column.
E. Concentration of Fuel above the Fuel Column.

F. Region Containing Relatively Sparse Fuel Deb-is Located above the Fuel Column.

G. Extent of Original Fuel Column.

H. Upper Portion of Cluster with Insulator Pellets and Reflector Pieces.

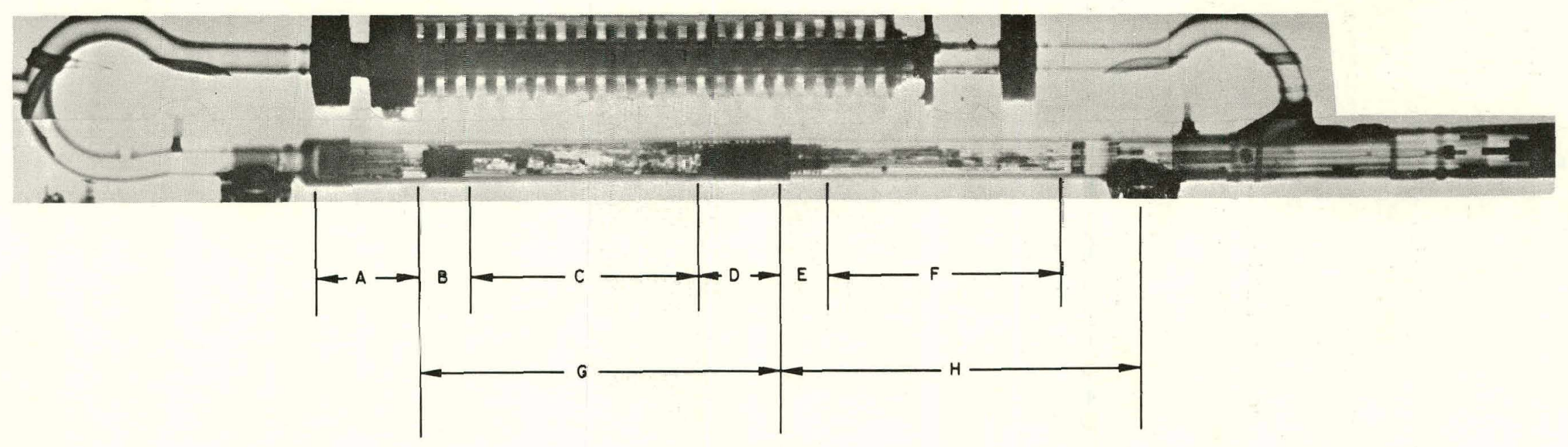

Fig. D.1. Post:est Neutron Radiograpin for Test H4 
A. Lower End Plugs and Insulator Pellets.

B. Lower Portior of Fuel Column with Little or No Evident Pin Damage.

C. Upper Portion of Fuel Column with Some Pin and Test-section Damage Apparent.

D. Probable Location of Initial Failure of Central Pin.
E. Region Containing Sparse Fuel Debris Loc ated above Fuel Column.

F. Extent of Original Fuel Column.

G. Upper Portion of Cluster with Reflector Pieces in Peripheral Pins.

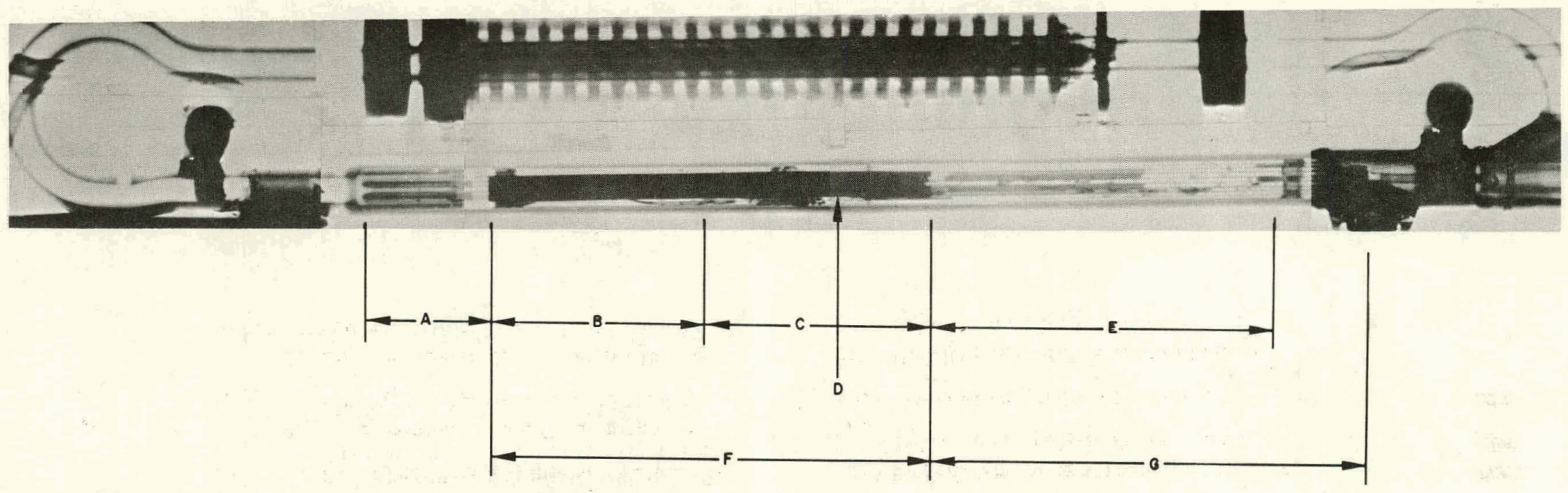

Fig. D.2. Posttest Neutron Radiograph for Test H5 
A. Lower End Flugs and Insulato: Pellets.

B. Lower Portion of Fuel Column Showing Pin Bending but Apparent Limited Lamage.

C. Upper Portion of Fuel Column with Mo:e Extensive Damage to Pins and Fuel Holder.
D. Region Contcining Relatively Sparse Fuel Lebris Loc ated above Fuel Column.

E. Extent of Origina: Fuel Column.

F. Upper Portion of Cluster with Insulator Pellets and Reflector Pieces.

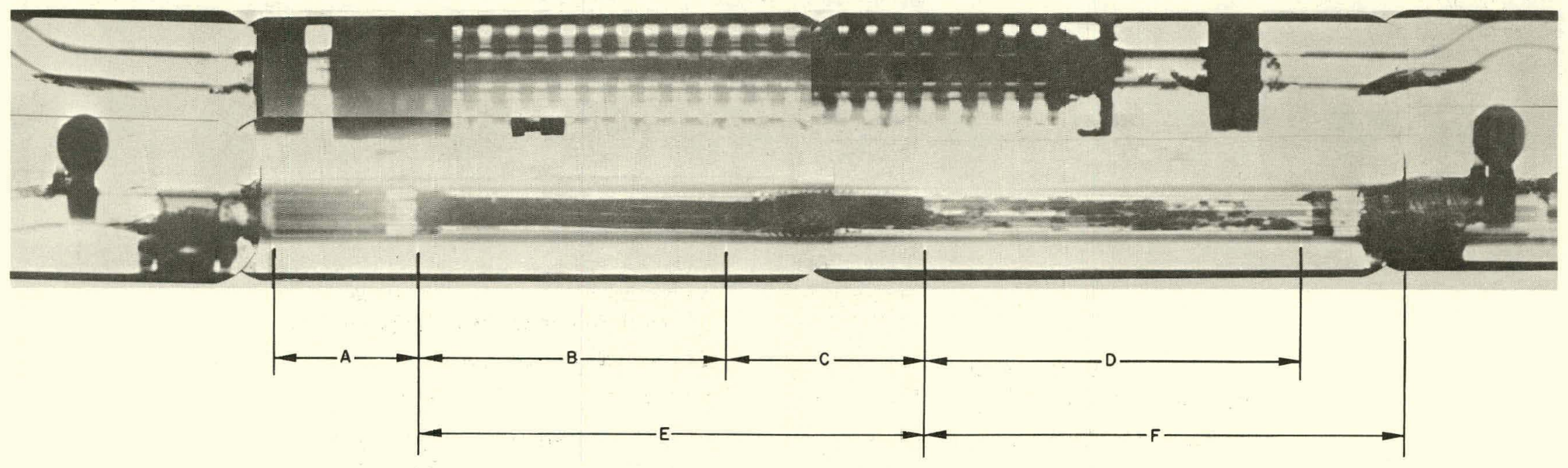

Fig. D.3. Posttest Neutron Radiograph for Test E6 
A. Lower End Plugs and Insulator Pellets with a Small Amount of Fuel in Channels.

B. Lower Portion of Original Fuel Column with Relatively Low Density Fuel.

C. Middle Portion of Fuel Column Essentially Void of Fuel.

D. Upper Region of Fuel Column with Relatively Low Density FLel.
E. High Concentration of Fuel near Top of Original Fuel Column.

F. Region Containing Relatively Dense Fuel Loc ated above the Original Fuel Column.

G. Region Containing Relatively Sparse Fuel Loc ated in Reflector and Insulator Region.

H. Extent of Original Fuel Column.

I. Upper Insulator Pellets and Reflector Pieces.

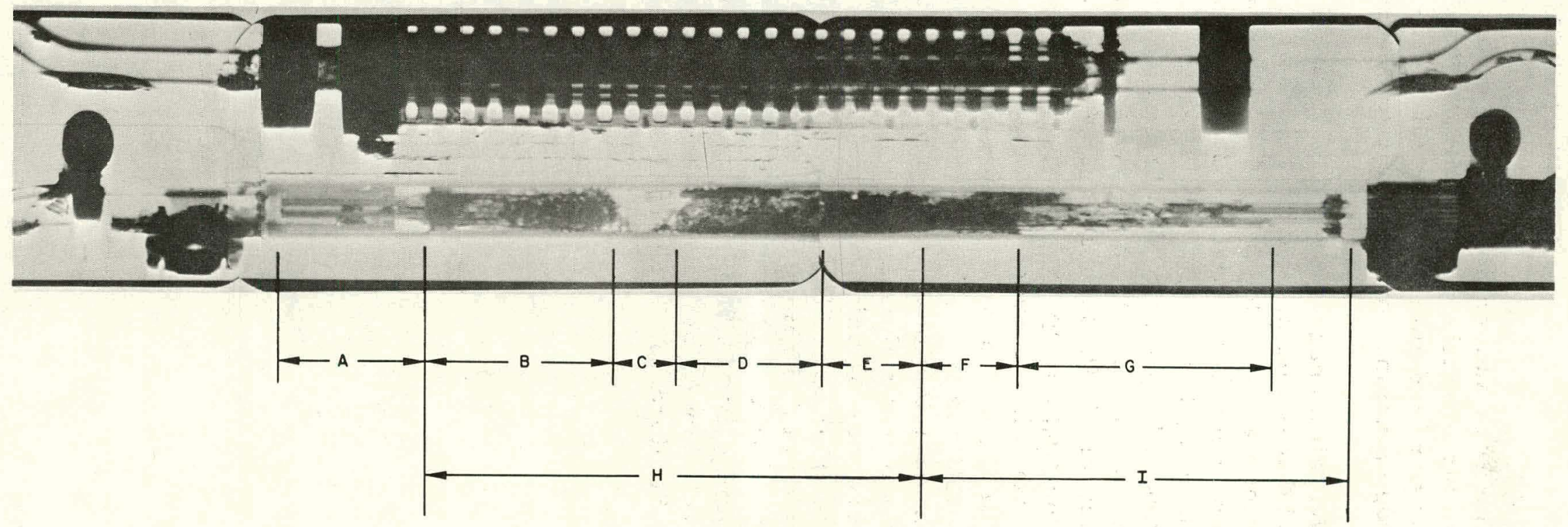

Fig. D.4. Posttest Neutron Radiograph for Test E7 


\section{ACKNOW LEDGMENTS}

The work summarized in this report covers about five years; it would be impossible to single out every individual who contributed to test preparation, execution, and analysis over this period. We would like to particularly acknowledge a number of persons who had leadership roles in the program.

Overall management of the program was the responsibility of C. E. Dickerman and R. O. Ivins. Technical leadership of the program from its inception was provided by C. E. Dickerman, who also served as lead experimenter for Tests El and E2. Other lead experimenters include A. B. Rothman (H2 and H3), as well as the authors of this report. Development of the Mark-II loop system was originated by L. E. Robinson; loop outfitting was conducted by K. J. Schmidt, R. T. Purviance, R. J. Schlitz, E. R. Maslowicz, J. E. Emerson, J. P. Burghardt, C. August, and G. G. Dewey. Leadership in test engineering and operations was provided by R. A. Noland, with able assistance from H. V. Rhude, J. P. Burelbach, and V. M. Kolba. Analytical support for the overpower experiments was originally provided by A. K. Agrawal. R. C. Schmitt and W. T. Sha contributed to code development and application. Significant contributions in data management, computer graphics, and computercode development and usage were made by P. H. Froehle. Handling of loops and test sections in Idaho was directed by J. H. Cook, D. L. Mitchell, and J. F. Kerr at HFEF. TREAT Operations, including data acquistion was under the direction of J. F. Boland and L. J. Harrison. Posttest metallurgical examinations were conducted under the leadership of L. A. Neimark, W. F. Murphy, and D. Stahl. Hodoscope operations and data interpretations were directed by A. De Volpi, with assistance from R. R. Stewart, J. P. Regis, and G. S. Stanford. J. G. Eberhart assisted in calculations of the loop flow data. 


\section{REFERENCES}

1. W. F. Murphy and L. A. Neimark, Reactor DeveZopment Program Progress Report: December 1971, ANL-7900, p. 8.14 (Jan 28, 1972).

2. D. Stahl and T. J. Patrician, Fission-gas Behavior during a Mild Overpower Transient, ANI-8069 (Feb 1974).

3. D. Stah1, Reactor Development Program Progress Report: March 1973, ANL-RDP-15, p. 9.34 (Apr 26, 1973); Reactor DeveZopment Progrom Progress Report: July 1973, ANL-RDP-18, p. 7.34 (Aug 29, 1973).

4. D. Stahi, ANL/MSD, to L. W. Deitrich, personal communication (Oct 1973).

5. J. Ingham, HEDL, to R. C. Doerner, personal communication (Aug 1973).

6. A. E. Waltar, HEDL, to L. W. Deitrich, personal communication (May 1974).

7. H. K. Fauske, CSMI Meeting on Fuel-Coolant Interactions, Nuc1. Safety 16(4), 436-443 (July-Aug 1975).

8. T. C. Chawla, ANL, to L. W. Deitrich, personal communication (Sept 1973).

9. G. A. Freund, P. Elias, D. R. MacFarlane, J. D. Geier, and J. F. Boland, Design Surmary Report on the Transient Reactor Test Facility. (TREAT), ANL-6034 (June 1960).

10. J. F. Boland, Operating Experience with TREAT, Trans. Am. Nucl. Soc. 12, Supp., 15 (1969).

11. L. E. Röbinson, R. T. Purviance, and K. J. Schmidt, The Mark-II Integral Sodium TREAT LOOP, ANL-7692 (Nov 1971).

12. L. E. Robinson and R. D. Carlson, The Development of Pumps for Use in Fast-reactor-safety Integral-Zoop Experiments, ANL-7369 (Apr 1968).

13. A. De Volpi, R. J. Pecina, R. T. Daly, D. J. Travis, R. R. Stewart, and E. A. Rhodes, Fast-Neutron Hodoscope at TREAT: Development and operation, Nuc1. Tech. 27, 449 (1975); A. De Volpi, R. R. Stewart, J. P. Regis, G. S. Stanford; and E. A. Rhodes, Fast-Neutron Hodoscope at TREAT: Data Processing, Analysis, and Results, Nucl. Tech. 30, 398.(1976).

14. V. L. Streeter, Fluid Mechanics, 2nd Ed., McGraw-Hill Book Co., Inc., New York (1950).

15. W. W. Marr, COBRA-3M: A Digital Computer Códe for Analyzing I'hermalHydraulic Behavior in Pin Bundles, ANL-8131 (Mar 1975).

16. A. Watanabe, The DEFORM-II: Mathematical Analysis of Elastic, Viscous, and Plastic Deformation of a Reactor Fuel Pin, ANL-8041 (Aug 1973).

17. D. S. Rowe, COBRA-IIIB: A Digital Computer Progrom for Steady-State and Transient Thermal-Hydraulic Analysis of Rod Bundle Nuclear Fuel Elements, BNWL-B-82 (1971).

18. G. H. Golden and J. V. Iokar, Thermophysical Properties of Sodium, ANL-7323 (Aug 1967). 
Internal:
J. A. Kyger
A. De Volpi
A. Amorosi
R. C. Doerner (2)
L. Burris
R. Simms
D. W. Cissel
R. K. Lo
S. A. Davis
G. S. Stanford
B. R. T. Frost
C. L. Fink
D. C. Rardin
R. G. Palm
R. G. Staker
R. G. Page
R. J. Teunis
R. N. Koopman
C. E. Till
R. O. McNary
R. S. Zeno
J. P. Tylka
R. Avery
L. A. Serrenza
D. H. Cho
J. F. Marchaterre
H. V. Rhude
A. J. Goldman
L. E. Robinson/J. P. Burelbach
H. K. Fauske
M. E. Stephens on
L. W. Person
E. A. Rhodes
N. J. Carson
R. R. Stewart
J. P. Regis
T. H. Bauer
B. D. LaMar
R. T. Purviance/K. J. Schmidt
J. B. Heineman
R. J. DiMelfi
J. M. Kramer
M. J. Mc Daniel
R. E. Henry
B. W. Spencer
M. A. Grolmes
G. H. Golden
F. Yaggee
D. Ruse
H. U. Wider
C. E. Dickerman (2)
T. H. Hughes
L. W. Deitrich (4)
W. W. Marr
D. R, Ferguson
E. E. Gruber
R. A. Noland
C. C. Meek
S. H. Fistedis
W. L. Wang
L. Baker
A. E. Wright (L)
K. H. Sevy
B. A. Korelc (4)
D. H. Lennox
I. Bornstein
A. B. Rotlinidi (2)
A. E. Klickman (L)
T. C. Chawla
L. Stahi
S. M. Gehl
W. F. Murphy
L. A. Neirnark
R. B. Poeppel
L. J. Harrison
J. H. Cook
A. B. Krisciunas
ANL Contract Copy
ANL Libraries (5)
TIS Files (6)

\section{External:}

ERDA-TIC, for distribution per UC-79p (282)

Manager, Chicago Operations Office

Chief, Chicago Patent Group

Director, ERDA-RDD (2)

Director, Reactor Programs Div., ERDA-CH

K. Davidson, RPD-CH

Director, CH-INEL

President, Argonne Universities Association

Reactor Analysis and Safety Division Review Committee:

S. Baron, Burns and Rne, inr.

W. Kerr, U. Michigan

$M$. Levenson, Electric Power Research Inst.

S. Levy, S. Levy, Inc.

R. B. Nicholson, Exxon Nuclear, Co., Inc.

D. Okrent, U. California, Los Angeles

N. C. Rasmussen, Massachusetts Inst. Technology 